\title{
II. ZUR MOTIVLAGE
}

\section{Eine Außenpolitik im Banne des Militärischen?}

\subsection{Der Kult der Offensive - Die Grundlagen des Plan XVII}

Mit der Berufung Joseph Joffres in das Amt des Generalstabschefs begann am 28. Juli 1911 ein neues Kapitel im Buch der militärischen Pläne Frankreichs ${ }^{1}$. Unter seiner Leitung gab man die für mehrere Dekaden verbindliche Maxime der Defensive auf und nahm einen Primat des uneingeschränkten Angriffs an. Hatten in der Frühphase der Dritten Republik die Aufmarschpläne, die der Generalstab für einen Krieg gegen das Deutsche Reich ausgearbeitet hatte, noch ganz im Zeichen der Defensive, dann - nach dem Abschluß der Militärkonvention mit Rußland an der Jahreswende 1893/ 1894 - im Zeichen des Gegenangriffs gestanden ${ }^{2}$, so erlag nun auch Frankreich einem Phänomen, das nach und nach den gesamten europäischen Kontinent erfaßte und von der historischen Forschung als "Kult der Offensive « bezeichnet worden ist ${ }^{3}$. Der die Mobilmachung und strategische Konzentration regelnde Plan XVI, den der Generalstab seit 1911 überarbeitete, um im Kriegsfall gegebenenfalls auch auf einen deutschen Angriff durch belgisches Territorium reagieren zu können ${ }^{4}$, wurde unter dem neuen $\mathrm{Ge}$ neralstabschef Joffre nicht mehr durch einen Plan ersetzt, der die Signa der Defensive oder des Gegenangriffs trug, sondern an seine Stelle trat mit Plan XVII eine Strategie, die ganz der Wille zum uneingeschränkten Angriff auszeichnete.

1 Eine wissenschaftlichen Ansprüchen genügende Biographie des Generalstabschefs zählt noch immer zu den Desiderata der Forschung. Zwar hat Arthur Conte im Jahr 1991 eine Darstellung mit dem Titel "Joffre" vorgelegt, doch auf einen Nachweis der benutzten Archivalien, Quellen und Forschungsliteratur verzichtet. Aus der älteren 'Forschung vgl. Raymond RECOULY, Joffre, Paris 521931 und die hagiographische Züge tragende Arbeit: Pierre VariLlon, Joffre, Paris 1955.

2 In der historischen Forschung fehlt darüber hinaus auch eine wissenschaftliche Analyse, die den strategischen Planungen Frankreichs über einen längeren Zeitraum hinweg nachgehen würde. Die Darstellung "Plans de concentration de 1871 à 1914«, die A. Marchand im Jahr 1926 publizierte, vermag sich noch auf keine Archivalien zu stützen. In den militärischen Archiven lassen sich zwei Abhandlungen zu dieser Thematik finden, die vom historischen Dienst des Generalstabs erstellt wurden, gleichfalls aber wissenschaftlichen Anforderungen nicht genügen. Vgl. Étude sur les plans I à XVII und die mehr als 130 Seiten umfassende Darstellung Historique des plans I (1874) à XVI (variante No 2) (1874-1913), in: SHA 7N1734. Vgl. auch die Ausführungen in: Les armées françaises dans la Grande Guerre, Bd. I/1, S. 1-17.

3 Zit. EVERA, Cult of the Offensive.

4 Vgl. Mémoire sur les modifications à apporter au Plan XVI, Mai 1911, in: SHA 7N1785 und Castelnau an Millerand, 24. 10. 1912, in: SHA 7N 1785. Vgl. ferner Bases du Plan. CSG, 18. 4. 1913, in: SHA 1N11, CXLIII, fol. 2. 
In der Historiographie sind unterschiedliche Gründe für diesen Wandel geltend gemacht worden. Schon ältere Untersuchungen haben ihn aus einer immanenten Evolution des strategischen Denkens erklärt, und diese These wird auch in der neueren Forschung vertreten ${ }^{5}$. Stärker den gesellschaftlichen Kontext des militärischen Denkens betonend hat hingegen der amerikanische Politikwissenschaftler Jack Snyder den neuen Primat des uneingeschränkten Angriffs als Versuch gedeutet, die militärischen Institutionen Frankreichs vor dem Zugriff der Politik zu schützen', während der Militärhistoriker Douglas Porch den Wandel darauf zurückgeführt, daß mit der neuen Doktrin sowohl eine Reihe von organisatorischen Mängeln als auch die defizitäre materielle Ausstattung der französischen Armee kompensiert werden sollte. Vor diesem Hintergrund nähme sich dann allerdings die offensive à outrance weniger als ein mutiger Angriff, denn als eine Flucht nach vorn aus?.

Eine eingehende Untersuchung der Ursachen, die für diesen Wandel des strategischen Denkens im französischen Generalstab maßgeblich waren, würde Forschungen erforderlich machen, die über den Rahmen dieser Arbeit weit hinausgingen. In ihrem Zentrum steht darüber hinaus nicht eine militärische Doktrin als vielmehr die Frage nach ihren außenpolitischen Konsequenzen. Zudem besteht in der historischen Forschung zumindest dahingehend Konsens, daß dem Plan XVII die Einschätzung zugrunde lag, daß nicht materielle, sondern moralische Faktoren für Triumph und Niederlage auf dem Schlachtfeld maßgeblich seien.

Am deutlichsten kommt dieser Primat moralischer Faktoren in zwei Vorträgen zum Ausdruck, die der Leiter der für strategische Fragen zuständigen Abteilung III des Generalstabs, Oberstleutnant Louis de Grandmaison, im Frühjahr 1911 vor hohen Offizieren hielt ${ }^{8}$. Grandmaison führte in diesen

5 Vgl. Basil H. LIDDELl HART, French Military Ideas before the First World War, in: Martin Gilbert ( $\mathrm{Hg}$.), A Century of Conflict, 1850-1950. Essays for A. J. P. Taylor, London 1966, S. 133-148 und Michael HOWARD, Men against Fire. Expectation of War in 1914, in: Steven E. Miller, Sean M. LyNN-Jones, Stephan VAN Evera (Hg.), Military Strategy and the Origins of the First World War. An International Security Reader, Princeton 21991, S. 3-19, hier S. 16-18.

6 Vgl. Jack SNYDER, Civil-Military Relations and the Cult of Offensive, 1914 and 1984, in: International Security 9 (1984), S. 108-146, hier S. 108-111 und DERS., The Ideology of the Offensive: Military Decision Making and the Disaster of 1914, London 1984, S. 42-106. Ähnliche Ansichten wurden auch schon in der Zeit zwischen den Weltkriegen vertreten. Vgl. in diesem Zusammenhang die Einleitung der Untersuchung: PORCH, March to the Marne, S. VIIIf.

$7 \mathrm{Vgl}$. Douglas PORCH, Clausewitz and the French, 1871-1914, in: Journal of Strategic Studies 9 (1986), S. 87-302, hier S. 297 f.; DERS., The French Army and the Spirit of the Offensive, 1900-1914, in: Brian BOND, Ian ROY (Hg.), War and Society. A Yearbook of Military History, New York 1975, S. 117-143, hier S. $136 \mathrm{f} ., 139 \mathrm{f}$. sowie Ders., The March to the Marne. The French Army 1871-1914, Cambridge 1981, S. $214 \mathrm{f}$.

$8 \mathrm{Vgl}$. Grandmaison, La crise des fronts et la notion de sûreté und Ders., La forme de l'engagement dans les grandes unités, in: SHA 1N16. Zum strategischen Denken 
Vorlesungen aus, daß auch unter den Bedingungen der modernen Kriegsführung allein die moralische Verfassung des Soldaten ausschlaggebend für den Sieg auf dem Schlachtfeld sei und sich aus diesem Grund eine defensive Haltung verbot. Le combat défensif, so erklärte Grandmaison unter dem großen Beifall seines Publikums, c'est une action d'ordre inférieur qui ne peut pas prétendre à la victoire parce qu'il suppose et surtout parce qu'il développe chez celui qui l'emploie une infériorité morale qu'aucun avantage matériel n'est capable de racheter'. Welche Berechtigung diese Ausführungen über das Wesen der Kriegführung auch gehabt haben mögen, angesichts der Pläne des Deutschen Reiches gab die von Grandmaison geforderte und dann vom französischen Generalstab vorbereitete attaque immédiate et totale wissentlich einen signifikanten Vorteil aus der Hand ${ }^{10}$.

Der Grundriß des strategischen Plans, den das Deutsche Reich für den Fall eines Koalitionskrieges besaß, war Frankreich bekannt ${ }^{11}$. Der vom ehemaligen Generalstabschef Alfred von Schlieffen zwischen den Jahren 1897 und 1905 erstellte Aufmarschplan, der trotz diverser, in ihrer Reichweite von der historischen Forschung unterschiedlich beurteilter Modifikationen ${ }^{12}$ im Juli 1914 immer noch die verbindliche Strategie des Deutschen Reiches formulierte, sah vor, den größten Teil der deutschen Armee zunächst gegen Frankreich zu wenden, um dort einen entscheidenden militärischen Erfolg zu er-

Grandmaisons vgl. F. de EsCAIBLES, La pensée militaire Grandmaison, in: Revue militaire d'information vom 25. Juni 1952, S. 19-26; Henry CONTAMINE, La revanche 1871-1914, Paris 1957, S. 167 f. und Georges MERLIER, L'esprit d'offensive dans l'armée française en 1914, à la lecture de Grandmaison et d'autres publications de l'époque, in: Bulletin de la Société d'histoire moderne 8 (1966), S. 2-5.

9 Zit. Grandmaison, La crise des fronts et la notion de sûreté, in: SHA 1N16. Vgl. auch Grandmaison, La crise des fronts et la notion de sûreté, in: SHA 1N16: Les facteurs moraux ne seront pas les plus importants; ce sont les seuls qui comptent à la guerre. Zur Wirkung der Vorträge Grandmaisons vgl. JOFFRE, Mémoires, Bd. I, S. 33 und FABRY, Joffre, S. 177.

10 Zit. Grandmaison, La forme de l'engagement dans les grandes unités, in: SHA 1N16. 11 Vgl. Jan Karl TANENBAUM, French Estimates of Germany's Operational War Plans, in: Ernest R. MAY (Hg.), Knowing one's enemies: intelligence assessment before the two World Wars, Harvard 1984, S. 150-171 und Christopher M. ANDREw, France and the German Menace, in: ibid., S. 127-149, hier S. $142 \mathrm{f}$.

$12 \mathrm{Zu}$ den Modifikationen, die Moltke an Schlieffens strategischen Plänen vornahm, vgl. insbesondere MOMBAUER, Moltke, S. 90-92. Während die ältere Forschung dem Generalstabschef im wesentlichen zum Vorwurf machte, das sgeniale Siegesrezept c seines Vorgängers verwässert zu haben, verweisen neuere Arbeiten auf die gefährlichen außenpolitischen Implikationen der Planungen Moltkes. Dabei handelt es sich insbesondere um den Umstand, daß unter Helmuth von Moltke die noch von Schlieffen geplante Invasion des niederländischen Territoriums aufgegeben wurde. Damit wurde jedoch die Vormarschroute des deutschen Angriffs derart verengt, daß man die militärische Infrastruktur Belgiens vollständig intakt in die Hände bekommen mußte. Dies setzte einen überraschenden Angriff auf die Festung Lüttich und damit eine unmittelbar zu Beginn der militärischen Auseinandersetzungen erfolgende Invasion des belgischen Territoriums voraus. 
ringen ${ }^{13}$. Maßgeblich für Schlieffens strategisches Kalkül war die Überzeugung, daß das Deutsche Reich einen langen Zweifrontenkrieg nicht bestehen könnte und es deshalb bereits in der Anfangsphase des Konfliktes den entscheidenden militärischen Erfolg durch die Ausschaltung eines der beiden kontinentalen Gegner zu suchen galt ${ }^{14}$. Um diesen raschen Anfangserfolg sicherzustellen, der nur unter der Bedingung zu erreichen war, daß sich das Deutsche Reich zunächst ganz auf einen Kontrahenten konzentrierte, beabsichtige Schlieffen, von dem Zeitfenster zu profitieren, das ihm durch die relativ langsame Mobilmachung und strategische Konzentration Rußlands geöffnet wurde. Da zum einen die russische Armee erst im zweiten Kriegsmonat ihre ganze Kraft entfalten würde und da zum anderen zu befürchten stand, daß das Heer des Zarenreiches sich dem allein einen entscheidenden Erfolg garantierenden Einkreisungsmanöver durch einen Rückzug in die

13 Grundlegend für die neuere Forschung zu den strategischen Planungen Schlieffens ist Gerhard RITTER, Der Schlieffenplan. Kritik eines Mythos, München 1956. Nach Ritter geht der Schlieffenplan auf eine Ende 1905 entstandene Denkschrift des scheidenden Generalstabschefs für seinen Nachfolger Moltke zurück und bildete die Grundlage der deutschen Aufmarsch- und Operationsplanung bis 1914. Diese in der historischen Forschung bislang als gesichert geltende Erkentnis ist 2002 von Terence Zuber in Frage gestellt worden. Folgt man dem amerikanischen Historiker, dann handelt es sich beim Schlieffenplan um einen der großer Irrtümer der Geschichtswissenschaft. Schlieffen so Zuber - habe niemals eine Umfassung der französischen Streitkräfte, sondern ausschließlich einen begrenzten Angriff im Westen beabsichtigt, um die als wahrscheinlich erachtete Offensive Frankreichs grenznah aufzuhalten. Zubers Thesen lösten zunächst in der britischen Zeitschrift "War in Histoy * eine kontroverse Debatte aus und standen dann auch im Mittelpunkt eines Symposiums am Militärgeschichtlichen Forschungsamt in Potsdam. Vgl. den Tagungsband Hans EhLERT, Michael EpkenHans, Gerhard P. Gross, Der Schlieffenplan. Analysen und Dokumente, Paderborn, München, Wien 2006 (Zeitalter der Weltkriege, 2). Vgl. dort insbesondere den von Gerhard P. Groß verfaßten Beitrag, in dem der Potsdamer Militärhistoriker die Thesen Zubers auf der Grundlage einer ganzen Reihe bislang unbekannter Quellen - darunter eine Abschrift der Schlieffenschen Denkschrift sowie Quellenabschriften zur deutschen Aufmarschplanung zwischen 1893 und 1915 - Schritt für Schritt widerlegt.

${ }_{14}$ Ausgehend von der Beobachtung, daß Moltke den Verzicht auf die Verletzung der niederländischen Neutralität mit den Auswirkungen begründete, die im Fall einer britischen Seeblockade zu befürchten standen, hat in der neueren Forschung insbesondere Stig Förster die These vertreten, daß der deutsche Generalstab im Juli 1914 nicht von einer kurzen Kriegsdauer ausgegangen sei. Vgl. insbesondere Stig FÖRSTER, Der deutsche Generalstab und die Illusion des kurzen Krieges, 1871-1914: Metakritik eines Mythos, in: MGM 54 (1995), S. 61-95. Erneut abgedruckt als: DERS., Der deutsche Generalstab und die Illusion des kurzen Krieges, 1871-1914. Metakritik eines Mythos, in: Johannes BURKHARDT u. a. (Hg.), Lange und kurze Wege in den Ersten Weltkrieg. Vier Augsburger Beiträge zur Kriegsursachenforschung, München 1996, S. 115-158. Vgl. ferner DERS., Dreams and Nightmares: German Military Leadership and the Images of Future Warfare, 1871-1914, in: Manfred BOEMEKE, Roger CHICKERING, Stig FÖRSTER (Hg.), Anticipating Total War. The German and American Experiences, 1871-1914, Cambridge, New York 1999, S. 343-376. Vgl. hiermit überstimmend MOMBAUER, Moltke, S. $95 \mathrm{f}$. Einen knappen Überblick über den Stand der Diskussion gibt: Holger H. HERWIG, Germany and the "Short-War « Illusion. Towards a New Interpretation?, in: Journal of Military History 66 (2002), S. 681-694, hier S. 681 f. 
Tiefen des russischen Raumes entziehen würde, mußte Frankreich das erste Opfer eines groß angelegten Cannae werden. Mit der Hauptstadt Paris im Rücken, so Schlieffens Überlegung, würde es den französischen Armeen nicht möglich sein, sich der entscheidenden Schlacht zu verweigern. Schlieffen und sein Nachfolger Moltke waren der Überzeugung, daß dieses Manöver nur dann gelingen werde, wenn die deutsche Armee unter Umgehung des französischen Festungssystems durch Belgien marschierte. Der Aufmarschplan des deutschen Generalstabs sah deshalb vor, den größten Teil der deutschen Armee zunächst durch Belgien und dann durch das nördliche Frankreich zu führen, dort die französische Armee einzuschließen und zu vernichten, um sich dann in einem zweiten Schritt der östlichen Front zu zuwenden, an der zu diesem Zeitpunkt den wenigen in Ostpreußen belassenen Truppen eine erdrückende russische Übermacht entgegenstehen würde.

Vor dem Hintergrund der strategischen Planungen des deutschen Generalstabs wird deutlich, daß zu Beginn der militärischen Auseinandersetzungen die Zeit für Frankreich arbeiten mußte. Der Gedanke, den Zeitpunkt der entscheidenden Konfrontation hinauszuzögern, um solchermaßen dem Deutschen Reich den für sein strategisches Kalkül grundlegenden Vorteil der inneren Linie zu nehmen, lag daher auf der Hand ${ }^{15}$. Die älteren Planungen des französischen Generalstabes hatten deshalb versucht, diesen Schwachpunkt der deutschen Strategie auszunutzen, indem sie, gestützt auf die Fortifikationswerke der Séré-de-Rivière-Linie im Osten Frankreichs, zunächst eine Phase des hinhaltenden Widerstands vorsahen, um dem Zarenreich die erforderliche Zeit zum simultanen Angriff zu verschaffen ${ }^{16}$. Auch unter dem Primat des uneingeschränkten Angriffs war man nicht vollkommen blind gegenüber den Vorzügen, die eine solche Defensive bot:

En retardant, so reflektierte mit Noël Marie Joseph Edouard de Castelnau ${ }^{17}$ der Premier sous-chef d'état-major und engste Mitarbeiter Joffres über die Absichten seiner Vorgänger, l'beure des premiers engagements, nous la rapprochons du moment où les forces russes seront en mesure de faire sentir le poids de leur masse sur les frontières Est de l'Allemagne et nous nous ménageons en temps utile, la collaboration du Corps expéditi-

${ }^{15}$ Ein entsprechendes Vorgehen hatte der russische Generalstabschef im Jahr 1908 angeraten. Vgl. Moulin an Piquart, 2. 9. 1908, in: DDF 2, 11, 442.

$16 \mathrm{Vgl}$. JOFFRE, Mémoires, Bd. I, S. 22.

17 Castelnau war am 28. Juli 1911 zum Premier sous-chef d'état-major ernannt worden. Unter seiner Leitung arbeiteten die für die militärische Aufklärung zuständige Abteilung II, die mit strategischen Fragen befaßte Abteilung III, und die für die Logistik verantwortliche Abteilung IV des Generalstabs an den Grundlagen des neuen Plans. Nachdem Castelnau im Dezember 1913 zum Kommandeur der zweiten Armee ernannt worden war, begann er mit der Niederschrift eines Memorandums, das seinen Ursprung wohl in dem Bemühen hatte, sich der konkreten strategischen Situation der ihm unterstellten Kontingente zu versichern, das sich dann aber unter seiner Feder zu einer umfassenden Betrachtung der strategischen Möglichkeiten auswuchs und aus dem hier zitiert wird. Vgl. Yves GRAS, Castelnau ou l'art de commander (1851-1944), Paris 1990, S. $139 f$. 
onnaire anglais. Nous allons aussi à l'encontre des projets de l'ennemi qui a certainement l'intention de nous mettre au plus tôt bors de cause et pour rendre illusoire l'intervention de l'armée anglaise et pour rendre rapidement disponible une partie de ses propres forces dont il escompte le transport sur le théâtre d'opération de la Prusse Orientale ${ }^{18}$.

Doch noch in seinen Memoiren urteilte Joffre mit unverkennbarer Geringschätzung über einen solchen Plan: Dans ce scénario, l'armée française avait à jouer tout d'abord le rôle d'armée de couverture de la Triple Entente [... Il] ne correspondait ni à nos traditions guerrières ni à notre tempérament national si prompt à s'alarmer aux premiers revers; elle portrait encore l'empreinte de la défaite ${ }^{19}$. Welchen Vorzug die Defensive für Frankreich auch angesichts der deutschen Pläne haben mochte, er wurde als zu leicht befunden und ein entsprechendes Handeln verworfen. Maßgeblich wurde für das militärische Handeln im Kriegsfall nunmehr das, was der Generalstabschef im Jahr 1914 in die allgemeine Direktive hineinschreiben ließ: En tout état de cause, l'intention du général commandant en chef est de se porter, toutes forces réunies, à l'attaque des armées allemandes ${ }^{20}$.

Obgleich mit diesem Wandel eine ganze Reihe von Forderungen an die Außenpolitik Frankreichs verbunden war, wurde die neue Ausrichtung des Aufmarschplanes von der politischen Staatsführung uneingeschränkt begrüßt. Für die Sitzung des Conseil supérieur de la défense nationale am 9. Januar 1912, in deren Rahmen mit dem Beschluß der Konzentration aller aktiven Kontingente gegen das Deutsche Reich die Grundlage für Frankreichs offensive à outrance bei Kriegsausbruch geschaffen und Joffre grünes Licht für seine Planungen gegeben wurde, hielt das Protokoll fest: $M$. le Président de la République constate avec plaisir qu'on renonce aux projets défensifs qui constituaient de notre part un aveu d'infériorité. Nous sommes désormais résolus à marcher droit à l'ennemi, sans arrière pensée. L'offensive qui convient au tempérament de nos soldats, doit nous assurer la victoire ${ }^{21}$. Worin bestanden aber nun diese neuen militärischen Parameter im einzelnen?

18 Zit. Mémoire pour servir a l'établissement d'un plan de guerre, in: NL Castelnau, SHA 1 K795/5.

19 Zit. JOFFre, Mémoires, Bd. I, S. 22 f. Vgl. auch die damit übereinstimmende Aussage in den Memoiren seines Kabinettschefs: Jean FABRY, Joffre et son destin. La Marne, Verdun, la Somme, l'Amérique, Paris 21931, S. 181 f. Einem Redakteur des "Figaro«, der ihm nach dem Krieg die Frage stellte, warum Joffre gleich zu Beginn der militärischen Auseinandersetzungen den Angriff befohlen habe, erläuterte General Henri Berthelot: Il redoutait que le souvenir de 1870 , la terrible défaite que nous avaient infligée les Allemands ne fissent par trop sentir leur influence sur nos généraux comme sur nos soldats, sur ceux-ci moins encore peut-être que sur ceux-là. Il fallait donc détruire au plus tôt cette mystique, cette légende de l'Allemand supérieur militairement au Français. Zit. RECOULY, Joffre, S. 79f. Henri Berthelot hatte im Krieg die Funktion des Aide-major général Joffres versehen und war vor 1914 der engste Mitarbeiter General Belins, der Castelnau in das Amt des Premier sous-chef d'état-major nachgefolgt war.

20 Zit. Directives générales, in: Les armées françaises, Bd. 1 Annexes, Annexe 8, 21.

21 Zit. Procès-verbal. CSDN, 9. 1. 1912, SHA, 2N1, VI/38. Vgl. damit übereinstimmend auch Poincaré: Le plan désormais établi comporte beureusement une offensive. 
Im Gegensatz zu den defensiven oder defensiv-offensiven Strategien der vorangegangenen Dekaden, die dem Bündnispartner die erforderliche Zeit zum simultanen Angriff auf das Deutsche Reich geben konnten, mußte eine offensive à outrance die an den russischen Aufmarsch gestellten Ansprüche erhöhen ${ }^{22}$. Sicherlich gilt es zu bedenken, daß auf französischer Seite die Forderung nach einer raschen russischen Mobilmachung und Konzentration nicht erst entstand, als man sich nach 1911 unter Joffre dem Primat der Offensive zuwandte. Vielmehr war sie schon im Zuge der Verhandlungen erhoben worden, die zum Abschluß der Militärkonvention im Jahr 1892 geführt hatten ${ }^{23}$. Gleichwohl akzentuierte der Wandel in den strategischen Planungen Frankreichs diese Forderung nochmals in beträchtlichem Maße. Ferner setzte ein französischer Angriff schon zu Beginn der militärischen Auseinandersetzung eine numerische Superiorität der angreifenden Armeen voraus, die angesichts des Umstands, daß das Deutsche Reich seinerseits seine Kontingente in nahezu uneingeschränktem Umfang an der französischen Grenze konzentrieren würde, als ehrgeiziges Unterfangen anmutet. Schließlich sollte die offensive à outrance die militärische Führung Frankreichs vor ein nicht aufzulösendes Dilemma stellen, als es notwendig wurde, sich mit Belgien oder Lothringen für die Stoßrichtung der geplanten Offensive festzulegen. Alle drei Faktoren und ihre außenpolitischen Implikationen werden sukzessive zu untersuchen sein. Beginnen mag man bei der Frage der numerischen Superiorität.

\subsection{Die Bedingungen eines militärischen Triumphes I: Numerische Superiorität}

Ein uneingeschränkter Angriff auf das Deutsche Reich setzte nach Ansicht des Generalstabs als technische Notwendigkeit voraus, daß Frankreich schon ummittelbar zu Kriegsbeginn auf dem Schlachtfeld über eine numerische Superiorität verfügen konnte. So erklärte das in der entscheidenden Sitzung am 9. Januar dem Conseil supérieur de la défense nationale vom Generalstab als Note de présentation vorgelegte Exposé der strategischen Gesamtsituation, daß allein die numerische Superiorität Frankreich gestatten werde, de prendre l'offensive et de porter la guerre en pays ennemi ${ }^{24}$.

Zit. Notes journalières, in: NL Poincaré, BNF, Nafr. 16026, fol. 58 (Eintrag vom 2. 2. 1914).

22 Vgl. SNYDER, Ideology of the Offensive, S. $43 \mathrm{f}$.

23 Vgl. KENNAN, Schicksalhafte Allianz, S. 138-142.

24 Zit. Note de présentation. CSDN, 9. 1. 1912, in: SHA 2N1, VI/36. Auch die französisch-russische Militärkonvention unterstrich diesen Zusammenhang sehr nachdrücklich, indem sie noch in ihrer letzten Fassung von 1913 konstatierte, daß es essentiel sei, que les armées françaises puissent avoir une supériorité numérique marquée sur les forces allemandes de l'ouest. Zit. Procès-verbal des entretiens du mois d'août 1913 entre les chefs d'état-major des armées française et russe, in: DDF 3, 8, 79. In seinen Memoiren führte Joffre die defensive Grundausrichtung der strategischen Pläne der vorangegan- 
Im Rahmen einer numerischen Kalkulation der Kräfte, die sich zu Beginn der militärischen Auseinandersetzungen an der deutsch-französischen Grenze gegenüberstehen würden, stellte sich für den Generalstab ganz grundsätzlich die Frage, mit welcher Unterstützung Frankreich im Kriegsfall rechnen konnte, welche Mächte Frankreichs Freunde oder Feinde sein und welche Staaten in wohlwollender oder feindseliger Neutralität verharren würden ${ }^{25}$. Die Analyse der außenpolitischen Gesamtlage war deshalb vom Generalstab schon ganz zu Beginn seiner Arbeiten am Plan XVII auf die politische Agenda gesetzt worden ${ }^{26}$. Am 3. Juli 1911 hatte er dem Kriegsminister eine Note übersandt, in der eine Reihe von konkreten Fragen in bezug auf Frankreichs Stellung im internationalen Staatensystem formuliert wurden und deren Beantwortung der Ausarbeitung des neuen Mobilmachungsund Aufmarschplanes vorangehen sollte ${ }^{27}$. Mit dieser Note wurde ein Prozeß eingeleitet, in dessen Verlauf es in den folgenden Monaten - sei es in direkten Gesprächen zwischen dem Generalstab und dem Außenministerium, sei es in den Beratungen des Conseil supérieur de la défense nationale zu einer Sichtung und Bewertung der Abkommen kam, die Frankreich für den Fall der militärischen Eskalation einer internationalen Krise getroffen hatte.

Zwischen den politischen und militärischen Entscheidungsträgern war dabei unstrittig, daß es unter Frankreichs internationalen Verpflichtungen nur ein Arrangement gab, das den Charakter einer förmlichen Allianz, verstanden als a treaty binding two or more independent states to come to each other's aid with armed forces under circumstances specified in the casus foede-

genen Dekaden auf den Umstand zurück, daß man von einer infériorité numérique der französischen Kontingente ausgegangen sei. Vgl. JOFFre, Mémoires, Bd. I, S. 22, $26 \mathrm{f}$. 25 Zur Frage der belgischen Neutralität vgl. die Ausführungen im Abschnitt $\gg \mathrm{Die} \mathrm{Be}-$ dingungen eines militärischen Triumphes II: Die Invasion Belgiens«. Das Urteil, das sich die französische Staatsführung über die spanische Haltung im Kriegsfall gemacht hatte, bedarf in diesem Zusammenhang keiner eingehenden Untersuchung. In einer der Noten, mit der das Außenministerium das die außenpolitische Gesamtlage resümierende Exposé des Generalstabs ergänzte, wird konstatiert: Enfin, les moyens dont dispose l'Espagne sont limités à tous égards et nous devrions donc en cas de guerre avec l'Allemagne, considérer comme négligeables les velléités de l'Espagne. Zit. Note, 20. 11. 1911, in: SHA 2N1, VI/34/1. Vgl. auch die mit diesem Urteil übereinstimmende Aussage in: Note de présentation. CSDN, 9. 1. 1912, in: SHA 2N1, VI/36. In den Beratungen des Conseil supérieur de la défense nationale fand Spanien am 9.1.1912 mit keinem Wort Erwähnung. Vgl. Procès-verbal. CSDN, 9. 1. 1912, in: SHA 2N1, VI/38. Zu den spanisch-französischen Beziehungen in den letzten Jahren vor Kriegsausbruch vgl. Jean-Marie DELAUNAY, L'Espagne, un allié oublié: les relations franco-espagnoles au début du XX $\mathrm{XX}^{\mathrm{e}}$ siècle, in: Relations internationales 115-118 (2001), S. 151-163 und DERS., Méfiance cordiale: les relations franco-espagnoles au début du XX ${ }^{\mathrm{e}}$ siècle (18991914), Paris 2000.

26 Vgl. Note pour M. le Ministre de la Guerre, 3. 7. 1911, in: SHA 2N1, V/28/1.

$27 \mathrm{Vgl}$. in diesem Zusammenhang auch Messimy an Caillaux, 28. 9. 1911, in: SHA 2N1, $\mathrm{V} / 29$ und Note au sujet des renseignements qui doivent servir de bases pour l'établissement d'un plan de guerre, Oktober 1911, in: SHA 2N1, V/30/1. 
ris article of the treaty, besaß28. Es handelte sich dabei um die Militärkonvention, die 1892 mit Rußland geschlossen und dann um die Jahreswende 1893/ $1894 \mathrm{zu}$ einem Bündnis ausgebaut worden war ${ }^{29}$. Anfänglich auch gegen Großbritannien, später allein gegen das Deutsche Reich gerichtet, verpflichtete diese Allianz zu gegenseitigem militärischen Beistand für den Fall, daß eines ihrer Mitglieder durch das Deutsche Reich angegriffen wurde oder aber sich mit einem Angriff Italiens respektive der Habsburgermonarchie konfrontiert sah, der die militärische Unterstützung des Deutschen Reiches geno ${ }^{30}$. Für beide Staaten repräsentierte dieses Bündnis den cornerstone ${ }^{31}$ ihrer Außen- und Sicherheitspolitik. La France, so lautete deshalb die Einschätzung in der Note de présentation der Sitzung des Conseil supérieur de la défense nationale am 9. Januar 1912, peut donc compter entièrement sur le concours le plus actif, de la part de son allie ${ }^{32}$. Obgleich die detaillierte Untersuchung dieser Allianz einem gesonderten Kapitel dieser Arbeit vorbehalten sein wird, sei schon an dieser Stelle darauf aufmerksam gemacht, daß die Note de présentation im Hinblick auf die russische Intervention eine unumschränkte Sorglosigkeit anzudeuten scheint, die weder das Kabinett noch der Generalstab besaßen.

Doch in den Beratungen des Conseil supérieur de la défense nationale stand die Frage nach der russischen Intervention nicht im Mittelpunkt des Interesses. Es waren vielmehr zwei andere Mächte, über deren Verhalten man sich im Kriegsfall Klarheit zu verschaffen suchte. Dabei handelte es sich zum einen um Italien, zum anderen um Großbritannien.

\subsubsection{Die außenpolitischen Rahmenbedingungen}

Italien: Die opportunistische und unbedeutende Macht Was zunächst den italienischen Fall betrifft, so ist zu bemerken, daß die Beziehungen beider Nationen für den Fall einer militärischen Auseinandersetzung unter Beteiligung einer der beiden Staaten durch ein geheimes Abkommen aus dem Jahr 1902 geregelt wurden, das beide Mächte unter bestimmten Bedingungen zur

28 Zit. Paul W. SChroeder, Alliances 1815-1945: Weapons of Power and Tools of Management, in: Klaus KNORR (Hg.), Historical Dimension of National Security Problems, Lawrence 1976, S. 227-262, hier S. 227. In der Forschungsliteratur wird der Begriff "Allianz« nicht einheitlich definiert. Die unterschiedlichen Fassungen ähneln sich jedoch. Vgl. SNYDER, Alliance Politics, S. 3 f.

29 Vgl. den Text der Militärkonvention in: DDF 1, 9, 444 und DDF 1, 9, 461. Vgl. ferner Giers an Montelbello, 27. 12. 1893, in: DDF 1, 10, 488 (Annexe) und Montebello an Giers, 4. 1. 1894, in: DDF 1, 11, 7 (Annexe). Zur Modifikation des Abkommens im Jahr 1899 vgl. ANDREW, German World Policy, S. $138 \mathrm{f}$.

$30 \mathrm{Vgl}$. Procès-verbal des entretiens du mois d'août 1913 entre les chefs d'état-major des armées française et russe, in: DDF 3, 8, 79.

31 Zit. KeIgER, France, S. 88; Ders., Poincaré, S. 138 und LIEvEN, Russia and the Origins, S. 28.

${ }^{32}$ Zit. Note de présentation. CSDN, 9. 1. 1912, in: SHA 2N1, VI/36. 
strikten Neutralität verpflichtete ${ }^{33}$. Diesem Abkommen war eine lange Phase ökonomischer und außenpolitischer Konfrontation vorausgegangen, und zu seiner Unterzeichnung war es erst gekommen, lange nachdem Italien im Jahr 1882 ein Defensivbündnis mit den Gegnern Frankreichs abgeschlossen hatte, das in mehrfach gewandelter Form bis zum Ausbruch des Großen Krieges Bestand haben sollte ${ }^{34}$.

$\mathrm{Daß}$ sich Italien um 1880 dem Deutschen Reich und der Habsburgermonarchie genähert und dann mit den Mittelmächten einen Bündnisvertrag unterzeichnet hatte, lag zwar nicht ausschließlich, so aber doch zu einem nicht unbeträchtlichen Teil in den kolonialen Expansionsabsichten begründet, die der italienische Nationalstaat im nördlichen Afrika hegte ${ }^{35}$. Insbesondere waren es die Auseinandersetzung um das französische Protektorat in Tunesien und die italienischen Ansprüche auf Libyen, die Italien in einen Gegensatz zu Frankreich gebracht und es Rückhalt bei den Gegnern seines kolonialen Rivalen hatte suchen lassen ${ }^{36}$. In den folgenden Jahren hatte Italien aber konstatieren müssen, daß seine Bündnispartner im Dreibund keine »Erwerbsgemeinschaft $\aleph^{37}$, sondern ausschließlich eine $\gg$ Versicherungsgesellschaft « ${ }^{38}$, das heißt ein »Bündnis für den Frieden ${ }^{39}$ erblickten und daß folglich weder im Deutschen Reich noch in der Habsburgermonarchie Neigung bestand, Italien mit dem Dreibund ein machtpolitisches Instrument in die Hand zu geben, das ihm die Möglichkeit zu kolonialer Landnahme gab ${ }^{40}$. Eine entsprechende Ernüchterung, gefördert zu einem bedeutenden Teil auch durch den Umstand, daß Berlin und Wien die "Least of the Great Powers « ${ }^{41}$ mit einiger Herablassung behandelten, war die Folge.

Nach der Katastrophe von Adua im Jahr 1896 und der Blamage von San Mun im Jahr 1899 sah sich Italien gezwungen, auf internationalem Terrain bescheidener aufzutreten. Sein Außenminister, Marquis Visconti-Venosta, versuchte die Interessen seines Landes insbesondere dort, wo sie in einem Konflikt mit Frankreich standen, nicht mehr durch Konfrontation, sondern

33 Vgl. den Text des Abkommens in: DDF 2, 2, 389.

${ }^{34}$ Der Text des Defensivbündnisses ist abgedruckt in: GP 3, 562 und DDI 2,14, 792.

35 Zur Geschichte des Dreibundes vgl. grundlegend: AFFLERBACH, Dreibund und FELLNER, Dreibund.

${ }^{36} \mathrm{Zu}$ den Ursachen der italienischen Annäherung an das Deutsche Reich und die Habsburgermonarchie vgl. AfFLERBACH, Dreibund, S. 52-92. Zu den Beziehungen zwischen Italien und Frankreich in diesem Zeitraum vgl. grundlegend: Pierre MiLZA, Français et Italiens à la fin du XIX'e siècle: aux origines du rapprochement franco-italien de 1900-1902, Bd. I., Diss. Paris 1976, S. 32-56.

${ }^{37}$ Zit. Fritz FELLNER, Der Dreibund. Europäische Diplomatie vor dem Ersten Weltkrieg, Wien 1960, S. 36.

38 Zit. ibid., S. 36.

${ }^{39}$ Zit. AFFLERBACH, Dreibund, S. 422.

40 Vgl. ibid., S. 422 f. und Feliner, Dreibund, S. $38 \mathrm{f}$.

41 So der Titel von Richard Bosworths Untersuchung über die italienische Außenpolitik vor dem Ersten Weltkrieg. Vgl. Richard J. B. BOSWORTH, Italy, the Least of the Great Powers: Italian Foreign Policy before the First World War, London u.a. 1979. 
durch Konzessionen und Kooperation zu verfolgen ${ }^{42}$. Die Bemühungen des neuen Außenministers führten im Jahr 1900 schließlich zu einem Notenaustausch, mit dem beide Mächte ihre kolonialen Interessenssphären abgrenzten und derart die Grundlage für eine Koexistenz im nördlichen Afrika schufen ${ }^{43}$.

Nachdem einmal der koloniale Interessenkonflikt zwischen Italien und Frankreich eingeebnet worden war, lag es in der Natur der Dinge, daß sich der stets latente Gegensatz zwischen der Habsburgermonarchie und Italien deutlicher abzeichnen mußte. Er lag zum einen in den Ansprüchen des noch unvollendeten italienischen Nationalstaates auf die in der Habsburgermonarchie gelegene terra irredenta begründet und resultierte zum anderen aus dem zunehmenden Interessenskonflikt auf der altera sponda des Adriatischen Meeres, den Auseinandersetzungen beider Mächte um politischen und ökonomischen Einfluß auf dem Balkan ${ }^{44}$. Deutlicher als zuvor trat damit an ihrer Allianz ein Zug hervor, der ihr stets, wenn auch zu unterschiedlichen Zeiten in unterschiedlichem Maße, angehaftet hatte und der ihr weniger den Charakter einer »weapon of power « 45 , denn eines »tool of management « 46 gab, eines Werkzeugs, mit dem sich "verbündete Feinde « 47 beobachten, kontrollieren und notfalls auch an einer militärischen Konfrontation hindern konnten.

Mit dem kolonialen Abkommen von 1900 hatte die Phase des französischitalienischen Ausgleichs zwar einen ersten Höhepunkt erreicht, war aber noch nicht zu ihrem Abschluß gelangt. Bereits im Laufe der Verhandlungen, die zum Abschluß des Abkommens geführt hatten, hatte der französische Außenminister Théophile Delcassé deutlich zu verstehen gegeben, daß eine von Frankreich unterstützte koloniale Landnahme Italiens, die beide Mächte auch im nördlichen Afrika zu Nachbarn machen würde, eine Wandlung in den vertraglichen Pflichten nach sich ziehen müsse, die Italien an das Deut-

42 Zum außenpolitischen Konzept Visconti-Venostas vgl. AfFlerbACH, Dreibund, S. $418 \mathrm{f}$.

${ }^{43}$ Die Noten sind abgedruckt in: DDF 2, 1, 17. Diesem Ausgleich war 1896 die Anerkennung des französischen Protektorats in Tunesien und 1898 der Abschluß eines Handelsvertrages vorausgegangen. Was den Kern des kolonialpolitischen Abkommens betrifft, so sicherte es Frankreich im wesentlichen freie Hand in Marokko zu, während es Italiens Interessen in Tripolis und dessen Hinterland anerkannte.

44 Zur Irredenta vgl. AfFlerbaCH, Dreibund, S. 501-511. Zu den Interessensgegensätzen der Habsburgermonarchie und Italiens auf dem Balkan vgl. ibid., Dreibund, S. 491-498.

45 Zit. SCHROEDER, Alliances, S. 227. Schroeder macht in diesem Artikel grundsätzlich darauf aufmerksam, daß ein maßgebliches Motiv für eine Allianzbildung in der Absicht bestehen kann, mäßigend auf den Bündnispartner einwirken zu wollen. In dieser Perspektive nehmen sich Bündnisse dann nicht als » weapons of power», sondern als »tools of management « aus. Vgl. auch SNYDER, Alliance Politics, S. 13-15.

46 Zit. SCHROEDER, Alliances, S. 227. Vgl. auch SCHROEDER, Life and Death of a Long Peace, S. $38 \mathrm{f}$.

47 Zit. AfFLERBACH, Dreibund, 487. 
sche Reich und die Habsburgermonarchie banden. Von der italienischen Regierung war die Berechtigung dieser Forderung durchaus anerkannt worden, und der neue italienische Außenminister Prinetti hatte, nachdem er im Rahmen der Verhandlungen zur Erneuerung des Dreibundes im Jahr 1902 keine Revision des Vertragstextes durchzusetzen vermochte, den Weg direkter Verhandlungen mit Paris eingeschlagen ${ }^{48}$.

Sie mündeten schließlich in den berühmten Briefwechsel zwischen Barrère und Prinetti vom 10. Juli 190249. Trotz seines privaten Charakters und seiner vorsichtigen diplomatischen Form handelte es sich dabei um nichts anderes als ein verbindliches Abkommen, das Italien zur strikten Neutralität in einem Krieg verpflichtete, der Frankreich durch eine direkte oder indirekte Aggression, gar durch eine direkte Provokation seitens einer dritten Macht aufgezwungen wurde. In den einleitenden Passagen dieser Briefe wurde zunächst das kolonialpolitische Abkommen von 1900 dahingehend präzisiert, daß was den Kern der Sache anbetraf - Italien Frankreich nunmehr vollkommen freie Hand in Marokko gewährte, während Italien freie Hand in Tripolis erhielt. Der italienische Außenminister erklärte darüber hinaus in seinem Schreiben an den Botschafter Frankreichs, daß er anläßlich der kolonialen Ausgleichsverhandlungen Gelegenheit gefunden habe, den Zustand der allgemeinen Beziehungen zwischen beiden Nationen zu bestimmen, und er stellte fest, daß er dem Botschafter Camille Barrère im Namen der italienischen Regierung und des Königs folgende Erklärung gemacht habe:

Au cas où la France serait l'objet d'une agression directe ou indirecte de la part d'une ou de plusieurs Puissances, l'Italie gardera une stricte neutralité. Il en sera de même au cas où la France, par suite d'une provocation directe, se trowverait réduite à prendre, pour la défense de son bonneur ou de sa sécurité, l'initiative d'une déclaration de guerre. Dans cette éventualité, le Gouvernement de la République devra communiquer préalablement son intention au Gouvernement royal, mis ainsi à même de constater qu'il s'agit bien d'un cas de provocation directe.

Pour rester fidèle à l'esprit d'amitié qui a inspiré les présentes déclarations, je suis autorisé, en outre, à vous confirmer qu'il n'existe de la part de l'Italie, et qu'il ne sera conclu par elle aucun protocole ou disposition militaire d'ordre contractuel international qui serait en désaccord avec les présentes déclarations.

J'ai à ajouter que, [...] les déclarations qui précèdent étant en barmonie avec les engagements internationaux actuels de l'Italie, le Gouvernement royal entend qu'elles auront leur pleine valeur aussi longtemps qu'il n'aura pas fait savoir an Gouvernement de la République que ces engagements ont été modifiés ${ }^{50}$.

48 Vgl. ibid., S. 445-464.

49 Vgl. Barrère an Delcassé, 10. 7. 1902, in: DDF 2, 2, 329.

50 Zit. DDF 2, 2, 329. Während Delcassé in den Verhandlungen versucht hatte, eine möglichst ausgedehnte Definition des Begriffs "Provokation « durchzusetzen, beharrte der italienische Außenminister auf dem Epitheton "directe «. In einem gesonderten Brief hob Prinetti hervor, daß er darunter eine Provokation verstehe, die den direkten Beziehungen der beteiligten Mächte entstammen mußte, und nannte als Beispiele die Emser Depesche, den Schnaebelé-Zwischenfall und bestimmte Phasen der FaschodaKrise. Vgl. AfFLERBACH, Dreibund, S. 462. Vgl, in diesem Zusammenhang auch ALBERTINI, Origins, Bd. I, S. 130. 
Insbesondere die letzten Passagen des Briefes, in denen Außenminister Prinetti konstatierte, daß sich seine Erklärung in keinem Widerspruch zu den sonstigen internationalen Abkommen Italiens befand, sind in der historischen Forschung zum Gegenstand der Diskussion geworden. Das Spektrum der Meinungen erstreckt sich dabei von der Ansicht, daß das Neutralitätsabkommen von 1902 entlang der Grenzen des Dreibundvertrages formuliert worden sei ${ }^{51}$, bis hin zu der Auffassung, daß das Arrangement den italienischen Verpflichtungen gegenüber der Habsburgermonarchie und dem Deutschen Reich direkt widersprach ${ }^{52}$. Doch welche dieser unterschiedlichen Interpretationen man auch immer teilen mag, im Rahmen einer Untersuchung zur französischen Außenpolitik in den letzten Jahren vor Ausbruch des Großen Krieges ist allein die Frage bedeutend, welchen Wert man in Frankreich dem Abkommen von 1902 zumaß, oder allgemeiner formuliert: welchen Einfluß das Abkommen auf das Urteil besaß, das sich die militärische und politische Führung über die italienische Haltung im Kriegsfall gebildet hatte.

Grundsätzlich gilt es in diesem Zusammenhang zunächst festzuhalten, daß im Hinblick auf die Frage, ob Italien dem Deutschen Reich und der Habsburgermonarchie in einer militärischen Auseinandersetzung Beistand leisten würde, Übereinstimmung in den Einschätzungen der bedeutendsten Entscheidungsträger bestand, wenn auch die Argumente, die im Einzelfall angeführt wurden, leicht unterschiedlich gelagert waren. Nicht zu verkennen ist, $\mathrm{daß}$ insbesondere der Generalstab und das Kriegsministerium dem Abkommen von 1902 erhebliche Bedeutung zumaßen. Schon in der Sitzung des Conseil supérieur de la défense nationale, in der am 11. Oktober 1911 erstmals die Frage beraten worden war, ob Italien in einer militärischen Auseinandersetzung zwischen dem Deutschen Reich und Frankreich intervenieren werde, sprach Kriegsminister Alphonse Messimy davon, daß das Neutralitätsabkommen von 1902 eine weitgehende Vernachlässigung der italienischen Grenze und die uneingeschränkte Konzentration aller Kontingente gegen das Deutsche Reich gestatte ${ }^{53}$. Zu einer identischen Lagebeurteilung gelangte auch das umfangreiche, die außenpolitische Gesamtlage beschreibende Memorandum, das im Anschluß an diese Zusammenkunft aus der Feder des Generalstabs entstand und am 16. Oktober 1911 als Grundlage einer Besprechung zwischen Joffre und dem Politischen Direktor des Außenministeriums diente ${ }^{54}$. Zwar räumte das Memorandum des Generalstabs ein, daß sich

5t Vgl. AfFlerbach, Dreibund, S. $463 \mathrm{f}$. Auch Fellner vertritt die These, daß das Neutralitätsabkommen von 1902 mit dem Dreibundvertrag kompatibel gewesen sei. Vgl. FELLNER, Dreibund, S. 57-60. Ähnlich argumentierte auch schon ALBERTINI, Origins, Bd. I, S. 127-132.

52 Vgl. Cedric James Lowe, Frank MarZari, Italian Foreign Policy 1870-1940, London 1975, S. $82 \mathrm{f}$.

53 Vgl. Procès-verbal. CSDN, 11. 10. 1911, in: SHA 2N1, V/29.

$54 \mathrm{Vgl}$. Note indiquant les points relatifs à la situation extérieure à élucider dans la Conférence du 16 octobre 1911, in: SHA $2 \mathrm{N1}, \mathrm{V} / 32$. 
das Handeln Italiens nicht mit Sicherheit vorhersagen lasse, und dementsprechend wurde der italienische Fall unter dem Abschnitt der Puissances dont la neutralité est douteuse ${ }^{55}$ verhandelt. Gleichwohl erblickte der Autor des $\mathrm{Me}-$ morandums aber in dem Neutralitätsabkommen, dem er eine valeur réelle beimaß, des garanties sérieuses ${ }^{56}$ für die Neutralität Italiens.

Zurückhaltender als der Generalstab und das Kriegsministerium beurteilte hingegen der Quai d'Orsay den Wert des Abkommens. Außenminister de Selves gab schon in der Sitzung des Conseil supérieur de la défense nationale am 11. Oktober 1911 zu bedenken, daß im entscheidenden Augenblick nicht juristischer Sachverstand, sondern machtpolitische Realitäten und nationale Interessen über die Interpretation des Abkommens entscheiden würden ${ }^{57}$. Auch sein Nachfolger sollte diese Auffassung grundsätzlich teilen. Es ist nicht zweifelhaft, so sagte Poincaré dem russischen Botschafter einige Monate später, daß [...] Italien immer die Möglichkeit finden wird, dem Vertrag die ibm erwünschte Auslegung zu geben ${ }^{58}$.

Bedauerlicherweise liegen nun keine weiteren Quellenzeugnisse für die Unterredung vor, die am 16. Oktober nach der Sitzung des Conseil supérieur de la défense nationale zwischen dem Generalstabschef und dem Politischen Direktor des Außenministeriums geführt wurde. Dennoch wird man mit Sicherheit annehmen können, daß im Hinblick auf Italien weitgehender Konsens herrschte. Denn in dem Exposé der außenpolitischen Gesamtlage, das im Anschluß an diese Besprechung für die nächste Sitzung des Conseil supérieur de la défense nationale entstand, wird vermerkt, daß sich das Außenministerium grosso modo mit den Ausführungen des Generalstabs einverstanden erklärt habe ${ }^{59}$. Zudem erachtete es das Ministerium am Quai d'Orsay in der italienischen Frage nicht für notwendig, das Memorandum des Generalstabs, das dann auf der Sitzung am 9. Januar 1912 als Note de présentation vorgelegt wurde, durch eine Note schriftlich zu ergänzen, während dies für einige andere Fragen durchaus der Fall war ${ }^{60}$.

Begreift man diese Note de présentation, mit deren Vortrag die Sitzung des Conseil supérieur de la défense nationale eröffnet wurde, als Summe der vorausgegangenen Besprechungen, dann waren sich die politischen und militärischen Entscheidungsträger einig, [que l'] Italie [...] restera probablement neutre $^{61} . \mathrm{Zu}$ rechnen war nach Ansicht des höchsten Gremiums in strategi-

55 Zit. ibid.

56 Zit. ibid.

57 Vgl. Procès-verbal. CSDN, 11. 10. 1911, in: SHA 2N1, V/29.

$58 \mathrm{Zit}$. Iswolski an Sasonow, 5. 12. 1912, in: STIEVE, Iswolski-Schriftwechsel II, 606. Ausdrücklich zog Poincaré diese Möglichkeit auch für den Fall in Betracht, daß eine militärische Auseinandersetzung zwischen der Habsburgermonarchie und Serbien in einen europäischen Koalitionskrieg einmündete. Vgl. ibid.

59 Vgl. Note de présentation. CSDN, 9. 1. 1912, in: SHA 2N1, VI/36.

60 Die das Memorandum des Generalstabs ergänzenden Noten des Außenministers betrafen Spanien, Belgien, die Schweiz und Rumänien. Vgl. SHA 2N1, VI/34, 1-4.

61 Zit. Note de présentation. CSDN, 9. 1. 1912, in: SHA 2N1, VI/36. 
schen Fragen allerdings damit, daß Italien im Fall einer sich abzeichnenden Niederlage Frankreichs zur Intervention schreiten würde, um sich an der Aufteilung der Kriegsbeute zu beteiligen ${ }^{62}$. Mit dieser Einschätzung hatte man am 9. Januar 1912 das Verhalten Italiens im Kriegsfall auf eine Formel gebracht, der auch Raymond Poincaré in den folgenden Monaten und Jahren uneingeschränkt zustimmte. Nachdem im November 1912 der russische Botschafter eine Reihe von Unterredungen mit Poincaré über die italienische Haltung im Fall einer Eskalation des ersten Balkankrieges geführt hatte ${ }^{63}$, faßte Iswolski seine Eindrücke in einem privaten Brief an Sasonow wie folgt zusammen: Im allgemeinen glaubt man bier, daß weder der Dreiverband noch der Dreibund auf die Loyalität Italiens rechnen können, und daß die italienische Regierung alle Anstrengungen machen wird, um den Frieden zu erhalten; im Fall eines Krieges aber werde sie zunächst eine beobachtende Haltung einnebmen und sich dann der Seite anschließen, auf die der Sieg sich neigt ${ }^{64}$.

$\mathrm{Daß}$ die Besprechungen, die zwischen den militärischen und außenpolitischen Entscheidungsträgern hinsichtlich eines möglichen Kriegseintritts Italiens geführt wurden, nicht den Ton oder die Form einer ernsten Auseinandersetzung annehmen konnten, hatte seinen Grund nicht zuletzt darin, daß nach Ansicht des Generalstabs auch eine Fehlkalkulation der italienischen Absichten keine katastrophalen Folgen haben würde. Denn sollte sich der südöstliche Nachbar Frankreichs entgegen aller Erwartungen zu einer umgehenden Intervention an der Seite des Deutschen Reiches und der Habsburgermonarchie entschließen, so hatte das Abkommen von 1902 gleichwohl Früchte getragen. Hatte doch Italien seit seiner Unterzeichnung auf die Konzentration umfangreicher Kontingente und den Ausbau der militärischen Infrastruktur an der französischen Grenze verzichtet ${ }^{65}$. Aufmerksam hatte man in Frankreich darüber hinaus wahrgenommen, daß die Expeditionsstreitmacht, die Rom im September 1911 nach Afrika entsandt hatte, um dem Osmanischen Reich Tripolitanien und die Cyrenaika zu entreißen, aus Kontingenten zusammengestellt worden war, die vormals an der Grenze zu Frankreich stationiert waren, während die gegen die Habsburgermonarchie gerichteten Bestände unangetastet blieben ${ }^{66}$. Der verringerte Umfang der

$62 \mathrm{Vgl}$. ibid.

63 Vgl. Iswolski an Sasonow, 9. 11. 1912, in: IB III/4,1 201. Vgl. ferner Ders. an Dens., 20. 11. 1912, in: IB III/4,1 300; Ders. an Dens., 21. 11. 1912, in: IB III/4,1 309; Ders. an Dens., 25. 11. 1912, in: IB III/4,1 339 und Ders. an Dens., 5. 12. 1912, in: STIEVE, Iswolski-Schriftwechsel II, 606.

64 Zit. Iswolski an Sasonow, 5. 12. 1912, in: STIEVE, Iswolski-Schriftwechsel II, 608.

$65 \mathrm{Vgl}$. Note indiquant les points relatifs à la situation extérieure à élucider dans la Conférence du 16 octobre 1911, in: SHA 2N1, V/32 und Barrère an Poincaré, 30. 3. 1912, in: DDF 3, 2, 280. Vgl. auch das ausführliche Memorandum des Militärattachés de Gondrecourt in: DDF 3, 2, 280 (Annexe).

66 Vgl. Note de présentation. CSDN, 9. 1. 1912, in: SHA 2N1, V/36. Vgl. ferner Iswolski an Sasonow, 12. 9. 1912, in: STIEVE, Iswolski-Schriftwechsel II, 429. Vgl. auch 
italienischen Kontingente und die unzureichende militärische Infrastruktur mußten aber nach Ansicht des französischen Generalstabes zu einer vergleichsweise langsamen Mobilmachung und Konzentration führen. Dieser Umstand und das alpine Terrain, das eine strategische Defensive außerordentlich begünstigte, machten nach der Einschätzung Joffres Italien zu Beginn der militärischen Auseinandersetzungen eine wirksame Offensive unmöglich 67 .

Ungeachtet der Haltung, die Italien im entscheidenden Augenblick einnehmen würde, bezeichnete der Generalstabschef dann auch die Konzentration von aktiven Kontingenten an der italienischen Grenze zu unterschiedlichen Gelegenheiten als lourde faute ${ }^{68}$. Einige Reserve-Divisionen, so lautete deshalb am 9. Januar 1912 der Beschluß des Conseil supérieur de la défense nationale, sollten, gestützt auf das für eine Defensive günstige Terrain sowie entsprechende Festungen, Italien an einer Invasion des französischen Territoriums hindern ${ }^{69}$. Dementsprechend sah der neue Aufmarschplan nur die Konzentration eines geringfügigen Kontingents von vier Reserve-Divisionen und einigen alpinen Formationen an der italienischen Grenze vor ${ }^{70}$. Nach Ansicht der Militärs, so resümierte der russische Botschafter am 5. Dezember 1912 in einem Brief an seinen Außenminister nach einem Gespräch mit Poincaré die Lage der Dinge, wird [...] das Schicksal des Krieges entschieden sein, ehe Italien Zeit hat, ernstliche Kräfte gegen Frankreich zu konzentrieren ${ }^{71}$, und fuhr dann fort: die französische Regierung [mißt] vom rein militärischen

den Abschnitt »Influence de l'Occupation actuelle de la Libye «, in: Situation sur le pied de guerre des principales armées européennes, 10.11. 1913, in: SHA 7N1771. Vgl. ferner Autriche et Italie, juni 1914, in: SHA 7N1771.

67 Das die Sitzung des Conseil supérieur de la défense nationale am 9. Januar 1912 einleitende Exposé der strategischen Lage kalkulierte, daß Italien zu Beginn der militärischen Auseinandersetzung nur sechs aktive Korps an der Grenze zu Frankreich konzentrieren und frühestens am 18. Tag nach Beginn der Mobilmachung zu einer begrenzten Offensive schreiten konnte. Der Generalstab zog daraus die Schlußfolgerung, que son intervention se produirait trop tard pour exercer une influence sur les premières grandes batailles. Zit. Note de présentation. CSDN, 9. 1. 1912, in: SHA 2N1, V/36. Vgl. in diesem Zusammenhang auch Nostitz an Shilinksi, 17. 1. 1912, in: IB III/2 460.

68 Zit. 2N1, VII/ohne Signatur. Es handelt sich bei diesem Dokument um das maschinenschriftliche Manuskript der Ausführungen, die der Generalstabschef am 21. Februar 1912 dem Kreis der bedeutendsten militärischen und politischen Entscheidungsträger vortrug. Fast wörtlich griff Joffre damit eine Formulierung auf, die sich auch schon in der Note de présentation vom 9. Januar 1912 fand. Dort heißt es: Ce serait, par conséquent, dans tous les cas, une lourde faute de laisser sur notre frontière du Sud-Est des Corps d'Armée actifs dont l'intervention en Lorraine pourrait amener la décision. Zit. Note de présentation. CSDN, 9.1. 1912, in: SHA 2N1, V/36. Vgl. auch JOFFRE, Mémoires, Bd. I, S. 23.

69 Vgl. Procès-verbal. CSDN, 9. 1. 1912, in: SHA 2N1, VI/38.

70 Vgl. Bases du Plan. CSG, 18. 4. 1913, in: SHA 1N11, CXLIII/fol. 3. Der entsprechende Beschluß des Conseil supérieur de la défense nationale ist zum ersten Mal numerisch konkretisiert worden im Rahmen der Ausführungen, die Joffre am 21. Februar 1912 machte. Vgl. 2N1, VII/ohne Signatur.

71 Zit. Iswolski an Sasonow, 5. 12. 1912, in: STIEVE, Iswolski-Schriftwechsel II, 608. 
Standpunkt aus der Stellung, die Italien zu Beginn der kriegerischen Ereignisse einnebmen wird, keine sebr große Bedeutung bei2. So zutreffend diese Einschätzung war, wird man ihr gleichwohl nicht uneingeschränkt zustimmen können. Fanden doch in diesem Brief Iswolskis nicht alle Auswirkungen einer militärischen Intervention Italiens gleichermaßen Berücksichtigung.

Keine Beachtung schenkte Iswolski in diesem Zusammenhang der Tatsache, daß Italien nicht allein einen territorialen, sondern darüber hinaus auch einen nicht unbeträchtlichen maritimen Faktor darstellte. Die Herausforderungen, die aber mit einer militärischen Auseinandersetzung verbunden waren, die das Deutsche Reich und die Habsburgermonarchie in einer Koalition mit Italien fand, bereiteten der französischen Admiralität ersichtliches Unbehagen $^{73}$, zumal diese in ihren Kalkulationen zu der Erkenntnis gelangte, daß Frankreich aufgrund der maritimen Rüstungen Italiens und Österreich-Ungarns seine numerische Superiorität im Mittelmeer zwischen 1913 und 1915/ 1916 einbüßen würde ${ }^{74}$.

Zwar war die Admiralität der Ansicht, daß auch im Fall einer militärischen Intervention Italiens die Kampfkraft ihrer Flotten ausreichen würde, um den Gegnern eine Niederlage beizubringen, doch die unumschränkte Herrschaft im Mittelmeer konnte dann erst in einem fortgeschrittenen Stadium des Konflikts errungen werden. In diesem Fall sah sich aber die Admiralität außerstande, die Sicherheit der Transporte zu garantieren, mit denen unmittelbar

72 Zit. Iswolski an Sasonow, 5. 12. 1912, in: STIEVE, Iswolski-Schriftwechsel II, 608. Vgl. auch Les armées françaises dans la Grande Guerre, Bd. I/1, S. 19.

${ }^{73} \mathrm{Vgl}$. die Ausführungen des Marineministers und Vize Admirals Aubert in der Sitzung des Conseil supérieur de la défense nationale am 9. Januar 1912. Vgl. Procès-verbal. CSDN, 9. 1. 1912, in: SHA 2N1, VI/38. Vgl. auch Grey an Bertie, 24. 5. 1912, in: BD 10/2, 391. Der britische Außenminister unterrichtete in diesem Brief seinen Botschafter von einem Gespräch mit Paul Cambon, in dessen Verlauf dieser ihm mitgeteilt hatte: Poincaré considered that France would have great difficulty in making bead against such a combination, and would, in the event of war, incur great risks and difficulties in transporting troops from Algeria to Europe. Vgl. ferner den nicht signierten Bericht, der im Januar 1912 über eine Unterredung mit Admiral Boue de Lapeyrère an die britische Admiralität gesandt wurde. Lapeyrère, der im Fall einer militärischen Konfrontation das Kommando über die Mittelmeerflotten Frankreichs erhalten sollte, wird dort mit den Worten wiedergegeben: His first preoccupation, and one that would put him in a most difficult position, would be to know whether Italy would join ber allies in case of such a war. Der Admiral führte darüber hinaus aus, daß er in einem solchen Fall weder die Sicherheit des mediterranen Handels noch die Sicherheit des Transportes des 19. Korps gewährleisten könne. Vgl. Report of an interview with Admiral Boue de Lapeyrère, 21. 1. 1912, in: PRO, ADM 116/3109, dort auch das Zitat.

$74 \mathrm{Vgl}$. die Ausführungen in: Collaboration de l'Armée et de la Flotte, 3. 11. 1911, in: SHA 2N1, VI/35. In diesem Memorandum machte die Admiralität ferner darauf aufmerksam, daß sich die Situation zusätzlich verschlechtern würde, sollte das Deutsche Reich eine Reihe von Panzerkreuzern des Typs Moltke im Mittelmeer stationieren. Zur maritimen Rüstung der Habsburgermonarchie und Italiens und ihrer Auswirkung auf das Gleichgewicht der Kräfte im Mittelmeer vgl. HALPERN, Naval Situation, S. $47 \mathrm{f}$. 
zu Kriegsbeginn das 19. Korps von Algerien nach Frankreich verbracht werden sollte ${ }^{75}$.

Nur gegen den Widerstand der Admiralität und unter massivem Druck des Kriegsministeriums und des Generalstabs hatte deshalb der Conseil supérieur de la défense nationale in seiner ersten Sitzung im Jahr 1912 beschlossen, die in Algerien stationierten Kontingente notfalls coûte que coûte ${ }^{76}$ nach Europa überzusetzen. Beide Auffassungen standen sich noch im Mai 1913 unversöhnlich gegenüber, als der Admiralstab das höchste Gremium in Fragen der nationalen Sicherheit abermals mit dieser Angelegenheit befaßte ${ }^{77}$. Doch dieses Mal beendete Poincaré die Aussprache schon nach kurzer Zeit mit einem Argument, das alle anderen Überlegungen dominierte: la question sera simplifiée par le fait que l'Italie ne se déclarera pas immédiatement contre nous $^{78}$.

In dieser Eindeutigkeit, mit der Poincaré im Mai 1913 erklärte, daß Italien im Fall einer militärischen Auseinandersetzung zunächst in Neutralität verharren würde, und mit der auch Joffre schon im August 1911 dem britischen Militärattaché erklärt hatte: Italy will make no move. Her interest lies on our side, not on that of Germany and Austria ${ }^{79}$, haben sich die französischen Entscheidungsträger niemals über die Haltung einer anderen Macht ausgesprochen, deren Entscheidungen ungleich schwerer zu kalkulieren und doch ungleich bedeutender waren. Aber bevor der Frage nachgegangen werden soll, welches Bild sich die militärische und politische Führung vom britischen Verhalten im Krisenfall gemacht hatte, gilt es noch folgendes festzuhalten:

Im Zusammenhang mit den Beratungen über die Frage der Neutralität Italiens zeigt sich zum ersten Mal ein Phänomen, das auch eine bedeutsame Rolle in Frankreichs Beziehungen zu Rußland spielen sollte. Dabei handelt es sich um den Umstand, daß die französische Regierung nicht mehr im politischen Wert eines Abkommens seine herausragende Bedeutung erblickte, sondern vielmehr in seinen Auswirkungen auf die Balance der militärischen Kräfte. Besonders deutlich tritt dies an einer Erwiderung Poincarés auf ein Schreiben des Botschafters in Rom zu Tage, in dem dieser die politische Bedeutung des Neutralitätsabkommens von 1902 betont und hervorgehoben hatte, daß durch seinen Abschluß die Ausgestaltung des Dreibundes zu einer Allianz verhindert worden sei, die eine offensive Außenpolitik des Deut-

\footnotetext{
75 Vgl. den Abschnitt: „Collaboration de l'Armée et de la Flotte«, in: Note de présentation. CSDN, 9. 1. 1912, in: SHA 2N1, VI/36. Vgl. ferner Collaboration de l'Armée et de la Flotte, 3. 11. 1911, in: SHA 2N1, VI/35.

76 Zit. Procès-verbal. CSDN, 9. 1. 1912, in: SHA 2N1, VI/38. Die Formulierung coûte que coûte deutet schon daraufhin, daß die numerische Superiorität der angreifenden französischen Kontingente nur gering sein würde.

77 Vgl. Rapport de Présentation. CSDN, 17. 5. 1913, in: SHA 2N1, VIII/45.

78 Zit. Procès-verbal. CSDN, 17. 5. 1913, in: SHA 2N1, VIII/46.

79 Zit. Fairholme an Bertie, 24. 8. 1911, in: BDFA France 13/70.
} 
schen Reiches begünstige ${ }^{80}$. Plus encore que les résultats diplomatiques de ce pacte, so korrigierte Poincaré den Botschafter, $j$ 'en apprécie les conséquences militaires. Il est avéré que, depuis bientôt dix ans, la défense de notre frontière des Alpes ne nous impose plus que de simples mesures de précaution: notre puissance d'action sur la frontière du Nord-Est est donc sensiblement accrue ${ }^{81}$. Ähnlich sollte sich der Ministerpräsident dann auch rund sechs Monate später gegenüber dem russischen Botschafter äußern. Der Wert dieses Vertrages, so umschrieb Iswolski den Kommentar, den ihm Poincaré zu dem Neutralitätsabkommen von 1902 gegeben hatte, liege für Frankreich nicht in diesen oder jenen Worten, sondern darin, daß seit seinem Abschluß Italien an der französischen Grenze alle Defensiv- und Offensivmaßregeln tatsächlich unterlassen und seine Vorbereitungen an die österreichische Grenze verlegt habe ${ }^{82}$. Wörtlich sagte Poincaré dem Botschafter: sein praktisches Resultat bestand für Frankreich darin, daß es seine militärische Stellung an der italienischen Grenze [...] schwächer gestalten und mithin seine ganzen Kräfte und Maßnabmen gegen Deutschland richten konnte ${ }^{83}$. Deutlich zeigt sich, daß der politische Charakter des Arrangements in den Hintergrund trat und mehr und mehr von seiner militärischen Funktion überlagert wurde. Die Bedeutung des Abkommens bestand nach Auffassung Poincarés nicht mehr primär in der Bewahrung des Friedens, sondern in der Vorbereitung des militärischen Triumphes. Vor dem Hintergrund eines uneingeschränkten Angriffs auf das Deutsche Reich lag sein größter Vorzug eben darin, daß es Frankreich im entscheidenden Augenblick gestatten würde, seine Kontingente uneingeschränkt im Norden und Osten des Landes zu konzentrieren, während im Südosten nur einige wenige Reserveformationen vorgehalten werden mußten. Was im italienischen Fall zum ersten Mal aufblitzte, wird sich später auch in den Absprachen nachweisen lassen, die Frankreich mit Rußland verbanden.

Großbritannien: Der unberechenbare Freund Neueren Datums als das Abkommen mit Italien und von gänzlich unterschiedlicher Qualität waren die

80 Vgl. Barrère an Poincaré, 10. 3. 1912, in: DDF 3, 2, 181. Das Dokument wird in der Aktenpublikation leicht gekürzt wieder gegeben. Das Original befindet sich in: MAE, NS Italie 22, fol. 60/2f.

81 Zit. Poincaré an Barrère, 18. 3. 1912, in: DDF 3, 2, 218. Vgl. in diesem Zusammenhang auch die Erinnerungen des ersten Sekretärs an der französischen Botschaft in Rom. Vgl. Jules LAROCHE, Quinze ans à Rome avec Camille Barrère (1898-1913), Paris 1948, S. 270 f. Ähnlich ließ sich Poincaré auch kurze Zeit später gegenüber dem russischen Botschafter vernehmen. Vgl. Iswolski an Sasonow, 6. 6. 1912, in: STIEvE, Iswolski-Schriftwechsel II, 316.

82 Zit. Iswolski an Sasonow, 5. 12. 1912, in: STIEVE, Iswolski-Schriftwechsel II, 606. Vgl. Ders. an Dens., 5. 12. 1912, in: ibid., 608.

${ }^{83}$ Zit. Iswolski an Sasonow, 5. 12. 1912, in: ibid., 606. Vgl. in diesem Zusammenhang auch den Bericht des britischen Botschafters für das Jahr 1912. Vgl. Bertie, Annual Report France 1912, 1. 8. 1913, in: BDFA France 13/108. 
Abmachungen, die Großbritannien und Frankreich für den Fall der militärischen Eskalation einer Krise getroffen hatten ${ }^{84}$. Was ihre Form anbetraf, so handelte es sich bei ihnen weder um eine Allianz noch um ein Neutralitätsabkommen oder einen Nichtangriffspakt. Im Unterschied zur Militärkonvention, die Frankreich an Rußland, und dem Abkommen, das Frankreich an Italien band, lag der Entente cordiale kein förmliches Beistandsversprechen und keine Bestimmung zugrunde, die beide Staaten unter bestimmten Bedingungen zur Neutralität oder gar zu gegenseitigem militärischen Beistand verpflichtete ${ }^{85}$. Bei Ausbruch des Großen Krieges beruhten die Beziehungen zwischen beiden Staaten auf mehreren kolonialpolitischen Abkommen, einer Reihe letztlich unverbindlicher Marine- und Militärkonventionen sowie einem Konsultationsversprechen für den Fall einer den Frieden Europas akut gefährdenden internationalen Krise.

Nach einer langen Phase des kolonialpolitischen Konflikts, in der Frankreich und Großbritannien ihre Rivalität bis hart an den Rand einer militärischen Auseinandersetzung geführt hatten, war es ihnen erst 1904 gelungen, ihre gegensätzlichen Interessen in Amerika, Asien und Afrika zu vergleichen. Der Form nach handelte es sich bei der am 8. April 1904 unterzeichneten Entente cordiale um eine Reihe kolonialer Abkommen, die - was ihre folgenreichste Bestimmung betraf - Frankreich freie Hand in Marokko gewährten, während sie Großbritannien im Gegenzug Ägypten überließen ${ }^{86}$. Schon bald sollten allerdings diese kolonialen Abkommen Rückwirkungen auf den europäischen Kontinent zeitigen.

Ihren Ausdruck fanden sie in den Gesprächen, die zwischen den Militärs beider Staaten geführt und vom britischen Außenminister erstmals 1906 genehmigt worden waren ${ }^{87}$. Sie mündeten nach einer längeren Phase der Un-

${ }^{84}$ Zum folgenden vgl. Christel GADE, Gleichgewichtspolitik oder Bündnispflege? Maximen britischer Außenpolitik (1909-1914), Göttingen, Zürich 1997 (Veröffentlichungen des Deutschen Historischen Instituts London, 40), S. 158-164 und grundlegend: Williamson, Grand Strategy, S. 264-299.

${ }^{85}$ Zum Unterschied zwischen Allianzen und Ententen vgl. grundsätzlich Geoff R. BERRIDGE, Ententes and Alliances, in: Review of International Studies 15 (1989), S. 251-260, hier S. 251 f.; Robert KANN, Alliances versus ententes, in: World Politics 28 (1976), S. 611-621, hier S. 611 f. und Rudolf KJELLÉN, Dreibund und Dreiverband. Die diplomatische Vorgeschichte des Weltkrieges, München 1921, S. 9.

86 Vgl. den Text des Abkommens in: DDF 2, 4, 389. Für die Verhandlungen, die zum Abschluß der Entente cordiale führten vgl. grundlegend Christopher M. ANDREw, France and the Making of the Entente Cordiale, in: HJ 10 (1967), S. 89-105 und DERS., Delcassé and the Making of Entente Cordiale, London 1968, S. 201-215, hier insbesondere S. 210-212.

${ }^{87}$ Nur ein kleiner Kreis des britischen Kabinetts war zunächst in diese Verhandlungen eingeweiht worden. Vgl. Keith A. HAMILTON, Great Britain and France, 1905-1911, in: Francis Harry HiNSLEY (Hg.), British Foreign Policy under Sir Edward Grey, Cambridge 1977, S. 113-132, hier S. 114. Zur Frage, wer im britischen Kabinett zu welchem Zeitpunkt über diese Gespräche informiert wurde, vgl. John W. COOGAN, Peter F. CoOGAN, The British Cabinet and the Anglo-French Staff Talks. 1905-1914, in: Journal of British Studies 24 (1984), S. 110-131, hier insbesondere S. 121, $126 \mathrm{f}$. 
terbrechung schließlich in ein ausführliches, die technischen Details regelndes Memorandum über die Entsendung eines britischen Expeditionskorps nach Frankreich, das am 20./21. Juli 1911 vom Leiter der militärischen Operationsabteilung des britischen Stabes, Sir Henry Wilson, und vom Generalstabschef der französischen Armee, Auguste Dubail, unterzeichnet wurde ${ }^{88}$. Darüber hinaus zeitigte die Entente cordiale auch Rückwirkungen auf dem maritimen Sektor ${ }^{89}$. So wurden 1912 intensive Gespräche zwischen den Admiralstäben beider Staaten aufgenommen, die in den ersten Monaten des Jahres 1913 ihren schriftlich fixierten Niederschlag in verschiedenen Marinekonventionen für den Ärmelkanal, das Mittelmeer und den Fernen Osten fanden ${ }^{90}$. Was den Kern der Sache anbetraf, so übertrugen sie für den Fall einer gemeinschaftlichen Kriegsführung Großbritannien den Schutz der französischen Kanal- und Atlantikküste, während Frankreich die britischen Interessen im Mittelmeer wahren sollte.

Politisch sanktioniert worden waren diese Besprechungen zwischen den Militärs beider Staaten schon einige Monate zuvor, als der britische Außenminister und der französische Botschafter am 22./23. November 1912 jene noch genauer zu untersuchenden Briefe austauschten, die das eingangs erwähnte Konsultationsversprechen für den Fall einer akuten europäischen Kriegsgefahr enthielten ${ }^{91}$.

Die militärischen Absprachen zwischen Frankreich und Großbritannien waren damit bis zur Julikrise zu einem solchen Grad ausgebaut und die politischen Beziehungen bis zu einem Punkt konsolidiert worden, daß einer ihrer besten Kenner sogar von einer quasi-alliance ${ }^{92}$ gesprochen hat. Allerdings darf diese Formel nicht darüber hinwegtäuschen, daß die Entente cordiale bis zum Kriegsausbruch keinen Allianzcharakter trug und daß ihr Charakter wie James Joll einmal urteilte - »rätselhaft « ${ }^{93}$ blieb.

Schon diese beiden unterschiedlichen Einschätzungen der Entente cordiale deuten an, daß die Frage, ob und bis zu welchem Grad Großbritannien in den letzten Jahren vor Ausbruch des Großen Krieges seine Handlungsfreiheit eingeschränkt hatte, kontrovers diskutiert wird. Das Spektrum der Meinungen reicht von der - insbesondere in der älteren Forschung anzutreffenden These, daß die Militär- und Marinekonventionen bindenden Charakter gehabt und im materiellen Sinn eine Verpflichtung zu militärischem Beistand

$88 \mathrm{Vgl}$. Memorandum de la conférence du 20 juillet 1911, in: MAE, NS Grande Bretagne 22, fol. 111-113.

89 Vgl. grundlegend: WILliamSON, Grand Strategy, S. 227-248, 264-283.

90 Vgl. den Text der Marinekonventionen, in: MAE, NS Grande Bretagne 22, fol. 214 227.

91 Vgl. Grey an Paul Cambon, 22. 11. 1912, in: BD 10/2, 416. Vgl. auch Paul Cambon an Grey, 23.11. 1912, in: BD 10/2 417.

92 Zit. Williamson, Grand Strategy, S. 299.

93 Zit. James Joll, Die Ursprünge des Ersten Weltkrieges, München 1988, S. 95. 
nach sich gezogen hätten ${ }^{94}$, über die zumeist mit einem Hinweis auf die unterschiedlichen Flottenkonzentrationen begründete These eines moral commitments Großbritanniens ${ }^{95}$ bis hin zu den Interpretationen, die allein aus den British Interests eine Verpflichtung zur militärischen Unterstützung Frankreichs ableiten möchten ${ }^{96}$.

Als Ausgangspunkt für die Beantwortung der Frage, in welchem Umfang die zwischen beiden Staaten bestehenden Abmachungen die Handlungsfreiheit der britischen Regierung einschränkten und - was in dem hier zu behandelnden Zusammenhang noch weitaus bedeutsamer ist - ob die militärische und politische Führung Frankreichs glaubte, daß dies der Fall sei, mag eine Untersuchung der Genese der Marineabkommen und des Grey-CambonBriefwechsels dienen, also jener Dokumente, an denen sich die Geister der Historiker scheiden.

Angesichts der maritimen Herausforderung durch das Deutsche Reich, die im Mai 1912 mit der dritten Flottengesetzesnovelle einen neuen Höhepunkt erreicht hatte, sah sich Großbritannien gezwungen, den seit 1889 für seine maritimen Planungen grundlegenden two-power standard aufzugeben ${ }^{97}$. Das Kabinett beschloß am 16. Juli 1912, die britischen Flotten verstärkt in den Gewässern der Inseln oder ihrer Nähe zu konzentrieren und in diesem $\mathrm{Zu}$ sammenhang die in Malta stationierten Linienschiffe nach Gibraltar zu verlegen $^{98}$. Mit dieser Entscheidung waren folgenreiche Konsequenzen für Großbritanniens Stellung im Mittelmeer verbunden. Bedeutete doch der partielle Rückzug der britischen Flotten aus diesen Gewässern, daß in einer militärischen Auseinandersetzung mit dem Deutschen Reich, in die die Habsburgermonarchie und Italien eintraten, die bedeutendste Seemacht Europas nicht mehr in der Lage war, aus eigener Kraft die mediterranen Kommunikations-

$94 \mathrm{Vgl}$. die entsprechenden Hinweise in: Hermann LuTz, Sir Edward Greys »Freie Hand «, in: Archiv für Politik und Geschichte 6 (1926), S. 352-401, hier S. 389 f.

$95 \mathrm{Zu}$ dieser Ansicht tendieren: Keith A. HamilTON, Great Britain and France, 19111914, in: Hinsley (Hg.), British Foreign Policy, S. 324-341, hier S. 335; DeRS., Bertie, S. 296; Thomas OTTE, The Elusive Balance. British Foreign Policy and the French Entente before the First World War, in: Alan SHARP, Glyn STONE (Hg.), Anglo-French Relations in the Twentieth Century. Rivalry and Co-operation, London, New York 2000, S. 11-35, hier S. 27 und Williamson, Grand Strategy, S. 370.

96 So z. B. GADE, Gleichgewichtspolitik, S. 158; Keith M. Wilson, The Policy of the Entente. Essays on the Determinants of British Foreign Policy 1904-1914, Cambridge, New York 1985, S. 96; Ders., To the Western Front: British War Plans and the »Military Entente " with France before the First World War, in: British Journal of International Studies 3 (1977), S. 151-168, hier S. 167f. und Trevor WILSON, Britain's "Moral Commitment « to France in August 1914, in: History 64 (1979), S. 380-390, hier S. 389 f. 97 Vgl. Robert K. MASSIE, Die Schalen des Zorns: Großbritannien, Deutschland und das Heraufziehen des Ersten Weltkrieges, Frankfurt am Main 1993, S. 696 f.

98 Zur Dislozierung der britischen Flotten vgl. WILliamSON, Grand Strategy, S. 264283 und Paul G. HALPERN, The Mediterranean Naval Situation, 1908-1914, Cambridge (Mass.) 1971, S. 13-46. Vgl. ferner Arthur Jacob MARDER, From the Dreadnought to Scapa Flow. The Royal Navy in the Fisher era, 1904-1919, Bd. I, London 1961, S. 287311. 
linien ihres Empires zu sichern"9. Erst im Jahr 1915 wäre Großbritannien wieder imstande gewesen, sich im Mittelmeer gegenüber der Habsburgermonarchie zu behaupten und den vom Committee of Imperial Defence angestrebten one-power mediterranean standard, excluding France zu erreichen $^{100}$.

Die Frage, wer im Fall einer militärischen Auseinandersetzung die britischen Interessen im Mittelmeer schützen würde, war nach langem Zögern vom Kabinett dahingehend beantwortet worden, daß eine Marinekonvention mit Frankreich ausgehandelt werden sollte. Schon einen Tag, nachdem das Kabinett die Entscheidung zum partiellen Rückzug aus dem Mittelmeer getroffen hatte, begannen am 17. Juli 1912 die nunmehr offiziell autorisierten Gespräche zwischen den militärischen Experten beider Länder. Sie mündeten in jene Abkommen aus dem Februar 1913, die in aller erforderlichen Detailfülle die maritime Kooperation beider Staaten für den Fall einer gemeinsamen Kriegsführung regelten und Großbritannien de facto den Schutz der französischen Kanal- und Atlantikküste übertrugen, während Frankreich, das seine Flotten im Herbst 1912 nunmehr vollständig im Mittelmeer konzentrierte, die militärischen Operationen in diesen Gewässern führen sollte ${ }^{101}$.

Es kann nun nicht bestritten werden, daß die Existenz dieser Marinekonventionen die von Frankreich im Jahr 1912 vorgenommene Umverteilung seiner Flotten auch für die Zukunft festschrieb und daß damit - auch für den Fall, daß Großbritannien sich im entscheidenden Moment zu keiner Intervention entschloß - jegliche maritime Strategie Frankreichs von einer Konzentration seiner Flotte im Mittelmeer ausgehen mußte ${ }^{102}$. Dieser Aspekt der Marineabkommen bereitete den Verantwortlichen in London sichtlich Sorge. Sah doch beispielsweise der britische Marineminister in seinem Brief an Grey und Asquith vom 23. August 1912 eine erhebliche Einschränkung der Handlungsfreiheit voraus, falls Frankreich im Krisenfall sagen könnte: on the advice of and by arrangement with your naval authorities we bave left our Northern Coasts defenceless. We cannot possibly come back in timer. Indeed it would probably be decisive whatever is written down now. Everyone must feel who knows the fact that we have the obligations of an alliance without its advantages, and above all without its precise definitions ${ }^{103}$.

99 Vgl. Committee of Imperial Defence: Minutes from the 118th Meeting, 11. Juli 1912, in: Esmond W. R. LUMBY (Hg.), Policy and operations in the Mediterranean 1912-1914, London 1970 (Publications of the Navy Records Society, 115), S. 86-89. Vgl. ferner StEINER, NeILSON, Britain and the Origins, S. $108 \mathrm{f}$. und HALPERN, Naval Situation, S. $41-43$.

100 Zit. Committee of Imperial Defence: Minutes from 117th Meeting, 4. Juli 1912, in: LumBY, Policy, S. 83.

101 Der Text dieser Abkommen findet sich in: MAE, NS Angleterre 22, fol. 213-227.

102 Vgl. Williamson, Grand Strategy, S. 234.

103 Zit. Churchill an Grey und Asquith, 23. 8. 1912, in: CHurCHILl, Churchill-Companion II Part 3, S. 1639. 
Tatsächlich hatte Churchill mit diesen Sätzen die Argumentationsfigur treffend beschrieben, die Frankreich nutzen wollte, um Großbritannien fester an den Kontinent zu binden. In einem Gespräch mit dem britischen Außenminister bezeichnete der französische Botschafter dementsprechend den Hinweis des Marineministers, that [the] disposition of naval forces bad been made by each Government quite independently of the other to suit their own interest ${ }^{104}$ umgehend als error ${ }^{105}$. Auch Poincaré, dem Sir Francis Bertie zu erklären suchte, daß es sich bei dieser Einschätzung Cambons seinerseits um ein Mißverständnis handeln müsse, beharrte, it would not have been taken if they [gemeint ist das französische Kabinett, St. S.] could suppose that in the event of Germany making a descent on the Channel or Atlantic ports of France, England would not come to the assistance of France. If such was to be the case the conversations between the Naval Experts would be useless and the French Government must have their best ships to face Germany in the Channel 106 . Dementsprechend insistierte der französische Botschafter in seinen Gesprächen mit Grey darauf, daß die Marinekonvention eine moral ¿Entente 107 begründete, und noch im August 1914 sollte er ähnlich argumentieren, als er hervorhob, that it was at our request that France had moved her fleets to the Mediterranean, on the understanding that we undertook the protection of her Northern and Western coasts ${ }^{108}$. Diese Bemerkung konnte den britischen Außenminister zwar nicht davon abhalten, jegliche Verpflichtung gegenüber dem französischen Botschafter zurückzuweisen ${ }^{109}$, führte letztlich aber doch dazu, daß auch Grey im Kabinett von Frankreichs Vertrauen auf die Entente respektive von den ungeschützten französischen Küsten sprach und dies als Argument benutze, nto lever his colleagues into a decision for war « 110 .

Um nun das zu vermeiden, was im August 1914 dann tatsächlich geschah um zu vermeiden, daß Frankreich unter Hinweis auf die mit der Existenz der Marinekonvention einhergehende Konzentration seiner Flotten im Mittelmeer den militärischen Beistand Großbritanniens einforderte - hatte Churchill schon zu einem frühen Zeitpunkt in die maritimen Arrangements einen

104 Zit. Grey an Carnegie, 26. 7. 1912, in: BD 10/2, 402. Auch Tyrell beharrte in seiner Untersuchung mit dem britischen Botschafter in Paris darauf, daß die Flottenkonzentration unabhängig voneinander vorgenommen worden sei. Vgl. die Aufzeichnung Berties vom 25. 7. 1912 in: NL Bertie, PRO, FO 800/165, fol. 156.

105 Zit. Grey an Carnegie, 26. 7. 1912, in: BD 10/2, 402.

106 Zit. Bertie an Grey, 30. 7. 1912, in: BD 10/2, 404. Vgl. auch Ders. an Dens., 13. 8. 1912, in: NL Grey, PRO, FO 800/ 53, fol. 114.

107 Zit. Grey an Carnegie, 22. 7. 1912, in: BD 10/2, 400.

108 Zit. Nicolson an Grey, 1. 8. 1914, in: NL Nicolson, PRO, FO 800/375, fol. 156. Vgl. auch Grey an Bertie, 1. 8. 1914, in: BD 11, 426 und Paul Cambon an Viviani, 1. 8. 1914, in: DDF 3, 11, 532.

109 Vgl. Grey an Bertie, 1. 8. 1914, in: BD 11, 447.

110 Zit. Keith M. WILSON, Policy of Entente. Essays on the Determinants of British Foreign Policy 1904-1914, Cambridge, New Yok 1985, S. 144. 
die britische Handlungsfreiheit bewahrenden Passus aufnehmen wollen ${ }^{111}$. Zwar fanden seine Bedenken letztlich keinen Eingang in die Marinekonventionen, wohl aber in den Grey-Cambon-Briefwechsel - also in jenes Dokument, von dem der britische Außenminister sagte, daß es die maritimen Abkommen in das rechte Licht ${ }^{112}$ setze. So wurde in dem Brief Greys ausdrücklich festgehalten, [that] the disposition [...] of the French and British fleets respectively at the present moment is not based upon an engagement to cooperate in war ${ }^{113}$. Dieser Einschub mochte nun Großbritannien vielleicht in einem formal juristischen Sinne exkulpieren, konnte aber den Inselstaat nicht von einer moralischen Beistandspflicht lösen, wenn das, was der Botschafter und der Ministerpräsident Frankreichs behaupteten, in der Sache zutraf. Prima facie leuchtet der Hinweis Poincarés ein, daß Frankreich in einem Krieg gegen das Deutsche Reich ohne britische Beteiligung seine besten Schiffe in der Nordsee benötige, und besitzt große Plausibilitä ${ }^{114}$. Geht man jedoch den Dingen auf den Grund, so erkennt man, daß es sich bei dieser Behauptung um eine kalkulierte Unwahrheit handelte. Denn beide Staaten hatten in der Tat die Entscheidung zur Konzentration ihrer Flotten in den britischen Gewässern respektive im Mittelmeer unabhängig voneinander getroffen.

Auf diesen Umstand hatte Churchill schon in seinem Schreiben vom 23. August 1912 an Grey und Asquith aufmerksam gemacht hatte. If the

111 Vgl. den ersten Entwurf der Marinekonvention, die Churchill dem französischen Marineattaché am 23. Juli 1912 unterbreitete, in: BD 10/2, 400 (Ed. Note). Vgl. auch Delcassé an Poincaré, 17. 9. 1912 (Annexe I), in: DDF 3, 3, 420. Schon in seiner ersten Unterredung mit Le Gouz de Saint-Seine am 17. Juli hatte der erste Lord der Admiralität dem Franzosen deutlich zu verstehen gegeben, [qu']il est bien entendu que cette convention ne lierait en rien la politique des deux pays, et qu'elle ne prendrait de valeur que le jour où les cabinets de France et d'Angleterre décideraient d'un commun accord de la faire entrer en action. [...] Je désire même, [...] que cette restriction soit expressément formulée, dans les termes qui devront être soigneusement étudiés, en tête des notes qui seront échangées entre les Etats-majors. Zit. Le Gouz de Saint-Seine an Delcassé, 18. 7. 1912, in: DDF 3, 3, 207. Vgl. auch Churchills Aufzeichnung über diese Unterredung in: $\mathrm{BD} 10 / 2,399$.

112 Zit. Benckendorff an Sasonow, 23. 5. 1914, in: STIEvE, Iswolski-Schriftwechsel III, 1348. Vgl. in diesem Zusammenhang auch eine Aufzeichnung, die Bertie über ein Gespräch mit Grey anfertigte, das am 17. Juli 1912 stattfand. In ihr wird der Außenminister mit den Worten wiedergegeben: He told me that it had been found that the communications between the British and French Naval Experts under the late Board of Admiralty had been much more far-reaching and committal than the Cabinet was aware of. The Cabinet had sanctioned a renewal of the discussion as to bring the plans up to date but a communication was to be made to the French Government through Cambon and me to the effect that anything arranged between the experts was not to be beld to bind or commit the Governments and that the discussion between the experts were to be entirely without prejudice. Zit. NL Bertie, PRO, FO 800/165, fol. 151.

113 Zit. Grey an Paul Cambon, 22. 11.1912, in: BD 10/2, 416. Bezeichnenderweise griff Cambon in seiner Antwort diese Formel nicht auf. Vgl. Paul Cambon an Grey, 23. 11. 1912, in: BD 10/2, 417.

114 Vgl. Bertie an Grey, 30. 7. 1912, in: BD 10/2, 404. 
French [...] say that they have denuded their Atlantic seaboard, and concentrated in the Mediterranean on the faith of naval arrangements made with us, this will not be true. If we did not exist, the French could not make better dispositions than at present. They are not strong enough to face Germany alone, still less to maintain themselves in two theatres. They therefore rightly concentrate their Navy in the Mediterranean where it can be safe and superior and can assure their African communications ${ }^{115}$. Mit diesen Sätzen sind nun tatsächlich die maßgeblichen Gründe benannt, die Frankreich im Jahr 1912 veranlaßten, auch seine letzten großen Schlachtschiffe aus dem Atlantik abzuziehen.

Bei dieser Entscheidung handelte es sich nämlich keinesfalls - dies gilt es zunächst festzuhalten - um einen Bruch mit der bis zu diesem Zeitpunkt verbindlichen Praxis. Sie entsprach vielmehr einem Muster, das schon 1907 angelegt worden war, als Frankreich die Schiffe der Patrie-Klasse in seinen südlichen Gewässern stationierte, und das man in den folgenden Jahren fortschrieb, als die Schlachtschiffe der neuen Danton-Klasse sukzessive im Mittelmeer konzentriert wurden, so daß bis zum Herbst 1911 nur sechs alte Schlachtschiffe im Atlantik verblieben ${ }^{116}$. Die Konzentration der maritimen Kontingente im Mittelmeerraum ging ab Juli 1911 darüber hinaus mit einer instruction de guerre einher, die auch für den Fall einer militärischen Auseinandersetzung mit dem gesamten Dreibund das Deutschen Reich als den Gegner benannte, gegen den Frankreichs Flotten primär zum Einsatz gebracht werden sollten ${ }^{117}$. Mit anderen Worten: Schon zu diesem Zeitpunkt lag einer maritimen Strategie, die den Atlantik und die Nordsee zum eigentlichen Kriegstheater machte, die Stationierung der bedeutendsten maritimen Kontingente im Mittelmeer zugrunde.

Unter Vize-Admiral Marie Aubert, der im Februar 1912 zum Chef des Admiralstabes ernannt wurde, sollte die Konzentration der französischen Schlachtflotte im Mittelmeer noch forciert werden, und unter seiner Leitung wurden darüber hinaus auch die instructions de guerre einer gründlichen $\mathrm{Re}-$ vision unterzogen, so daß diese nunmehr die Erringung der Herrschaft im Mittelmeer zum primären strategischen Ziel erklärten. Dies sollte auch dann der Fall sein, wenn Großbritannien nicht in die militärischen Auseinandersetzungen mit dem Dreibund eingreifen würde ${ }^{118}$.

115 Zit. Churchill an Grey und Asquith, 23. 8. 1912, in: CHURCHILl, Churchill-Companion II Part 3, 1639. Vgl. auch CHURCHILL, World Crisis, Bd. I, S. $115 \mathrm{f}$. Vgl. ferner die Aufzeichnung des britischen Botschafters in Paris vom 27. Juli 1912 in: NL Bertie, PRO, FO 800/165, fol. 156.

116 Vgl. HalPERn, Naval Situation, S. $70 \mathrm{f}$., $84 \mathrm{f}$. sowie WILliamSON, Grand Strategy, S. $284 \mathrm{f}$.

117 Vgl. Halpern, Naval Situation, S. 69f. und Williamson, Grand Strategy, S. 285. 118 Schon im Jahr 1906 hatte sich Aubert für eine Konzentration aller disponiblen Kontingente im Mittelmeer ausgesprochen. Vgl. HalperN, Naval Situation, S. 63-65, 72 sowie Williamson, Grand Strategy, S. 233-235. 
Maßgeblich für das Handeln des Admiralstabschefs war zum einen die Einsicht, daß das Deutsche Reich auf dem maritimen Sektor für Frankreich zu einem weit überlegenen Gegner geworden war und eine direkte Konfrontation mithin ein ungleicher und aussichtsloser Kampf sein würde ${ }^{119}$. Zum anderen - darauf ist schon in Zusammenhang mit der Frage aufmerksam gemacht worden, welches Urteil sich die bedeutendsten militärischen und politischen Entscheidungsträger vom italienischen Verhalten im Kriegsfall machten - hatten sowohl die Habsburgermonarchie als auch Italien ihre maritime Rüstung in einem Maße gesteigert, das nunmehr alle disponiblen Kräfte ${ }^{120}$ erforderlich machte, um im Kriegsfall die Kommunikationslinien zwischen dem nördlichen Afrika und Frankreich zu sichern. Ihrem Schutz maß aber der neue Admiralstabschef ganz erhebliche Bedeutung $\mathrm{zu}^{121}$. Sowohl für die Entsendung des dritten Schlachtschiffgeschwaders vom Atlantik in das Mittelmeer ${ }^{122}$ als auch für die Revision der strategischen Planungen hatte Aubert bis zum Juli 1912 die Zustimmung des Marineministers erhalten, das heißt zu einem Zeitpunkt, als die Verhandlungen mit dem britischen Admiralstab noch nicht einmal begonnen hatten ${ }^{123}$ !

Schon allein diese Entscheidung macht deutlich, daß Frankreich nicht aufgrund seiner maritimen Arrangements mit Großbritannien seine Flotten im Mittelmeer konzentriert hatte und daß folglich auch nach der subjektiven Einschätzung der Verantwortlichen an der Seine für Großbritannien keine moralische Pflicht zu einer militärischen Intervention bestand. Aber allein die Existenz dieser Abkommen führte dann doch - als ein Faktor unter anderen - dazu, daß die militärische und politische Führung Frankreichs mit einer gewissen Zuversicht der Entscheidung entgegenblickte, die Großbritannien im Fall der militärischen Eskalation einer internationalen Krise treffen würde.

Am weitesten gingen in dieser Hinsicht die Erwartungen des Generalstabs. In den die außenpolitische Gesamtlage resümierenden Passagen der sogenannten »Grundlagen des Plan XVII«, die der Generalstabschef am 18. April

$119 \mathrm{Zu}$ Aubert vgl. Halpern, Naval Situation, S. $71 \mathrm{f}$. und Williamson, Grand Strategy, S. $285 \mathrm{f}$.

120 Schon in dem Memorandum, das der Marineminister am 3. November $1911 \mathrm{dem}$ Conseil supérieur de la défense nationale übermittelte, war darauf aufmerksam gemacht worden, daß angesichts der maritimen Rüstungen der Habsburgermonarchie und Italiens sich die Admiralität im Kriegsfall gezwungen sehen könnte, d'attendre l'arrivée de notre $3^{e}$ escadre pour frapper les coups décisifs. Zit. Collaboration de l'Armée et de la Flotte, 3. 11. 1911, in: SHA 2N1, VI/35.

121 Vgl. Memorandum, 7. 5. 1912, in: SHM, SSEd 38.

122 Durch einen Irrtum wurden die entsprechenden Instruktionen noch während der Verhandlungen über den endgültigen Wortlaut des Grey-Cambon Briefwechsels ausgeführt, was den französischen Botschafter in einige Verlegenheit setzte. Vgl. Grey an Bertie, 19. 9. 1912, in: BDFA France 13/98 und Ders. an Dens., 21. 9. 1912, in: BDFA France 13/99. Vgl. ferner Paul Cambon an Poincaré, 19. 9. 1912, in: DDF 3, 3, 431 und HALPERN, Naval Situation, S. 74, 94.

123 Vgl. HALPERN, Naval Situation, S. 73. 
1913 dem Conseil supérieur de la guerre zur Abstimmung unterbreitete, wurde zwar darauf hingewiesen, daß Großbritannien zu keinem militärischen Beistand verpflichtet sei. Gleichwohl sprachen die Bases du Plan dann aber doch davon, daß Frankreich sans témérité auf eine Unterstützung durch die britischen Flotten rechnen könne ${ }^{124}$, und ein entsprechender Hinweis ist auch schon in der Note de présentation für die Sitzung des Conseil supérieur de la défense nationale am 9. Januar 1912 enthalten ${ }^{125}$. Überhaupt läßt sich feststellen, daß die militärische Führung Frankreichs - möglicherweise aufgrund der sich weit weniger Zurückhaltung auferlegenden britischen Militärs - die Frage, ob Großbritannien in einen Krieg eintreten würde, optimistischer beurteilte und eindeutiger bejahte als die politische Führung. So findet sich in dem die außenpolitische Gesamtlage Frankreichs analysierenden Memorandum des Generalstabs, das am 16. Oktober 1911 der Besprechung zwischen Joffre und dem Politischen Direktor des Außenministeriums zugrunde lag, der Satz: Des conversations échangées avec les état-majors anglais, se dégage l'impression très nette que nous pouvons entièrement compter sur le concours de l'Angleterre, en cas de guerre avec l'Allemagne ${ }^{126}$.

Mit sehr viel mehr Zurückhaltung, aber mit gleichfalls nicht zu verkennender Zuversicht fanden die Militär- und Marinekonventionen in dem Gespräch Erwähnung, das Poincaré mit dem russischen Botschafter am 5. Dezember 1912 führte. So berichtete der französische Ministerpräsident und Außenminister Iswolski, daß Großbritannien zwar einerseits keine Verpflichtung für den Fall der militärischen Eskalation einer Krise eingegangen sei, andererseits aber stellte er dem gegenüber, daß die bestebenden Abmachungen $z u$ Lande und $z u$ Wasser [...] in allerletzter Zeit eine noch größere Erweiterung erfabren bätten, so daß augenblicklich die engl.-frz. Militärkonvention [...] in allen Einzelheiten durchgearbeitet und erschöpfend ${ }^{127}$ sei.

Daß Poincaré in seinen Gesprächen mit dem russischen Botschafter nur mit aller Vorsicht auf die Militär- und Marinekonventionen verweisen konnte, wenn es galt, Großbritanniens Haltung für den Fall einer militärischen Konfrontation zu bestimmen, hatte seinen Grund nicht zuletzt in dem schon mehrfach genannten Grey-Cambon-Briefwechsel aus dem November 1912. Bei diesem handelte es sich ähnlich wie bei den Briefen, die zehn Jahre zuvor zwischen dem italienischen Außenminister und dem Botschafter Frankreichs ausgetauscht worden waren, um ein streng geheimes Abkommen, das trotz seiner vorsichtigen diplomatischen Form verbindlichen Charakter besaß und das durch die Beteiligung des britischen Kabinetts in den Augen Paul Cambons gar einen caractère officiel ${ }^{128}$ erhalten hatte.

124 Zit. Bases du Plan. CSG, 18. 4. 1913, in: SHA 1N11, CXLIII/fol. 5.

125 Vgl. Note de présentation. CSDN, 9. 1. 1912, in: SHA 2N1, VI/36.

$126 \mathrm{Zit}$. Note indiquant les points relatifs à la situation extérieur à élucider dans la Conférence du 16 octobre 1911, in: SHA 2N1, V/32.

$127 \mathrm{Zit}$. Iswolski an Sasonow, 5. 12. 1912, in: STIEVE, Iswolski-Schriftwechsel II, 608.

128 Zit. Paul Cambon an Poincaré, 31. 10. 1912, in: DDF 3, 4, 301. 
Inhaltlich - und darauf ist schon aufmerksam gemacht worden - sanktionierten die Briefe zunächst die Besprechungen zwischen der militärischen Führung Großbritanniens und Frankreichs und gaben ihnen damit die von Poincaré angestrebte approbation explicite du gouvernement britannique ${ }^{129}$.

From time to time in recent years, so lautete dann allerdings die entscheidende Passage im Brief des britischen Außenministers, the French and British naval and military experts have consulted together. It has always been understood that such consultation does not restrict the freedom of either Government to decide at any future time whether or not to assist the other by armed force. We have agreed that consultation between experts is not, and ought not to be regarded as an engagement that commits either Government to action in a contingency that bas not arisen and may never arise.

Hatte der britische Außenminister mit diesen an Deutlichkeit nichts zu wünschen lassenden Worten jegliche militärische Beistandspflicht, die möglicherweise aus den gemeinsamen Besprechungen der Militärs resultieren konnte, negiert, so gestand er Frankreich jedoch zu,

that, if either Government had grave reason to expect an unprovoked attack by a third Power, or something that threatened the general peace, it should immediately discuss with the other, whether both Governments should act together to prevent aggression and to preserve peace, and if so what measures they would be prepared to take in common. If these measures involved action, the plans of the Generals Staffs would at once be taken into consideration, and the Governments would then decide what effect should be given to them ${ }^{130}$.

$\mathrm{Zu}$ keinem militärischen Beistand verpflichtend und die Militär- und Marinekonventionen selbst im Fall einer gemeinschaftlichen Kriegsführung nicht automatisch in Kraft setzend, begründeten die Briefe gleichsam einen casus consultationis für den Fall einer den Frieden Europas bedrohenden Krisensituation. "Uncommitted to act«, so hat Samuel R. Williamson den Inhalt dieser Briefe auf eine prägnante Formel gebracht, »the two governments were committed to consult «131.

Insgesamt betrachtet stellte der Austausch sicherlich einen bedeutenden Schritt zur Konsolidierung der Entente cordiale dar. Auch wenn Frankreich sich eine umfassendere, möglichst gar öffentlich bekanntzugebende Bindung Großbritanniens gewünschte hätte, so zeigte sich Poincaré letztlich zufrieden und sprach von la baute valeur de ces documents ${ }^{132}$. Sehr viel zurückhaltender hingegen fiel die Bewertung dieser Dokumente auf britischer Seite

129 Zit. Poincaré an Paul Cambon, 25. 11. 1912, in: DDF 3, 4, 562. Vgl. auch Ders. an Millerand und Ders. an Delcassé, 25. 11. 1912, in: DDF 3, 4, 563.

130 Zit. Grey an Paul Cambon, 22. 11. 1912, in: BD 10/2, 416, dort auch das vorhergehende Zitat. Vgl. ferner Paul Cambon an Grey, 23. 11. 1912, in: BD 10/2, 417.

131 Zit. Williamson, Grand Strategy, S. 298.

132 Zit. Poincaré an Paul Cambon, 25. 11. 1912, in: DDF 3, 4, 562. Vgl. auch Poincarés Schreiben an Kriegsminister Millerand und Marineminister Delcassé vom 25. 11. 1912 in: DDF 3, 4, 563. 
aus. Premierminister Asquith maß den Briefen keine große Bedeutung bei und erachtete das Konsultationsversprechen gar als almost a platitude ${ }^{133}$.

Grundsätzlich betrachtet - und es ist wesentlich, dies festzuhalten - erblickten weder das britische Kabinett noch der Außenminister in den militärischen Arrangements und in dem Briefwechsel eine Beistandspflicht für den Fall eines militärischen Konflikts zwischen Frankreich und dem Deutschen Reich. Was das Kabinett betrifft, so hatte es sich schon 1911 auf den Standpunkt gestellt, daß aus den Besprechungen zwischen den Militärs beider Staaten keine Beistandspflicht resultieren könne ${ }^{134}$. Insbesondere die $\mathrm{Kabi}^{-}$ nettsmitglieder, die dem radikalen Flügel der liberalen Partei angehörten und die Gesprächen dieser Art mit großer Skepsis gegenüberstanden, erblickten dann im Brief des britischen Außenministers an den Botschafter Frankreichs eine Garantie dafür, that anything arranged between the experts was not to be beld to bind or commit the Governments ${ }^{135}$.

In dieselbe Richtung führte auch Greys Deutung der Absprachen. In den Gesprächen, die der britische Außenminister mit dem französischen Botschafter führte, negierte er stets jegliche Beistandspflicht und betonte statt dessen die volle Handlungsfreiheit Großbritanniens für den Fall der militärischen Eskalation einer Krise. Nachdem im Juli 1912 die Expertengespräche offiziell vom britischen Kabinett autorisiert worden waren, machte er Paul Cambon sogleich darauf aufmerksam, that what passed between the experts did not commit the two Governments, and left their decision perfectly free ${ }^{136}$. Angesichts der eindeutigen Aussagen des britischen Außenministers bestand dann auch in Frankreich kein Zweifel, daß Großbritannien weder in den militärischen Abkommen noch in dem Briefwechsel vom 22./23. November 1912 eine Verpflichtung zur Beteiligung an einem kontinentalen Krieg erblickte. Der französische Botschafter, der im Dezember 1912 seinen Bruder über den Briefwechsel mit dem britischen Außenminister unterrichtete, stellte fest, daß zwar eine Etappe in dem Bemühen erreicht worden sei, Großbritannien fester an Frankreich zu binden, betonte aber zugleich, daß

133 Zit. Asquith an Grey, 11.10. 1912, in: NL Grey, PRO, FO 800/100, fol. 282. Vgl. auch die entsprechende Einschätzung des Kabinettmitgliedes Hobhouse in: Charles Hobhouse, Inside Asquith's Cabinet, hg. von Edward DAvID, London 1997, S. 124 (Eintrag vom 18. 11. 1912).

134 Vgl. Keith M. WILson, The Making and Putative Implementation of a British Foreign Gesture, December 1905 to August 1914: the Anglo-French Entente Revisited, in: Canadian Journal of History 31 (1996), S. 227-255, hier S. $233 \mathrm{f}$.

135 Zit. Memorandum Berties über ein Gespräch mit Grey, 25. 7. 1912, in: NL Bertie, PRO, FO 800/165, fol. 151. Der britische Historiker Keith Wilson hat in diesem Zusammenhang sogar davon gesprochen, Greys Brief an Cambon vom 22. November 1912 whad been originally conceived and subsequently regarded as a safeguard for the peace party«. Zit. WILSON, Policy of Entente, S. 143. Ähnlich argumentiert auch WILLIAMSON, Grand Strategy, S. 298.

136 Zit. Grey an Carnegie, 22. 7. 1912, in: BD 10/2, 400. 
aus ihm keinerlei Verpflichtungen für Großbritannien entstanden ${ }^{137}$. Mehr als einen ersten Schritt erkannte auch der Politische Direktor des Außenministers nicht in den Dokumenten, die zwischen dem britischen Außenminister und Paul Cambon ausgetauscht worden waren. Gegenüber dem ehemaligen Ministerpräsidenten Ribot sprach Paléologue davon, daß mit ihnen die Gespräche zwischen den Militärs beider Staaten eine politische Sanktion erhalten hätten, daß aber bien entendu Großbritannien maître de ses décisions $^{138}$ bleibe, und auch Poincaré betonte gegenüber Iswolski im Frühjahr 1913, daß England [...] Frankreich gegenüber durch keinerlei bestimmte politische Verpflichtungen gebunden ${ }^{139}$ sei.

Von Interesse sind in diesem Zusammenhang auch zwei Briefe des russischen Botschafters in Paris an seinen Außenminister vom 18. März und 9. April 1914140. Der Botschafter zeigte sich in ihnen gut über den Inhalt des Grey-Cambon-Briefwechsels unterrichtet, und seine Briefe sind deshalb von besonderem Wert, da er seine Informationen direkt aus französischer Hand erhielt und damit wohl ein getreues Bild der Interpretation zeichnete, die man in Frankreich den Dokumenten gab. Iswolski machte in seinem Brief vom 18. März ausdrücklich darauf aufmerksam und im Gespräch am 9. April bestätigte ihm der Ministerpräsident noch einmal, daß das politische Abkommen keine bindende Bedeutung, sondern vielmehr fakultativen Charakter habe, und daß, ob England an einem Kriege teilnebmen wird oder nicht, [...] von der großbritannischen Regierung den Umständen gemäß entschieden werden [wird] ${ }^{141}$.

Nur eine Quelle oder genauer: nur ein - allerdings bedeutsamer - Kronzeuge widerspricht diesen Ausführungen und gibt an, daß Frankreich von Großbritannien Zusicherungen gemacht worden seien, die weit über das in den militärischen Konventionen oder im Grey-Cambon-Briefwechsel schriftlich Niedergelegte hinausgingen. Es handelt sich um den russischen Außenminister, der in zwei Berichten den Zaren über den Inhalt seiner Unterredungen in Kenntnis setzte, die er im August 1912 mit dem französischen Ministerpräsidenten und dann im September 1912 mit dem britischen AuBenminister geführt hatte. Der Aufzeichnung Sasonows über seine Unterredung mit Grey kann man entnehmen, daß der britische Außenminister sich auch Informationen über die militärischen Arrangements entlocken ließ, die zu diesem Zeitpunkt schon zwischen Frankreich und Großbritannien bestanden, und daß Grey aus eigenem Antriebe bestätigte, was ich bereits durch Poincaré wußte: es besteht zwischen Frankreich und England eine Vereinba-

-137 Vgl. Paul Cambon an Jules Cambon, 4. 12. 1912, in: NL Jules Cambon, MAE, PAAP 43/100, fol. 281.

138 Zit. Aufzeichnung Ribots vom 28.[Lesart unsicher] 12. 1913, in: NL Ribot, AN, 563

AP 5.

139 Zit. Iswolski an Sasonow, 27. 2. 1913, in: STIEVE, Iswolski-Schriftwechsel III, 747.

140 Vgl. Ders. an Dens., 18. 3. 1914 und 9. 4. 1914, in: IB I/2 42 und IB I/2 188.

141 Zit. Ders. an Dens., 18. 3. 1914, in: IB I/2 42. 
rung, nach der im Fall eines Krieges mit Deutschland England die Verpflichtung eingegangen ist, Frankreich nicht allein $z u$ Wasser Hilfe zu leisten, sondern auch zu Lande durch eine Truppenlandung auf dem Kontinent ${ }^{142}$. In der Tat hatte der russische Außenminister schon in seinem Bericht aus dem August 1912 vermerkt, daß der französische Ministerpräsident von einem dauernde[n] Ideenaustausch zwischen den militärischen Experten beider Staaten gesprochen habe. Dieser [...] habe zu einer mündlichen Vereinbarung zwischen den Regierungen Frankreichs und Englands gefübrt, in der England sich bereit erklärt babe, Frankreich mit seiner Land-und Seemacht zu Hilfe zu kommen, falls dieses von Deutschland angegriffen würde. England habe versprochen, Frankreich $z u$ Lande durch ein an die belgische Grenze zu entsendendes Detachement in Stärke von 100000 Mann zu unterstützen ${ }^{143}$.

Trotz dieser beiden Berichte wird man jedoch aus einer Reihe von Gründen nicht behaupten können, daß Großbritannien - möglicherweise gar im Geheimen - eine militärische Beistandsverpflichtung übernommen hatte. Die Aussagen des russischen Außenministers widersprechen allen anderen verfügbaren Quellenzeugnissen, und Sir Edward Grey hat ihnen, in einem privaten Gespräch mit John W. Headlam-Morley, ausdrücklich widersprochen, als sie ihm nach dem Krieg bekannt wurden ${ }^{144}$. Darüber hinaus existiert mit den Aufzeichnungen des britischen Außenministers vom 24. September 1912 eine weitere zeitgenössische Quelle für die in Balmoral geführten Gespräche, in der nichts von einer britischen Beistandspflicht zu lesen ist und der zufolge Grey vielmehr betonte, daß die Frage, ob Großbritannien militärisch in eine Auseinandersetzung der kontinentalen Mächte eingreifen werde, letztlich von der öffentlichen Meinung abhinge ${ }^{145}$.

Geht man nicht von einer bewußten Entstellung der Tatsachen durch den russischen Außenminister aus, so muß man annehmen, daß Sasonow seine Gesprächspartner mißverstand, daß er aus den militärischen Abkommen, die ausschließlich im Fall einer gemeinschaftlichen Kriegsführung Gültigkeit erhalten konnten, eine Verpflichtung zu militärischem Beistand herauslas. Auch können in diesem Zusammenhang Fehler bei der Übersetzung des russischen Textes nicht ausgeschlossen werden, die möglicherweise ihren Grund in mißverständlichen oder zumindest, was den Bericht aus dem September 1912 betrifft, in semantisch nicht ganz eindeutigen Formulierungen des $\mathrm{Au}$ -

142 Zit. Bericht Sasonows an den Zaren, im Oktober 1912, in: STIEVE, Iswolski-Schriftwechsel II, 508.

${ }^{143}$ Zit. Bericht des russischen Außenministers an den Zaren über die Unterredungen mit Poincaré während dessen Aufenthaltes in St. Petersburg, 17. 8. 1912, in: STIEVE, Iswolski-Schriftwechsel II, 401.

$144 \mathrm{Vgl}$. Headlam-Morleys Note of Interview with Viscount Grey«, 6. 12. 1923, in: PRO, FO 370/194. Diesen Hinweis verdankt der Verfasser Herrn Stephen Schröder. Auch Poincaré widersprach in seinen Erinnerungen ausdrücklich der Interpretation des russischen Außenministers. Vgl. POINCARÉ, Au service de la France, Bd. I, S. $185 \mathrm{f}$. Vgl. auch Edward GREY, Twenty-Five Years 1892-1916, Bd. I, Toronto 1925, S. 287.

145 Aufzeichnung Greys, 24. 9. 1912, in: BD 9/1, 805. 
Benministers hatten. Geht schon aus den vorangegangenen Untersuchungen deutlich hervor, daß die außenpolitischen Entscheidungsträger Frankreichs sich durchaus nicht im Unklaren darüber waren, daß die militärischen Arrangements und der Grey-Cambon-Briefwechsel Großbritannien nicht zu militärischem Beistand verpflichteten, so wurde ihnen die britische Handlungsfreiheit in den letzten Jahren vor Ausbruch des Großen Krieges auch bei anderen Gelegenheiten demonstriert. Die Briefe, die der britische Außenminister und der Botschafter Frankreichs ausgetauscht hatten, waren erst wenige Tage alt, als Poincaré angesichts der sich zuspitzenden internationalen Lage Großbritanniens Haltung für den Fall einer militärischen Eskalation des Balkankonflikts zu ermitteln suchte. Dabei antizipierte er genau jene Kaskade militärischer Interventionen, die in nicht einmal zwei Jahren Wirklichkeit werden und zum Ausbruch des Großen Krieges führen sollte. Si l'Autriche attaquait la Serbie, so lautete die Frage, die der Botschafter dem britischen Außenminister stellen sollte, si la Russie était entraînée à défendre celle-ci, si l'Allemagne intervenait pour appuyer l'Autriche contre la Russie et si enfin la France était amenée à soutenir la Russie, que ferait le Gouvernement britannique?146

Der Botschafter folgte dieser Aufforderung Poincarés nur ungern, wußte er doch, daß Grey die Haltung Großbritanniens erst bestimmen werde, wenn es nicht mehr über Hypothesen zu entscheiden galt ${ }^{147}$. Tatsächlich wich der britische Außenminister dann auch der entsprechenden Anfrage Cambons aus. Als dieser ihn daraufhin fragte, ob er glaube, daß die öffentliche Meinung Großbritanniens unter den gegebenen Umständen eine militärische Intervention befürworten würde, antwortete ihm Grey, that much would depend upon bow the war broke out. If Servia provoked Austria, and gave ber just cause of resentment, feeling would be different from what it would be if Austria was clearly aggressive. I did not think that public opinion could take things seriously unless Germany moved; and, if things did become serious, I thought that public opinion would first require an attempt to secure that Germany, France and England kept out of the trouble ${ }^{148}$.

146 Zit. Poincaré an Paul Cambon, 3. 12. 1912, in: DDF 3, 4, 612.

147 Vgl. Paul Cambon an Jules Cambon, 4. 12. 1912, in: NL Jules Cambon, MAE, PAAP 43/100, fol. 281. Vgl. in diesem Zusammenhang auch schon Paul Cambon an de Selves, 6. September 1911, in: DDF 2, 14, 272.

148 Zit. Grey an Bertie, 4. 12. 1912, in: BD 9/2, 328; in ähnlichen Worten auch an den britischen Botschafter in Rußland. Vgl. Grey an Buchanan, 17. 2. 1913, in: BD 9/2, 626. Die Antwort des französischen Botschafters fiel etwas knapper aus. Il $m^{\prime}$ a répondu, so telegraphierte Cambon an Poincaré, que le moment n'était pas encore venu d'envisager cette éventualité, que l'attitude du Gouvernement dépendrait des dispositions des Chambres et de l'opinion qui dépendrait elle-même de la façon dont nâttrait le conflit. Zit. Paul Cambon an Poincaré, 4. 12. 1912, in: DDF 3, 4, 622. Daß Poincaré dennoch der recht genaue Wortlaut übermittelt wurde, zeigt der Brief des russischen Botschafters vom 5. Dezember 1912. Vgl. Iswolski an Sasonow, 5. 12. 1912, in: STIEVE, IswolskiSchriftwechsel II, 606. 
Mochten die Einlassungen des britischen Außenministers auch unter den gegebenen Umständen für Poincaré unbefriedigend sein, so hatte Grey mit ihnen doch einen deutlichen Hinweis auf die Bedingungen gegeben, unter denen Frankreich auf eine militärische Intervention Großbritanniens rechnen konnte. Viel würde davon abhängen, welcher Seite im entscheidenden Augenblick das Odium des Aggressors zufallen würde. Und viel, wenn nicht gar alles, würde davon abhängen, ob sich die öffentliche Meinung Großbritanniens für eine militärische Intervention aussprach.

Der britische Außenminister hat diese beiden Bedingungen zu unterschiedlichen Gelegenheiten, früheren wie späteren, im vertraulichen Gespräch mit Vertretern der politischen Führung Frankreichs und auch öffentlich mehrfach wiederholt. In einer Rede im britischen Parlament am 27. November 1911 konstatierte er, daß keine Regierung seines Landes eine militärische Auseinandersetzung beginnen könne, without public opinion behind $i t^{149}$. Und im Frühjahr 1914 wiederholte er in einer Unterredung mit Poincaré und Ministerpräsident Doumergue, daß $[\mathrm{w}]$ hether we engaged in a Continental war or kept aloof would depend on public opinion in Great Britain when the time came. If there were a really aggressive and menacing attack made by Germany upon France, it was possible that public feeling in Great Britain would justify the Government in belping France ${ }^{150}$. Angesichts dieser deutlichen Worte des britischen Außenministers konnte Frankreich sich nicht über die spezifischen Bedingungen im unklaren sein, unter denen Großbritannien militärischen Beistand leisten würde, und weder seine Vertreter in Großbritannien noch seine Regierung gaben sich in dieser Hinsicht Illusionen hin. So sagte Paul Cambon in einem privaten Gespräch mit dem britischen Botschafter in Paris am 24. April 1914, daß Großbritannien keine

149 Zit. Parliamentary Debates: House of Commons, 5. Series, Bd. 32, Sp. 58.

150 Zit. Grey an Bertie, 1.5. 1914, in: BD 10/2 541. Vgl. auch die Aufzeichnung des Ministerpräsidenten, in der die Einlassung Greys mit den Worten wiedergegeben wird: En ce qui concerne la France aucun Gouvernement anglais, je vous en donne l'assurance, ne lui refuserait son aide militaire et navale si elle était injustement menacée et attaquée. Le Gouvernement qui hésiterait ne pourrait pas résister à la pression de l'opinion publique anglaise. Zit. Note du Ministre. Conversation au ministère des Affaires étrangères entre Sir Edward Grey et M. Gaston Doumergue, en présence de M. Paul Cambon, Sir William Tyrell, M. de Margerie, 24. 4. 1914, in: DDF 3, 10, 155. In diesem Zusammenhang sei darauf aufmerksam gemacht, daß entsprechende Hinweise nicht allein über das Außenministerium, sondern auch über die Kontakte der Militärs ihren Weg in das französische Kabinett fanden. Vgl. die Aussagen des Generalstabschefs, des Generalstabschefs des Heeres und des Kriegsministers auf der Sitzung des Conseil supérieur de la défense nationale am 9. Januar 1912 in: Procès-verbal. CSDN, 9. 1. 1912, in: SHA 2N1, VI/38. Kriegsminister Alexandre Millerand notierte am 21. Oktober $1912 \mathrm{im}$ Anschluß an ein Gespräch mit Foch, der über hervorragende persönliche Beziehungen zum Leiter der Operationsabteilung des britischen Stabes verfügte: Ils [die britischen Kabinettsmitglieder, St. S.] feront ce que voudra l'opinion publique. Zit. NL Millerand, AN, 470 AP 9. Ähnlich ließ sich Wilson dann auch gegenüber dem französischen Militärattaché vernehmen. Vgl. de la Panouse an Millerand, 13.11. 1912, in: SHA 7N1227. 
förmliche Beistandsgarantie geben könne, unless at the time when trouble arrived public sentiment in England was prepared to undertake a War ${ }^{151}$, und Poincaré hatte Iswoslki schon im Dezember 1912 geklagt: Das Kabinett von London antwortet immer wieder, daß dies [der Kriegseintritt, St. S.] von den Umständen abbängen werde, und daß die Frage über Krieg und Frieden von der öffentlichen Meinung entschieden werden würde ${ }^{152}$.

Solch große Bedeutung maß der Ministerpräsident der öffentlichen Meinung Großbritanniens in dieser Frage bei, daß er dem russischen Botschafter einmal - sicherlich überzeichnend, aber im Kern doch nicht unzutreffend sagte, daß selbst die Unterzeichnung einer förmlichen Allianz keine hinreichende Garantie für einen britischen Kriegseintritt darstelle, denn die englische Regierung [würde] im entscheidenden Augenblick nur das beschließen [...], was ibr der Wille der englischen Nation eingeben werde ${ }^{153}$. Von nicht geringem Gewicht dürfte deshalb sein, daß Poincaré im Sommer 1913 während eines Staatsbesuchs einen sehr günstigen Eindruck von der Stimmungslage innerhalb der britischen Öffentlichkeit erhalten hatte. Gegenüber dem britischen Botschafter zeigte er sich überzeugt, that the Entente bad been thoroughly adopted by the people of England ${ }^{154}$, und in fast wörtlicher Entsprechung wiederholte er dann gegenüber Sir Francis Bertie, was er rund ein Jahr zuvor schon Iswolski gesagt hatte, daß nämlich diese Tatsache a much more satisfactory and reliable bond between the two Countries sei than any formal Treaty engagement ${ }^{155}$. Sir Francis Bertie glaubte gar, daß der Präsident es aufgrund dieses Eindrucks unterlassen habe, während seines Besuchs erneut die Frage nach einer engeren vertraglichen Bindung Großbritanniens an Frankreich aufzuwerfen ${ }^{156}$. In dieselbe Richtung wie die Eindrücke des Präsidenten wies auch die wohl übertrieben optimistische Beurteilung der öffentlichen Meinung Großbritanniens durch Paul Cambon, respektive sein Vertrauen auf die Aussagen, die Unterstaatssekretär Sir Arthur Nicolson in diesem Zusammenhang machte ${ }^{157}$.

Last but not least gilt es noch einen weiteren Faktor zu benennen, der unter anderen dazu beitrug, daß die militärischen und außenpolitischen Entscheidungsträger in Frankreich die Frage des britischen Kriegseintritts mit

151 Zit. Aufzeichnung Berties, 24. 4. 1914, in: NL Bertie, PRO, FO 800/166, fol. 65.

152 Zit. Iswolski an Sasonow, 5. 12. 1912, in: STIEVE, Iswolski-Schriftwechsel II, 608.

153 Zit. Iswolski an Sasonow, 6. 6. 1912, in: STIEVE, Iswolski-Schriftwechsel II, 318.

154 Zit. Bertie an Grey, 25. 7. 1913, in: NL Grey, PRO, FO 800/54, fol. 252.

155 Zit. Ders. an Dens., 25. 7. 1913, in: ibid., fol. 253.

156 Vgl. Ders. an Dens., 25. 7. 1913, in: ibid., fol. 252.

157 Vgl. Paul Cambon an Poincaré, 4. 12. 1912, in: DDF 3, 4, 622. Vgl. Paul Cambon an Jonnart, 23. 1. 1913, in: DDF 3, 5, 248. Vgl. auch Christopher M. ANDREw, The Entente Cordiale from its Origins to 1914, in: Neville WAITES (Hg.), Troubled Neighbours. Franco-British Relations in the Twentieth Century, London 1971, S. 11-39, hier S. $26 \mathrm{f}$. und ANDREW, France and the German Menace, S. 148; KEIGER, France, S. 106, $115 \mathrm{f}$. sowie Ders., Poincaré, S. 143 f. Ähnlich auch Patricia Elisabeth PRESTWICH, French Attitudes towards Britain. 1911-1914, Diss. Stanford 1973, S. 240. 
vorsichtiger Zuversicht betrachteten. Es handelt sich dabei um das grundlegende Muster, das die Verantwortlichen an der Seine hinter dem außenpolitischen Handeln Großbritanniens zu erkennen glaubten. Mag die historische Forschung, indem sie von einem britischen Appeasement gegenüber Rußland ${ }^{158}$ und einem zunehmend größeren Eigengewicht der britischen Ententen spricht ${ }^{159}$, auch darauf hinweisen, daß Großbritanniens Außenpolitik sich in den letzten Jahren vor Ausbruch des Großen Krieges immer weniger in gesamtsystemischen Bahnen bewegt habe: In Paris war man der Ansicht, daß Großbritannien seine Politik an der alten Maxime von Hegemonie und Gleichgewicht ausrichtete, und in dieser Tatsache erblickte man eine gewisse Garantie für eine militärische Intervention im Fall eines deutschen Angriffs. Begriff man doch den uneingeschränkten Fortbestand der eigenen großmächtlichen Existenz als konstitutiven Faktor des Gleichgewichts der Kräfte auf dem europäischen Kontinent.

Nach Ansicht des französischen Botschafters beruhte deshalb der deutschbritische Antagonismus nicht auf akzidentiellen, sondern essentiellen Grundlagen, hatte keine zufälligen Gründe, sondern causes supérieures et permanentes ${ }^{160}$. Das Deutsche Reich sah Paul Cambon eine Politik der globalen Expansion und der europäischen Hegemonie treiben, und Großbritannien, dessen Geschichte celle d'une lutte acharnée contre les Puissances suspectes de viser à la domination universelle sei, sera toujours opposée à la Puissance qui prétendra à l'hégémonie ${ }^{161}$.

Daß Großbritannien die großmächtliche Existenz Frankreichs als einen unverzichtbaren Bestandteil des Gleichgewichts der Kräfte erachtete, hat sein Außenminister dann auch einmal im Gespräch mit Ministerpräsident Doumergue vergleichsweise offen eingestanden. Zwar machte Sir Edward Grey in diesem Zusammenhang abermals darauf aufmerksam, daß die Frage, ob Großbritannien in einen Krieg eintrete, letztlich von der öffentlichen Meinung entschieden werden würde. Deren Haltung verknüpfte er aber direkt mit gleichgewichtspolitischen Überlegungen. So äußerte er im April 1914, daß im Fall eines deutschen Angriffs auf Rußland, Great Britain would

158 Vgl. Schroeder, World War I as Galloping Gertie, S. 331 f.; Michael Exstein, Great Britain and the Triple Entente on the eve of the Sarajevo Crisis, in: HINSLEY, British Foreign Policy, S. 342-348; WILSON, Policy of Entente, S. 74-85, 95-97, 115120; DerS., Imperial Interest in the British Decision to War, 1914: The Defence of India in Central Asia, in: Review of International Studies 10 (1984), S. 189-203. Vgl. kritisch zu dieser These NEILSON, Britain and the Last Tsar und STEINER, NEILSON, Britain and the Origins, S. 242-257.

159 Vgl. GADE, Gleichgewichtspolitik, S. 204f. Vgl. ferner Sönke NEITZEL, Kriegsausbruch. Deutschlands Weg in die Katastrophe 1900-1914, München 2002, S. 159.

160 Zit. Paul Cambon an Poincaré, 7. 2. 1912, in: DDF 3, 1, 629. Vgl. in diesem Zusammenhang auch die kurzen Bemerkungen in Villate, Paul et Jules Cambon, S. $302 \mathrm{f}$. und PrESTWICH, French Attitudes, S. $240 \mathrm{f}$.

161 Zit. Paul Cambon an Poincaré, 23. 2. 1912, in: DDF 3, 2, 88. In derselben Depesche erklärte der Botschafter dann auch die deutsche Reichseinigung als einen Anflug von geistiger Umnachtung britischer Außenpolitik. 
be inclined to say that, though Germany might bave successes at first, Russia's resources were so great that, in the long run, Germany would be exhausted without our belping Russia'162. Anders waren jedoch die Dinge in bezug auf Frankreich gelagert. Elle [die öffentliche Meinung, St. S.] est moins certaine, so gab Doumergue die Ausführungen des Außenministers wieder, que la France, surprise, pourrait résister et c'est pourquoi si la France était victime d'une agression injuste, l'Angleterre interviendrait ${ }^{163}$.

Der britische Botschafter in Paris vermerkte schon in seinen Berichten für die Jahre 1911 und 1912, daß das französische Kabinett glaube, daß im Fall einer militärischen Auseinandersetzung Großbritannien aufgrund seiner eigenen Interessen an Frankreich gebunden se ${ }^{164}$, und auch Poincaré, so berichtete Iswolski in einem geheimen Brief an seinen Außenminister im Dezember 1912, neige zu der Annahme, daß der unaufbaltsame Lauf der Ereignisse die englische Regierung zu einer bewaffneten Intervention gegen Deutschland fübren werde ${ }^{165}$. Im Frühjahr 1913 war man in Frankreich sogar der Ansicht, daß - wie Iswolski optimistisch gestimmt an Sasonow berichtete - der Ton und die Art der Versicherungen, die die französische Regierung vom Londoner Kabinett erbält, es gestatteten, darauf zu recbnen, daß Frankreich bei der gegenwärtigen politischen Lage im Falle eines Konfliktes mit Deutschland von England mit Waffenbilfe unterstützt werden wird ${ }^{166}$.

162 Zit. Grey an Bertie, 1. 5. 1914, in: BD 10/2, 541.

163 Zit. Note du Ministre. Conversation au ministère des Affaires étrangères entre Sir Edward Grey et M. Gaston Doumergue, en présence de M. Paul Cambon, Sir William Tyrell, M. de Margerie, 24. 4. 1914, in: DDF 3, 10, 155.

164 Vgl. Bertie, Annual Report France 1911, 31. 12. 1912 [sic], in: BDFA France 13/76 und Ders., Annual Report France 1912, 1. 8. 1913, in: BDFA France 13/108. Vgl. auch PRESTWICH, French Attitudes, S. $257 \mathrm{f}$.

$165 \mathrm{Zit}$. Iswolski an Sasonow, 5. 12. 1912, in: STIEVE, Iswolski-Schriftwechsel II, 608. Vgl. Ders. an Dens., 18. 3. 1914, in: IB I/2 42. Vgl. auch Poincarés Einlassungen gegenüber dem belgischen Botschafter im Juni 1912, die unter Benutzung belgischen Archivgutes in BITSCH, Belgique, S. $457 \mathrm{f}$. überliefert werden. Ähnlich argumentierte Poincaré noch am 30. Juli 1914. So sagte er zu dem britischen Botschafter: If war broke out between Russia and Austria, and Germany came to the assistance of Austria, France would be bound by ber treaty engagements to aid Russia. There would be a general war on the Continent in which England would inevitably be involved in the course of it for the protection of interest vital to ber position [...]. Zit. Bertie an Grey, 30. 7. 1914, in: PRO, FO 146/4382. Bei der Aufzeichnung handelt es sich um den Entwurf eines Briefes an Grey, der sich ausschließlich in den Archiven der britischen Botschaft in Paris findet. Vgl. auch POINCARÉ, Au service de la France, Bd. I, S. 178, 188f. Zur Einschätzung Paul Cambons vgl. Benckendorff an Sasonow, 25. 2. 1913, in: SIEBERT, Benckendorff-Schriftwechsel III, 896. Vgl. auch in diesem Zusammenhang die Angaben, die Paul Cambon nach dem Krieg gegenüber Raymond Recouly machte: Que l'Angleterre fût obligée d'intervenir tôt ou tard dans le conflit franco-allemand, la chose pour moi n'était pas douteuse. Zit. Raymond RECOULY, Les heures tragiques d'avant-guerre, Paris [1921], S. 44. Für Paléologue vgl. PALÉOLOGUE, Journal, S. 28 (Eintrag vom 4. 2. 1913).

166 Zit. Iswolski an Sasonow, 27.2.1913, in: STIEVE, Iswolski-Schriftwechsel III, 747. 
Alles in allem wird man folglich festhalten können, daß die politische Führung Frankreichs und in noch stärkerem Maße seine militärischen Entscheidungsträger zwar einerseits mit vorsichtiger Zuversicht der britischen Entscheidung im Krisenfall entgegenblickten ${ }^{167}$, daß sie sich aber andererseits auch der Tatsache bewußt waren, daß das britische Handeln nicht für alle Konfliktfälle eindeutig prognostiziert werden konnte. Angesichts der herausragenden Bedeutung, welche dem Faktor »öffentliche Meinung « aus französischer Perspektive für das Verhalten Großbritanniens im Kriegsfall zufiel, konnte man dies letztlich wohl auch gar nicht. Insbesondere mußte dies aber in solchen Fragen der Fall sein, in denen die britischen Interessen nicht unmittelbar berührt waren und sich womöglich nicht ganz eindeutig entscheiden ließ, wem die Rolle des Angreifers zufiel.

Dieser Befund untermauert, was schon in Zusammenhang mit der Erörterung des uneingeschränkten Beistandsversprechens angeklungen ist, das Poincaré dem Zaren am 23. Juli 1914 gab. Das Bild, das sich die außenpolitischen Entscheidungsträger von den Umständen gemacht hatten, unter denen Großbritannien militärisch in eine Auseinandersetzung auf dem Kontinent eingreifen würde, macht sehr deutlich, daß Frankreich im Juli 1914 nicht mit einer unmittelbaren britischen Festlegung rechnen konnte. Eine Krisenstrategie, die auf einen geschlossenen machtpolitischen Druck der Triple Entente setzte, um das Deutsche Reich zu einem mäßigenden Einwirken auf die Habsburgermonarchie zu veranlassen, konnte aber unter diesen Voraussetzungen - wenn sie vielleicht letztlich auch nicht zum Scheitern verurteilt war - erst nach einer eindeutigen britischen Positionsbestimmung und das heißt: erst in einem fortgeschrittenen Stadium der Krise ihre ganze Wirkung entfalten. Sie barg damit aufgrund der Mechanik der Mobilmachungen ein äußerst großes Kriegsrisiko und kam tatsächlich einem Manöver am Rande des Abgrundes gleich.

\subsubsection{Ein militärisches Defizit und seine Konsequenz}

Die verstärkte Allianzbindung

Haben die Ausführungen des vorangegangenen Kapitels gezeigt, daß nach Ansicht der bedeutendsten französischen Entscheidungsträger im Falle einer militärischen Auseinandersetzung mit dem Deutschen Reich die Haltung Großbritanniens nicht mit Sicherheit vorherbestimmt werden konnte und folglich eine britische Unterstützung der angreifenden französischen Kontingente ungewiß blieb, so haben sie doch auch deutlich gemacht, daß man in Paris zumindest keine Aufspaltung der eigenen Kräfte durch eine Intervention Italiens befürchtete. Vor dem Hintergrund dieser Einschätzung faßte das höchste Gremium in strategischen Fragen zu Beginn des Jahres 1912 den Be- 
schluß, die eigenen Kontingente im Kriegsfall in unvermindertem Umfang gegen das Deutsche Reich zu konzentrieren ${ }^{168}$.

In dem Memorandum, das den Beratungen des Conseil supérieur de la défense nationale am 9. Januar zugrunde lag, führte der Generalstab aus, daß man in diesem Fall eine numerische Superiorität über das Deutsche Reich erlangen würde, mit der der Krieg auf gegnerisches Territorium getragen werden konnte ${ }^{169}$. Doch eine gründliche Betrachtung seiner Kalkulationen macht deutlich, daß sich auch unter der Bedingung einer umfassenden Konzentration die zahlenmäßige Überlegenheit der französischen Kontingente bescheiden ausnahm. Setzt man die Zahlen des Kalküls, die das in die Beratungen des Conseil supérieur de la défense nationale einleitende Exposé der strategischen Lage benannte, in eine Relation, so ergibt sich eine Überlegenheit der Kontingente Frankreichs im Verhältnis von 1,07:1 oder 1,08:1170. Diese geringe Marge büßt darüber hinaus noch an Bedeutung ein, wenn man die Komposition der deutschen und französischen Kontingente, die sich nach Ansicht des Generalstabs im Kriegsfall gegenüberstehen würden, einer eingehenden Analyse unterzieht.

Der zu Beginn des Jahres 1912 gültige Mobilmachungsplan sah vor, im Kriegsfall 22 Armeekorps und 22 Reservedivisionen aufzustellen ${ }^{171}$. Da der Generalstab beabsichtigte, im Rahmen des Plan XVII künftig nur noch vier Reservedivisionen an der italienischen Grenze zu konzentrieren, zwei Reservedivisionen im Raum Paris zu stationieren und vier Reservedivisionen in den großen Festungen entlang der deutschen Grenze einzusetzen, fanden zwar alle 46 aktiven Divisionen, aber nur zwölf der 22 Reservedivisionen Eingang in die Armeen gegen das Deutsche Reich ${ }^{172}$.

Im Generalstab kalkulierte man ferner, daß das Deutsche Reich im Zuge einer Generalmobilmachung 26 Korps, das heißt 52 aktive Divisionen, und 17 Reservekorps, das heißt 34 Reservedivisionen ${ }^{173}$ aufstellen und im ungün-

168 Vgl. Procès-verbal. CSDN, 9. 1. 1912, in: SHA 2N1, VI/38.

$169 \mathrm{Vgl}$. Note de présentation. CSDN, 9. 1. 1912, in: SHA 2N1, VI/36.

170 In den Anhängen zu diesem Memorandum kalkulierte der Generalstab, daß den 900000 französischen 830000 bis 840000 deutsche fusils entgegenstehen würden. Vgl. Indications sur les forces militaires de la France, de ses alliés et des petits Etat neutres. CSDN, 9. 1. 1912, in: SHA 2N1, VI/36 und Indications sur les forces militaires de l'Allemagne et de ses alliés. CSDN, 9. 1. 1912, in: SHA 2N1, VI/36.

171 Vgl. Indications sur les forces militaires de la France, de ses alliés et des petits État neutres. CSDN, 9. 1. 1912, in: SHA 2N1, VI/36. Darüber hinaus sollten auch acht Kavalleriedivisionen mobilisiert werden, denen dieselbe Anzahl an deutschen Kavalleriedivisionen gegenüberstehen würden. Vgl. Indications sur les forces militaires de l'Allemagne et de ses alliés. CSDN, 9. 1. 1912, in: SHA 2N1, VI/36.

$172 \mathrm{Vgl}$. Indications sur les forces militaires de la France, de ses alliés et des petits État neutres. CSDN, 9. 1. 1912, in: SHA 2N1, VI/36.

$173 \mathrm{Vgl}$. Indications sur les forces militaires de l'Allemagne et de ses alliés. CSDN, 9. 1. 1912, in: SHA 2N1, VI/36. In der Übersicht, die der Generalstab für den Conseil supérieur de la défense nationale erstellte, wird der Umfang der aktiven Kontingente und der deutschen Reserve entweder in Korps- oder Bataillonsstärke angegeben. Zur An- 
stigsten Fall seine östlichen Grenzen ausschließlich mit drei Armeekorps und fünf Reservekorps verteidigen würde ${ }^{174}$. Den 585 aktiven Bataillonen Frankreichs würden dann im Kriegsfall 591 deutsche, den 314 französischen Reservebataillonen aber nur 250 deutsche entgegenstehen ${ }^{175}$. Setzt man diese Angaben in eine Relation, so ergibt sich ein Verhältnis der aktiven Bataillone von 0,99:1, der Reservebataillone von 1,26:1 und eine Gesamtstärke der Bataillone von 1,07:1.

Dieses Kalkül zeigt, daß nach Lage der Dinge zu Beginn des Jahres 1912 die numerische Superiorität der Kontingente Frankreichs sich allein aufgrund einer überlegenen Anzahl von Reserveformationen konstituierte. Eine solchermaßen beschaffende Überlegenheit konnte aber - so gering diese sich ohnehin ausnahm - kaum eine ausreichende Grundlage einer offensive à outrance bilden.

Denn zum einen gilt es zu bedenken, daß die Komposition der Reserveformationen unterschiedlicher Natur war. Während die deutsche Reserve nur rund vier Jahrgänge umfaßte, von denen der älteste 26 Jahre zählte, setzte sich die französische Reserve aus elf Jahrgängen im Alter von 23 bis 34 Jahren zusammen ${ }^{176}$. Zum anderen vermochte der Generalstab nach der Reorganisation der deutschen Reserve keine exakte Kalkulation ihrer Zahl mehr vorzulegen, so daß sich nach 1912 ein Schleier der Unsicherheit über den Umfang der deutschen Kontingente breitete. Aus diesen Gründen sah sich der Generalstabschef außerstande, die deutschen und französischen Reserveformationen in einen direkten Vergleich zu setzen, als er im Oktober 1912 wohl nur dem kleinen Kreis der bedeutendsten politischen Entscheidungsträger über

zahl der aktiven Divisionen Frankreichs und des Deutschen Reiches vgl. Les armées françaises dans la Grande Guerre, Bd. I/1, S. 21 f. und Weltkrieg 1914 bis 1918, Bd. I, S. 664-687.

$174 \mathrm{Vgl}$. Indications sur les forces militaires de l'Allemagne et de ses alliés. CSDN, 9. 1. 1912, in: SHA 2N1, VI/36.

175 Vgl. die Tabelle in: ibid. Auf den in den Unterlagen des Conseil supérieur de la défense nationale genannten Umfang von Bataillonen der Reserve gelangt man grosso modo, wenn man annimmt, daß in diesem Kalkül auch die Reservedivisionen einbezogen wurden, die in Frankreichs Kapitale und seinen Grenzfestungen konzentriert werden sollten. Es wäre aber auch möglich, daß in dieser Berechnung das Quantum an Reservebataillonen Berücksichtigung fand, das im Fall einer Mobilmachung den aktiven Korps zugeteilt werden sollte. Vgl. auch die Ausführungen, die der Generalstabschef am 12. Oktober 1912 auf einer Sitzung im Außenministerium machte. Während seine Angaben hinsichtlich der aktiven Formationen grundsätzlich mit den für den Conseil supérieur de la défense nationale angestrengten Kalkulationen übereinstimmten, gab er in diesem Zusammenhang die Anzahl der Bataillone der Reserve mit 362 an. Vgl. Comparaison des forces qui pourraient se trouver en présence sur le théâtre du nord-est en cas de conflit avec l'Allemagne. CSDN, 19. 10. 1912, in: SHA 2N1, VII. Vgl. auch die Berechnungen, die Joffre und Castelnau rund ein Jahr zuvor in einer Unterredung mit dem Leiter der militärischen Operationsabteilung des britischen Stabes anstrengt hatten, in: NL Wilson, Diaries, IWM, DS/MISC/80, fol. 105 (Eintrag vom 29. 11. 1911). 176 Vgl. Edmond BUAT, L'armée allemande pendant la guerre de 1914-1918, Paris 1920, S. $13 \mathrm{f}$. 
die Stärkerelationen vortrug. Pour les formations de réserve, so erläuterte Joffre, dont le nombre et la composition ne sont pas exactement connus, il n'est pas possible de donner des indications susceptibles d'être rapprochées des indications similaires concernant l'armée française ${ }^{177}$. Ferner gilt es in diesem Zusammenhang zu berücksichtigen, daß die Anzahl der Reserveformationen, die Frankreich im Mobilmachungsfall aufstellen würde, schon bald eine beträchtliche Reduktion erfahren sollte. Denn als der Conseil supérieur de la guerre am 18. April 1913 den Grundlagen des Plan XVII seine Zustimmung erteilte, reformierte er zugleich die Struktur dieser Einheiten ${ }^{178}$. An die Stelle der 22 Reservedivisionen, die nach dem Mobilmachungsplan des Plan XVI noch je 18 Bataillone umfaßten, traten nun 25 Reservedivisionen, die sich aus je 12 Bataillonen zusammensetzten. Darüber hinaus wurde in den 18 Armeekorps, die im Fall der Mobilmachung ein bestimmtes Kontingent an Reservisten erhalten sollten, dieses von sechs auf vier Bataillone herabgesetzt ${ }^{179}$. Einer Übersicht aus dem Juli 1913 kann man entnehmen, daß die Kontingente Frankreichs, die im Fall einer militärischen Auseinandersetzung gegen das Deutsche Reich eingesetzt werden sollten, nur noch 573 aktive und 291 Reservebataillone umfaßten ${ }^{180}$. Die letztgenannte Zahl kam darüber hinaus nur deshalb zustande, da man in dieser Note, die die eigenen Anstrengungen betonte, um ein zusätzliches Engagement des Bündnispartners einzufordern, die Reservedivisionen der Festungen in das Kalkül mit einbezog181.

Das entscheidende Kriterium zur Beurteilung einer so beschaffenen numerischen Superiorität ist aber in dem Umstand zu suchen, daß ein strategisches Denken, das im Zeichen des uneingeschränkten Angriffs stand, den Wert der Reserveformationen ohnehin gering achtete. In der militärischen Führung Frankreichs herrschte weitgehend Konsens, [que] la valeur des troupes de réserve est à peu près nulle au début des hostilités ${ }^{182}$. Eine numerische Superio-

177 Zit. Comparaison des forces qui pourraient se trouver en présence sur le théâtre du Nord-Est en cas de conflit avec l'Allemagne. CSDN, 19. 10. 1912, in: SHA 2N1, VII. Weder über den Anlaß noch den Inhalt der Beratungen ist näheres bekannt. Ihre Existenz ist allein durch die Memoiren des Generalstabschefs bezeugt und wird dort auf den 12. Oktober 1912 datiert. Vgl. JofFre, Mémoires, Bd. I, S. 139.

178 Vgl. Procès-verbal de la séance. CSG, 18. 4. 1913, in: SHA 1N11, CXLIII. Vgl. ferner Les armées françaises dans la Grande Guerre, Bd. I/1, S. 22.

179 Vgl. Les armées françaises dans la Grande Guerre, Bd. I/1, S. 21.

$180 \mathrm{Vgl}$. Note faisant ressortir l'effort fait par la France pour répondre aux armements de l'Allemagne, 25. 7. 1913, in: SHA 7N1535. In dieser Note heißt es: Sur ce nombre 864 bataillons, dont 573 actifs [...] font partie des armées destinées à opérer sur la frontière du N.E.

181 Diese Anzahl von 291 Reservebataillonen läßt sich ungefähr erreichen, wenn man die 15 Divisionen zu je 12 Bataillonen (180), die Reservekontingente der aktiven Divisionen (72) und eben die Divisionen der Festungen (48) berücksichtigt.

182 Zit. Procès-verbal de la séance. CSG, 18. 4. 1913, in: SHA 1N11, CXLIII. (Bei dem Zitat handelt es sich um eine Einlassung General Paus.) Gegenteilige Auffassungen fanden unter den militärischen Entscheidungsträgern in den letzten Jahren vor Ausbruch des Großen Krieges keine Mehrheit mehr. Als der designierte Generalissimus, Victor 
rität, die sich allein aufgrund einer überlegenen Anzahl von Reserveformationen konstituierte, versank zwar nicht in Bedeutungslosigkeit - konnten diese doch eine Reihe sekundärer Funktionen erfüllen und solchermaßen ein gewisses Kontingent an kostbaren aktiven Formationen auf dem Schlachtfeld freisetzen ${ }^{183}$. Sie war jedoch prekär, denn der entscheidende Faktor im Kalkül des Generalstabs war letztlich der Bestand an aktiven Formationen: Sans doute, so konstatierte der Generalstab im Plan XVII, on ne saurait, dans aucun cas, assimiler des unités de réserve à des unités actives. C'est à ces dernières que le commandement fera surtout appel pour l'exécution des manouvres offensives, dont dépend le succès des opérations, comptant sur leur instruction meilleure, sur leur entraînement supérieur, et sur la solidité des liens tactiques qui unissent tous leurs éléments ${ }^{184}$. Daß im Rahmen einer Strategie, die das Signum des uneingeschränkten Angriffs trug, der Bestand der aktiven Kontingente die entscheidende Größe darstellte, zeigte sich auch, als die Reichsleitung im Jahr 1913 ein neues Gesetz in den Reichstag einbrachte, mit dem die Präsenzstärke des Heeres im Frieden auf rund 850000 Mann erhöht wurde, und Frankreich auf diesen Schritt mit der Einführung der dreijährigen Dienstzeit antwortete ${ }^{185}$.

Zwar ist der Hinweis des deutschen Historikers Gerd Krumeich durchaus zutreffend, daß durch den Plan XVII der Aufmarsch der französischen Kontingente erstmals dicht an die Grenze und damit in die Reichweite des deutschen Heeres verlegt worden war und daß die Aufrüstung des Deutschen Reiches insofern eine Gefahr für die Pläne Frankreichs darstellte, als sie nach Einschätzung des Generalstabs dem Deutschen Reich schon vor Abschluß der strategischen Konzentration eine attaque brusquée, das heißt einen partiellen Angriff gegen die den Aufmarsch sichernde couverture, möglich machte ${ }^{186}$. Doch handelt es sich bei dem von Krumeich geltend gemachten Grund nur um einen Faktor unter anderen, der die militärischen und politischen Entscheidungsträger Frankreichs zur Einführung der loi des trois ans veranlaßte ${ }^{187}$. Bedeutender, wenn nicht maßgeblich, war, daß durch das Gesetz vom 30. Juni 1913 das deutsche Heer im Kriegsfall ein Kontingent an

Constant Michel, im Frühjahr 1911 dem Conseil supérieur de la guerre einen neuen strategischen Plan unterbreitete, in dessen Rahmen von Frankreichs Reserveformationen extensiver Gebrauch gemacht werden sollte, sprach sich das Gremium gegen diesen Plan aus, was in der Folge zur Entlassung Michels führte. Vgl. FABRY, Joffre, S. $177 \mathrm{f}$. und Jan Karl TANEnBaUM, Général Maurice Sarrail, 1856-1929. The French army and Left-wing politics, Chapel Hill 1975, S. $27 \mathrm{f}$.

183 Vgl. Bases du Plan. CSG, 18. 4. 1913, in: SHA 1N11, CXLIII, fol. 19f. und Note faisant ressortir l'effort fait par la France pour répondre aux armements de l'Allemagne, 25. 7. 1913, in: SHA 7N1535.

184 Zit. Bases du Plan. CSG. 18. 4. 1913, in: SHA 1N11, CXLIII, fol. 19.

185 Zur Aufrüstung Frankreichs im Jahr 1913 vgl. grundlegend KRUMEICH, Aufrüstung und Innenpolitik; STEVENSON, Armaments and the Coming of War, S. 303-307 und HERRMANN, Arming of Europe, S. 191-195.

$186 \mathrm{Vgl}$. KRUMEICH, Aufrüstung und Innenpolitik, S. $46 \mathrm{f}$.

187 Vgl. JOFFre, Mémoires, Bd. I, S. 93. 
aktiven Mannschaften umfassen würde, das ihm eine überragende Qualität verlieh. Der Militärattaché Frankreichs betonte in seinen Berichten über die deutsche Heeresvorlage insbesondere dieses $F_{a k t u m}{ }^{188}$, und auch der Generalstab gelangte in seinen Untersuchungen zu einem entsprechenden Resultat ${ }^{189}$. Auf seiten Frankreichs stand dem eine Situation gegenüber, in der seit der Reduktion der Dienstzeit im Jahr 1905 die Mannschaftsstärke der Kompanien sukzessive von 150 auf 90 Mann gesunken war und damit im Kriegsfall die Eingliederung von 160 Reservisten erforderlich machte ${ }^{190}$. Die Auswirkungen dieses Sachverhalts ersichtlich über-, im Kern aber nicht verzeichnend, führte Kriegsminister Étienne im Militärausschuß der Assemblée nationale am 11. März 1913 aus, daß damit im Fall einer Mobilmachung es nicht mehr l'active sei, qui reçoit les réservistes, c'est une majorité de réservistes qui reçoit l'active ${ }^{191}$, und auf der Linie dieser Argumentation lagen dann auch die Ausführungen des Generalstabschefs, die dieser am 18. März an gleicher Stelle vortrug ${ }^{192}$. Schon im Rahmen einer um die bedeutendsten politischen Entscheidungsträger erweiterten Sitzung des Conseil supérieur de la guerre hatte Joffre am 4. März ausgeführt, daß allein die loi des trois ans dem Heer Frankreichs eine puissance offensive plus considérable ${ }^{193}$ geben könne.

Im Zusammenhang mit der Berichterstattung über die deutsche Aufrüstung und der Diskussion um die Einführung der loi des trois ans zeigt sich darüber hinaus, daß der Generalstab keinesfalls mit einer überragenden Qualität seiner Kontingente rechnete. Zwar war insbesondere Militärattaché Serret von der supériorité réelle der französischen race überzeugt ${ }^{194}$, doch

188 Les armées de 1ère ligne allemandes, celles qui livreront les premières batailles, vont acquérir une qualité supérieure, puisque la proportion des soldats actifs, en plein entraînement se trouvera augmentée, celle des réservistes, maris et chefs de famille, fortement diminuée [...]. Il faut avoir, nous aussi, une force prédominante de l'élément actif dans nos armées de 1ère ligne. Zit. Serret an Étienne, 1. 3. 1913, in: SHA 7N1112. Vgl. auch Ders. an Dens., 15. 2. 1913; Ders. an Dens., 14. 3.1913 und Ders. an Dens., 30. 3. 1913, in: SHA 7N1112. Vgl. auch Serret an Noulens, 20. 4. 1914, in: SHA 7N1112. Ähnlich argumentierte auch schon Serrets Vorgänger Pellé anläßlich der deutschen Aufrüstung im Jahr 1912. Vgl. Pellé an Millerand, 1. 4. 1912 und Ders. an Dens., 12. 5. 1912, in: SHA 7N1111. Vgl. auch Pellé an de la Panouse, 24. 5. 1912, in: NL Pellé, BIF 4405, fol. $321 \mathrm{f}$.

${ }_{189}$ Ce qui est décisif, c'est le nombre d'unités ayant une réelle valeur, par leur moral, fonction de leur instruction, de leur encadrement et de leurs moyens matériels. Zit. Nouvelle loi militaire allemande, 23. 4. 1913, in: SHA 7N1784.

190 Vgl. die Ausführungen des Kriegsministers im Militärausschuß der Assemblée nationale, in: AN, C7421, Commission de l'Armée: procès-verbaux des séances, Bd. II, 11. 3. 1913, fol. 19f. Vgl. auch Modification au regime de recrutement. Note de présentation au Conseil supérieur de la guerre. CSG, 3.3.1913, in: SHA 1N11, CXLII und Procès-verbal de la séance. CSG, 4. 3. 1913, in: ibid.

191 Zit. AN, C7421, Commission de l'Armée: procès-verbaux des séances, Bd. II, 11. 3. 1913 , fol. 20 .

192 Vgl. ibid., 18. 3. 1913, fol. $19 \mathrm{f}$.

193 Zit. Procès-verbal de la séance. CSG, 4. 3. 1913, in: SHA 1N1, CXLII.

194 Vgl. Serret an Étienne, 1. 3. 1913, in: SHA 7N1112, Ders. an Dens., 14. 3. 1913, in: 
sowohl er als auch sein Vorgänger Pellé machten zugleich darauf aufmerksam, daß hinsichtlich der materiellen Ausstattung ein deutliches Defizit bestand. Serret umschrieb in einem Bericht vom 20. April 1914 an Kriegsminister Noulens die Ausrüstung der französischen Kontingente gar als nettement inférieur ${ }^{195}$, und auch der Generalstabschef sprach noch post festum von einem redoutable retard ${ }^{196}$, den Frankreich - was die Ausrüstung seiner Kontingente anbetraf - in den letzten Jahren vor Ausbruch des Großen Krieges aufzuholen hatte. Kurzum: Frankreich konnte nicht darauf spekulieren, durch eine überragende Qualität die numerische Pattsituation zu kompensieren, und vor diesem Hintergrund gewannen nun die Allianzen Frankreichs eine herausragende Bedeutung ${ }^{197}$.

Denn eine signifikante numerische Superiorität, die den Erfolg der offensive à outrance sicherzustellen vermochte, würde sich nur unter der Bedingung einer britischen oder russischen Intervention ergeben: Sei es, daß Frankreich in den British Expeditionary Forces ein Auxiliarkontingent erwuchs, dessen Umfang im Protokoll vom 20./21. Juli 1911 auf 150000 Mann festgesetzt worden war ${ }^{198}$, sei es, daß Rußland durch einen rücksichtslosen Angriff ein deutsches Kontingent in Ostpreußen band, das in seinem Umfang deutlich über das noch zu Beginn des Jahres 1912 angenommene hinausging ${ }^{199}$. Schon das Exposé der strategischen Lage, mit dem am 9. Januar 1912

DDF 3, 5, 593, dort auch das Zitat. Vgl. ferner Serret an Étienne, 19. 7. 1913, in: DDF 3, 7,423 und Serret an Noulens, 20. 4. 1914, in: SHA 7N1112. Eine ähnliche Überzeugung klang auch einmal in einem Brief Pellés an Joffres an. Vgl. Pellé an Joffre, 29. 1. 1912, in: NL Pellé, BIF 4405, fol. 276.

195 Vgl. Pellé an Millerand, 1. 4. 1912, in: SHA 7N1111 und Serret an Étienne, 14. 3. 1913; Ders. an Noulens, 20. 4. 1914, in: SHA 7N1112, dort auch das Zitat.

196 Zit. Jofrre, Mémoires, Bd. I, S. 47. Auch Castelnau vertrat diese Auffassung. Vgl. GraS, Castelnau, S. 133, 144. Vgl. in diesem Zusammenhang auch die Übersicht der Rüstungsausgaben der europäischen Großmächte, in: STEVENSON, Armaments and the Coming of War, S. 2-8.

197 In der Forschung ist mitunter gar argumentiert worden, daß einer der Gründe jenes materielle Defizit war, das den Generalstab auf die uneingeschränkte Offensive setzen ließ. Vgl. Porch, Clausewitz, S. 297 f. Vgl. auch DerS., Spirit, S. 139 f.; Ders., French Army, S. $136 \mathrm{f}$. und DERS., March to the Marne, S. $214 \mathrm{f}$.

198 Vgl. Memorandum de la conférence du 20 juillet 1911, in: MAE, NS Grande Bretagne 22, fol. 111-113. Die British Expeditionary Forces würden in diesem Fall sechs aktive Divisionen mit insgesamt 76 Bataillonen umfassen. Vgl. ferner Indication sur les forces militaires de la France, de ses alliés et des petits Etats neutres. CSDN, 9. 1. 1912, in: SHA 2N1, VI/36. Vgl. auch die Tabelle in Indication sur les forces militaires de l'Allemagne et de ses alliés. CSDN, 9. 1. 1912, in: SHA 2N1, VI/36.

199 Si elle [gemeint ist Frankreich, St. S.] ne se laisse pas détourner par des considérations secondaires, elle pourra faire concourir à la bataille générale, autant de bataillons actifs et plus de bataillons de réserve que ses adversaires. Cette supériorité s'accentuera si la Russie, par une offensive vigoureuse, réussit à tenir des forces considérables sur la frontière de Pologne, et surtout, si l'Angleterre comme elle en a manifesté l'intention, transporte sur le continent la totalité de son armée de débarquement. Zit. Note de présentation. CSDN, 9. 1. 1912, in: SHA 2N1, VI/38. Vgl. auch die Ausführungen des Generalstabschefs vom 12. Oktober 1912: Nos forces actives seraient égales, à quelques unités 
die Beratungen des Conseil supérieur de la défense nationale eingeleitet wurden, hatte indirekt konstatiert, daß die umfassende Konzentration der französischen Kontingente gegen das Deutsche Reich ausschließlich eine notwendige, keinesfalls aber eine hinreichende Bedingung des militärischen Erfolgs sein würde 200 . Nous disposerons ainsi, so war dort nachzulesen, d'une supériorité numérique que pourrait rendre décisive la coopération de l'armée anglaise ${ }^{201}$. Entsprechendes galt für eine russische Intervention. Sollte es dem Bündnispartner durch einen raschen und wuchtigen Angriff möglich sein, zwölf statt sechs aktive deutsche Divisionen in Ostpreußen zu binden, so wäre damit ein numerisches Äquivalent zu den British Expeditionary Forces erreicht, das Dubail im Conseil supérieur de la défense nationale mit den Worten charakterisierte: Ce résultat serait de nature à nous donner pleine satisfaction et dépasserait même nos espérances ${ }^{202}$.

Betrachtet man nun die numerische Pattsituation unter dem Gesichtspunkt ihrer außenpolitischen Konsequenzen, so erscheint das Paradox, daß Frankreich aus einer Strategie, die seinen militärischen Triumph garantieren sollte, zugleich ein Quell politischer Schwäche erwuchs. Denn die Diskrepanz, die zwischen dem strategisch Erforderlichen und dem militärisch Möglichen bestand, mußte letztlich über den Weg einer verstärkten außenpolitischen Rücksichtnahme und Allianzbindung zu einer Einbuße an kostbarer großmächtlicher Autonomie führen. Zwar wurde Frankreich durch die Möglichkeit der britischen oder russischen Rochade ein gewisser Manövrierraum zurückgegeben. Doch sowohl mit einer britischen als auch mit einer russischen Intervention verbanden sich bestimmte Probleme. Beide Optionen waren nur unter spezifischen Bedingungen vorhanden, konnten zudem

près, aux forces allemandes correspondantes. Dans le cas où les troupes anglaises viendraient participer aux opérations de nos armées, les forces actives mises en ligne par la France et par l'Angleterre seraient nettement supérieures aux forces allemandes. Zit. Comparaison des forces qui pourraient se trouver en présence sur le thêatre du NordEst en cas de conflit avec l'Allemagne, 19. 10. 1912, in: SHA 2N1, VII.

200 Folglich kann keine Rede davon sein, daß $»[$ the] experts in the French army [...] had, on the basis of numerous assessments of Britain's situation, come to a general agreement that the British would play a decidedly limited role in any combined military operations for the defence of France«. Zit. PRESTWICH, French Attitudes, S. 284.

201 Zit. Note de présentation. CSDN, 9. 1. 1912, in: SHA 2N1, VI/36. Vgl. auch Joffres Einlassungen gegenüber dem britischen Militärattaché aus dem August 1911: The new chief attaches the very greatest importance to the co-operation of a British expeditionary force, which [...] falling on the right flank of the German advance, might produce great, and even decisive, results. Zit. Fairholme an Bertie, 24. 8. 1911, in: BDFA France 13/70. Vgl. in diesem Zusammenhang auch die Ausführungen in den Bases du plan, in denen das britische Expeditionskorps als un renfort des plus sérieux bezeichnet wird. Zit. Bases du plan. CSG, 18. 4. 13, in: SHA 1N11, CXLIII, fol. 5.

202 Zit. Procès-verbal. CSDN, 9. 1. 1912, in: SHA 2N1, VI/36. Vgl. auch Dubails Feststellungen in: Procès-verbal de l'entretien du 18/31 août 1911, entre les Chefs d'Étatmajor des armées française et russe, in: DDF 2, 14, 232. Vgl. auch JOFFRE, Mémoires, Bd. I, S. 26: Pour nous permettre de nous libérer d'une attitude purement défensive, le plus sûr moyen était d'obtenir de nos alliés un effort intensif. 
in einen gewissen Konflikt geraten und darüber hinaus von den Implikationen der eigenen strategischen Planungen unterlaufen werden.

Was zunächst den britischen Fall betrifft - der russische Fall wird in den nächsten Kapiteln gesondert zu behandeln sein -, so ist schon erläutert worden, daß für den Kriegseintritt Großbritanniens von ganz erheblicher Bedeutung sein würde, ob Frankreich es im entscheidenden Augenblick verstand, das Deutsche Reich mit dem Odium des Aggressors zu belasten. Mit seinen strategischen Planungen war aber zumindest ein militärischer Imperativ verbunden, der ein solches außenpolitisches Bemühen beeinträchtigen konnte. Es handelte sich dabei um den Umstand, daß es im Rahmen einer offensive à outrance galt, die strategische Initiative zu ergreifen, und dies konnte es gegebenenfalls erforderlich machen, die eigene Generalmobilmachung noch vor der des Deutschen Reiches einzuleiten ${ }^{203}$. Ein solches Handeln konnte aber kaum dazu angetan sein, den Gegner mit der Kriegsschuld zu belasten. Ähnlich waren in diesem Zusammenhang die Auswirkungen des russischen Handelns auf die Frage des britischen Kriegseintritts gelagert. Denn was durch ein kalkuliertes Hinauszögern der Mobilmachung im Westen gewonnen werden konnte, mußte durch ein ungestümes Handeln im Osten verloren gehen, sollte Rußland frühzeitig zur Generalmobilmachung schreiten.

Es wird später zu zeigen sein, daß sich Frankreich mit diesem Dilemma in der Endphase der Julikrise konfrontiert sah, als seine außenpolitischen Entscheidungsträger zwar nicht mit Sicherheit anzugeben vermochten, ob Großbritannien in die sich abzeichnende Auseinandersetzung eingreifen würde, sich aber gleichwohl die Anzeichen verdichteten, daß der russische Bündnispartner im Begriff stand, zur Generalmobilmachung überzugehen, und darüber hinaus auch von der eigenen militärischen Führung, die in den letzten Tagen der Krise zunehmend unter dem Eindruck stand, daß die Mobilmachung des Deutschen Reiches beträchtlich fortgeschritten war, die Forderung nach der Generalmobilmachung Frankreichs erhoben wurde.

Mit Blick auf den bedeutenden Faktor der öffentlichen Meinung gilt es darüber hinaus ganz allgemein und stärker auf den Anlaß des Kriegsausbruchs bezogen zu bemerken, daß in einer Situation, in der Frankreich für Rußland, nicht aber Rußland für Frankreich in den Krieg zog, das heißt in einer Situation, in der zwar eine uneingeschränkte russische Einsatzbereitschaft bestand, die Interessen Großbritanniens aber nur mittelbar betroffen waren, sich der so bedeutsame Faktor der britischen Öffentlichkeit nur schwer, zumindest erst nach einer gewissen Zeit, mobilisieren lassen würde. So zeigte sich beispielsweise der britische Botschafter im November 1912 gegenüber dem Ministerpräsidenten Frankreichs davon überzeugt, daß die britische Öffentlichkeit keinen Krieg führen werde, um das serbische Territo-

${ }^{203} \mathrm{Vgl}$. hierzu die einleitenden Ausführungen im Abschnitt "Der Eintritt in den großen Koalitionskrieg«. 
rium bis zur Adria auszudehnen ${ }^{204}$, und noch in der Julikrise erklärte er dem das Außenministerium kommissarisch leitenden Justizminister: $I$ felt sure that public opinion in England would not sanction a war in support of Russia if she, as a protector of Slavs, picked a quarrel with Austria over Austro-Servian difficulty 205 .

Was für die britische Einsatzbereitschaft verbindlich war, galt mutatis mutandis, wie die Marokkokrisen in der Vergangenheit gezeigt hatten, auch für das russische Handeln, sollte der Krieg über mitteleuropäische oder gar koloniale Interessen Frankreichs ausbrechen. Doch selbst ungeachtet dieser Frage und vorausgesetzt, daß Großbritannien sich zum Kriegseintritt bereit fand, vermochten weder die militärische noch die politische Führung Frankreichs mit Sicherheit anzugeben, ob das britische Kabinett die British Expeditionary Forces auf den Kontinent entsenden und ob die britischen Kontingente rechtzeitig und in vollem Umfang eintreffen würden, um ihre ganze Wirkung entfalten zu können.

Schon im Rahmen der Untersuchungen der Militär- und Marinekonventionen, die seit 1911 respektive 1913 zwischen Frankreich und Großbritannien bestanden, ist darauf hingewiesen worden, daß auch für den Fall einer gemeinschaftlichen Kriegsführung diese Abkommen nicht automatisch in Kraft traten. In den Verhandlungen, die schließlich in den Grey-CambonBriefwechsel einmündeten, hatte sich Frankreich vergeblich darum bemüht, einen solchen Automatismus sicherzustellen ${ }^{206}$, so daß die in diesem Zusam-

204 Vgl. Bertie an Grey, 26. 11. 1912, in: BD 9/2, 280. Der britische Außenminister teilte daraufhin dem Botschafter Frankreichs die schon in anderem Zusammenhang erwähnte Einschätzung mit: I did not think that public opinion could take things seriously unless Germany moved; and, if things did become serious, I thought that public opinion would first require an attempt to secure that Germany, France and England kept out of the trouble. Zit. Grey an Bertie, 4. 12. 1912, in: BD 9/2, 328. Vgl. auch Paul Cambon an Poincaré, 4. 12. 1912, in: DDF 3, 4, 622. In diesem Telegramm berichtete der Botschafter, daß ihm Nicolson gesagt habe: A la Chambre des Communes où l'on se soucie peu du différend austro-serbe, où même un conflit limité à l'Allemagne, l'Autriche-Hongrie et la Russie ne rencontrerait que l'indifférence. Zit. ibid. Vgl. auch die Erinnerungen Poincarés, in denen für den April 1913 eine ähnliche Wahrnehmung bezeugt wird. Vgl. POINCARE, Au service de la France, Bd. III, S. $169 \mathrm{f}$. Sehr viel optimistischer nahm sich - man ist geneigt zu sagen: natürlich - die Einschätzung des Leiters der militärischen Operationsabteilung des britischen Stabes aus. Dem Militärattaché Frankreichs erklärte er: En ce moment l'opinion publique anglaise est très nettement en faveur des États balkaniques, et le Gouvernement n'est pas sans le savoir; de plus la question Serbe actuelle est de celles qui présentent beaucoup plus d'intérêt pour le public britannique, que l'affaire marocaine. Zit. de la Panouse an Millerand, 13. 11. 1912, in: SHA 7N1227.

205 Zit. Bertie an Grey, 25. 7. 1914, in: BD 11, 129. Vgl. auch Bertie, Diary of Lord Bertie of Thame, Bd. I, S. 1 (Eintrag vom 26. 7. 1914). Gegenüber einem Redakteur des "Figaro« ließ sich Bertie am 25. Juli 1914 mit den Worten vernehmen: Est-ce que vraiment vous Français, vous vous intéressez aux Serbes? Nous, aucunement. Zit. RECOULY, Joffre, S. 9.

206 Vgl. in diesem Zusammenhang die Aufzeichnung des britischen Botschafters über seinen Aufenthalt in London vom 25. Juli 1912, in: NL Bertie, PRO, FO 800/165, 
menhang entscheidende Passage des Briefwechsels zum Verdruß der Franzosen schließlich lautete: If these measures involved action, the plans of the $\mathrm{Ge}$ nerals Staffs would at once be taken into consideration, and the Governments would then decide what effect should be given to them ${ }^{207}$. Natürlich kann argumentiert werden, daß das britische Kabinett im Fall einer gemeinsamen Kriegsführung alles tun würde, um den militärischen Triumph der Allianz sicherzustellen, und daß folglich Frankreich - auf die Macht des Faktischen vertrauend - die begründete Hoffnung haben konnte, daß Großbritannien sich im entscheidenden Augenblick nicht auf Improvisation, sondern auf das in den militärischen Konventionen Fixierte verlassen würde. In bezug auf die maritimen Absprachen war dies dann auch tatsächlich der Fall208, nicht so aber hinsichtlich des Einsatzes der British Expeditionary Forces. Was diese anbetraf, so befürchteten die Verantwortlichen an der Seine, daß im entscheidenden Augenblick kostbare Zeit verstreichen könnte - Zeit, die man nicht besaß, erklärte doch der Generalstabschef dem britischen Militärattaché schon im August 1911 nachdrücklich, daß die Expeditionary Forces would bave to be sent early in the day; its intervention, for instance, on the 18th day of the French mobilisation might not prove a bit too soon 209 .

Der Leiter der Operationsabteilung im britischen Stab berichtete Sir Arthur Nicolson in diesem Zusammenhang aber, that be found some doubts in the minds of the military men as to what would be our attitude, whether we should really in the case of conflict give them any material assistance on land, and whether, indeed, such assistance would be efficient and above all timely ${ }^{210}$. $\mathrm{Zu}$ dieser von Wilson bezeichneten Gruppe zählte nun niemand geringeres als Castelnau, der sich außerordentlich skeptisch zeigte, was die rechtzeitige Entsendung der British Expeditionary Forces anbetraf. En l'état actuel de l'opinion publique et des pratiques gouvernementales du Royaume $U n i$, so führte er in seinem großen, schon in anderem Zusammenhang behandeltem Memorandum aus, il n'est pas probable que l'beure origine de la mobilisation anglaise puisse concorder avec celle de notre propre mobilisation. Dès lors, la collaboration du Corps expéditionnaire anglais ne saurait être

fol. $154 \mathrm{f}$. Vgl. auch die Beschreibung der französischen Forderungen in: Bertie an Grey, 13. 8. 1912, in: NL Bertie, PRO, FO 800/165, fol. 165 f.

207 Zit. Grey an Paul Cambon, 22. 11. 1912, in: BD 10/2, 416. Vgl. ferner Paul Cambon an Grey, 23. 11. 1912, in: BD 10/2, 417.

208 Vgl. Bases du Plan. CSG, 18. 4. 1913, in: SHA 1N11, CXLIII, fol. 5.

209 Fairholme an Bertie, 24. 8. 1911, in: BDFA France 13/70. Obgleich die Militärkonvention erst einen Monat zuvor unterzeichnet worden war, verhehlte der Generalstabschef in seiner Unterredung mit dem Militärattaché nicht den Zweifel, ob sich das britische Kabinett tatsächlich bereit finden würde, die British Expeditionary Forces in ihrem gesamten Umfang auf den Kontinent zu entsenden. Vgl. ibid. Der Generalstab widmet der Frage, ob, zu welchem Zeitpunkt und in welchem Umfang das britische Expeditionskorps eintreffen würde, eine eigene Untersuchung. Vgl. La coopération militaire anglaise, 15. 5. 1912, in: SHA 7N1227.

210 Zit. Nicolson an Grey, 24. 2. 1913, in: BD 9/2, 656. 
sûrement escomptée pour les premières grandes rencontres ${ }^{211}$. Befürchtungen dieser Art waren schon im Frühjahr 1913 dafür maßgeblich gewesen, daß eine entsprechende Passage in die Grundlagen des Plan XVII einfügt worden war. Dort heißt es, in Anspielung auf die in der britischen Öffentlichkeit wenngleich nicht zu allen Zeiten im selben Maße herrschende Furcht vor einer deutschen Invasion: il est permis de se demander si le Gouvernement britannique consentirait à transporter sur le continent la totalité de ses forces disponibles. De bons esprits en Angleterre se sont élevés contre une pareille conception. Nous agirons donc prudemment, en ne faisant pas état des forces anglaises dans nos projets d'opérations ${ }^{212}$. Folglich kann keine Rede davon sein, daß - wie der kanadische Historiker Roy A. Prete behauptet hat - der Generalstab Frankreichs der Illusion verfallen war, "that British mobilization would be simultaneous with that of the French, and that dispatch of the B.E.F. would follow automatically «213.

Die Befürchtung, daß das britische Expeditionskorps verspätet oder in reduziertem Umfang eintreffen könnte, wurde von der politischen Führung Frankreichs geteilt. Seinem Außenminister berichtete der britische Botschafter, daß Poincaré214 ihm mehr als einmal auseinandergesetzt habe, [that] English support to be effective must come within a few days and the French Authorities thought that there might be protracted discussions and valuable time lost in considering whether the casus foederis had arisen ${ }^{215}$. Und in seinem Bericht für das Jahr 1913 vermerkte Bertie: many people in France, and military authorities [...] fear that if war should break out without much preliminary warning British military aid might not arrive in time or be numerically sufficient to stay a German invasion of France by land, and that in the

211 Zit. Mémoire pour servir à l'établissement d'un plan de guerre, in: NL Castelnau, SHA $1 \mathrm{~K} 795 / 5$, fol. 4 .

212 Zit. Bases du Plan. CSG, 18. 4. 1913, in: SHA 1N11, CXLIII. Auch das Memorandum "La coopération militaire anglaise führte aus: Il se pourrait peut-être, même si les circonstances sont favorables, que le Gouvernement, pour donner satisfaction à une certaine partie de l'opinion, ne fit d'abord partir que 4 Divisions. Zit. La coopération militaire anglaise, 15. 5. 1912, in: SHA 7N1227.

213 Zit. Roy A. PreTE, French Strategic Planning and the Deployment of the B.E.F. in 1914, in: Canadian Journal of History 24 (1989), S. 42-62, hier S. 61.

214 Als im Zuge der Haldane-Mission die deutsche Reichsleitung für ein flottenpolitisches Entgegenkommen Großbritanniens Neutralität im Fall eines französisch-russischen Angriffs einforderte, beunruhigte Poincaré nicht zuletzt der Gedanke, daß ein solches Abkommen im entscheidenden Augenblick zu einer Diskussion führen würde, durch die kostbare Zeit verloren gehen konnte. Nach einem Gespräch mit Poincaré berichtete Paul Cambon an Fleuriau: En un mot, il y aura du temps perdu et vous savez qu'au début des hostilités, le temps perdu, c'est une chance d'insuccès. [...] Voilà l'objet des préoccupations de notre président du Conseil. Zit. Paul Cambon an Fleuriau, 3. 4. 1912, in: DDF 3, 2, 295.

215 Zit. Memorandum, 23. 6. 1913, in: NL Bertie, PRO 800/166, fol. 43. Bei dieser Aufzeichnung handelt sich um eine Gesprächsnotiz, die der Botschafter unter dem angegebenen Datum über eine Unterredung mit dem britischen Außenminister anfertigte. Vgl. ferner Memorandum, 3. 7. 1913, in: NL Bertie, PRO 800/166, fol. 46. 
absence of adequate British military aid the useful assistance of England would be limited to dealing with the German navy and the cutting off of supplies to Germany by sea ${ }^{216}$.

Nicht allein in politischen, sondern auch in militärischen Angelegenheiten war Großbritannien ein schwer zu kalkulierender Partner, und aus diesem Grund konnte Frankreich, wenn es galt, das Deutschen Reich im Rahmen einer Offensive mit numerischer Superiorität anzugreifen, weder den strategischen Planungen noch dem außenpolitischen Handeln Rußlands mit Gelassenheit begegnen.

Letztlich machten es die strategischen Planungen Frankreichs den Entscheidungsträgern unmöglich, mit der wahrhaft großmächtlichen Geste souveräner Gelassenheit auf Machtschwankungen im internationalen System zu reagieren, gleichgültig, ob diese Schwankungen aus einer zusätzlichen Rüstung oder aber aus einer partiellen Neuausrichtung der außenpolitischen Konfiguration des Systems resultierten. Ganz allgemein gesprochen kann konstatiert werden, daß in einem internationalen Staatensystem, in dem das britische Expeditionskorps oder ein ihm äquivalenter russischer Angriff, das heißt: eine Superiorität der aktiven Kontingente im Verhältnis von 1,13:1 respektive 1,15:1 und nicht etwa ein Verhältnis von 1,5:1 oder gar 2:1 über Triumph und Untergang einer Nation zu entscheiden vermochten, auch prima facie unbedeutend anmutende Schwankungen im Gefüge der Macht Konsequenzen von revolutionärer Qualität zeitigen mußten ${ }^{217}$. Daß eine so geringe Marge solch weitreichende Auswirkungen haben konnte, akzentuierte aber auf dramatische Weise eines der grundlegenden Charakteristika eines multipolaren Systems, das durch das Merkmal der Anarchie bestimmt ist: das Sicherheitsdilemma.

In einer Betrachtung über das Sicherheitsdilemma aus dem Jahr 1978, in der Robert Jervis der Frage nachging, unter welchen Bedingungen ein $\mathrm{Zu}$ wachs an Sicherheit des einen Staates gleichbedeutend mit einem Verlust an Sicherheit für einen anderen Staat sei, hat der amerikanische Wissenschaftler die Ansicht vertreten, daß dies erst dann der Fall sein könne, wenn sich die Offensive der Defensive weit überlegen ausnehme, da unter entgegengesetzten Vorzeichen auch ein beträchtlicher Zuwachs an Sicherheit nur einen geringen Zuwachs an Unsicherheit zur Folge habe ${ }^{218}$. Die politische Wissen-

216 Das mit der recht vagen Umschreibung many people auch das Kabinett und Ministerpräsident Poincaré gemeint waren, geht aus einer privaten Aufzeichnung hervor, die der Botschafter am 3. Juli 1913 im Anschluß an ein Gespräch mit Grey verfaßte. Vgl. Memorandum, 3. 7. 1913, in: NL Bertie, PRO 800/166, fol. 46.

217 Die British Expeditionary Forces umfaßten sechs Divisionen. Im Fall ihrer rechtzeitigen Entsendung würden den 46 aktiven Divisionen des Deutschen Reiches dann 52 französische und britische Divisionen entgegenstehen. Sollte es dem russischen Bündnispartner durch seinen Angriff möglich sein, zwölf statt sechs aktive Divisionen des Deutschen Reiches zu binden, so würde sich ohne britische Beteiligung ein Verhältnis von 46:40 bei den französischen und deutschen Divisionen ergeben.

218 Vgl. Robert Jervis, Co-operation under Security Dilemma, in: World Politics 30 
schaft der internationalen Beziehungen hat diese Überlegung Jervis' aufgegriffen, zum Gegenstand einer umfangreichen Erörterung gemacht und aus ihr eine Theorie entwickelt, die in der Literatur als offense-defense-theory bezeichnet wird ${ }^{219}$. Der Frage ihrer Kritiker begegnend, was es denn genau bedeuten solle, daß es leichter sei anzugreifen, als in der Defensive zu verharren ${ }^{220}$, haben Charles Galver und Chaim Kaufmann den zentralen Begriff dieses Theorems mit den Worten definiert:

We prefer to define the offense-defense balance as the ratio of the cost of the forces the attacker requires to take territory to the cost of the forces the defender has deployed. That is, if the defender invest $\mathrm{X}$ in military assets, how large an investment $\mathrm{Y}$ must the attacker make to acquire the forces necessary for taking territory. The offense-defense balance is the ratio $\mathrm{Y} / \mathrm{X}$. Larger ratios indicate a balance more in favour of defense. [...] Defined as the cost ratio, the offense-defence balance plays the proper role, in combination with power (and skill), in determining a state's potential military capability and therefore its ability to maintain its security 221 .

Auf dieser Grundlage prognostiziert die offense-defense theory in einem System, in dem sich der Angriff der Verteidigung in einem spezifisch verstandenen Sinne überlegen ausnimmt, unter anderem die Phänomene des intensiven Rüstungswettlaufs, der verstärkten Allianzbildung und nicht selten auch das des militärischen Prävenire 222.

Ihre Anwendung haben diese Überlegungen auch auf das Staatensystem in den letzten Jahren vor Ausbruch des Großen Krieges erfahren ${ }^{223}$. So hat Stephen Van Evera die These vertreten, daß eine der maßgeblichen Ursachen für den Kriegsausbruch in eben jenem Kult der Offensive zu suchen sei $^{224}$, und

(1978), S. 167-214, hier S. 186-199. Einzelne der von Jervis ins Feld geführten Argumente finden sich auch schon in: George QUESTER, Offense and Defense in the International System, New York 1977, passim.

219 Einen Überblick über Fortgang und Stand der Diskussionen gibt Charles L. GLASER, Chaim Kaufmann, What Is the Offense-Defence Balance and Can We Measure it?, in: International Security 22 (1998), S. 44-82, hier S. 44-47.

$220 \mathrm{Vgl}$. Jack S. LEVY, The Offensive/Defensive Balance of Military Technology: A Theoretical and Historical Analysis, in: International Studies Quarterly 28 (1984), S. 219-239, hier S. 220f. Vgl. auch Sean M. LYNN-JONES, Offense-Defense Theory and Its Critics, in: Security Studies 4 (1995), S. 660-691.

221 Zit. GLASER, Offense-Defence Balance, S. 50f. Vgl. auch Stephan VAN EvERA, Offense, Defense and the Causes of War, in: International Security 22 (1997/8), S. 5-43, hier S. $5 \mathrm{f}$.

222 Vgl. Evera, Offense, Defence and Causes of War, S. 4-16, hier S. $13 \mathrm{f}$. Vgl. Thomas J. CHRISTENSEN, Jack SNYDER, Chain Gangs and Passed Bucks: Predicting Alliance Patterns in Multipolarity, in: International Organization 44 (1990), S. 137-168. Ähnlich auch schon in: Barry R. POSEN, Sources of Military Doctrine, Ithaca 1984, S. 232 f.

$223 \mathrm{Vgl}$. Evera, Cult of the Offensive; DERS., Why co-operation failed in 1914, in: World Politics 38 (1985/1986), S. 80-117 und Ders., Offense, Defense and Causes of War, passim. Vgl. zu den Ausführungen Van Everas kritisch Scott D. SAGAN, 1914 Revisited. Allies, Offense, and Instability, in: International Security 11 (1986), S. 151-175. Vgl. auch CHRISTENSEN; SNYDER, Chain Gangs and Passed Bucks, S. 151-167.

$224 \mathrm{Vgl}$. EVERA, Cult of the Offensive. 
in den einleitenden Passagen dieser Untersuchung ist bereits darauf hingewiesen worden, daß in den Ausführungen des Politikwissenschaftlers in diesem Zusammenhang eine alte These zur Außenpolitik Frankreichs in der Julikrise erneut auftaucht. Es handelt sich dabei um die Annahme des Historikers Jules Isaac, der schon 1935 die Ansicht vertreten hatte, daß die Bewahrung des Status quo auf der Balkanhalbinsel in der Julikrise ein genuines Ziel der Außenpolitik Frankreichs gewesen sei225.

Vor dem Hintergrund der Überlegung, daß die Entscheidungsträger von der Superiorität der Offensive überzeugt waren und mithin geringe Schwankungen der Macht Konsequenzen von revolutionärer Qualität zeitigen konnten, argumentiert Van Evera, daß zumindest einer der Gründe, die Frankreich im Juli 1914 zu einer uneingeschränkten Unterstützung Rußlands veranlaßten, der ungeschmälerte Fortbestand Serbiens und der mit ihm verbundenen Existenz einer bestimmten politischen Ordnung an der Peripherie Europas gewesen sein muß. Seien doch die militärische und politische Führung Frankreichs der Auffassung gewesen, »that Austrian expansion in the Balkans could shift the European balance of power in favour of the Central Powers and thereby threaten French security «226.

Diese These wird nicht aus den Augen zu verlieren und im letzten Kapitel dieses Abschnitts empirisch zu überprüfen sein. Doch noch sind nicht alle Faktoren benannt worden, die Frankreichs militärische Dependenz von seinem Bündnispartner konstituierten. Bevor im weiteren Fortgang der Untersuchung die militärische Bedeutung der Habsburgermonarchie eine gründliche Betrachtung erfahren wird, gilt es zunächst - mit Blick auf die strategischen Planungen Frankreichs - noch einen anderen Faktor zu behandeln, der diesen Staat ebenso tief in die osteuropäische Machtbalance verstrickte, wie es die Diskrepanz zwischen den tatsächlichen nationalen und den im Zuge eines uneingeschränkten Angriffs erforderlichen Machtmitteln tat.

\subsection{Die Bedingungen eines militärischen Triumphes II: Die Invasion Belgiens}

In der historischen Forschung ist bislang die eminente Bedeutung der russischen Offensive für den militärischen Erfolg Frankreichs nicht aus der Notwendigkeit einer numerischen Superiorität der angreifenden Kontingente, sondern aus einem anderen Zusammenhang abgeleitet worden. So hat Gerd Krumeich im Rahmen seiner Dissertation die These vertreten, daß Frankreich nach 1912 durch britisches Einwirken gezwungen worden sei, sein strategisches Konzept »alternativlos « auf eine Offensive in Lothringen festzulegen, und daß die damit verbundene "ungünstige Ausgangssituation im

$225 \mathrm{Vgl}$. IsAac, A l'occasion d'un livre récent, S. $430 \mathrm{f}$.

226 Zit. Evera, Cult of Offensive, S. 70. Vgl. auch ibid., S. $95 \mathrm{f}$. 
Kriegsfall« nur durch eine russische Offensive "verbessert «227 werden konnte, die erhebliche deutsche Kontingente in Ostpreußen band.

Nachdem sich der Generalstab Frankreichs dazu entschlossen hatte, einen Krieg gegen das Deutsche Reich mit einer offensive à outrance zu beginnen, wurde er im Stadium der detaillierten Planung dieses Unterfangens rasch mit dem Umstand konfrontiert, daß die Chancen für den Erfolg einer solchen Strategie je nach Frontabschnitt ungleich verteilt waren.

In militärischer Perspektive nahm sich beispielsweise das Elsaß als ein allzu schmaler Korridor aus, der im Norden durch das Festungssystem Straßburg-Molsheim und im Osten durch den Oberlauf des Rheins abgeschlossen wurde und der aus diesem Grund für die französischen Armeen niemals mehr sein konnte als ein théâtre d'opération secondaires et limités228.

Besser, aber nicht ungleich vorteilhafter nahm sich die Lage in Lothringen aus. Dort versperrte das mächtige Festungssystem Metz-Thionville den $\mathrm{Zu}$ gang zum Deutschen Reich, und ungünstiges Terrain unterteilte den Raum in zwei schmale Korridore, durch die sich ein Angriff nur mit begrenzten Kontingenten entwickeln ließ229. Unter diesen Bedingungen würde aber die französische Offensive einem frontalen Angriff auf eine Festung gleichen, der zudem durch deutsche Offensiven, die von Metz und Straßburg vorgetragen werden konnten, in seinen Flanken bedroht wurde. Das mit einem solchen Angriff verbundene Risiko stand darüber hinaus in keiner angemessenen Relation zu den Konsequenzen eines möglichen Erfolges. Denn ein militärischer Erfolg in Lothringen schnitt die deutschen Armeen nicht von den Kommunikationslinien ab, die von den westlichen Provinzen in das preußische Gravitationszentrum des Reiches führten ${ }^{230}$.

Ni en Alsace, ni en Lorraine, so resümierte Joffre deshalb die strategischen Untersuchungen des Generalstabs auf einer geheimen Sitzung im Außenministerium, zu der am 21. Februar 1912 nur der kleine Kreis der bedeutend-

227 Zit. Krumeich, Aufrüstung und Innenpolitik, S. 22f. Vgl. Ders., $\AA$ propos de la politique d'armement de la France avant la Première Guerre mondiale, in: Revue d'histoire moderne 29 (1982), S. 662-672, hier S. 667.

${ }^{228}$ Zit. Description sommaire du théatre du Nord-Est de part et d'autre des frontières, in: SHA 7N1784. Zu den Chancen und Risiken eines Angriffs im Elsaß vgl. ferner das von der Abteilung III des Generalstabs erstellte "Mémoire sur les modifications à apporter au Plan XVI« vom Mai 1911, in: SHA 7N1784 und die Ausführungen Joffres vom 21. Februar 1912. Vgl. Conférence tenue au ministère des Affaires étrangères, Minute. CSDN, 21. 2. 1912, in: SHA 2N1, VI/39.

229 Im Generalstab kalkulierte man, daß im Rahmen eines solchen Angriffs maximal elf Korps eingesetzt werden könnten. Vgl. Mémoire sur les modifications à apporter au Plan XVI, Mai 1911, in: SHA 7N1784.

${ }^{230} \mathrm{Zu}$ den Chancen und Risiken einer französischen Offensive in Lothringen vgl. Mémoire sur les modifications à apporter au Plan XVI, Mai 1911, in: SHA 7N1784. Vgl. ferner Description sommaire du théâtre du Nord Est de part et d'autre des frontières, in: SHA 7N1784 und Conférence tenue au ministère des Affaires étrangères, Minute. CSDN, 21. 2. 1912, in: SHA 2N1, VI/39. 
sten militärischen und politischen Entscheidungsträger zusammengetroffen war,

nous ne trouvons des terrains favorables à une offensive visant des résultats décisifs. La situation serait infiniment plus avantageuse s'il nous était loisible d'étendre notre gauche au-delà de nos frontières dans le Grand Duché de Luxembourg et sur le territoire belge ${ }^{231}$. De ce côté, so schwärmte der Chef des Generalstabs über die Möglichkeiten einer Invasion der neutralen Staaten, nous pouvons développer tous nos moyens d'action; nous passons au nord de tous les systèmes fortifiés contruits à grand frais par nos adversaires et qui deviendront inutiles. En cas de succès, nos armées rejettent les masses allemandes vers l'Allemagne du Sud et menaçent directement leur principale direction de retrait sur Mayence et Berlin. En outre, la violation de la neutralité belge nous donne le moyen de faire participer d'une manière effective à nos opérations l'armée anglaise de débarquement dont l'appoint nous procure une supériorité numérique marquée sur nos adversaires ${ }^{232}$.

In seiner Mitschrift der Sitzung zog der Politische Direktor des Ministeriums am Quai d'Orsay diese Ausführungen Joffres in dem Satz zusammen: Notre seule chance d'écraser l'ennemi est de porter immédiatement la lutte sur le territoire belge 233 .

Über die ungleich geringeren Risiken und die besseren Erfolgsaussichten, die sich mit einer Offensive der französischen Armeen durch neutrales Territorium verbanden, hatte der Generalstab die zivile Staatsführung auf dieser Sitzung im Außenministerium nicht zum ersten Mal unterrichtet. Schon als der Conseil supérieur de la défense nationale am 11. Oktober 1911 zusammentrat, um erstmals über den außenpolitischen Rahmen des neuen militärischen Plans zu beraten, hatte Joffre erklärt, daß Frankreich unter militäri-

231 Zit. SHA 2N1/VII. Bei diesem Dokument handelt es sich um eine ausführliche Mitschrift, möglicherweise gar um das Original der Ausführungen, die der Generalstabschef am 21. Februar 1912 machte. Im Protokoll der Sitzung wurde Joffres Feststellung durch den Zusatz immédiatement leicht abgemildert. Vgl. Conférence tenue au ministère des Affaires étrangères, Minute. CSDN, 21. 2. 1912, in: SHA 2N1, VI/39. An der Zusammenkunft im Außenministerium nahmen neben Poincaré, Joffre und Paléologue auch Delcassé und Millerand sowie der Chef des Marinestabes Vize-Admiral Aubert teil.

${ }^{232} \mathrm{Zit}$. ibid. Zu den Chancen einer Invasion des belgischen Territoriums vgl. ferner das nicht näher bezeichnete und undatierte Feldzugsmemorandum in: SHA 7N1784. Einer Annotation auf Seite 20 dieses Dokuments kann man entnehmen, daß Teile des umfangreichen Memorandums Eingang in eine Untersuchung fanden, die sich in den Akten zur Variante I des Plan XVI befindet. Das Memorandum muß damit in der zweiten Jahreshälfte 1911 entstanden sein. Der später von Joffre publizierte Artikel »Le problème belge« ist ein Auszug aus den zeitgleich publizierten Memoiren des Feldmarshalls. Vgl. Joseph Jacques Césaire JOFFRE, Le problème belge en 1912, in: Revue des deux mondes 102/4 (1932), S. 721-733.

233 Zit. Conférence du 21 février 1912, in: NL Paléologue. Dokument im Besitz von Roger Lebon. In das offizielle Protokoll wurde dieses Urteil des Generalstabschefs nicht aufgenommen. Dort heißt es ausschließlich: M. le Général Joffre conclut qu'il y aurait un intérêt majeur à ce que nos armées puissent, dans tous les cas, pénétrer sur le territoire de la Belgique, an Sud de la ligne Namur-Liège. Zit. Conférence tenue au ministère des Affaires étrangères, Minute. CSDN, 21. 2. 1912, in: SHA 2N1, VI/39. 
schen Gesichtspunkten le plus grand intérêt ${ }^{234}$ habe, in Luxemburg und Belgien einzumarschieren. Doch in dem dann folgenden Prozeß der Entscheidungsfindung lehnten die maßgeblichen politischen Instanzen, zuletzt auch gegen den Widerstand eines Teils des Kabinetts, eine unmittelbar zu Kriegsbeginn erfolgende Invasion Belgiens ab.

Maßgeblich für diese Haltung waren nicht moralische Skrupel. Denn die zivile Staatsleitung stellte das luxemburgische Territorium dem Generalstab umgehend zur Disposition. Il est évident, so erklärte Außenminister de Selves dem Conseil supérieur de la défense nationale am 20. Oktober 1911, que le droit sera violé si nous envahissons le territoire de G[ran]d Duché de Luxembourg dont la neutralité est garantie par des traités; mais dans l'espèce, il ne s'agit pas de discuter un point de jurisprudence internationale. Le Gouvernement grand ducal est inféode à la politique allemande; nos armées pourront donc, en fait, violer le territoire Luxembourgeois ${ }^{235}$. Der entsprechend dieser Ausführungen dann später im Conseil supérieur de la défense nationale einstimmig gefaßte Beschluß, im Kriegsfall zu einer Invasion Luxemburgs zu schreiten, macht deutlich, daß auch im französischen Fall letztlich nicht das Recht, sondern die Macht der entscheidende Bezugspunkt der strategischen Planungen war ${ }^{236}$. Nach den Gegebenheiten der Machtlage zu handeln, wurde auch bei der Behandlung des belgischen Problems maßgeblich.

Schon in der Note, mit der das Außenministerium im Oktober 1911 die umfassende Denkschrift des Generalstabs zur außenpolitischen Lage ergänzt hatte, war kategorisch festgestellt worden: Le souci que le gouvernement britannique a toujours manifesté à l'égard de la neutralité belge nous ferait un devoir, en cas de guerre entre la France et l'Allemagne, de n'assumer aucune initiative qui puisse être considérée comme une violation de cette neutralitê237. Mit Rücksicht auf Großbritannien, so beschloß dann auch der Conseil supérieur de la défense nationale auf seiner Sitzung am 9. Januar 1912, berechtige erst eine Verletzung der belgischen Neutralität durch das Deutsche Reich Frankreich zu entsprechendem Handeln ${ }^{238}$.

Doch daß die höchste Instanz in strategischen Fragen die Integrität des belgischen Territoriums mit diesem einschränkenden Zusatz versehen hatte, war für Joffre nur von geringem Wert. Zwar galt es dem Generalstab als eine

234 Zit. Procès-verbal. CSDN, 11. 10. 1911, in: SHA 2N1, V/29.

235 Zit. Procès-verbal. CSDN, 9. 1. 1912, in: SHA 2N1, VI/38. In der Note, mit der das Außenministerium am 20. Oktober 1911 das Memorandum des Generalstabs zur außenpolitischen Lage ergänzte, heißt es in Bezug auf Luxemburg: On peut envisager la neutralité du Grand-Duché de Luxembourg tout autrement que celle de la Belgique. L'Angleterre n'a aucun intérêt au maintien intégral de la convention de 1867 [...]. Dans ces conditions, la France pourrait, en cas de guerre, prendre à l'égard du Grand-Duché toutes les dispositions que les circonstances rendaient opportunes. Zit. Note. Neutralité belge. CSDN, 20. 10.1912, in: SHA 2N1, VI/34/3.

236 Vgl. Procès-verbal. CSDN, 9. 1. 1912, in: SHA 2N1, VI/38.

237 Zit. Note. Neutralité belge. CSDN, 20. 10. 1912, in: SHA 2N1, VI/34/3.

238 Vgl. Procès-verbal. CSDN, 9. 1. 1912, in: SHA 2N1, VI/38. 
gesicherte Erkenntnis, daß das Deutsche Reich in einem Koalitionskrieg zunächst einen militärischen Erfolg über Frankreich suchen und in dieser Absicht die Neutralität Belgien verletzen würde. Doch vermochte er hinsichtlich des konkreten Plans und insbesondere des zeitlichen Ablaufs der militärischen Operationen des Deutschen Reiches nur eine Reihe von Hypothesen $\mathrm{zu}$ formulieren. Untersuchungen der logistischen Möglichkeiten und des Festungssystems des Deutschen Reiches, die der Generalstab in den Jahren bis zum Kriegsausbruch anstrengte, entwickelten drei unterschiedliche Szenarien 239: Le premier, der zugleich am unwahrscheinlichsten anmutete, correspondant au cas où les territoires neutres seraient entièrement respectés; le second, die dem Generalstab als überaus wahrscheinlich galt, au cas où la Belgique serait violée à priori, avec maintien d'une attitude défensive en Alsace et en Lorraine, le troisième au cas d'une offensive partant de Lorraine avec violation limitée et peut-être retardée du Luxembourg belge ${ }^{240}$.

$\mathrm{Da}$ es nicht der zentrale Gegenstand dieser Untersuchung ist, den Ursachen nachzuspüren, die Frankreich zu Kriegsbeginn fast in den Abgrund der militärischen Niederlage stürzten, sei an dieser Stelle nur am Rande bemerkt, $\mathrm{da}$ der Generalstab mit Gewißheit annahm, daß die deutschen Armeen auch im Falle einer "umfassenden "Invasion Belgiens die Maas nicht überschreiten würden ${ }^{241}$. Für diese Fehlkalkulation waren unterschiedliche Faktoren maßgeblich, und insbesondere spielte dabei die Annahme eine Rolle, daß das Deutsche Reich keine reinen Reserveformationen in seiner Frontlinie einsetzen, ein Übergang der Maas mithin die deutschen Linien überdehnen würde ${ }^{242}$. Nicht zuletzt lag ihr auch die Fehleinschätzung zugrunde, daß Bel-

239 Vgl. zum folgenden die »Note sur la concentration « vom Februar 1912 in: SHA 7N1771 und den Abschnitt: »Concentration et condition d'entrée en action des armées allemandes « in: Étude du Plan d'opérations contre l'Allemagne, in: SHA 7N1771. Post festum berichtete der Kabinettschef Joffres, daß der Generalstabschef ihm ein »Mémoire relatif à l'établissement d'un plan d'opérations « anvertraut habe, das in den August 1911 datierte und zu identischen Schlußfolgerungen gelangte. Dieses Memorandum ist heute nicht mehr in den Archiven zu finden. Vgl. FabRY, Joffre, S. $181 \mathrm{f}$. Vgl. ferner Note sur les chemins de fer, Mai 1914, SHA 7N1771. Vgl. ferner Mobilisation et Concentration, Juni 1914, in: SHA 7N1771. Vgl. auch die instruktiven Ausführungen des Generalstabschefs in seinen Erinnerungen. Vgl. Joffre, Mémoires, Bd. I, S. 115$117,137-139$.

240 Zit. JOFFre, Mémoires, Bd. I, S. 115.

241 Der Blick auf den Forschungsstand macht deutlich, daß auch in dieser Hinsicht der "forgotten belligerant " (John W. Langdon) noch immer im Schatten des Deutschen Reiches steht. Der Fluchtpunkt der Analysen zu Frankreichs strategischen Planungen in den letzten Jahren vor Ausbruch des Großen Krieges ist nur allzu oft die Marneschlacht und nicht das außenpolitische Handeln der französischen Entscheidungsträger. Vgl. TANENBaum, French Estimates und AnDrEw, France and the German Menace, S. $142 \mathrm{f}$.

242 Der Leiter der Abteilung II des Generalstabs bekannte in seinen Memoiren: Je dois reconnaître loyalement que nous pensions que les Allemands n'iraient pas au-delà de la ligne de la Meuse et de la Sambre. Zit. Mémoires Dupont, NL Dupont, in: SHA 1T526, fol. 59. Aus der Literatur vgl. TANENBaum, French Estimates, S. 150-171; ANDREw, 
gien sich zwar einer umfassenden, nicht aber einer partiellen Invasion militärisch widersetzen und in letzterer gar die Möglichkeit erblicken würde, sich zu gegebener Zeit auf die unterlegene Großmacht zu stürzen, um, die Gunst des Augenblicks nutzend, sich an der Aufteilung ihrer Reichtümer und Territorien $\mathrm{zu}$ beteiligen ${ }^{243}$.

Festzuhalten bleibt, da diese militärische Kalkulation weitreichende Konsequenzen für Frankreichs Außenpolitik zeitigte, vielmehr folgendes: Die als wahrscheinlich erachtete Verletzung der belgischen Neutralität durch das Deutsche Reich erlaubte keine unmittelbar zu Beginn der militärischen Auseinandersetzung erfolgende Invasion. Denn in den Untersuchungen des französischen Generalstabs ging man von der Annahme aus, daß das Deutsche Reich aller Voraussicht nach mit der Invasion Belgiens nicht vor Abschluß der strategischen Konzentration seiner Kontingente beginnen würde ${ }^{244}$. $\mathrm{Zu}$ diesem Zeitpunkt mußte aber Frankreich über die grundsätzliche Ausrichtung seiner Offensive schon entschieden haben, da mit dem strategischen Aufmarsch am vierten Tag der Mobilmachung begonnen werden mußte ${ }^{245}$. Aus diesem Grund erklärte Joffre im Conseil supérieur de la défense nationale am 9. Januar 1912, daß bis zu diesem Datum die Haltung Großbritanniens durch das Außenministerium definitiv festgestellt worden sein müsse, worauf ihm Außenminister de Selve nur die hilflos wirkende Antwort erteilen konnte, daß die Diplomaten ihr Möglichstes tun würden ${ }^{246}$. An der grundsätzlichen Entscheidung, daß Joffre im Kriegsfall eine deutsche Invasion Belgiens abzuwarten haben würde, bevor er seinerseits Armeen auf belgisches Territorium entsenden konnte, änderte dies aber nichts.

Es entsprach der Bedeutung dieser Frage, daß der Generalstabschef ungeachtet der Entscheidung des Conseil supérieur de la défense nationale vom 9. Januar 1912 einigen ausgesuchten Mitgliedern des neuen Kabinetts Poincaré das belgische Problem abermals vorlegte. Die Sitzung des kleinen Krei-

France and the German Menace, S. 142f. und Douglas PORCH, The French Secret Services: From the Dreyfus Affair to the Gulf War, New York 1995, S. 50-52.

243 Vgl. die Ausführungen über die belgische Haltung im Kriegsfall in: Description sommaire du thêâtre d'opération du Nord-Est d'une part et d'autre de la frontière, in: SHA 7N1784. Vgl. ferner das undatierte und nicht näher bezeichnete Feldzugsmemorandum in: SHA 7N1784. Vgl. auch die Etude du plan d'opérations contre l'Allemagne, in: SHA 7N1771.

244 Le seul renseignement d'importance suffisante, so stellte das »Mémoire sur les modifications à apporter au Plan XVI « fest, pour justifier une décision sur l'ensemble de la concentration que nous puissions être sûrs d'obtenir, est la nouvelle de la violation $d u$ territoire belge. Mais cette violation n'aura lieu certainement qu'après la concentration, au moment où les armées entameront leur offensive. [...] Les Allemands s'abstiendront soigneusement de passer la frontière belge jusqu'au jour où leurs armées seront prêtes à poursuivre, sans désemparer, leur offensive. Zit. Mémoire sur les modifications à apporter au Plan XVII, Mai 1911, in: SHA 7N1784.

245 Vgl. Note au sujet de plan, 29. 8. 1911, in: SHA 7N1763 und Bases du Plan, CSG, 18. 4. 1913, in: SHA 1N11, CXLIII/fol. $50 \mathrm{f}$.

246 Vgl. Procès-verbal, CSDN, 9. 1. 1912, in: SHA 2N1, VI/38. 
ses der bedeutendsten Entscheidungsträger, die am 21. Februar 1912 im Außenministerium stattfand, war so geheim, daß selbst Castelnau von ihrer Existenz erst nach dem Großen Krieg durch die Lektüre der Erinnerungen Poincarés erfahren sollte ${ }^{247}$. In ihrem Rahmen ging es um nichts geringeres als die prekäre Frage, ob schon die mit Sicherheit erwartete Konzentration der deutschen Kontingente an der belgischen Grenze und nicht erst ihr Vordringen auf fremdes Territorium als eine Verletzung der Neutralität gewertet werden könne ${ }^{248}$. In diesem Fall aber hätten die Kontingente Frankreichs unmittelbar zu Kriegsbeginn auf belgisches Territorium vorstoßen können und nicht erst dessen Verletzung durch das Deutsche Reich abwarten müssen, die möglicherweise zu einem Zeitpunkt erfolgen würde, an dem Frankreich über die grundsätzliche Ausrichtung seines Angriffs schon entschieden haben mußte.

Die kontroverse Diskussion, die auf der Sitzung im Außenministerium über diese Frage anhob, war - und dies gilt es zunächst festzuhalten - keine Konfrontation zwischen militärischer und politischer Leitung. Denn zum einen fanden sich mit Kriegsminister Millerand und Marineminister Delcassé auch im politischen Lager Stimmen, die einer umgehenden Invasion Belgiens das Wort redeten, und zum anderen war auch der Generalstab nicht blind gegen die fatalen Konsequenzen, die sich mit einem solchen Handeln verbinden konnten ${ }^{249}$.

Daß sich die militärische und politische Staatsraison letztlich nicht unversöhnlich gegenüber standen, daß die militärischen Entscheidungsträger die politischen Restriktionen nicht einfach mißachteten und ihre strategischen Planungen alternativlos auf eine umgehende Invasion des belgischen Territoriums festlegten, um die politische Leitung im entscheidenden Augenblick mit einem fait accompli zu konfrontieren, hatte seinen Grund darin, daß letztlich auch der Generalstab sich nicht dazu bereit fand, die Aussicht auf eine britische Intervention den Chancen einer Invasion des belgischen Territoriums zu opfern. Unterschiedlich beurteilten die Entscheidungsträger aus-

247 Vgl. Garros, L’armée, S. 204. (Unter Benutzung privaten Archivgutes.)

248 Vgl. PolNCARE, Au Service, Bd. I, S. 225-227. Vgl. damit überstimmend die Aufzeichnungen Paléologues vom 22. und 24. Februar 1912 über seine Unterredungen mit Joffre und Poincaré, die sich im Besitz von Roger Lebon befinden.

249 Auf der genannten Sitzung sprachen sich insbesondere Kriegsminister Millerand und Marineminister Delcassé für eine umgehende Invasion des belgischen Territoriums aus. Auf die Konsequenzen, die ein solches Handeln zeitigen konnte, hatte der Generalstab schon in dem Memorandum aufmerksam gemacht, das als Grundlage der Besprechung zwischen dem Politischen Direktor des Außenministeriums und dem Generalstabschef am 16. Oktober 1911 diente. Dort heißt es an entsprechender Stelle: Une pareille décision pourrait être interprétée par les puissances étrangères comme une provocation. Elle serait de nature à nous enlever l'appui de la Russie et de l'Angleterre, tout en entrainant le casus foederis pour les Etats de la Triple Alliance. Zit. Note indiquant les points relatifs à la situation extérieure à élucider dans la Conférence du 16 octobre 1911, CSDN, in: SHA 2N1, V/32. Vgl. ferner die Ausführungen Joffres auf den Sitzungen des Conseil supérieur de la défense nationale am 11. Oktober 1911 und am 9. Januar 1912. Vgl. Procès-verbal. CSDN, 11. 10. 1911 und 9. 1. 1912, in: SHA 2N1, V/29 und VI/38. 
schließlich die britischen Interessen und die Belastbarkeit der französischbritischen Beziehungen, nicht aber die Bedeutung einer britischen Intervention im Kriegsfall250.

Durch diesen Konsens wurde aber die Entscheidung über die grundlegende Ausrichtung der Offensive Frankreichs Großbritannien übertragen, und die Verantwortlichen an der Themse - das ergab eine im Jahr 1912 erfolgende vorsichtige Sondierung - waren nicht bereit, Frankreich carte blanche für eine Invasion Belgiens zu geben ${ }^{251}$. Damit aber war die Entscheidung, die der Conseil supérieur de la défense nationale am 9. Januar 1912 getroffen hatte, zu einer unverrückbaren Konstante im militärischen Planen Frankreichs geworden, und im Horizont dessen, was die militärischen und politischen Entscheidungsträger vor Ausbruch des Krieges als wahrscheinlich erachteten, würde Frankreich gezwungen sein, die ausgesprochen riskante und in ihrem Ertrag nicht anders als bescheiden zu nennende Offensive in Lothringen zu führen.

Doch - anders als zu erwarten wäre - führte dieser Umstand nun nicht dazu, daß sich der Generalstab "alternativlos « 252 auf ein solches Handeln festlegte und bei Kriegsbeginn tatsächlich ausschließlich über einen Aufmarschplan verfügte, der allein eine Offensive in Lothringen gestattete. Schon im August 1911, als Joffre die Arbeiten am Plan XVII einleitete, hatte er den Generalstab aufgefordert, die Möglichkeit einer Offensive durch Belgien als Variante eines Angriffs in Lothringen zu prüfen ${ }^{253}$. In den entsprechenden Untersuchungen stellte sich dann heraus, daß die unterschiedlichen strategischen Konzentrationen, die der einen oder anderen Offensive voraus-

$250 \mathrm{Vgl}$. Conférence tenue au ministère des Affaires étrangères, Minute, CSDN, 21. 2. 1912, in: SHA 2N1, VI/39. So argumentierte beispielsweise Joffre: Voulant la fin qui ne peut être obtenue par l'écrasement définitif de l'adversaire commun, le gouvernement Britannique ne se montrera sans doute pas trop scrupuleux sur le choix des moyens. Zit. ibid. Fast wörtlich griff der Generalstabschef damit eine Formel auf, die Marineminister Delcassé schon in der Sitzung des Conseil supérieur de la défense nationale am 9. Januar 1912 benutzt hatte. Vgl. Procès-verbal. CSDN, 9. 1. 1912, in: SHA 2N1, VI/ 38.

251 Vgl. Joffre, Mémoires, Bd. I, S. $125 \mathrm{f}$. Als Frankreichs Botschafter in einer Unterredung mit Sir Arthur Nicolson andeutete, daß der Generalstab sich gezwungen sehen könnte, die Neutralität des belgischen Territoriums zu verletzen, falls das Deutsche Reich umfangreiche Kontingente im Raum Aachen konzentrieren würde, antwortete ihm der Unterstaatssekretär im Foreign Office nur mit der knappen Bemerkung C'est bien grave. Zit. Paul Cambon an Poincaré, 21. 3. 1912, in: DDF 3, 2, 240. Vgl. ferner Poincaré an Paul Cambon, 28. 3. 1912, in: DDF 3, 2, 269. Da weder die Archive des AuBenministeriums noch die Nachlässe Cambons, Poincarés oder Paléologues Material zu dieser Frage enthalten, lassen sich keine Angaben über den weiteren Fortgang der Sondierungen machen. Das auffällige Schweigen der Quellen legt den Verdacht nahe, daß der Botschafter sich in dieser streng geheimen Angelegenheit auf einen mündlichen Bericht beschränkte, zumal er sich Anfang April 1912 ohnehin in Paris aufhielt. Vgl. Paul Cambon an Fleuriau, 3. 4. 1912, in: DDF 3, 2, 295.

252 Zit. KRUMEICH, Aufrüstung und Innenpolitik, S. 22.

$253 \mathrm{Vgl}$. Note au sujet du plan, 29. 8. 1911, in: SHA 7N1763. 
zugehen hatten, nicht von grundlegend unterschiedlicher Gestalt waren und daß eine Invasion des belgischen Territoriums einen Angriff in Lothringen als subordiniertes Manöver voraussetzte, um das Gros der deutschen Armeen im südlichen Abschnitt der Front zu fixieren ${ }^{254}$. Frankreich verfügte deshalb bei Kriegsausbruch mit dem Plan XVII schließlich über ein Konzept, auf dessen Grundlage sich sowohl eine Offensive in Belgien als auch in Lothringen umsetzen ließ. Welche von diesen Varianten letztlich Wirklichkeit werden sollte, würde durch die britische Haltung in den ersten Tagen des Krieges konditioniert werden.

Die eingangs erwähnte These, daß Frankreich alternativlos für eine Offensive in Lothringen optiert habe, vermag mithin nur auf die Wahrheit hinzudeuten, nicht aber sie zu erfassen. Zudem versperrt sie den Zugang zu den profunden Bedeutungsschichten der Außenpolitik Frankreichs in der Endphase der Julikrise, als es zur obersten Maxime der Staatsführung wurde, das Deutsche Reich mit der Schuld am Kriegsausbruch zu belasten. Denn mit der raschen militärischen Intervention Großbritanniens verband sich mehr als nnur das Faktum einer großmächtlichen Unterstützung. Mit ihr wurde zugleich über die Möglichkeit eines Angriffs durch belgisches Territorium entschieden, der nach Auffassung des Generalstabs die einzige Chance bot, das Deutsche Reich vernichtend zu schlagen.

Sollte aber man aber gezwungen sein, die offensive à outrance in Lothringen zu führen - und nach der Einschätzung der militärischen und politischen Entscheidungsträger war genau dies zu befürchten - so war es unmöglich, dem Deutschen Reich die Mittel zur Fortsetzung der militärischen Auseinandersetzungen zu nehmen. Ein solcher Angriff versprach nicht den Triumph, sondern ausschließlich den partiellen Erfolg in einem Ringen, über dessen Ausgang dann andere Großmächte entscheiden würden. Schon Guy Pedroncini hat in seiner Untersuchung der strategischen Planungen Joffres allerdings ohne auf die außenpolitischen Konsequenzen seines Befundes aufmerksam zu machen - überrascht festgestellt: »Il a finalement arrêté le plan XVII dont il avait cependant démontré lui-même, [...] l'inefficacité des solutions stratégiques « 255 .

Angesichts der ungünstigen strategischen Ausgangslage, die sich mit einem Angriff in Lothringen verband, mußte den Absichten des Zarenreiches eine ganz erhebliche Bedeutung zuwachsen. Ein rascher und uneingeschränkter

254 Vgl. das undatierte und nicht näher bezeichnete Feldzugsmemorandum in: SHA 7N1771 und die instruktiven Ausführungen Joffres in dem Kapitel »Le plan XVII Idées qui ont servi de base au plan de concentration" seiner Memoiren. Vgl. JOFFRE, Mémoires, Bd. I, S. 141-162. Vgl. hierzu kritisch: Robert A. DOUGHTY, Strategy in 1914, Joffre's Own, in: Journal of Military History 67 (2003), S. 427-454, hier S. 453 f., der den Angriff im Elsaß und in Lothringen auf Verpflichtungen gegenüber dem russischen Bündnispartner zurückführt.

255 Zit. Pedroncini, Stratégie et relations internationales, S. 143. Vgl. auch Ders., Influence de la neutralité belge, S. $189 \mathrm{f}$. 
russischer Angriff auf das Deutsche Reich war nicht allein in der Hinsicht eine notwendige Voraussetzung der offensive à outrance, daß er ihr die erforderliche numerische Superiorität sichern sollte, sondern reichte in seiner Bedeutung noch weit darüber hinaus. Mußte doch Frankreich vor dem Hintergrund der Annahme, daß man sich im entscheidenden Augenblick zu einem Angriff in Lothringen gezwungen sehen könnte, und angesichts des nicht auszuräumenden Restes an Unsicherheit, der sich stets mit der britischen Intervention verband, befürchten, daß der große Krieg, daß über seinen Triumph oder Untergang nicht am Rhein, sondern an der Weichsel entschieden werden würde.

Die Gründe zu benennen, die für den Verzicht auf die umgehende Verletzung der belgischen Neutralität maßgeblich waren, fällt nicht leicht. Schon in anderem Zusammenhang ist konstatiert worden, daß unter den politischen und militärischen Entscheidungsträgern Frankreichs Konsens bestand, daß die Aussicht auf eine britische Intervention nicht den mit einer Invasion des belgischen Territoriums verbundenen Chancen zu opfern sei. Möglicherweise sind aufgrund dieser grundlegenden Übereinstimmung in den Beratungen, die schließlich in den entsprechenden Beschluß einmündeten, die Faktoren, die den militärischen Nutzen einer britischen Intervention begründeten, niemals namhaft gemacht worden ${ }^{256}$. Nur gelegentlich lassen sich in den Quellen Hinweise auf die Umstände finden, die im Urteil der Führung Frankreichs einer britischen Intervention solch herausragende Bedeutung zukommen ließen, daß man auf eine unmittelbar zu Beginn der militärischen Auseinandersetzung erfolgende Invasion Belgien verzichtete, obgleich diese nach Ansicht des Generalstabs la seule chance ${ }^{257}$ bot, um dem Deutschen Reich eine entscheidende Niederlage beizubringen.

In einer Rede, die einer der besten Kenner der britischen Verhältnisse im französischen Generalstab, Militärattaché Huguet, vor Stabsoffizieren hielt, führte er aus, daß der britische Kriegseintritt insbesondere von moralischer Bedeutung für die Nation sei ${ }^{258}$. Ähnlich argumentierte Foch, der Sir Henry Wilson einmal auf die Frage, welches britische Kontingent für Frankreich in einer militärischen Auseinandersetzung noch von Nutzen wäre, antwortete: One single private soldier and we would take good care to see that he was kil-

256 In keinem der Sitzungsprotokolle des Conseil supérieur de la défense nationale oder der Memoranden und Untersuchungen, mit denen die Entscheidungen des höchsten Gremiums in strategischen Fragen vorbereitet wurden, findet sich ein entsprechender Hinweis: Vgl. Procès-verbal, CSDN, 11. 10. 1911, 9.1. 1912 und 21.2. 1912, in: SHA $2 \mathrm{~N} 1, \mathrm{~V} / 29, \mathrm{VI} / 38$ und VI/39. Vgl. ferner Note indiquant les points relatifs a la situation extérieure à élucider dans la Conférence du 16 octobre 1911, CSDN, in: SHA 2N1, V/ 32; Note, Neutralité belge, CSDN, 20.10. 1912, in: SHA 2N1, VI/34/3 und Note de présentation, CSDN, 9. 1. 1912, in: SHA 2N1, VI/36.

${ }_{257}$ Zit. Conférence du 21 février 1912, in: NL Paléologue. Dokument im Besitz von Roger Lebon.

258 Vgl. PrESTwICH, French Attitudes, S. 317. 
led ${ }^{259}$. Auch Castelnau und Joffre hoben in einer Unterredung mit dem Leiter der militärischen Operationsabteilung des britischen Stabes hervor, daß der Kriegseintritt seines Landes von hohem moralischem Wert für Frankreich sei ${ }^{260}$. In diesen Bahnen argumentierte ebenfalls der britische Botschafter in Paris, der in einem Gespräch mit seinem Außenminister the moral forces betonte, which would be given to the French people by the feeling that England was with them ${ }^{261}$. Gerade angesichts der Bedeutung, die der Generalstab in seinem Kalkül der über Triumph oder Niederlage entscheidenden Faktoren moralischen Fragen zumaß, wird man diese Überlegungen nicht gering achten dürfen. Darüber hinaus läßt sich aber mit der Bedeutung, die die militärische und politische Führung Frankreichs der britischen Marine zumaß, noch ein zusätzlicher Faktor ausmachen.

Zwar notierte der Leiter der militärischen Operationsabteilung des britischen Stabes unter dem Datum des 14. Februar 1913 in seinem Diarium, daß Castelnau und Joffre die Bedeutung der britischen Flotte nicht einmal auf ein Bayonett bezifferten 262. Doch bezogen sich die Repräsentanten des Generalstabs in diesem Fall auf einen Artikel Repingtons in der »Times « vom 7. Februar 1913, in dem der Militärkorrespondent des Blatts argumentiert hatte, daß allein schon die Existenz der Royal Navy Italien vor einer militärischen Intervention zugunsten seines deutschen Bündnispartners zurückschrecken lassen und damit Frankreich in die ungemein günstige Lage versetzen würde, seine Kontingente uneingeschränkt gegen das Deutsche Reich konzentrieren zu können ${ }^{263}$ - eine Auffassung, die der französische Generalstab aus ganz anderen Gründen teilte. Weit davon entfernt, den Wert der britischen Flotte gering zu erachten, war Castelnau vielmehr der Auffassung, that the French even if they suffer reverses must win in the end provided that England will aid by closing the sea approaches to Germany. In such case Germany must be starved out in four months ${ }^{264}$, und auch Poincaré erklärte dem britischen Botschafter am 30. Juli 1914: Germany [...] would not run the risk of having ber sea-borne trade destroyed and of being starved by the British fleet ${ }^{265}$.

Auch wenn nicht ersichtlich ist, auf welche Kalkulationen sich diese Einschätzungen Castelnaus und Poincarés stützten - eine Untersuchung der Auswirkungen, die eine britische Blockade auf das Deutsche Reich haben würde, ist dem Verfasser nicht bekannt -, so muten die Erklärungen des engsten Mitarbeiters des Generalstabschefs und des Präsidenten nicht unglaubwürdig an. Waren doch auch nachweislich Repräsentanten der russischen

259 Zit. WILSON, Diaries, Bd. I, S. $78 \mathrm{f}$.

260 Vgl. WILSON, Diaries, Bd. I, S. 122 (Eintrag vom 14. 2. 1913).

261 Zit. Memorandum, 25. 7. 1912, in: NL Bertie, PRO, FO 800/165, fol. 152.

262 Vgl. Wilson, Diaries, Bd. I, S. 122 (Eintrag vom 14. 2. 1913).

263 Vgl. RePINGTON, Military Policy, in: »Times « vom 7. 2. 1913, S. 7.

264 Zit. Bertie an Grey, 4. 8. 1914, in: NL Bertie, PRO, FO 800/166, fol. 92. Vgl. auch den Entwurf dieses Telegramms vom 3. August 1914, in: ibid., fol. 91.

265 Zit. Bertie an Grey, 30. 7. 1914, in: BD 11, 373. 
Führung der Auffassung, daß die britische Flotte in einer militärischen Auseinandersetzung ein tödliches Instrument darstellte. So erklärte beispielsweise der russische Außenminister Sasonow dem britischen Botschafter mehrfach, England was the only Power that could strike a mortal blow at Germany 266 und that Germany has weighed the chances of a conflict with France and Russia and may be prepared to run the risk, but that she would not face the additional danger of a naval war ${ }^{267}$. Nicht allein gegenüber britischen Repräsentanten, sondern auch in rein russischem Kreis gab der Außenminister solche, die Bedeutung Großbritanniens ersichtlich überschätzende Erklärungen ab. Auf einer Sonderkonferenz der bedeutendsten Entscheidungsträger, die während der Liman-von-Sanders-Krise zusammentrat, erklärte er: In Wirklichkeit würde Deutschland ein Auftreten Rußlands, das nur die Unterstützung von Frankreich allein bätte, nicht sonderlich gefäbrlich erscheinen. Beide Staaten wären wohl kaum imstande, Deutschland einen tödlichen Schlag zu versetzen [...]. Ein Kampf unter Beteiligung von England dagegen, könnte für Deutschland verhängnisvoll werden, das sich ganz klar ist über die Gefabr, bei einem englischen Eingreifen binnen sechs Wochen einer völligen sozialen inneren Katastrophe entgegen geführt zu werden. England ist für Deutschland gefäbrlich ${ }^{268}$.

Macht man sich diese Auffassung zu eigen und betrachtet von diesem Standpunkt aus den Verzicht auf eine Verletzung der belgischen Neutralität, so nimmt er sich als eine Rückversicherung für den Fall aus, daß Frankreichs offensive à outrance kein entscheidender Erfolg beschieden sein würde. Doch darf diese Rückversicherung nicht in dem Sinne verstanden werden, daß Frankreich mit einer britischen Intervention für den Fall Vorsorge traf, daß sich die militärischen Auseinandersetzungen über einen längeren Zeitraum erstrecken würden. Schon die Einschätzung Castelnaus, daß die Flotten Großbritanniens das Deutsche Reich in einem Zeitraum von vier Monaten auszuhungern vermochten, deutet darauf hin, daß man im Generalstab nicht von einer langen Kriegsdauer ausgegangen ist.

Mag die neuere historische Forschung auch durch eine Untersuchung des deutschen Falls die These anfechten, daß Europa vor Ausbruch des Großen Krieges der Illusion seiner Kürze verfallen war ${ }^{269}$, im Blick auf Frankreich

266 Zit. Buchanan, Annual Report Russia 1913, 4. 4. 1914, in: BDFA Russia 6/172. Vgl. Buchanan an Grey, 1.5. 1913, in: BD 9/2, 925: England alone of all Powers was in a position to strike a mortal (group omitted: ? blow) at Germany.

267 Zit. O'Beirne an Nicolson, 11. 12. 1913, in: BD 10/1, 418. Vgl. auch Ders. an Grey, 1. 12. 1913, in: BD 10/1 385 .

$268 \mathrm{Zit}$. Journal einer russischen Sonderkonferenz, 13. 1. 1914, in: HöLZLE, Quellen, 75. 269 Vgl. insbesondere FöRSTER, Metakritik. Erneut abgedruckt als: DERS., Illusion des kurzen Krieges. Vgl. ferner DERS., Nightmares. Vgl. für den Chef des deutschen Generalstabs MOMBaUER, Moltke, S. $95 \mathrm{f}$. Einen knappen Überblick über die Diskussion gibt: HERWIG, Toward a New Interpretation? Sollte tatsächlich der deutsche Generalstab von einem Volkskrieg und einer entsprechend langen Kriegsdauer ausgegangen 
behält sie uneingeschränkte Gültigkeit. Zwar war sich die militärische und die politische Führung des Landes durchaus sicher, daß der zukünftige Krieg einem Existenzkampf der Staaten gleichen werde, doch zog man daraus, so paradox dies auch anmuten mag, keinesfalls die Schlußfolgerung, daß sich eine militärische Auseinandersetzung der europäischen Großmächte über einen langen Zeitraum hinziehen würde.

So war etwa der französische Botschafter in Petersburg davon überzeugt, daß die Auseinandersetzung, die im August 1914 ihren Ausgang nahm, nicht mehr im Stile eines duellartig geführten Kabinettskrieges ausgetragen werden sollte, der, der Kontrolle der Verfügbarkeit unterworfen, bei Zeiten einen politischen Abschluß hatte finden können, sondern daß dieser Koalitionskrieg einem Konflikt gleichen würde, in dem Staaten um ihre Existenzen rangen und in dem auch erste militärische Niederlagen den Gegner nicht zu einem Einlenken veranlassen konnten. Anläßlich einer Besprechung mit dem russischen Außenminister notierte Paléologue unter dem Datum des 20. August 1914 in sein Tagebuch: La guerre actuelle n'est pas de celles qui se terminent par un traité politique, après une bataille de Solférino ou de Sadowa; c'est une guerre à mort, où chaque groupe de belligérents joue son existence nationale 270 . Obwohl diese Einsicht eigentlich nichts Gutes im Hinblick auf die Dauer des Krieges hätte erwarten lassen müssen, zog der ehemalige Politische Direktor aus ihr nicht die Schlußfolgerung, daß das Ringen der Völker sich über einen geraumen Zeitraum hinziehen würde. Kurz nach Ausbruch des Krieges prophezeite Paléologue dem britischen Botschafter eine Kriegsdauer von drei Monaten ${ }^{271}$, und sein engster Mitarbeiter an der Botschaft berichtete im August 1914 an seinen Freund de Manneville, daß man in Sankt Petersburg allgemein die Hoffnung hege, daß diese Auseinandersetzung gar in zwei Monaten beendet sein würde ${ }^{272}$. Obgleich widersprüchlich, entsprach doch das Bild, das sich Paléologue von diesem Großen Krieg machte, durchaus den Erwartungen der militärischen Führung Frankreichs.

So war der Direktor der École supérieure de la guerre, Ferdinand Foch, davon überzeugt, daß die guerre absolue der Nationalstaaten derart in das Leben der Völker eingriffe, daß die Krieg führenden Länder schließlich zum Friedensschluß gezwungen sein würden, sollte nicht schon nach kurzer Zeit

sein, so erweist sich in dieser Hinsicht die militärische Elite des Kaiserreiches als sehr viel moderner als die militärischen Entscheidungsträger der französischen Republik. 270 Zit. PalÉologue, La Russie des tsars, Bd. I, S. 92 (Eintrag vom 20. 8. 1914).

271 Vgl. Buchanan an Nicolson, 23. 12. 1914, in: NL Nicolson, PRO, FO 800/376, fol. 43: He [gemeint ist Paléologue, St. S.] is jumping from one extreme to another. [...] The war was to be over by the end of October and, when that prophecy failed, he made me a bet that it would be finished by Christmas. Der Brief wurde falsch datiert in: HALFOND, Paléologue, S. 281.

272 Vgl. Doulcets an de Manneville, 19. 8. 1914. Dokument im Besitz von André de Manneville. 
ein Triumph auf dem Schlachtfeld errungen worden $\operatorname{sein}^{273}$. Daß auch Generalstabschef Joffre von einem Existenzkampf der Staaten und zugleich von einer relativ kurzen Kriegsdauer ausging, wird durch das Protokoll der bereits in einem anderen Zusammenhang erwähnten Konferenz vom 21. Februar 1912 bestätigt. Auf dieser Zusammenkunft war dem nachmaligen Botschafter Paléologue auf die Frage, über welchen Zeitraum sich ein zukünftiger Krieg erstrecken werde, von Joffre die Antwort erteilt worden:

Je fais, à cet égard deux hypothèses. Première bypothèse: nous sommes vainqueurs au début. J'estime qu'il nous faudra au moins six mois pour arriver jusqu'au Rhin. Alors, mais alors seulement commencera la véritable résistance nationale de l'Allemagne, l'entrée en scène de toutes les Puissances, une durée indéfinie. Deuxième bypothèse: nous sommes vaincus au début. J'estime que je pourrai soutenir pendant quatre mois notre retraite sur le Morvan. Alors, mais alors seulement commencera la véritable résistance nationale de la France, l'entrée en scène de toutes les Puissances, une durée indéfinie ${ }^{274}$.

Welches Zeitmaß Joffre an die Erwartung einer durée indéfinie des von ihm prophezeiten Existenzkampfes auch immer geknüpft haben mag, zeitlich kann es nicht wesentlich über die Frist von sechs Monaten hinausgegangen sein. Denn, so mußte der Generalstabschef in seinen Memoiren rückblickend eingestehen: nous croyions tous que la guerre serait courte. À cet égard, tout le monde s'est trompé: civils et militaires, les stratèges, les diplomates, les économistes et les financières ${ }^{275}$. Und in diesem Zusammenhang sei auch daran erinnert, daß unter der Leitung Joffres die uneingeschränkte Konzentration der französischen Kontingente gegen das Deutsche Reich unter anderem mit der Begründung gerechtfertigt worden war, daß das Schicksal des Krieges entschieden sein [wird], ehe Italien Zeit hat, ernstliche Kräfte gegen Frankreich $z u$ konzentrieren ${ }^{276}$ - eine Einschätzung, die sich am 5. Dezember 1912 auch der Ministerpräsident und das spätere Staatsoberhaupt Poincaré in einem Gespräch mit dem russischen Botschafter zu eigen gemacht hatte ${ }^{277}$. Daß man in der militärischen und politischen Führung Frankreichs allgemein von einer kurzen Kriegsdauer ausgegangen sei, berichtete nach dem Krieg auch

$273 \mathrm{Vgl}$. Ferdinand Foch, Des principes de la guerre. Hg. von André MARTEL, Paris 1996, S. 115-120, 130-132.

274 Zit. Conférence du 21 février 1912, NL Paléologue. Dokument im Besitz von Roger Lebon. Diese Aussage Joffres ist ausschließlich in der Mitschrift des Politischen Direktors des Außenministeriums und nicht im offiziellen Protokoll der Sitzung überliefert. 275 Zit. JOFFre, Mémoires, Bd. I, S. 142. Paléologue hat jedoch später glauben machen wollen, daß Joffre von einem sehr langen Krieg ausgegangen sei. Vgl. PALÉOLOGUE, Journal, S. 22 (Eintrag vom 30. 1. 1914): Le général Joffre [...] estime que la prochaine guerre durera plusieurs années! Vgl. auch PALÉOLOGUE, Journal, S. 312 (Eintrag vom 19. 6. 1914).

276 Zit. Iswolski an Sasonow, 5. 12. 1912, in: STIEVE, Iswoslki-Schriftwechsel II, 608. Vgl. auch Ders. an Dens., 5. 12. 1912, in: ibid., 606.

$277 \mathrm{Vgl}$. Iswolski an Sasonow, 5. 12. 1912, in: ibid., 608. Soweit der Verfasser dieser Untersuchung die Quellenlage zu überblicken vermag, handelt es sich bei dieser Einlassung um den einzigen Hinweis auf das Bild, das sich Poincaré von Dauer und Intensität einer militärischen Auseinandersetzung der europäischen Großmächte gemacht hatte. 
der ehemalige Finanzminister Lucien Klotz. Die Angaben, die Klotz in seinen Erinnerungen machte, stimmen dabei ungefähr mit dem Bild überein, das der französischen Regierung von Joffre gezeichnet worden war. Interrogé par mes soins en 1912, so erinnerte sich Klotz, alors que la conflagration balkanique pouvait déja mettre l'Europe entière en feu, sur l'éventuelle durée des hostilités [...], l'État-major général répondit qu'au bout de six mois tout devait être fini. Et cette conception prévalut longtemps dans les conseils mêmes $d u$ Gouvernement ${ }^{278}$. Als dann im September 1914 die Fronten auf dem westlichen Kriegsschauplatz erstarrten, als sich schließlich abzuzeichnen begann, daß sich in einem Krieg unter modernen Bedingungen die Defensive der Offensive weit überlegen ausnehmen würde, war das eingetreten, was kritische Stimmen seit langer Zeit vorausgesehen, was man aber im französischen $\mathrm{Ge}-$ neralstab stets ausgeschlossen hatte ${ }^{279}$. Unter dem Datum des 11 . November 1914 notierte Edmond Buat, der Kabinettschef des Kriegsministers Millerand, in seinem Kriegstagebuch: La guerre! Est-ce la guerre que nous avons pensé [sic]. [...] C'est Sevastopol [...] ou plutôt [unleserliches Wort] une fleuve gigantesque, où tous les moyens de la guerre de siège sont employés [...]. Qui nous aurait dit que nous en arriverions avant le siège de Metz ou de Strasbourg à de pareils moyens, nous aurait bien étonnés 280 .

Nur wenige nahmen wie der französische Botschafter in Berlin und der Directeur adjoint des Außenministeriums am Quai d'Orsay an, daß der Krieg der europäischen Großmächte »sehr lange Zeit« dauern würde281. Doch auch Cambon und Berthelot konnten wohl nicht ermessen, welche

278 Zit. Louis-Lucien KLOTZ, De la guerre à la paix. Souvenirs et documents, Paris 1924, S. 16f. Bestätigt wird die Aussage Klotz' durch: Martin HorN, Britain, France, and the Financing of the First World War, London 2002, S. 27: »In France and Britain the administrative mechanisms to plan for the financing of war were weak or absent. Neither the Conseil supérieur nor the CID, both of which might have fulfilled this task, actually did so, and individual government departments, even the respective treasuries, did not regard the matter as pressing. Arguably, only the Bank of France - a private bank - had a clear sense of what to do when war came. But even the Bank of France was expecting a short war «.

279 Für das Kriegsbild der französischen Generalität vor 1914 ist es bezeichnend, daß General Jean Delmas im Jahr 1992 noch ein Papiermesser zur Hand nehmen mußte, um die Seiten des in der Bibliothek des Kriegsministeriums verwahrten Exemplars von Johann von Blochs Werk »Der zukünftige Krieg « aufzuschneiden. Vgl. Jean DELMAS, La guerre imaginée par les cinq grands états-majors, in: Jean-Jacques BECKER, Jay M. WINTER, Gerd KRUMEICH u. a. (Hg.), Guerre et cultures. 1914-1918, Paris 1994, S. 4955, hier S. $54 \mathrm{f}$.

280 Zit. Souvenirs du général Edmond Buat, in: NL Buat, BIF 5390 (Eintrag vom 31. 10.-11.11. 1914).

$281 \mathrm{Vgl}$. den Brief Jules Cambons an seine Schwägerin vom 30. August 1914. Dokument in Privatbesitz. Zit. nach: TABOUIS, Jules Cambon, S. 282. Vgl. auch BARRE, Philippe Berthelot, S. 276. Hingegen ging Paul Cambon von einer kurzen Kriegsdauer aus. Noch im September 1914 schrieb er an Delcassé, daß der Krieg nicht länger als bis zum Frühling dauern werde. Vgl. Paul Cambon an Delcassé, 18.9. 1914, in: NL Delcassé, MAE PA-AP 221/3, fol. 339. 
Konsequenzen mit dem Großen Krieg verbunden sein würden, der im Juli und August 1914 seinen Ausgang nahm. Hätte die politische Führung Frankreichs genügend Phantasie besessen, um sich vorzustellen, $\mathrm{da} ß$ an seinem Ende die »Selbstentmachtung Europas « 282 stehen würde, so hätte sie vermutlich darauf verzichtet, sich auf ein solches Wagnis einzulassen. In gewisser Weise läßt sich folglich tatsächlich davon sprechen, daß der Ausbruch des Krieges von 1914/1918 durch einen »lack of imagination « befördert wurde ${ }^{283}$ und daß sich in der Julikrise der außenpolitische Kurs eines Teils der französischen Führung nur von dem Hintergrund eines Zeitalters erklären läßt, das auch in einem Großen Krieg noch kein "menschheitsgefährdende[s] Instrument« erkannte 284 .

Doch mit diesen Ausführungen ist der Verfasser dem Gang der Untersuchung weit vorausgeeilt. Im Hinblick auf die strategischen Planungen Frankreichs gilt es zunächst festzuhalten, daß es nicht in der Absicht seiner militärischen und politischen Führung gelegen hat, mit einem britischen Kriegseintritt in den Besitz einer Rückversicherung für den Fall zu gelangen, daß sich der große europäische Krieg über einen längeren Zeitraum erstreckte, zumal eine solche Rückversicherung ohnehin vorausgesetzt hätte, daß dem deutschen Angriff in Belgien kein durchschlagender Erfolg beschieden sein würde. Erfolg und Scheitern der strategischen deutschen Planungen würden aber ganz wesentlich von Art und Umfang des Angriffs bestimmt werden, den Rußland im entscheidenden Augenblick unternahm, und vor diesem Hintergrund vermag es nicht zu verwundern, daß - wie nun im nächsten $\mathrm{Ka}$ pitel zu zeigen sein wird - der französische Generalstab sich in den letzten Jahren vor Ausbruch des Großen Krieges intensiv mit den russischen Plänen auseinandersetzte.

\subsection{Frankreichs Analyse der strategischen Planungen Rußlands}

Der Bedeutung des russischen Faktors im militärischen Kalkül Frankreichs entsprach die Intensität, mit der man im Generalstab dem Studium der strategischen Absichten nachging, die das Deutsche Reich und Rußland für ihre militärische Konfrontation hegten. In den Jahren zwischen 1911/1912 und 1914 entstand eine nicht unbeträchtliche Zahl von Untersuchungen, deren Charakter sich durchaus unterschiedlich ausnahm und deren Erkenntnisse von ungleicher Dignität waren. Doch in nuce gelangten sie zu übereinstimmenden Einsichten und zeichneten das folgende Bild:

282 Zit. Erwin HÖLZLE, Die Selbstentmachtung Europas. Das Experiment des Friedens vor und im Ersten Weltkrieg, Göttingen, Frankfurt am Main, Zürich 1975.

$283 \mathrm{Vgl}$. Joachim REMAK, The Origins of World War I. 1871-1914, New York u. a. 1967, S. 147-149. Vgl, auch Lancelot L. FARRAR, The Short-War Illusion, in: Holger H. HeRWIG (Hg.), The Outbreak of World War I. Causes and Responsibilities, Boston, New York ${ }^{6} 1997$, S. 35-41, hier S. $35 \mathrm{f}$.

284 Zit. Hildebrand, Julikrise, S. 493. 
Um unter den Bedingungen eines Koalitionskrieges einen militärischen Triumph zu erringen, besaß das Deutsche Reich nach Ansicht des Generalstabs keine andere Möglichkeit, als durch einen machtvollen Angriff zunächst Frankreich in den Abgrund der Niederlage zu stoßen. Da ein solches Unterfangen die uneingeschränkte Konzentration aller disponiblen Kräfte erforderlich machte, konnte sich mit ihm in der ersten Phase des Krieges an der östlichen Front nur eine defensive Haltung verbinden. Erst nach einem bedeutenden militärischen Erfolg über Frankreich würde das Deutsche Reich in signifikantem Umfang Kontingente verlegen, um der fortschreitenden russischen Invasion seines Territoriums mit einem massiven Gegenangriff zu begegnen 285 .

Eine Untersuchung der logistischen Möglichkeiten des Deutschen Reiches ergab, daß der Transport beträchtlicher Kontingente in dem relativ geringen Zeitraum von fünfzehn Tagen bewerkstelligt werden konnte ${ }^{286}$. Da man der Überzeugung war, daß über Erfolg oder Scheitern der militärischen Operation im Westen nach Ablauf des ersten Kriegsmonats entschieden sein würde, mußte sich im Fall eines deutschen Triumphs über Frankreich die Lage für Rußland nach dem fünfundvierzigsten Tag kontinuierlich verschlechtern. Für den Bündnispartner Frankreichs resultierte aus dieser Kalkulation ein Zeitfenster, das sich aufgrund seiner relativ langsamen Mobilmachung und Konzentration bescheiden ausnahm und das angesichts der militärischen Herausforderungen, die im Rahmen einer Invasion Ostpreußens zu meistern waren, gar prekär anmutete.

Ein systematisches Studium des östlichen Kriegstheaters unterstrich die besondere Bedeutung der Weichsellinie. Nach Ansicht der militärischen Führung Frankreichs bildete dieser Fluß für das Deutsche Reich eine letzte

285 Vgl. die Ausführungen im Abschnitt $»$ Der Kult der Offensive-Die Grundlagen des Plan XVII«. Vgl. ferner Étude relative à l'importance, à la répartition et à l'emploi des forces allemandes sur le théâtre d'opérations russo-allemandes, Mai 1914, in: SHA 7N1535. Die Untersuchungen des Generalstabs zu den strategischen Absichten des Deutschen Reiches fanden in diesem Memorandum aus dem Mai 1914 ihren Kulminationspunkt. Die Studie umfaßt über vierzig Seiten und wird von mehr als zwanzig Anhängen begleitet, bei denen es sich zum Teil um die Zusammenfassung von Detailuntersuchungen handelt. Die Untersuchung zeichnet sich insbesondere durch den Umstand aus, daß in ihr alle verfügbaren Informationen zusammengetragen und die unterschiedlichen Aspekte des Gegenstandes gleichmäßig beleuchtet werden. Ihre Erkenntnisse erhalten dadurch ein beeindruckendes empirisches und gedankliches Fundament. Vgl. SHA 7N1535. Eine Kopie dieser Note findet sich auch in: SHA 7N1538 und in den Dossiers des Plan XVII, in: SHA 7N1785.

286 In der Studie "Au sujet d'un transport éventuel des forces allemandes de la Lorraine française vers la frontière russe ", die der "Étude relative à l'importance, à la répartition et à l'emploi des forces allemandes sur le théâtre d'opérations russo-allemandes « als Anhang hinzugefügt ist, wurde errechnet, daß das Deutsche Reich in einem Zeitraum von dreizehn bis achtzehn Tagen vierzehn aktive Korps an die östliche Front transportieren könnte. Vgl. Au sujet d'un transport éventuel des forces allemandes de la Lorraine française vers la frontière russe, Mai 1914, in: SHA 7N1538. 
Widerstandslinie, um Rußland an einer umfassenden Invasion seines Territoriums und an einem Einmarsch in Berlin zu hindern. Die Bedeutung der Weichsel beschränkte sich aber nicht allein auf diese defensive Funktion. Ein mächtiges Fortifikationswerk in der Region Thorn-Graudenz gab dem Deutschen Reich zugleich auf dem östlichen Ufer des Flusses einen Brückenkopf in die Hand, von dem nach einer Phase des defensiven Widerstandes ein Gegenangriff seinen Ausgang nehmen konnte ${ }^{287}$. Aufgrund dieser Betrachtungen erhob der Generalstab den Fall der Weichsel zum primären strategischen Ziel, das es innerhalb des errechneten Zeitfensters zu erreichen galt: Les opérations russes doivent donc avoir pour objectif principal de faire tomber avant le $45 e$ jour la défense de la Vistule ${ }^{288}$.

Daß das Deutsche Reich nichts unversucht lassen würde, um den Fall dieser Linie zu verhindern, lag auf der Hand. In dieser Absicht würde das Deutsche Reich nach Ansicht des französischen Generalstabes seine Kontingente östlich der Weichsel in zwei Gruppen konzentrieren ${ }^{289}$. Eine im Abschnitt

287 Zur militärischen Bedeutung der Weichsellinie vgl. Au sujet de la valeur de la coopération russe, Dezember 1911, in: SHA 7N1538. Die Studie ist Teil der im November 1911 von Oberstleutnant Janin verfaßten »Étude sur la concentration et les transports russes«. Nach der Umstellung der russischen Mobilmachungspläne war Janin zu einem Studienaufenthalt nach Sankt Petersburg entsandt worden, um Informationen über Mobilmachung, Konzentration und die strategischen Intentionen des Bündnispartners zusammenzutragen. Vgl. die Aufzeichnung »Programme du Lieutenant-Colonel Janin « und seine Berichte aus der russischen Hauptstadt, in: SHA 7N1485. Auf der Grundlage dieser Informationen fertigte Janin dann die "Etude sur la concentration et les transports russes « an. Ihr dritter Teil, der den Titel: »Au sujet de la valeur de la coopération russe « trägt, wurde von der Abteilung II mit einem uneingeschränkt zustimmenden Kommentar versehen und in mehreren Exemplaren im Generalstab verbreitet. Vgl. SHA 7N1538.

288 Zit. Étude relative à l'importance, à la répartition et à l'emploi des forces allemandes sur le théâtre d'opérations russo-allemandes, Mai 1914, in: SHA 7N1535.

$289 \mathrm{Vgl}$. zum folgenden Étude relative à l'importance, à la répartition et à l'emploi des forces allemandes sur le théâtre d'opérations russo-allemandes, Mai 1914, in: SHA 7N1535. Vgl. ferner Note sur l'action militaire de la Russie, Fascicule II, Juli 1912, in: SHA 7N1538. In dieser Untersuchung wird spekuliert, ob es nicht zu einer kombinierten Offensive des Deutschen Reiches und der Habsburgermonarchie kommen könnte, um den russischen Teil Polens in die Zange zu nehmen. Die "Étude sur le plan de concentration russe de 1913 «, deren Augenmerk insbesondere der Mobilmachung und dem Aufmarsch der russischen Armee galt, verwirft jedoch ausdrücklich den Gedanken einer deutschen Offensive. Vgl. Étude sur le plan de concentration russe de 1913, Dezember 1913, in: SHA 7N1771. Zur Überlieferungssituation der "Note sur l'action militaire de la Russie« sei bemerkt, daß sie im Juli 1912 von der Abteilung III des Generalstabs für den Ministerpräsidenten angefertigt wurde. In den Archiven des Generalstabs findet sich darüber hinaus auch eine von der Abteilung II erstellte und als »Geheim « eingestufte Fascicule II dieses Memorandums. In ihren Ausführungen bezieht sich die Fascicule II noch auf die Angaben, die der russische Generalstabschef im Rahmen der Konferenz von 1911 machte, was eine Datierung auf die Zeit vor dem August 1912 erlaubt. Die Erläuterung der grundlegenden strategischen Optionen Rußlands nimmt in ihr breiten Raum ein. Vgl. SHA 7N1538. Ein weiteres Exemplar der Fascicule II findet 
Thorn und Deutsch-Eylau versammelte Armee würde die rechte Flanke einer zweiten, um Königsberg konzentrierten Armee sichern und sowohl die linke Flanke eines russischen Angriffs auf Graudenz als auch die rechte Flanke eines russischen Angriffs entlang den Ufern der Weichsel bedrohen. Ferner würde die Existenz dieser Armee es dem Bündnispartner unmöglich machen, zu einem Marsch auf Berlin durch Schlesien anzusetzen. Die um Königsberg konzentrierten Kontingente würden einem russischen Angriff dann mit hinhaltendem Widerstand begegnen, sich nach und nach bis zur Weichsel zurückziehen und diese Linie hartnäckig verteidigen. Stellte die Weichsel schon ein beträchtliches natürliches Hindernis dar, so machte die Fortifikation ihres Unterlaufs sie in diesem Abschnitt zu einer fast unüberwindlichen Barriere, die Ostpreußen nahezu hermetisch vom Reich abschloß und jeden russischen Angriff in eine "Sackgasse «290 führte. Doch dabei handelte es sich nicht um die einzige Herausforderung, mit der sich die Generäle des Zaren konfrontiert sehen würden. Darüber hinaus führte das Studium der der Weichsel vorgelagerten Gebiete den französischen Generalstab zu der ernüchternden Erkenntnis, daß die militärische Topographie Ostpreußens einen hinhaltenden Widerstand des Deutschen Reiches außerordentlich begünstigte. Eine Reihe geographischer Faktoren und eine systematische Fortifikation ließen den östlichsten Winkel des Reichs nach Ansicht des französischen Generalstabes zu einem veritablen Labyrinth werden, das selbst geringe deutsche Kontingente gegen einen numerisch deutlich überlegenen Angreifer, der zur Eroberung des Reichs von der Memel und Narrew her ansetze, lange Zeit verteidigen konnten ${ }^{291}$. Allein aufgrund der beträchtlichen Distanz von dreihundert Kilometern, die zwischen der Memel und der Weichsel lag, konnte eine russische Offensive, auch unter günstigsten Bedingungen, den letztgenannten Fluß erst erreichen, nachdem im Westen schon über Triumph oder Untergang Frankreichs entschieden war.

Toute avance, so lautete deshalb die ernüchternde Schlußfolgerung des Generalstabs, dans la date à laquelle les armées russes seront prêtes à entrer en opérations aura sa ré-

sich auch in SHA 7N1535. In den Archiven des Außenministeriums läßt sich nur die Fassung der Abteilung III finden. Vgl. MAE, NS Russie, 41, fol. 255-268.

$290 \mathrm{Zit}$. Au sujet de la valeur de la coopération russe, Dezember 1911, in: SHA 7N1538. Auch die "Étude relative à l'importance, à la répartition et à l'emploi des forces allemandes sur le théâtre d'opérations russo-allemandes « gelangte zu der Erkenntnis: Toute offensive russe qui a pénétré en Prusse orientale venant du Niémen ou de la Narrew aboutit obligatoirement à cette impasse. Zit. Étude relative à l'importance, à la répartition et à l'emploi des forces allemandes sur le théâtre d'opérations russo-allemandes, Mai 1914, in: SHA 7N1538.

291 Zur Untersuchung des ostpreußischen Terrains vgl. auch Au sujet de la valeur de la coopération russe, Dezember 1911, in: SHA 7N1538. Vgl. ferner den Abschnitt "Description sommaire du thêâtre d'opérations «, in Note sur le plan russe de 1913, Dezember 1913, in: SHA 7N1771. Die gründlichste Betrachtung findet sich in: Étude relative à l'importance, à la répartition et à l'emploi des forces allemandes sur le thêâtre d'opérations russo-allemandes, Mai 1914, in: SHA 7N1538. 
percussion assurément sur le moment de la bataille décisive, mais jamais de telle sorte que la ligne de la Vistule puisse être dépassée pour le 45e jour si les Russes se bornent à attaquer d'une part sur Insterburg et le barrage de Mazovie avec un groupement de forces rassemblées sur le Niémen, et d'autre part vers Allenstein avec une armée partant de la Narrew. En effet, des opérations dirigées contre les forces allemandes de Prusse en partant du Niémen et de la Narrew ne peuvent avoir d'autre aboutissement que le cul-desac de la Vistule 292 .

Diese Erkenntnis führte nun zu der bedeutsamen Einsicht, daß allein eine rasche Mobilmachung und Konzentration der russischen Kontingente noch keine hinreichende Bedingung für einen militärischen Erfolg war. Von der historischen Forschung ist diese Einschätzung oftmals übersehen worden. Seinen Grund mag das in dem Umstand haben, daß diese Einsicht des französischen Generalstabs in den Dokumenten, die aus den militärischen Archiven nach 1918 zur Publikationen gelangten, nicht recht greifbar wird, wenn sich in ihnen auch deutliche Hinweise finden. Schon Dubail hatte den russischen Generalstabschef 1911 belehrt, daß die Wirksamkeit des Angriffs nicht allein von einer raschen Mobilmachung und Konzentration der Kontingente, sondern noch durch zwei zusätzliche Faktoren bestimmt werde: L'effet de cette offensive sera d'autant plus certain qu'elle se produira plus tôt, s'effectuera avec plus de forces, et prendra une direction plus dangereuse pour l'adversaire $^{293}$. Die militärische Führung hatte ihr Augenmerk aber insbesondere auf diese direction dangereuse gerichtet, und der russische Generalquartiermeister sollte später in seinen Memoiren angeben, daß sich in den letzten Jahren vor Ausbruch des Krieges der Fluchtpunkt der russischen Offensive zu einer »Kardinalfrage " in den Besprechungen zwischen den Generalstäben entwickelt habe ${ }^{294}$.

In der gesamten deutsch-russischen Front gab es nach Ansicht des französischen Generalstabs nur zwei Abschnitte, die einen Angriff begünstigten. Es handelte sich dabei zum einen um den Abschnitt zwischen Thorn und Deutsch-Eylau und zum anderen um das Gebiet zwischen Thorn und Posen. Während sich der erste Abschnitt für einen Angriff uneingeschränkt anbot und im Fall des Erfolgs gar die Linie der Masurischen Seen zu Fall brachte, mußten seine Konsequenzen doch beschränkt bleiben. Denn der Fluchtpunkt einer solchen Offensive war stets die unüberwindliche Weichselli-

292 Zit. Étude relative à l'importance, à la répartition et à l'emploi des forces allemandes sur le théâtre d'opérations russo-allemandes, Mai 1914, in: SHA 7N1538.

293 Zit. Procès-verbal de l'entretien du 18/31 août 1911, entre les chefs d'état-major des armées française et russe, in: DDF 2, 14, 232.

294 Vgl. DaNILOFF, Rußland im Weltkriege, S. 111. Vgl. ferner Youri DanILOFF, La Russie dans la Guerre mondiale (1914-1917), Paris 1927, S. 116f. Die Memoiren des Generalquartiermeisters erschienen zuerst 1925 in russischer Sprache. Eine deutsche Übersetzung folgte noch im selben Jahr, während eine französische Übersetzung erst 1927 publiziert wurde. Beide Fassungen weichen in einigen Passagen deutlich voneinander $\mathrm{ab}$. 
nie ${ }^{295}$. Aufgrund dieser Betrachtungen stand fest, daß der Abschnitt zwischen Thorn und Posen der sensible Punkt ${ }^{296}$ der Front war. Einer Offensive, der es gelang, die Festung Thorn südlich zu umgehen, brachte ipso facto die Weichsel und mit ihr die letzte deutsche Widerstandslinie zu Fall. Mochte sich die Einnahme einer preußischen Kernprovinz noch so verführerisch ausnehmen; im Fall einer Niederlage Frankreichs setzte die Invasion Ostpreußens den Triumph der Allianz aufs Spiel297. Le résultat essentiel à obtenir le plus tôt possible par les Russes, so konstatierte der französische Generalstab im Mai 1914, ne consiste pas à se rendre mâttre de la Prusse Orientale, mais à obtenir le plus tôt possible dans la région de Thorn un succès [...] dont les conséquences militaires et morales seront de premier ordre. Les opérations n'ont de valeur qu'autant qu'elles contribuent à la réussite de cette opération principale ${ }^{298}$. Um die Weichsel zu Fall zu bringen, mußte der Bündnispartner starke Kontingente in der Region um Warschau konzentrieren und auf beiden Ufern des Flusses direkt auf die Region Thorn-Graudenz marschieren ${ }^{299}$. Um die rechte Flanke dieses Angriffs gegen eine Offensive zu schüt-

$295 \mathrm{Vgl}$. Étude relative à l'importance, à la répartition et à l'emploi des forces allemandes sur le théâtre d'opérations russo-allemandes, Mai 1914, in: SHA 7N1538.

296 Zit. ibid. Schon Oberstleutnant Janin unterschied in seiner Untersuchung drei mögliche Offensiven. Vgl. Au sujet de la valeur de la coopération russe, Dezember 1911, in: SHA 7N1538. Vgl. ferner die übereinstimmenden Ausführungen in der Fascicule II der "Note sur l'action militaire de la Russie en Europe«, in: SHA 7N1538. Dort heißt es: Toute offensive sérieuse contre l'Allemagne demande à être conduite non seulement avec l'aile droite, mais aussi avec le centre du dispositif [Hervorhebung im Original, St. S.]. 297 In seinen Erinnerungen berichtet Ignatjew über die Generalstabskonferenz des Jahres 1913: „Aber zu meinem große Erstaunen begann nun Joffre, anstatt diese Angriffspläne zu billigen, Shilinski von der Gefäbrlicbkeit eines Einfalls in Ostpreußen zu überzeugen. , Diese Richtung ist für uns am ungünstigsten', erklärte er. , C'est un guet-apens، (Das ist eine Falle), wiederholte er einige Male. Zit. Aleksej A. IGNATJEw, Fünfzig Jahre in Reih und Glied, Berlin 1956, S. 269. Die Memoiren des Militärattachés werden nach der ersten deutschen Übersetzung aus dem Jahr 1956 zitiert. Bei dieser Publikation handelte es sich um eine gekürzte Ausgabe der russischen Fassung. Im Jahr 1987 sind die Erinnerungen Ignatjews in neuer Übersetzung erschienen. Bei dieser Ausgabe handelt es sich jedoch - auch wenn dies im Untertitel des Buches nicht mehr vermerkt wird - um eine nochmals gegenüber der ersten deutschen Fassung gekürzten Ausgabe. Vgl. Aleksej A. IgnatJew, In Hoher Mission. Autobiographie, Berlin 1987.

$298 \mathrm{Zit}$. Étude relative à l'importance, à la répartition et à l'emploi des forces allemandes sur le théâtre d'opérations russo-allemandes, Mai 1914, in: SHA 7N1538. Schon im Jahr 1908 erklärte der russische Generalstabschef dem französischen Militärattaché: S'il s'agissait d'une offensive partant du Niémen vers la pointe de la Prusse orientale, il serait possible de l'avoir très vite; mais cette opération [...] gênerait bien peu les Allemands et ne promet aucun résultat sérieux. Une offensive partant de la Narew, ayant comme axe la direction Lomja-Allenstein ne mène pas non plus à aucun objectif sérieux. La seule direction inquiétante pour les Allemands serait celle de Varsovie-Berlin. Zit. Moulin an Piquart, 2. 9. 1908, in: DDF 2, 11, 442.

$299^{\circ} \mathrm{Vgl}$. zum folgenden die Ausführungen in Étude relative à l'importance, à la répartition et à l'emploi des forces allemandes sur le théâtre d'opérations russo-allemandes, Mai 1914, in: SHA 7N1538. Zur gewünschten strategischen Konzentration der russi- 
zen, sollte das Zarenreich ferner eine zweite Gruppe an den Ufern der Narrew bereitstellen. Zuletzt galt es zu verhindern, daß diese zweite Gruppe in ihrem Vormarsch aufgehalten werden würde. Zu diesem Zweck sollten Kontingente von der Memel in Richtung Königsberg vorstoßen. Cette concentration serait extrêmement menaçante pour l'Allemagne, qui serait ainsi obligée de laisser dès la première beure des forces sérieuses sur sa frontière Orientale 300 .

\subsection{Frankreichs Forderungen - Der Verlust gesamtsystemischen Denkens}

Mit den Ausführungen des vorangegangenen Kapitels ist ein militärischer Plan in seinen Grundzügen umrissen worden, auf den Frankreich seinen Bündnispartner in den letzten Jahren vor Ausbruch des Ersten Weltkrieges beharrlich festzulegen versuchte. Quant à la question de la manière dont nous devions conduire notre offensive sur le territoire de l'Allemagne, elle occupait toujours la place centrale dans le programme des conférences et attirait le plus d'attention de la part de nos alliés. [...] Les Français, so erinnerte sich Generalquartiermeister Danilow nach dem Krieg, insistaient toujours sur la nécessité de notre part d'une offensive vers le centre du pays ennemi pour atteindre les points vitaux de l'Allemagne ${ }^{301}$.

Ihren schriftlich fixierten Niederschlag fanden die Anstrengungen Frankreichs zunächst in einer Passage der Militärkonvention, mit der Rußland im Jahr 1912 den Nutzen einer Konzentration seiner Kontingente anerkannte, die es ihm ermöglichen würde, soit de prendre l'offensive dans la direction générale d'Allenstein [...] soit de manoeuvrer par la rive gauche de la Vistule pour marcher sur Berlin ${ }^{302}$. Im darauffolgenden Jahr war dieser Passus, mit der die strategische Konzentration des französischen Bündnispartners zum ersten $\mathrm{Mal}$ in der Geschichte der Militärkonvention eine genauere Festlegung erfahren hatte, dann noch durch die Formel ergänzt worden, daß sowohl Rußland als auch Frankreich in der Notwendigkeit übereinstimmten, den gemeinsamen Angriff gegen das Zentrum des Deutschen Reiches zu führen ${ }^{303}$. Unmittelbar nach Ausbruch des Krieges sollte dann Kriegsminister Messimy noch einmal sehr nachdrücklich diese alte Forderung Frankreichs in Erinnerung rufen, als er dem russischen Generalstab durch dessen Militärattaché

schen Kontingente vgl. ferner Etude sur le plan russe de 1913, Dezember 1913, in: SHA $7 \mathrm{~N} 1771$.

300 Zit. Étude sur le plan russe de 1913, Dezember 1913, in: SHA 7N1771.

301 Zit. DANILOFF, La Russie dans la Guerre mondiale, S. 117. Vgl. auch die übereinstimmenden Aussagen des russischen Kriegsministers in: SUCHOMLINOW, Erinnerungen, S. 243.

302 Zit. Procès-verbal de l'entretien du 13 juillet 1912 entre les chefs d'état-major des armées française et russe, in: DDF 3, 3, 200.

303 Zit. Procès-verbal de l'entretien du mois d'août 1913 entre les chefs d'état-major des armées française et russe, in: DDF 3, 8, 79. 
übermitteln ließ: Die den Franzosen erwünschteste Richtung unseres Stoßes bleibt weiterbin Warschau-Posen ${ }^{304}$.

Doch als der Bündnispartner Frankreichs dann im August 1914 tatsächlich zu einem Angriff im Zentrum der Front und in Richtung auf Berlin ansetzte, handelte es sich, anders als es die Lektüre der Protokolle der Generalstabskonferenzen vielleicht erwarten lassen mag, nicht um die Umsetzung eines seit langer Zeit gehegten Planes, sondern um eine Improvisation, die durch besonders günstige Umstände kurzfristig möglich geworden war ${ }^{305}$.

Unter den militärischen Entscheidungsträgern Rußlands hatte es vor Ausbruch des Großen Krieges keinen Konsens hinsichtlich der Frage gegeben, welche strategischen Absichten im Fall einer militärischen Auseinandersetzung mit den Mittelmächten zu verfolgen waren ${ }^{306}$. Danilow, der als Gene-

304 Zit. Iswolski an Sasonow, 1. 8. 1914, in: IB I/5 408. Vgl. in diesem Zusammenhang auch das Manuskript der Memoiren des französischen Kriegsministers. Le lendemain $1^{\text {er }}$ août, au cours d'un nouvel entretien avec Ignatieff, j'exprime le désir d'être mis au courant des conditions dans lesquelles se préparent les opérations russes contre l'Allemagne et de voir celles-ci se développer dans la direction de Posen. [...] Il fallait que l'offensive russe fut rapide, devançant si possible d'un, deux ou trois jours les dates prévues dans les entretiens de 1912 et 1913. Il faillait, surtout, qu'elle fut énergique et poussée à fond, en direction générale de Berlin. Zit. L'Accélération de l'offensive russe, in: NL Messimy, AN, 509 AP 6, fol. 26. Vgl. ferner Iswolski an Sasonow, 4. 8. 1914, in: IB I/5 541. Vgl. auch Adlophe Messimy, Mes souvenirs, Paris 1937, S. 187, 202 f.

${ }^{305}$ Sich einen fundierten Überblick über die strategischen Planungen Rußlands in den letzten Jahren vor Kriegsausbruch zu verschaffen, fällt nicht leicht. Das umfangreichste Werk zu diesem Gegenstand, das darüber hinaus aus den Archiven gearbeitet wurde, ist nur in russischer Sprache erhältlich. Vgl. A. M. ZAIONTCHKOVSKY, Podgotovka Rossii k imperialisticheskoi voine: Plany voiny, Moskau 1926. Rund zehn Jahre nach Zaïontchkovsky verfaßte ein ehemaliger Dozent an der Akademie des russischen Generalstabs einen hilfreichen Aufsatz zu den russischen Kriegsplänen. Vgl. Nikolai N. Golovin, The Russian war plan of 1914, in: The Slavonic and East European Review 14 (1936), S. 564-584. Vgl. auch DeRs., The Russian Army in the World War, New Haven 1931 und DERS., The Russian Campaign of 1914. The Beginning of the War and Operations in East Prussia, Fort Leavenworth 1938. Eine Untersuchung neueren Datums stammt aus der Feder des Politikwissenschaftlers Jack Snyder. Vgl. SNYDER, Ideology of the Offensive. Snyders Abhandlung, die nahezu identisch mit seiner unveröffentlichten Dissertation ist, hat den Vorzug, insbesondere die russischen Forschungen berücksichtigt und damit zugänglich gemacht zu haben, ist aber nicht auf der Grundlage archivalischer Kenntnisse entstanden. Vgl. DERS., Defending the Offensive. Biases in French, German, and Russian War Planning, 1870-1914, Diss. New York 1981. Von den Arbeiten neueren Datums vermag allein William C. Fuller seinen Gegenstand auf einer solchen Grundlage abzuhandeln. Vgl. William C. FULLER, Strategy and Power in Russia 1600-1914, New York 1992, passim. Einzelne interessante Ausführungen lassen sich auch finden in: Bruce W. MENNING, Bayonets before Bullets: The Imperial Russian Army. 1861-1914, Bloomington 1992, S. 240-252. Sehr summarisch hingegen bleibt Boris KHAVKIN, Russland gegen Deutschland. Die Ostfront des Ersten Weltkrieges in den Jahren 1914 bis 1915, in: Gerhard P. Gross (Hg.), Die vergessene Front. Der Osten 1914/15. Ereignis, Wirkung, Nachwirkung, Paderborn, München, Wien 2006 (Zeitalter der Welkriege, 1), S. 65-87, hier S. 67-69.

$306 \mathrm{Vgl}$. SNYDER, Ideology of the Offensive, S. $165 \mathrm{f}$. 
ralquartiermeister einen bedeutenden, keinesfalls aber immer maßgeblichen Einfluß auf die entsprechenden Planungen geltend machen konnte, schätzte die Gefahr, die schon von einem begrenzten deutschen Angriff für Rußland ausgehen konnte, als außerordentlich hoch ein und erachtete es aus diesem Grund für erforderlich, umfangreiche Kontingente gegen das Deutsche Reich zu konzentrieren ${ }^{307}$. Darüber hinaus band der Generalquartiermeister in seinen Überlegungen das Schicksal Rußlands eng an das des Bündnispartners und war folglich der Ansicht, daß schon zu Beginn der Auseinandersetzungen Frankreich durch einen massiven Entlastungsangriff zu unterstützen sei ${ }^{308}$.

Im Gegensatz zu Danilow hob der designierte Befehlshaber für die südliche Front Aleksew die bedeutenden Probleme eines russischen Angriffs auf das Deutsche Reich hervor. Die gründliche Fortifikation Ostpreußens und das für einen Angriff ungünstige Terrain bargen nach seiner Auffassung das beträchtliche Risiko, daß auch ein umfangreiches Kontingent durch einen numerisch weit unterlegenen Gegner immobilisiert werden konnte. Ein Angriff, der zudem nicht gleich zu Beginn der militärischen Auseinandersetzungen mit der Absicht unternommen wurde, die Weichsel zu Fall zu bringen, konnte zu keinem entscheidenden Erfolg führen. Darüber hinaus schien Aleksew ein früher Entlastungsangriff auf das Deutsche Reich weit weniger dringlich zu sein als dem Generalquartiermeister. Traute er doch Frankreich eine beträchtliche Widerstandskraft zu und glaubte, daß selbst im Fall einer Niederlage Frankreichs das Deutsche Reich seinen Erfolg mit bedeutenden Verlusten erkaufen mußte, die seinen vermeintlichen Triumph letztlich in einen Pyrrhussieg verwandeln würden. Dementsprechend empfahl Aleksew zu Beginn der militärischen Auseinandersetzungen gegen das Deutsche Reich mit geringen Kontingenten in der Defensive zu verharren und statt dessen einen massiven Angriff auf die Habsburgermonarchie auszuführen, für den nach seiner Auffassung nicht zuletzt gewichtige politische Argumente sprachen. Ein russischer Erfolg in Galizien, so spekulierte er, würde nicht allein zu einer militärischen Intervention Italiens und Rumäniens, sondern darüber hinaus zu einem Aufstand der slawischen Bevölkerungsteile in der Habsburgermonarchie führen, deren morsches Staatsgebäude zum Einsturz bringen und damit Rußlands imperialen Zielen den Weg ebnen, die eben nicht in Ostpreußen, sondern auf dem Balkan und am Bosporus lagen $^{309}$.

Die unterschiedlichen Einschätzungen und Absichten Danilows und Aleksews hatten einen notdürftigen und widersprüchlichen Kompromiß gefunden, der letztlich kein Lager zufrieden stellen konnte, als im Mai des Jahres 1912 die Modifikationen des älteren Plans 19 in Kraft traten, die für den

307 Vgl. ibid., S. 166-169, $180 \mathrm{f}$.

308 Vgl. ibid., S. $194 \mathrm{f}$.

309 Vgl. ibid., S. 169f., 172-179. 
Fall einer militärischen Konfrontation die Konzentration der 28 Korps der europäischen Militärbezirke Rußlands regelten ${ }^{310}$. Während kleine Kontingente im Raum um Petersburg und Odessa konzentriert werden sollten, um Rußland gegen eine militärische Intervention Schwedens oder Rumäniens beziehungsweise seine Kapitale gegen eine deutsche Landung zu schützen, wurden aus den verbleibenden 25 Korps fünf respektive sechs Armeen gebildet und diese zu einer nordwestlichen und einer südwestlichen Gruppe zusammengefaßt.

Hinsichtlich der Konzentration dieser Kontingente entwarfen die Modifikationen des Plans 19 zwei unterschiedliche Varianten, die der russische $\mathrm{Ge}-$ neralstab mit den Buchstaben $» A \ll-$ Awstria (Österreich) und $» G \ll-G e r m a-$ nia (Deutschland) bezeichnete. Da die letztgenannte Fassung nur in dem als unwahrscheinlich erachteten Fall in Kraft treten sollte, daß das Deutsche Reich schon zu Beginn der militärischen Auseinandersetzungen ein Kontingent gegen Rußland einsetzen würde, das in seinem Umfang signifikant über die Zahl von 25 Divisionen hinausging, formulierte Variante $A$ « die eigentlichen strategischen Absichten. Nach den Bestimmungen dieser Fassung umfaßte die gegen das Deutsche Reich gerichtete Gruppe neun Korps und setzte sich aus zwei Armeen zusammen, die zum einen südlich der Festung Kowno und zum anderen im Raum zwischen Grodno und Lomza konzentriert werden sollten. Die südwestliche Gruppe hingegen, die gemäß den Ausführungen des Plans »A « zunächst aus drei, dann, nach einer nochmaligen Modifikation der Pläne im Jahr 1913, aus vier Armeen bestand ${ }^{311}$, sollte in den Regionen um Ljublin, Cholm-Kowel, Dubno und Proskurow aufmarschieren und würde sechzehn Korps umfassen ${ }^{312}$.

In einer numerischen Relation zum Ausdruck gebracht bedeutet dies, daß Rußland zu Beginn einer militärischen Auseinandersetzung nur rund ein Drittel seiner in Europa disponiblen Kontingente gegen das Deutsche Reich zum Einsatz bringen würde, während im Rahmen des Angriffs auf die Habs-

310 Vgl. zum folgenden: Golovin, Russian War Plan, S. 374-376 und SNYDER, Ideology of the Offensive, S. 179.

311 In der Absicht, den Angriff auf das Deutsche Reich und die Habsburgermonarchie zu beschleunigen, wurden im Jahr 1913 die Modifikationen des Plans 19 noch einmal überarbeitet. Um den Zeitraum der strategischen Konzentration zu reduzieren, wurden die Divisionen, die erst in einem fortgeschrittenen Stadium der militärischen Auseinandersetzung die westliche Grenze erreichen konnten, nicht mehr den angreifenden Kontingenten, sondern der strategischen Reserve zugeteilt. Entscheidend ist in diesem Zusammenhang aber, daß Plan 20, der erst in der zweiten Jahreshälfte 1914 in Kraft treten sollte, weder zu einer Umverteilung von Kontingenten zwischen der nordwestlichen und südlichen Gruppe noch zu einem grundlegenden Wandel der strategischen Absichten führte. Vgl. SNYDER, Ideology of the Offensive, S. $183 \mathrm{f}$.

312 Für den Fall, daß das Deutsche Reich schon zu Beginn der militärischen Auseinandersetzungen beträchtliche Kontingente gegen Rußland konzentrieren würde, sah Fassung » $\mathrm{G}$ « vor, die dritte Armee nicht mehr gegen die Habsburgermonarchie, sondern südlich von Riga gegen das Deutsche Reich einzusetzen. Vgl. GoloviN, Russian War Plan, S. 573 und SNYDER, Ideology of the Offensive, S. 178. 
burgermonarchie mehr als 50 Prozent der Kontingente Verwendung finden sollten. Sicherlich gilt es zu bedenken, daß nicht das Deutsche Reich, sondern die Habsburgermonarchie den substantiellen Teil ihrer Kontingente gegen Rußland konzentrieren und folglich in der ersten Phase der militärischen Auseinandersetzungen der gefährlichste Gegner sein würde ${ }^{313}$. Doch unbeschadet dieses Faktums gibt diese Relation einen deutlichen Hinweis auf die Absichten, denen Rußland in den letzten Jahren vor Ausbruch des Großen Krieges nachging und die den französischen Wünschen diametral widersprachen: Während die gegen das Deutsche Reich gerichtete Gruppe allein südlich und nördlich der Masurischen Seen angreifen und Ostpreußen bis zur Weichsel einnehmen sollte, würde es gleichzeitig zu einem uneingeschränkten Angriff auf die Habsburgermonarchie kommen ${ }^{314}$. Mochte sich das Unterfangen einer Invasion Ostpreußens auch gewaltig ausnehmen; in Anbetracht des gigantischen Manövers, mit dem Rußland die Kontingente der Habsburgermonarchie zu umfassen und zu vernichten suchte, handelte es sich ausschließlich um einen begrenzten Angriff, der dem primären Ziel untergeordnet war, dem verhaßten österreichischen Rivalen eine vernichtende Niederlage beizubringen. Denn erst nachdem Ostpreußen besetzt und die Habsburgermonarchie geschlagen worden war, würde man zu dem von Frankreich nachdrücklich geforderten Angriff im Zentrum der Front und in Richtung auf Berlin ansetzen, der allein erhebliche deutsche Kontingente binden und dem Gegner die Mittel zur Fortsetzung der militärischen Auseinandersetzungen nehmen konnte.

Ganz offensichtlich hatten beide Bündnispartner unterschiedliche Prioritäten: Empfahl Frankreich dem russischen Generalstab, schon zu Beginn des Krieges durch einen entsprechenden Angriff den Fall der Weichsel sicherzustellen und in Richtung Berlin zu marschieren, um ein Maximum an deutschen Kontingenten zu binden, so sollte nach russischer Auffassung dieses Unterfangen erst nach der Niederlage der Habsburgermonarchie und damit in einem späteren Stadium erfolgen. Ein solches Vorgehen stand aber in direktem Widerspruch zu den Verpflichtungen der Militärkonvention, mit der vereinbart worden war, que la défaite des armées allemandes reste, quelles que soient les circonstances, le premier et le principal objectif des armées alliées ${ }^{315}$.

Als der ehemalige Generalquartiermeister mit der Publikation seiner Erinnerungen im Jahr 1925 einen Einblick in diese strategischen Planungen Rußlands gewährte, dürften deshalb selbst die in Frankreich mit den militäri-

313 Vgl. die Ausführungen des russischen Generalstabschefs, in: Procès-verbal de l'entretien du 13 juillet 1912 entre les chefs d'état-major des armées française et russe, in: DDF 3, 3, 200.

314 Vgl. Golovin, Russian War Plan, S. 575f. und SNYDER, Ideology of the Offensive, S. $179 \mathrm{f}$.

315 Zit. Procès-verbal de l'entretien du 13 juillet 1912 entre les chefs d'état-major des armées française et russe, in: DDF 3, 3, 200. 
schen Geheimnissen der Allianz vertrauten Personen nicht wenig gestaunt haben; entsprachen doch seine Ausführungen gleich in mehrfacher Hinsicht nicht dem Bild, das vor 1914 den militärischen Entscheidungsträgern Frankreichs entworfen worden war ${ }^{316}$. Bemerkenswert ist in diesem Zusammenhang, daß Rußland seinen Bündnispartner erst 1913 über seinen neuen strategischen Plan unterrichtete, obwohl dieser schon im Vorfeld der Generalstabskonferenz von 1912 in $\mathrm{Kraft}$ getreten war ${ }^{317}$. Sehr viel bedenklicher aber war noch, daß der russische Generalstabschef auf der letzten Konferenz vor Ausbruch des Großen Krieges gänzlich unrichtige Angaben über den Einsatz der vierten Armee gemacht und damit die Franzosen über die Hauptstoßrichtung des russischen Angriffs in die Irre geführt hatte. So entwarf er einen strategischen Plan, der den Aufmarsch der vierten Armee nicht in der Region um Lublin, sondern in der Region um Warschau und ihren Einsatz nicht gegen die Habsburgermonarchie, sondern gegen das Deutsche Reich vorsah ${ }^{318}$. Erst aufgrund dieses Trugbildes konnte der französische Generalstab zu der irrigen Annahme gelangen, daß der Bündnispartner 13 oder gar 14 Korps gegen das Deutsche Reich einsetzen würde ${ }^{319}$.

Entscheidend für den in dieser Untersuchung zu behandelnden Gegenstand ist nun aber, daß Frankreich - auch wenn es über die strategische Konzentration Rußlands in die Irre geführt wurde - doch zumindest erkannte, $\mathrm{daß}$ das Zarenreich keinesfalls beabsichtigte, schon in der ersten Phase der militärischen Auseinandersetzungen durch einen entsprechenden Angriff

316 Vgl. DANiloff, La Russie dans la Guerre mondiale, S. 121-139.

317 Folgt man den Ausführungen Snyders, so traten die Modifikationen des Plans $19 \mathrm{im}$ Mai 1912 in Kraft. Vgl. SNYDER, Ideology of the Offensive, S. 179.

$318 \mathrm{Vgl}$. die handschriftliche Aufzeichnung Renseignements donnés par le Général Gilinski au G[énér]al Joffre dans la conférence préliminaire du $20-12$ août 1913, in: SHA 7N1535. In der historischen Forschung ist dies bislang unbemerkt geblieben. Vgl. LANEY, Military Implementation, S. 325f. Die Generalstabskonferenz von 1913 wird vom finnischen Historiker Pertti Luntinen in seiner Untersuchung nicht mehr berücksichtigt. Vgl. Pertti LunTINEN, French Information on Russian War Plans, 1880-1914, Helsinki 1984 (Studia Historica, 17).

319 Vgl. Note sur le plan russe de 1913, Dezember 1913, in: SHA 7N1771. Kann schon hinsichtlich der Ausführungen, die Shilinski auf der letzten Konferenz vor Ausbruch des Großen Krieges über die strategischen Planungen Rußlands machte, konstatiert werden, daß diese in bedeutenden Teilen nicht der Wahrheit entsprachen, so lassen sich die Angaben von 1911 und 1912 grundsätzlich nicht mehr in Einklang mit den tatsächlichen Absichten Rußlands bringen. So konzentrierte Plan 19 zwar beträchtliche Kontingente gegen das Deutsche Reich, war aber zugleich vom Primat der Defensive bestimmt. Dementsprechend beabsichtigte man im Fall einer militärischen Auseinandersetzung, große Teile des russischen Territoriums zu evakuieren, die russischen Kontingente im Landesinneren zu sammeln und erst zu einem fortgeschrittenen Zeitpunkt zu einem Angriff überzugehen. Vgl. SNYDER, Ideology of Offensive, S. 166-172. Einer der besten Kenner der russischen Militärgeschichte, William C. Fuller, hat in diesem Zusammenhang gar geurteilt: »It would not be too much to describe his [gemeint ist Suchomlinow, St. S.] defensist strategy as a plot against Russia's traditional foreign policy, for the strategy clearly subverted the alliance with Paris«. Zit. FuLLER, Strategy and Power, S. 432. 
dem Deutschen Reich die Mittel zur Fortsetzung des Krieges zu nehmen. Hatte der französische Generalstab auf der Grundlage der Informationen, die ihm im Rahmen der Konferenzen von 1911 und 1912 übermittelt worden waren ${ }^{320}$, noch kritisiert, daß das Gravitationszentrum der russischen Konzentration zu weit im Norden und die den entscheidenden Angriff ausführende Armée centrale zu weit im Osten lag321, so mußte man bei einer gründlichen Untersuchung der strategischen Planungen Rußlands im Dezember 1913 nun zu der Erkenntnis gelangen:

Le procès-verbal de 1913 définit ainsi le but de l'offensive russe: ssoit combattre les forces ennemies concentrées dans la Prusse Orientale, soit marcher sur Berlin en prenant une ligne d'opération au Sud de cette province, si la concentration des forces allemandes se fait sur la rive gauche de la Vistuler. Le plan russe ne semble guère tendre vers ces deux buts; il vise en effet nettement et exclusivement à l'envabissement de la Prusse Orientale 322 .

War schon die Einsicht ernüchternd, daß sich aufgrund der russischen Konzentration kein Angriff entwickeln ließ, der einen entscheidenden Erfolg gegen das Deutsche Reich versprach, so unterzog die Untersuchung darüber hinaus auch die Art, in der der russische Angriff auf Ostpreußen ausgeführt werden sollte, einer vernichtenden Kritik. Selbst in dem günstigen Fall, daß das Deutsche Reich in seiner östlichen Provinz eine Niederlage erlitt, konnte nach Ansicht des französischen Generalstabs durch den russischen Angriff nicht verhindert werden, daß die deutschen Kontingente sich hinter die fortifizierte Weichsel zurückzogen und dort lange Zeit erfolgreich Widerstand leisteten ${ }^{323}$.

Was diese Untersuchung ausführlich darlegte und noch durch eine weitere Analyse im Juni 1914 untermauert wurde ${ }^{324}$, hatte sich dem Generalstabschef Frankreichs schon 1913 auf der letzten Konferenz vor Ausbruch des Großen Krieges abgezeichnet und zu seiner massiven Intervention geführt. So berichtet der damals anwesende Militärattaché Ignatjew in seinen Memoiren, $\mathrm{da}$ - als der russische Generalstabschef begann, seine Planungen zur Invasion Ostpreußens zu erläutern - Joffre, wobei er seine aufgedunsene Hand

$320 \mathrm{Vgl}$. in diesem Zusammenhang: Russie. Renseignements donnés verbalement le 22 mars 1911 par M. le Général Comte Nostitz, Agent Militaire de Russie, in: SHA 1K666; Annexe au procès-verbal de l'entretien du 18/31 août 1911 entre les chefs d'état-major des armées française et russe à Krasnoe Celo, in: ibid. und Annexe au procès-verbal de l'entretien du 6 juillet 1912 entre les chefs d'état-major des armées française et russe à Paris, in: ibid. Vgl. ferner die Étude sur la concentration et les transports russes, November 1911, in: SHA 7N1538; Note sur l'action militaire de la Russie en Europe, Fascicule II, in: SHA 7N1535; Note sur l'action militaire de la Russie en Europe, August 1912, in: 7N1538 und La concentration russe, Juli 1913, in: SHA 7N1535.

$321 \mathrm{Vgl}$. Note sur l'action militaire de la Russie en Europe, August 1912, in: SHA 7N1538.

322 Zit. Note sur le plan russe de 1913, Dezember 1913, in: SHA 7N1771.

$323 \mathrm{Vgl}$. ibid.

$324 \mathrm{Vgl}$. Note pour le 3e Bureau (avant propos pour le plan), 12.6. 1914, in: SHA 7N1771. 
über die auf dem Tisch ausgebreitete Karte unserer Westgrenze fübrte, anstatt diese Angriffspläne zu billigen, Shilinski von der Gefährlichkeit eines Einfalls in Ostpreußen zu überzeugen suchte. ,Diese Richtung ist für uns am ungünstigsten', erklärte er. 'C'est un guet-apens` (Das ist eine Falle), wiederbolte er einige Male ${ }^{325}$.

Daß der Bündnispartner nur einen begrenzten Angriff gegen den gemeinsamen Gegner unternehmen würde, der zwar unter günstigen Umständen zu einer partiellen Niederlage des Deutschen Reiches führen, gleichwohl aber diesem nicht die Mittel zur Fortsetzung der militärischen Auseinandersetzung nehmen konnte, ist der sachliche Kern einer Furcht, die in den Quellen ihren übersteigerten Ausdruck in der Formel findet, daß Rußland im entscheidenden Augenblick mausschließlich « gegen die Habsburgermonarchie vorgehen könnte.

Einen deutlichen Hinweis auf diese Furcht gibt beispielsweise die Beharrlichkeit, mit der Joffre in den letzten Jahren vor Ausbruch des Großen Krieges und noch bis in den Juli 1914 hinein auf vermeintlich Evidentes aufmerksam machte. In den Generalstabskonferenzen der Jahre 1912 und 1913 versuchte er den russischen Militärs einzuschärfen, daß die Niederlage des Deutschen Reiches selbst einen militärischen Rückschlag gegen die Habsburgermonarchie in der Bedeutungslosigkeit versinken lasse, daß es die Vernichtung der deutschen Kontingente sei, qu'il faut poursuivre à tout prix ${ }^{326}$ sowie dès le début des opérations ${ }^{327}$. Und noch in der Julikrise sollte er abermals fordern, daß der russische Angriff fut principalement dirigée contre l'Allemagne et non contre l'Autriche 328 .

Entsprechend dieser Forderungen setzte auch Kriegsminister Messimy dem russischen Militärattaché am 31. Juli auseinander, daß die Habsburgermonarchie in dem sich abzeichnenden Krieg letztlich nur die "Rolle eines Komparsen "spielen werde und folglich als quantité négligeable ${ }^{329} \mathrm{zu}$ behandeln sei. Die Erinnerungen des Kriegsministers, denen dieses letzte Zitat entnommen ist, dokumentieren darüber hinaus, daß es sich bei diesen Gedan-

${ }^{325}$ Zit. IgNaTjEw, Fünfzig Jahre, S. 269.

326 Zit. Procès-verbal de l'entretien du 13 juillet 1912 entre les chefs d'état-major des armées française et russe, in: DDF 3, 3, 200.

327 Zit. Procès-verbal des entretiens du mois d'août 1913 entre les chefs d'état-major des armées française et russe, in: DDF 3, 8, 79. Vgl. auch die übereinstimmende Aussage in den Erinnerungen Poincarés. Dort heißt es: Ce qui ressort, en tout cas, du procès-verbal de la réunion tenue le 13 juillet 1912 [...] c'est que l'état-major français avait, pour le cas où la guerre éclaterait, des préoccupations de plusieurs sortes. Le général Joffre craignait qu'en cas de conflagration générale, la Russie ne toumât une trop grande partie de ses armées contre l'Autriche et ne nous prêtât pas assez largement son concours contre l'Allemagne. Zit. PoINCARÉ, Au service de la France, Bd. II, S. 87.

${ }^{328}$ Zit. L'Accélération de l'offensive russe, in: NL Messimy, AN, 509 AP 6, fol. 8. Vgl. ferner MESSIMY, Mes souvenirs, S. $202 \mathrm{f}$.

329 Zit. L'Accélération de l'offensive russe, in: NL Messimy, AN, AP 509 AP 6, fol. 7. Vgl. auch Iswolski an Sasonow, 31. 7. 1914, in: IB I/5 356 und Ders. an Dens., 4. 8. 1914, in: IB I/5 451. 
kengängen nicht allein um die Befürchtungen der militärischen, sondern auch der politischen Führung handelte ${ }^{330}$. En entier accord avec le ministre des Affaires Étrangères et avec le président de la République, so ist in den $\mathrm{Me}-$ moiren Messimys zu lesen, $j$ 'ai, dès le 31 juillet, et inlassablement jusqu'à mon départ, marqué à l'attaché militaire russe que les principes de la plus élémentaire stratégie, comme le bon sens, commandaient d'agir offensivement contre le principal, le seul adversaire, l'Allemagne ${ }^{331}$.

Vor dem Hintergrund dieser Ausführungen erscheinen aber dann die Angaben, die Paléologue im Jahr 1936 dem Historiker Pierre Renouvin machte, nicht mehr - wie man quellenkritisch argwöhnen könnte - als Konfabulationen oder die das eigene Handeln rechtfertigenden Unwahrheiten eines Botschafters, den die Historiographie noch ante mortem mit der Anklage konfrontiert hatte, den russischen Bündnispartner trotz ausdrücklicher Anordnung seiner Regierung nicht vor dessen Generalmobilmachung gewarnt zu haben, sondern als der prägnante Ausdruck einer Furcht, die alle Entscheidungsträger Frankreichs erfaßt hatte.

Le grand souci non seulement des milieux militaires, mais du gouvernement français, so resümierte Renouvin in seinen Gesprächsnotizen die Aussagen Paléologues, c'était d'avoir l'assurance qu'en cas d'attaque allemande la Russie s'engagerait rapidement contre l'Allemagne - et non pas seulement contre l'Autriche-Hongrie. Cette question avait une telle importance, aux yeux du gouvernement français que $M$ [onsieur] $P$ [aléologue] lorsqu'il a été nommé ambassadeur à Saint-Pétersbourg, a emporté une copie du procès-verbal de la Conférence du 21 février 1912, afin de montrer ce document au ministre russe - et cela sur l'avis même de M. Poincaré et de M. Doumergue ${ }^{332}$.

Mit diesem Hinweis auf die geheime Zusammenkunft der bedeutendsten militärischen und politischen Entscheidungsträger am 21. Februar hatte aber der ehemalige Politische Direktor und Botschafter dem Historiker den ent-

330 Als der Ministerpräsident und Außenminister Frankreichs im Jahr 1912 mit dem russischen Finanzminister über den Ausbau des strategischen Eisenbahnnetzes sprach und dieser ihm mitteilte, daß erste Schritte schon unternommen worden seien, um den Forderungen des französischen Generalstabs Genüge zu tun, und in diesem Zusammenhang auf den Ausbau einer Linie aufmerksam machte, die dem Aufmarsch gegen die Habsburgermonarchie dienen sollte, erwiderte Poincaré, daß es sehr viel dringlicher sei, die Konzentration der russischen Kontingente gegen das Deutsche Reich zu beschleunigen. Denn, so vergaß er nicht seinem Gesprächspartner ins Gedächtnis zu rufen: Il est probable que c'est sur la frontière allemande que se décidera le sort de la guerre. Zit. Notes de M. Poincaré sur ses entretiens de Saint-Pétersbourg, August 1912, in: DDF 3, 3, 264. Somit dürften nicht allein die militärischen Entscheidungsträger, wie Poincaré in seinen Erinnerungen glauben machen wollte, befürchtet haben: $q u$ 'en cas de conflagration générale, la Russie ne tournât une trop grande partie de ses armées contre l'Autriche et ne nous prêtât pas assez largement son concours contre l'Allemagne. Zit. POINCARÉ, Au service de la France, Bd. II, S. 87. Vgl. auch: Bericht des russischen Außenministers an den Zaren über die Unterredungen mit Poincaré während dessen Aufenthalt in St. Petersburg, 17. 8. 1912, in: STIEVE, Iswolski-Schriftwechsel II, 401.

331 Zit. L'Accélération de l'offensive russe, in: NL Messimy, AN, 509 AP 6, fol. 26. Vgl. auch IGNATJEW, Fünfzig Jahre, S. 319 und MEssimY, Mes souvenirs, S. $180 \mathrm{f}$.

332 Zit. GIRAUlT, Maurice Paléologue répond à Pierre Renouvin, S. 61. 
scheidenden Hinweis gegeben und ihn auf die außerordentliche Bedeutung der Frage aufmerksam gemacht, ob der Bündnispartner primär gegen die Habsburgermonarchie vorgehen würde. War doch in ihrem Rahmen der Beschluß gefaßt worden, auf eine unmittelbar zu Kriegsbeginn erfolgende Invasion des belgischen Territoriums zu verzichten. Ni en Alsace, ni en Lorraine, so hatte damals der Generalstabschef die dann aller Voraussicht nach verbleibende strategische Option charakterisiert, nous ne trouverons des terrains favorables à une offensive visant immédiatement des résultats décisif ${ }^{333}$, und in seiner Mitschrift hatte Paléologue diese Ausführungen Joffres mit dem Satz resümiert: Notre seule chance d'écraser l'ennemi est de porter immédiatement la lutte sur le territoire belge ${ }^{334}$. Vor diesem Hintergrund mußte sich aber die Einsicht, daß sich aus den russischen Planungen kein Angriff entwickeln ließ, der dem Deutschen Reich die Möglichkeit zur Fortsetzung der militärischen Auseinandersetzung nahm und ein Maximum an feindlichen Kontingenten band, nicht allein ernüchternd, sondern gar katastrophal ausnehmen und es zu einem dringenden außenpolitischen Anliegen werden lassen, die militärischen Planungen Rußlands entsprechend der eigenen strategischen Forderungen auszurichten ${ }^{335}$.

Aber es war nicht allein die Frage, gegen welchen seiner Gegner der Bündnispartner zuerst einen tödlichen Schlag führen würde, der die ungeteilte Aufmerksamkeit Frankreichs galt. Von besonderer Bedeutung ist in diesem Zusammenhang darüber hinaus, daß man erkannte, daß ein entsprechender russischer Angriff auf das Deutsche Reich eine militärische Infrastruktur voraussetzte, die in den letzten Jahren vor Ausbruch des Großen Krieges nicht oder zumindest nur in Teilen vorhanden war. In einer Untersuchung der strategischen Konzentration des Bündnispartners war der Generalstab Frankreichs im Jahr 1913 zu der Erkenntnis gelangt, daß Rußland im gegenwärtigen Augenblick nicht in der Lage sei, die von Frankreich geforderte Konzentration durchzuführen ${ }^{336}:$ La Russie est elle en état dès à présent de mettre en ouvre un plan de cette nature? Nous ne le pensons pas [...]. Le déplacement du centre de gravité des forces vers l'Ouest ne peut que suivre le développement du réseau ferré de Pologne 337.

Bei dieser Einsicht handelte es sich nun keineswegs um eine neue Erkenntnis $^{338}$. Schon im Rahmen des Memorandums, das Poincaré vor Antritt seiner

333 Zit. Conférence tenue au ministère des Affaires étrangères, CSDN, 21. 2. 1912, in: SHA 2N1, VI/39.

334 Zit. Conférence du 21 février 1912, in: NL Paléologue. Dokument im Besitz von Roger Lebon.

$335 \mathrm{Vgl}$. KRUMEICH, Aufrüstung und Innenpolitik, S. 23.

336 Vgl. Note sur le plan russe de 1913, Dezember 1913, in: SHA 7N1771.

337 Zit. ibid.

338 So gelangte schon ein Memorandum des Generalstabs aus dem Jahr 1910 zu der Erkenntnis, daß ein russischer Angriff im Zentrum der Front den Ausbau des strategischen Eisenbahnnetzes in Polen erforderlich mache. Vgl. Note au sujet des voies ferrés dont la construction serait désirable en Russie, 30. 5. 1910, in: SHA 7N1535. 
Rußlandreise im August 1912 über die militärischen Möglichkeiten des Bündnispartners unterrichtet hatte, war konstatiert worden, daß die Verlagerung des Gravitationszentrums der strategischen Konzentration nach Westen erst mit einem entsprechenden Ausbau des russischen Eisenbahnnetzes einhergehen könne ${ }^{339}$. Entsprechend dieser Einsicht hatte Joffre auf der Konferenz der Generalstabschefs im Juli 1912 auf den Ausbau der militärischen Infrastruktur des Bündnispartners gedrängt und mit Erfolg eine Reihe von Linien in das Protokoll der Militärkonvention aufnehmen können, deren Bau Rußland in Angriff nehmen sollte ${ }^{340}$.

In dem Memorandum, durch das Poincaré in Vorbereitung seiner Rußlandreise dann im August 1912 Kenntnis der militärischen Möglichkeiten und Grenzen des Bündnispartners erhielt, strich der Generalstab noch einmal die Punkte heraus, die ihm von besonderer Bedeutung waren. Die dem Ministerpräsidenten und Außenminister ausgehändigte "Note sur l'action militaire de la Russie en Europe « hat dabei gegenüber den Ausführungen im Protokoll der Generalstabskonferenz den Vorzug, daß in ihrem Rahmen unter der Überschrift »Améliorations possibles du réseau ferré de la Russie« die technischen Einzelheiten der Militärkonvention in einen direkten Zusammenhang mit einem strategischen Konzept gebracht werden. Derart wird auch für den militärischen Laien verständlich, welche Absichten Joffre mit dem Ausbau der militärischen Infrastruktur des Bündnispartners verband. Zwei der drei Maßnahmen, deren besondere Bedeutung man hervorhob, betrafen Linien, die eine rasche Konzentration der russischen Kontingente in der Region um Warschau ermöglichen sollten. So machte der Generalstab in seiner Note Poincaré noch einmal auf die Notwendigkeit aufmerksam, den Ausbau der Linien Lida-Siedlce (frz. Siedlets) und Orel-Brjansk-Jabinka voranzutreiben. Um das Zentrum der russischen Konzentration in die Nähe der deutschen Grenze zu verlagern, sollte die erstgenannte Linie nicht östlich von Warschau enden, sondern bis dorthin verlängert werden, während die letztgenannte Strecke zumindest bis nach Brest Litowsk geführt werden sollte ${ }^{341}$. Um darüber hinaus einen russischen Angriff auf dem westlichen Ufer der Weichsel zu ermöglichen, forderte der Generalstab ferner den Umbau der Strecken Warschau-Thorn und Warschau-Krakau, die im Gegensatz zum russischen Netz noch die normale europäische Spurbreite besaßen, was

339 La possibilité de [...] déplacer le centre de gravité des forces vers le Sud, dans la région de Varsovie, est liée à une série d'améliorations des lignes de transport. Zit. Note sur l'action militaire de la Russie en Europe, August 1912, in: SHA 7N1538.

$340 \mathrm{Vgl}$. Procès-verbal de l'entretien du 13 juillet 1912 entre les chefs d'état-major des armées française et russe, in: DDF 3, 3, 200.

${ }^{341}$ La masse centrale des forces, et par suite le centre de gravité de l'ensemble, se trouverait ainsi plus rapproché de Varsovie. Zit. Note sur l'action militaire de la Russie en Europe, August 1912, in: SHA 7N1538. Mit Blick auf dieses Defizit heißt es in der Aufzeichnung 》Améliorations possibles du réseau ferre «, die in Vorbereitung auf das $\mathrm{Ge}$ neralstabstreffen von 1912 entstand: Il en résulte qu'une concentration rapide sur la Vistule n'est pas possible. Zit. Améliorations possibles du réseau ferre, in: SHA 7N1538. 
im Kriegsfall zeitraubende Verladungsprozesse erforderlich machen wür$\operatorname{den}^{342}$.

Mit dem Ausbau der militärischen Infrastruktur verbanden der Generalstab und die politischen Entscheidungsträger aber noch ein zusätzliches und nicht minder bedeutendes Ziel: So sollte nicht allein das Zentrum der russischen Konzentration nach Westen verlagert, sondern darüber hinaus auch der Zeitraum der Mobilmachung und Konzentration insgesamt reduziert und derart dem Bündnispartner die Möglichkeit gegeben werden, schon zu einem frühen Zeitpunkt der militärischen Auseinandersetzung seine numerische Superiorität zur Geltung zu bringen ${ }^{343}$. Insbesondere dieser Absicht galt dann auch das umfangreiche Programm, auf das sich die Generalstäbe Rußlands und Frankreichs im darauffolgenden Jahr verständigten ${ }^{344}$. Durch den Bau eines "veritablen Netzes « ${ }^{345}$ mit einer Gesamtlänge von mehr als 5000 Kilometern sollte nun endlich ein Zustand behoben werden, der für Frankreich alles andere als zufriedenstellend war und sich in den vergangenen Jahren wie folgt präsentiert hatte 346 :

Als der russische Militärattaché Nostitz den Generalstab Frankreichs am 22. März 1911 zum ersten Mal mit den Einzelheiten der neuen strategischen Planungen bekannt machte, führte er aus, daß die Mobilmachung der russi-

342 Il résulte de cet état de choses qu'un mouvement offensif au delà de la Vistule, rencontrerait des difficultés réelles. Ce sont là des questions de fait, qui limitent singulièrement l'initiative stratégique de la Russie, au profit de son adversaire éventuel [Hervorhebung im Original, St. S.]. Zit. Améliorations possibles du réseau ferre, in: SHA 7N1538. Zur Bedeutung dieser Linien vgl. auch Matton an Millerand, 24. 5. 1912, in: MAE, NS Russie 65, fol. 130-132.

343 Vgl. Note sur l'action militaire de la Russie en Europe, August 1912, in: SHA 7N1538.

344 Vgl. Procès-verbal des entretiens du mois d'août 1913 entre les chefs d'état-major des armées française et russe, in: $\operatorname{DDF} 3,8,79$.

345 So die Einschätzung des russischen Finanzministers. Zit. Delcassé an Doumergue, 31. 12. 1913, in: DDF 3, 8, 698.

346 Ein Memorandum, das die Forderung des Generalstabs von 1913 näher erläutern würde, läßt sich in den Archiven nicht finden. Vgl. aus diesem Grund die Ausführungen in: Gunther FrANTZ, Das strategische Eisenbahnnetz Rußlands 1914 unter besonderer Berücksichtigung des Bündnisses mit Frankreich, in: BM 8 (1930), S. 259-280, hier S. 264, 270-272. Rußland hatte im Jahr 1910 die Mobilmachung und Konzentration seiner Kontingente grundlegend reformiert. War vormals ein großer Teil seiner aktiven Kontingente in Polen stationiert worden, so daß im Fall einer militärischen Auseinandersetzung nur die Reservisten zu ihren Einheiten transportiert werden mußten, ging nun auch Rußland zum Prinzip der territorialen Mobilmachung über, das für die meisten europäischen Großmächte verbindlich war. Mit dieser Reform wurden die aktiven Kontingente in den Regionen stationiert, aus denen sie im Fall einer Mobilmachung ihre Reservisten erhalten würden. In Anbetracht der unterschiedlichen Bevölkerungsdichte bedeutet dies, daß ein umfangreicher Teil der aktiven Formationen im Landesinneren stationiert werden und im Fall einer militärischen Auseinandersetzung über große Distanzen transportiert werden mußte. Dementsprechend erfuhr der Zeitraum der strategischen Konzentration eine deutliche Ausdehnung. Vgl. SNYDER, Ideology of the Offensive, S. $171 \mathrm{f}$. 
schen Kontingente 15, ihre strategische Konzentration hingegen 23 und die Konzentration der Reserven gar 40 Tage in Anspruch nehmen werde 347. Hinsichtlich der Frage, zu welchem Zeitpunkt der Bündnispartner zum Angriff übergehen konnte, beteuerte Nostitz zwar, daß man nicht den Abschluß der Konzentration der aktiven Formationen abwarten werde, doch in den entsprechenden Untersuchungen ging der Generalstab Frankreichs weiterhin davon aus, daß Rußland die Absicht habe, de ne prendre l'offensive, $q$ 'une fois la masse de leurs forces réunies ${ }^{348}$. Unter dieser Bedingung errechnete man im November/Dezember 1911, daß der Bündnispartner im Rahmen eines Angriffs, der der Invasion Ostpreußens galt, erst einen Monat nach Beginn der Mobilmachung die Linie der Masurischen Seen angreifen konnte und daß in Anbetracht der starken Fortifikationswerke und des die Defensive außerordentlich begünstigenden Terrains dieser Angriff auch unter günstigen Umständen die Weichsel erst am fünfzigsten Tag erreichen würde. Besser, aber nicht ungleich vorteilhafter nahmen sich die Möglichkeiten einer Offensive entlang den Ufern der Weichsel aus, die nach 35 Tagen den sensiblen Punkt der Front erreichen konnte. Aber aufgrund der noch näher zu behandelnden Auswirkungen des Angriffs der Habsburgermonarchie glaubte man auch hier, zwischen 45 und 50 Tage in Rechnung stellen zu müssen ${ }^{349}$. $\mathrm{Zu}$ ähnlichen Erkenntnissen gelangten im August 1912 auch die im Rahmen der »Note sur l'action militaire de la Russie en Europe « 350 durchgeführten Kalkulationen sowie eine Analyse des russischen Aufmarsches, die im Vorfeld des Treffens der Generalstäbe im Jahr 1913 entstand ${ }^{351}$. Um die Bedeu-

347 Vgl. Renseignements donnés verbalement le 22 mars 1911 par M. le Général Comte Nostitz, Agent Militaire de Russie, in: SHA 1K666. In einer Untersuchung des Sachverhaltes gelangte der Generalstab zu der Einsicht, daß bis zum diesem Zeitpunkt die russischen Kontingente zwar nicht vollständig, gleichwohl aber ihre größten Teile konzentriert werden konnten, so daß man die Angaben zwar nicht als unrichtig, gleichwohl aber als wohlwollend bezeichnete. Vgl. Etudes sur la concentration et les transports russes, November 1911, in: SHA 7N1538.

348 Zit. Études sur la concentration et les transports russes, November 1911, in: SHA 7N1538.

349 Vgl. ibid.

350 Vgl. Note sur l'action militaire de la Russie en Europe, August 1912, in: SHA $7 \mathrm{~N} 1538$.

351 Vgl. La concentration russe, Juli 1913, in: SHA 7N1535. Nur in margine sei bemerkt, daß eine unzureichende militärische Infrastruktur und die Befürchtung, daß Rußland mit allzu umfangreichen Kontingenten oder gar primär die Habsburgermonarchie angreifen könnte, nicht die einzigen Faktoren waren, die die militärische Führung Frankreichs an einem raschen russischen Angriff auf den gemeinsamen Gegner zweifeln machten. So wurde beispielsweise im Rahmen eines 1912 an der École supérieure de la guerre gehaltenen Kollegiums zur russischen Armee konstatiert, daß der Gedanke des uneingeschränkten Angriffs dem Geist der russischen Nation widerspreche. Vgl. Conférence sur l'Armée Russe, 1910/12, in: SHA 7N1535. In seiner umfangreichen Abhandlung »Physionomie de l'Armée Russe* gelangte im Jahr 1913 einer der besten Kenner des russischen Militärs im Generalstab Frankreichs, der stellvertretende Militärattaché in Sankt Petersburg Wehrlin, zu einer ähnlichen Einschätzung. Vgl. La 
tung dieser Kalkulationen einschätzen zu können, sei an dieser Stelle noch einmal in Erinnerung gerufen, daß nach Ansicht des Generalstabs über Erfolg oder Scheitern der großen Offensiven im Westen nach Ablauf des ersten Kriegsmonats entschieden sein würde und daß die Untersuchung der logistischen Möglichkeiten des Deutschen Reiches ergeben hatte, daß der Transport beträchtlicher Kontingente in dem relativ kurzen Zeitraum von $15 \mathrm{Ta}-$ gen bewerkstelligt werden konnte ${ }^{352}$.

Dubail hatte deshalb schon 1911 den russischen Generalstabschef gedrängt, mit einem kleinen Kontingent frühzeitig gegen den gemeinsamen Gegner vorzugehen, und Shilinski hatte entsprechendes auch zugesichert ${ }^{353}$. Doch eine solche Verpflichtung, die schon nach eigenem Eingeständnis des russischen Generalstabschefs gewagt anmutete ${ }^{354}$, änderte nichts an dem unverrückbaren Faktum, daß zu einem frühen Zeitpunkt ein Angriff nur mit begrenzter Kraft vorgetragen werden konnte. Entsprechend vorsichtig war dann auch die Formulierung im Protokoll der Militärkonvention von 1912 ausgefallen, mit der konstatiert wurde, der russische Generalstab sei entschlossen, à faire sentir l'action offensive de ses armées aussitôt après le 15e jour de la mobilisation ${ }^{355}$. Was hingegen den Angriff in Richtung Berlin anbetraf, der dem Deutschen Reich die Mittel zur Fortsetzung des Krieges nehmen sollte, so war weiterhin gültig, daß dieser erst zu einem Zeitpunkt entfaltet werden konnte, an dem sich, im Fall einer Niederlage Frankreichs, das Fenster deutscher Verwundbarkeit nahezu geschlossen hatte ${ }^{356}$.

Angesichts einer solchen Lage der Dinge vermag es nicht zu verwundern, daß sich die politischen Entscheidungsträger Frankreichs die Forderung des Generalstabs nach dem Ausbau der militärischen Infrastruktur des Bündnispartners zu eigen machten. Als Ministerpräsident und Außenminister Poincaré im August 1912 nach Rußland reiste ${ }^{357}$, forderte er sowohl in seinen Un-

Physionomie de l'Armée Russe, in: SHA 7N1535. Vgl. damit übereinstimmend auch de Laguiche an Noulens, 10.12. 1913, in: SHA 7N1478. Je suis sceptique quant à une offensive russe vigoureuse ce n'est pas dans leur tempérament. Zit. ibid. Vgl. auch de Laguiche an Millerand, 16. 11. 1912, in: SHA 7N1478.

$352 \mathrm{Vgl}$. Au sujet d'un transport éventuel de forces allemandes de la Lorraine française vers la frontière russe, Mai 1914, in: SHA 7N1538.

353 Vgl. Procès-verbal de l'entretien du 18/31 août 1911, entre les chefs d'état-major des armées française et russe, in: DDF 2, 14, 232.

354 Vgl. Matton an Millerand, 23. 2. 1912, in: SHA 1 K666.

355 Zit. Procès-verbal de l'entretien du 13 juillet 1912 entre les chefs d'état-major des armées française et russe, in: DDF 3, 3, 200.

$356 \mathrm{Vgl}$. Note sur l'action militaire de la Russie en Europe, August 1912, in: SHA 7N1538.

357 Als Poincaré den Generalstabschef vor seiner Reise nach Rußland fragte, ob während seines Aufenthaltes auch militärische Angelegenheiten zu besprechen seien, forderte Joffre ihn auf, die Aufmerksamkeit des Bündnispartners insbesondere auf den Ausbau seines strategischen Eisenbahnnetzes gemäß den Forderungen der Militärkonvention vom 13. Juli 1912 zu lenken. Vgl. Joffre an Paléologue, 30. 7. 1912, in: SHA $1 \mathrm{~K} 666$. 
terredungen mit Sasonow, als auch in seinen Gesprächen mit dem Ministerpräsidenten und Finanzminister, dem Kriegsminister und dem Monarchen den Ausbau der militärischen Infrastruktur gemäß den Ausführungen des Protokolls von 1912 ein $^{358}$. Mußte er sich zu diesem Zeitpunkt auch noch mit eher vagen Zusicherungen des russischen Bündnispartners zufrieden geben, die die ganze Sache erst einmal im Sande verlaufen ließen, so sollte die politische Leitung diese Frage doch nicht mehr aus den Augen verlieren ${ }^{359}$. Als Frankreich im Frühjahr 1913 die Aufrüstung des Deutschen Reiches mit der Einführung der loi des trois ans konterte, nahm man die eigenen Anstrengungen umgehend zum Anlaß, um ein entsprechendes Handeln des Bündnispartners zu fordern ${ }^{360}$.

Folgt man einem Brief des Außenministers Pichon, so scheint am 10. März 1913 gar eine eigens dieser Frage gewidmete Konferenz einberufen worden $\mathrm{zu}$ sein, über deren genauen Inhalt die Quellen leider schweigen ${ }^{361}$. Doch was auch immer im Rahmen dieser Zusammenkunft besprochen worden sein mag - fest steht, daß das primäre Ziel des neuen französischen Botschafters in Sankt Petersburg darin bestand, den Ausbau der militärischen Infrastruktur Rußlands voranzutreiben ${ }^{362}$. In einem das Akkreditiv Delcassés begleitenden Brief machte Poincaré den russischen Monarchen abermals auf den erforderlichen Ausbau der militärischen Infrastruktur aufmerksam ${ }^{363}$, und schon einen Tag nach seiner Ankunft in Petersburg trug der neue Botschafter die Desiderata Frankreichs im Rahmen seines Antrittsbesuches vor ${ }^{364}$. Depuis ce jour, so berichtete Delcassé dann rückblickend an Außenminister Pichon, $j e$ n'ai pas cessé, m'emparant des événements qui se déroulaient pour en tirer des précisions sur ce qui pourrait en sortir, d'insister sur la nécessité d'avoir le plus tôt possible l'outillage qui, permettant à l'armée russe de prendre l'offensive en même temps que la nôtre, obligerait l'Allemagne à diviser ses forces ${ }^{365}$.

358 Vgl. Notes de M. Poincaré sur ses entretiens de Saint-Pétersbourg, August 1912, in: $\operatorname{DDF} 3,3,264$.

359 Als Poincaré in seinem Gespräch mit dem russischen Monarchen den Ausbau der militärischen Infrastruktur erwähnte, antwortete ihm Nikolaus II., daß diese Frage très intéressante sei und verwies den französischen Ministerpräsidenten an Kokowzow. Zit. ibid.

$360 \mathrm{Vgl}$. Note faisant ressortir l'effort fait par la France pour répondre aux armements de l'Allemagne, 25. 7. 1913, in: SHA 7N1535.

361 Vgl. Pichon an Delcassé, 27. 3. 1913, in: DDF 3, 6, 85.

362 Vgl. Iswolski an Sasonow, 13. 3. 1913, in: STIEVE, Iswolski-Schriftwechsel III, 762 und Bertie an Grey, 6. 3. 1913, in: NL Bertie, PRO, FO 800/166, fol. 103. Bei diesem Dokument handelt es sich um den Entwurf eines letztlich nicht abgesandten Briefes. Vgl. ferner François ROTH, Raymond Poincaré et Théophile Delcassé: histoire d'une relation politique, in: Delcassé et l'Europe à la veille de la Grande Guerre. Actes du colloque tenu à Foix les 22-25 octobre 1998. Colloque organisé par le conseil général de l'Ariège, archives départementales, [Foix] 2001, S. 231-246, hier S. 235 f.

363 Vgl. Poincaré an Nikolaus II., 20. 3. 1913, in: DDF 3, 6, 39.

364 Vgl. Delcassé an Pichon, 24. 3. 1913, in: DDF 3, 6, 59.

365 Zit. Delcassé an Pichon, 1. 8. 1913, in: DDF 3, 7, 513. 
Eine unerwartete Möglichkeit, den französischen Forderungen Nachdruck zu verleihen, die mit der letzten Generalstabskonferenz vor Ausbruch des Großen Krieges ein bislang unbekanntes $\mathrm{Maß}$ erfahren hatten, ergab sich im Sommer 1913, als der Bündnispartner um eine beträchtliche Anleihe auf dem französischen Markt nachsuchte ${ }^{366}$. Es erscheint nicht notwendig, die Verhandlungen im einzelnen nachzuzeichnen, an deren Ende Rußland schließlich zusicherte, die Konstruktion der in der Fassung der Militärkonvention von 1913 genannten Bahnlinien bis 1918 fertigzustellen, während Frankreich seinem Bündnispartner im Gegenzug gestattete, über einen Zeitraum von fünf Jahren Anleihen im Gesamtumfang von 2,5 Milliarden aufzunehmen ${ }^{367}$. Bemerkenswert ist in diesem Zusammenhang das deutliche und im Rahmen einer Betrachtung der Allianz noch näher zu untersuchende Mißtrauen, daß Frankreich Rußland entgegenbrachte ${ }^{368}$. Es fand seinen Ausdruck sowohl in der Forderung, mit der Konstruktion der genannten Bahnlinien unmittelbar zu beginnen und diese in einem sehr begrenzten Zeitraum fertigzustellen ${ }^{369}$, als auch in dem Umstand, daß Frankreich keinesfalls auf die Möglichkeit finanzieller Pression zu verzichten gedachte ${ }^{370}$. Sicherte man sich doch in dem abschließenden Kontrakt das Recht, jährlich über die

$366 \mathrm{Zu}$ den Verhandlungen über die große russische Staatsanleihe des Jahres 1913/1914 vgl. Krumeich, Aufrüstung und Innenpolitik, S. 140-145 und GIRAULT, Emprunts russes, Bd. II, S. 984-990.

367 Vgl. Sasonow an Delcassé, 30. 12. 1913, in: DDF 3, 8, 698 (Annexes I) und Delcassé an Sasonow, 30. 12. 1913, in: ibid.

368 Vgl. Doulcet an Pichon, 27. 9. 1913, in: DDF 3, 8, 204. Vgl. auch Wehrlin an Noulens, 6. 11.1913, in: SHA 7N1478. Vgl. ferner Poincarés skeptische Randbemerkung zu einem Telegramm Delcassés, mit dem der Botschafter über beachtliche Fortschritte beim Ausbau der militärischen Infrastruktur des Bündnispartners berichtete. Vgl. Notes journalières, in: NL Poincaré, BNF, Nafr 16026, fol. 53 (Eintrag vom 30. 1. 1914): Delcassé n'est il pas ici un peu optimiste? Les engagements pris ont ils été tenu? Vgl. ferner Delcassé an Doumergue, 29.1. 1914, in: DDF 3, 9, 189. Vgl. ferner den Bericht "Durée de construction des chemins de fer stratégiques russes ", den Wehrlin unter dem Datum des 6. Juni 1914 an das Kriegsministerium sandte, in: SHA 1478. Eine Kopie dieses Berichtes findet sich auch in: MAE, NS Russie 42, fol. 261. In dieser Untersuchung der russischen Finanzplanung für die Entwicklung des Streckennetzes im Zeitraum 1915-1919 gelangte Wehrlin zu dem Ergebnis, daß - obgleich der Kontrakt vom 30. 12. 1913 dem Bündnispartner eine Frist von vier Jahren setzte - mit der Fertigstellung der von Frankreich geforderten Linien nicht vor dem Jahr 1922 zu rechnen sei! $369 \mathrm{Vgl}$. Wehrlin an Dupont, 8. 11. 1913, in: SHA 7N1478: Il est bien certain que les $C b[\mathrm{emin}]$ de fer et les Finances ne se soucient guère des lignes stratégiques et ne commenceront à s'en occuper que lorsque le programme des travaux en Asie sera à peu près épuisé. [...] Nous n'obtiendrons les lignes qui nous intéressent qu'en les imposant comme condition à l'emprunt. [Hervorhebung im Original, St. S.]; les $R$ [usses] accepteront toujours les conditions des lignes stratégiques, comme clause de l'emprunt, mais si on ne leur fixe pas de délai, ils lambineront volontairement et en fin de compte ne commenceront pas les travaux avant 3 ans, $c$ ['est] à $d$ [ire] avant la fin des travaux d'Asie. Et en fin de compte 3 ans de retard pour l'utilisation des augmentations russes.

370 Vgl. de Verneuil an Pichon, 16. 6. 1913, in: DDF 3, 7, 134. 
Summe zu befinden, die Rußland auf dem Pariser Geldmarkt aufnehmen konnte ${ }^{371}$.

In der historischen Forschung ist in diesem Zusammenhang mitunter die Frage aufgeworfen worden, ob Frankreich seinem Bündnispartner den Ausbau seiner militärischen Infrastruktur aufgezwungen habe ${ }^{372}$. Sicherlich ist zutreffend, daß in dieser Angelegenheit Rußlands militärische und ökonomische Staatsraison in entgegengesetzte Richtungen führten und daß der Ministerpräsident und Finanzminister volkswirtschaftliche Bedenken gegen den Bau eines primär militärischen Zwecken dienenden Eisenbahnnetzes vorbrachte, das konsiderable Summen verschlang, aber keinen monetären Profit eintrug ${ }^{373}$. Sicherlich ist auch zutreffend, daß sich Kokowzow - wie aus einem seiner Berichte an den Zaren hervorgeht - der Notwendigkeit einer großen Anleihe bewußt war und daß man sich nach Lage der Dinge dem Angebot Frankreichs, mochten seine Bedingungen auch drückend sein, nicht verschließen konnte ${ }^{374}$. Doch ob die Möglichkeit finanzieller Pression der maßgebliche Grund für den russischen Entschluß zum Bau der neuen Bahnlinien war, ob nicht letztlich auch gegen den Widerstand seines Ministerpräsidenten und Finanzministers Zar Nikolaus II. eine entsprechende Entscheidung getroffen hätte, läßt sich angesichts des Quellenmaterials, das in dieser Frage zur Verfügung steht, kaum beantworten.

Welchen Einfluß der begrenzte russische Handlungsspielraum auf den Entscheidungsprozeß auch immer gehabt haben mag, ihre ganze Bedeutung gewinnt diese Frage erst vor dem Hintergrund der außenpolitischen Konsequenzen, die die Entgrenzung der strategischen Möglichkeiten Rußlands zeitigte. Nahm mit ihr doch die Machtentfaltung Rußlands und damit einer der maßgeblichen Faktoren Gestalt an, die bis zur Julikrise 1914 die außenpolitische Gesamtsituation des Deutschen Reiches in einem Maße verschlechterten, daß letztlich auch seine politische Leitung keine andere Möglichkeit mehr sah, als diese notfalls in Rekurs auf militärische Mittel zu korrigieren. In diesem Zusammenhang muß aber konstatiert werden, daß weder Frankreich noch Rußland den möglichen außenpolitischen Rückwirkungen ihrer Entscheidung Beachtung schenkten oder, um eine vorsichtigere Formulierung zu wählen, diese zumindest nicht als Einwand gegen das Projekt gelten ließen. Erst post festum fand sich Poincaré zu einer Rechtfertigung mit den Worten bereit: Il ne s'agissait [...] nullement de préparer contre l'Allemagne

371 Vgl. Doulcet an Pichon, 11. 10. 1913, in: DDF 3, 8, 306 und Delcassé an Dens., 28. 10. 1913, in: DDF 3, 8, 392.

372 Vgl. Derek W. SPRING, Russia and The Franco-Russian Alliance, 1905-1914: Dependence or Interdependence?, in: The Slavonic and East European Review 66 (1988), S. 565-592, hier S. 564, 580 f.

373 Vgl. Doulcet an Pichon, 27. 9. 1913, in: DDF 3, 8, 204 und Delcassé an Dens., 31. 12. 1912, in: DDF 3, 8, 698.

374 Vgl. Kokowzow an Nikolaus II., 13. 12. 1913, in: STIEVE, Iswolski-Schriftwechsel III, 1169. 
une agression, ni même de prendre des mesures immédiates de défense. C'est une cuvre de longue haleine qu'on entreprenait pour faire cesser l'état d'infériorité dans lequel se trouvait le système russe de mobilisation ${ }^{375}$.

Wenn der Verfasser dieser Untersuchung die Quellen vollständig zu überblicken vermag, so ist nur ein einziges Mal darauf aufmerksam gemacht worden, daß über den Ausbau des russischen Eisenbahnnetzes nicht allein nach Maßgabe des militärisch Erforderlichen, sondern auch unter Berücksichtigung außenpolitischer Faktoren zu entscheiden sei. Es handelte sich dabei um eine Einlassung des russischen Finanzministers, der Poincaré, als dieser auf der Dringlichkeit der Forderung seines Generalstabs beharrte, verstimmt entgegnete: Ces messieurs [...] seraient capables de nous engager un peu à la légère. Ils causent, ils causent, et ne se préoccupent guère des possibilités financières ou même des considérations diplomatiques. [...] Ils finiront par nous mener un peu loin ${ }^{376}$. Wohlgemerkt: Bei dieser Bemerkung handelt es sich um die einzige Quelle, die das Programm der Konferenz von 1912, ganz zu schweigen von den noch sehr viel weitergehenden Forderungen der Konferenz von 1913, auch aus einer außenpolitischen Perspektive in den Blick nahm und seine möglichen Folgen in die Richtung eines Einwandes zu entwickeln versuchte. Dieses Faktum ist um so bemerkenswerter, als gerade die wirkungsmächtigsten Konsequenzen der französischen Forderungen jenseits der Grenzen Rußlands lagen. Strebte doch Frankreich mit dem Ausbau der strategischen Möglichkeiten des Bündnispartners nach nichts Geringerem, als dem Deutschen Reich im Rahmen einer militärischen Auseinandersetzung die Möglichkeit zu nehmen, über sein Territorium hinauszugreifen, und handelte es sich dabei in der Sache doch um nichts anderes als einen Wunsch nach absoluter Sicherheit, der - einmal Wirklichkeit geworden - die Konfiguration der Macht im europäischen Staatensystem fundamental verändern mußte:

La diminution possible de l'écart de temps entre l'entrée en action des forces russes et celle des forces françaises, so hatte der Generalstab schon mit Blick auf seine bescheideneren Forderungen von 1912 ausgeführt, entraînera l'Allemagne, par le fait même de l'existence de cette possibilité, à renoncer à tout espoir de manouvre en lignes intérieures, lui imposera l'obligation absolue de faire face, simultanément, sur ses deux frontières, à ses deux adversaires, et par suite à diviser ses forces au détriment de toute chance de succès 377 .

In vorsichtigerer Formulierung hatte diese Beschreibung der Konsequenzen des Ausbaus der russischen Infrastruktur dann auch Eingang in das Memorandum gefunden, das der Generalstab dem Ministerpräsidenten im August 1912 unterbreitete und das vom Ministerium am Quai d'Orsay dann im

375 Zit. POINCARE, Au service de la France, Bd. III, S. 322.

376 Zit. Notes de M. Poincaré sur ses entretiens de Saint-Pétersbourg, August 1912, in: DDF 3, 3, 264.

377 Zit. Améliorations possibles du réseau ferre, in: SHA 7 N1538. 
Frühjahr 1913 in einer überarbeiteten Fassung an seinen neuen Botschafter in Petersburg gesandt wurde ${ }^{378}$. Noch in seinen Erinnerungen bekannte Joffre:

Cette volonté offensive affirmée en commun était susceptible de faire échoner le plan allemand tel que nous le soupçonnions, en amenant nos adversaires à modifier la répartition initiale de leur forces, peut-être même à abandonner l'idée fondamentale d'une offensive contre nous dès le début, et à renverser une fois de plus leur plan ${ }^{379}$.

Folglich konnten sich die politischen Entscheidungsträger Frankreichs grundsätzlich nicht über die Dimensionen der Forderungen im Unklaren sein, die im Rahmen der militärischen Konferenzen von 1912 und 1913 formuliert und dann von ihnen aufgegriffen worden waren.

Was bereits im Zusammenhang mit den Abkommen konstatiert werden konnte, die Frankreich und Italien für den Fall einer militärischen Auseinandersetzung getroffen hatten, gilt auch hinsichtlich der Machtentfaltung Rußlands. Es scheint, als habe in den letzten Jahren vor Ausbruch des Großen Krieges im außenpolitischen Kalkül der politischen Führung Frankreichs der Primat des Militärischen alle anderen Überlegungen in den Hintergrund treten und letztlich gar aus dem Blick geraten lassen. Hinsichtlich des von Frankreich nachdrücklich eingeforderten und tatkräftig unterstützten Ausbaus der militärischen Infrastruktur Rußlands ist gültig, was einmal der amerikanische Historiker Paul W. Schroeder im Zusammenhang mit den Konsequenzen beobachtet hat, die der partielle Zusammenbruch des Osmanischen Reiches und die daraus resultierende Neuordnung des Balkans nach sich zog:

No government addressed itself to the most obvious and critical question of all: how was this new, crucial development to be managed? How, that is, could it be harmonized with the overall European balance, incorporated into the prevailing international system, without raising the already fearful strains upon that system to the point of explosion? No one thought of this problem or suggested doing anything about $\mathrm{it}^{380}$.

Einer der Faktoren, die für ein Handeln bestimmend waren, das den Bedingungen keine Beachtung mehr schenkte, unter denen alle europäischen Großmächte über ein ausreichendes Maß an Sicherheit verfügen konnten, mag im Rahmen der vorangegangenen Ausführungen deutlich geworden sein. Unter den Maßgaben eines uneingeschränkten Angriffs war für Frankreich eine prekäre strategische Gesamtsituation entstanden, in der die nationalen Machtmittel nicht mehr den Anforderungen gerecht zu werden vermochten, die ein großer europäischer Krieg an dieses Land stellen würde. Da ein Angriff auf das Deutsche Reich eine numerische Superiorität der attackie-

378 Die Note sur l'action militaire de la Russie en Europe schloß mit den Worten: L'exécution des améliorations énumérées ci-dessus aurait en outre l'avantage d'attirer l'attention des Allemands sur l'activité des travaux effectués sur les voies ferrées russes, et les inciterait peut-être à apporter des modifications à leurs projets, et notamment à la répartition de leurs forces. Zit. Note sur l'action militaire de la Russie en Europe, August 1912, in: SHA 7N1538.

${ }^{379}$ Zit. JOFFre, Mémoires, Bd. I, S. 27.

380 Zit. SCHROEDER, Rumania, S. 19. 
renden Kontingente erforderte, die nicht in ausreichendem Maße vorhanden war, da man mit Rücksicht auf Großbritannien, dessen Intervention gleichwohl ungewiß blieb, den Gedanken an eine umgehende Invasion Belgiens verworfen hatte, mußten selbst geringe Konzessionen an das Deutsche Reich die eigene Sicherheitslage gefährlich beinträchtigen. Ein Plan, der ersonnen wurde, um den militärischen Triumph Frankreichs zu garantieren, führte damit letztlich zu zusätzlicher Unsicherheit und entsprechenden Kompensationsbemühungen: Er machte die Aufrüstung und den Ausbau der militärischen Infrastruktur Rußlands erforderlich und Frankreich von seinem Bündnispartner abhängig. Vor dem Hintergrund dieser Dependenz wird es nun auch möglich sein, die Bedeutung des habsburgischen Faktors im militärischen Kalkül Frankreichs abzuschätzen.

\subsection{Der habsburgische Gulliver im strategischen Konzept Frankreichs}

Neben einer raschen Mobilmachung und Konzentration mußte für einen russischen Marsch auf Berlin noch eine zusätzliche Bedingung erfüllt sein. In seinen Untersuchungen erkannte der französische Generalstab schon an der Jahreswende 1911/1912, daß die Möglichkeit eines solchen Angriffs maßgeblich durch das Handeln der Habsburgermonarchie beeinflußt wurde ${ }^{381}$. Nach Ansicht des Generalstabes würde ihr im Fall eines Koalitionskrieges die Aufgabe zufallen, durch einen machtvoll geführten Angriff einen russischen Durchbruch im Zentrum der deutsch-österreichischen Front zu verhindern ${ }^{382}$. Erst der Erfolg oder Mißerfolg dieses österreichischen Angriffs würde letztlich darüber entscheiden, ob Rußland auf Berlin marschieren und damit seiner Offensive eine Richtung geben konnte, die das Deutsche Reich tödlich bedrohte 383 .

Im Dezember 1911 kalkulierte man im Generalstab, daß im Fall eines Scheiterns des österreich-ungarischen Angriffs das Zarenreich zwischen dem

$381 \mathrm{Vgl}$. Au sujet de la valeur de la coopération russe, Dezember 1911, in: SHA 7N1538. Vgl. ferner Note sur l'action militaire de la Russie en Europe. Fascicule II, in: SHA 7N1535: Une offensive de la Russie contre l'Allemagne, en utilisant cette situation particulière de la Pologne sera décisive [...]. Mais elle n'est possible qu'à condition de maintenir de front les forces allemandes de Prusse Orientale et de pouvoir masquer effectivement les armées autrichiennes de Galicie.

$382 \mathrm{Vgl}$. Au sujet de la valeur de la coopération russe, Dezember 1911, in: SHA 7N1538. Vgl. ferner Étude relative à l'importance, à la répartition et à l'emploi des forces allemandes sur le théâtre d'opérations russo-allemandes, Mai 1914, in: SHA 7N1538 und Autriche et Italie, Juni 1914, in: SHA 7N1771.

$383 \mathrm{Vgl}$. Au sujet de la valeur de la coopération russe, Dezember 1911, in: SHA 7N1538. Vgl. auch Note sur l'action militaire de la Russie en Europe, Fascicule II, in: SHA 7N1535: Par contre, si le jeu de l'armée du centre permet d'obtenir une certaine supériorité sur l'un ou l'autre des deux adversaires, il faut remarquer qu'une offensive décidée et en force de l'Autriche dans la direction de Brest-Litovsk attirerait à elle toute cette armée et limiterait ainsi singulièrement les possibilités de l'offensive russe contre l'Allemagne. 
vierzigsten und fünfzigsten Tag zu einer Offensive in Richtung Berlin ansetzen konnte, das heißt zu einem Zeitpunkt, der gefährlich nahe an die kritische Marke heranreichte, bis zu der im Fall einer französischen Niederlage die Weichsellinie zu Fall gebracht sein mußte. Zugleich war man aber der Überzeugung, daß es möglich sei, diesen Zeitraum merklich zu verkürzen, si l'Autriche était dans l'impossibilité de prononcer une offensive sérieuse contre les Russes (complications graves du coté de l'Italie et des Balkans, par exemple $)^{384}$.

Welche Bedeutung das militärische Handeln Österreich-Ungarns für Frankreich hatte, illustriert eine Episode aus dem Winter 1912. Als im Zuge des ersten Balkankrieges serbische Kontingente in die albanische Provinz des Osmanischen Reichs eingefallen und dort trotz des Widerspruchs der Habsburgermonarchie bis zur Adria vorgedrungen waren, löste dieser Vormarsch eine internationale Krise aus, in deren Verlauf Österreich-Ungarn einen Teil seiner Streitkräfte mobilisierte und Rußland seinen zur Entlassung anstehenden Rekrutenjahrgang unter den Fahnen hielt ${ }^{385}$. Obwohl das Zarenreich damit die Stärke seines Heeres um nicht unbeträchtliche 400000 Mann erhöht hatte, schien dieses Vorgehen Frankreichs Kriegsminister nicht ausreichend zu sein. Vielmehr drängte Millerand mit nachdrücklicher Unterstützung Poincarés auf zusätzliche militärische Maßnahmen ${ }^{386}$.

Bestimmend für diese französische Intervention dürfte dabei weniger wie der russische Militärattaché vermutete - der Gedanke gewesen sein, daß Österreich-Ungarn Serbien überrennen und dann seine gesamte Streitmacht gegen Rußland werfen könnte ${ }^{387}$. Denn in einer Untersuchung der Erfolgs-

384 Zit. Au sujet de la valeur de la coopération Russe, Dezember 1911, in: SHA 7N1538. Vgl. damit übereinstimmend Note sur l'action militaire de la Russie en Europe. Fascicule II, in: SHA 7N1535. Schon im Jahr 1908 hatte der russische Generalstabschef den Militärattaché Frankreichs auf diesen Zusammenhang aufmerksam gemacht. Vgl. Moulin an Piquart, 2. 9. 1908, in: DDF 2, 11, 442.

385 Vgl. Egmont ZECHLIN, Die Adriakrise und der »Kriegsrat« vom 8. Dezember 1912, in: DERS., Krieg und Kriegsrisiko, S. 115-159, hier insbesondere S. $118 \mathrm{f}$. und Jost DÚlfFER (Hg.), Vermiedene Kriege. Deeskalation von Konflikten der Großmächte zwischen Krimkrieg und Erstem Weltkrieg 1865-1914, München 1997, S. 641-655, hier insbesondere S. 647f.

386 Vgl. Poincaré an Louis, 9. 12. 1912, in: DDF 3, 5, 22 und Ders. an Dens., 12. 12. 1912, in: ibid. 3, 5, 48. Vgl. auch Louis an Poincaré, 10. 12. 1912, in: DDF 3, 5, 33 und Ders. an Dens., 12. 12. 1912, in: ibid. 3, 5, 46. Vgl. ferner Iswolski an Sasonow, 9. 12. 1912, in: STIEVE, Iswolski-Schriftwechsel II, 614; Ders. an Dens., 11. 12. 1912, in: ibid., 620; Ders. an Dens., 14. 12. 1912, in: ibid., 630 und Ders. an Dens., 18. 12. 1912, in: ibid., 639. Vgl. auch LANEY, Military Implementation, S. 389-391. Vgl. ferner das Schreiben Ignatjews vom 18. Dezember 1912, das als Annexe 8 veröffentlicht wurde in: A. M. ZAIONTCHKOVSKY, Relations franco-russes avant la guerre de 1914, in: Les Alliés contre la Russie avant, pendant et après la guerre mondiale. Faits et documents, Paris 1926, S. 1-44, hier S. $43 \mathrm{f}$.

387 Vgl. ADAMOw, Konstantinopel und die Meerengen I, S. $55 \mathrm{f}$. Vgl. ferner IGNATJEw, Fünfzig Jahre, S. $243 \mathrm{f}$. Mit ähnlicher Begründung auch in Iswolski an Sasonow, 11. 12. 1912, in: STIEVE, Iswolski-Schriftwechsel II, 620. 
aussichten, die für Frankreich in einem Koalitionskrieg bestanden, der seinen Ausgang auf dem Balkan nahm, war Joffres Stab zu dem Ergebnis gelangt, daß eine militärische Niederwerfung Serbiens mehrere Monate in Anspruch nehmen würde ${ }^{388}$. Ausschlaggebend dürfte deshalb vielmehr gewesen sein, was Poincaré unter dem Datum des 9. Dezember an seinen Botschafter in Sankt Petersburg telegraphierte: Toute supériorité de préparation qui serait acquise à l'Autriche-Hongrie pourrait, en effet, amener l'Allemagne à diriger vers notre frontière une partie des corps d'armée stationnés sur sa frontière orientale $^{389}$. Wie Poincaré dem russischen Botschafter am 11. Dezember nachdrücklich erläuterte, würde Frankreich dann aber gezwungen sein, einen europäischen Krieg unter böchst ungünstigen Bedingungen ${ }^{390} \mathrm{zu}$ führen.

Angesichts dieser Ausführungen Millerands und Poincarés aus dem Jahr 1912, die für den Fall eines europäischen Krieges, der seinen Ausgang von der Balkanhalbinsel nahm, ein Interesse Frankreichs an weitreichenden militärischen Maßnahmen Rußlands bezeugen, ist es deshalb nicht verwunderlich, daß Frankreich - wie im weiteren Fortgang der Untersuchung noch zu zeigen sein wird - am 29. Juli 1914 in keiner Weise auf die Nachricht von einer partiellen russischen Mobilmachung reagierte ${ }^{391}$. Doch für den im Rahmen

388 Vgl. Action éventuelle de l'Autriche Hongrie dans les Balkans, in: CADN, Berlin A/224. Vgl. auch Poincaré an Millerand, 22. 8. 1912, in: DDF 3, 3, 314. In seiner Anfrage an das Kriegsministerium schloß der Ministerpräsident ausdrücklich eine unmittelbar erfolgende Reaktion des Bündnispartners aus. Das Kriegsministerium antwortete auf das Schreiben des Ministerpräsidenten mit dem umfangreichen Memorandum "Acrion éventuelle de l'Autriche-Hongrie dans les Balkans«, das leider nur in Auszügen in der französischen Aktenedition veröffentlicht wurde. Vgl. DDF 3, 3, 359. Dem Verfasser ist es weder in den Archiven des Außenministeriums noch in den Archiven des Generalstabs gelungen, eine Kopie respektive das Original dieses Memorandums ausfindig zu machen. Eine Abschrift wurde jedoch unter dem Datum des 13. September an die französische Botschaft in Berlin gesandt und kann deshalb heute in CADN, Berlin A/224 konsultiert werden.

${ }^{389}$ Zit. Poincaré an Louis, 9. 12. 1912, in: DDF 3, 5, 22.

390 Zit. Iswolski an Sasonow, 11. 12. 1912, in: STIEVE, Iswolski-Schriftwechsel II, 620. Im Gegensatz zu diesen Ausführungen hat Leonard Turner die These vertreten, daß die russische Teilmobilmachung unter militärischen Gesichtspunkten nicht nur nicht notwendig, sondern gar schädlich war. Turner gründet diese These auf den Gedanken, daß Rußland durch ein kalkuliertes Abwarten an seiner südlichen Front einen signifikanten Vorteil erhalten mußte, da mit fortschreitender Zeit substantielle österreichische Kontingente in Auseinandersetzungen mit serbischen Formationen verwickelt worden wären. Vgl. Leonard Charles Frederick TURNER, The Russian Mobilization, in: JCH 3 (1968), S. 65-88, hier S. 69. So auch schon ALBERTINI, Origins, Bd. II, S. 482f. Turners These setzt jedoch voraus, daß die Habsburgermonarchie im entscheidenden Augenblick tatsächlich gegen Serbien und nicht gegen Rußland vorging. Vgl. kritisch zu Turner auch LIEVEN, Russia and the Origins, S. $148 \mathrm{f}$.

${ }^{391}$ Folgt man dem Bericht des Innenministers Malvy, den der ehemalige Ministerpräsident und politische Gegner Poincarés, Joseph Caillaux, in seinen Memoiren angeführt hat, so ist in der Kabinettssitzung am Abend des 29. Juli die russische Teilmobilmachung vom Kabinett ausdrücklich gebilligt worden. Vgl. Joseph CAILlAUX, Mes mémoires, Bd. III, Paris 1947, S. 170 f. 
dieses Kapitels zu behandelnden Gegenstand gilt es zunächst festzuhalten, daß nach Ansicht des Generalstabs und der politischen Führung Frankreichs offensichtlich ein deutlicher Nexus zwischen der ost- und westeuropäischen Machtbalance bestand und daß eine Modifikation der östlichen Machtbalance umgehend Konsequenzen für die Erfolgschancen der offensive à outrance zeitigte. Vor dem Hintergrund dieses Zusammenhangs ist es dann nicht mehr überraschend, daß Frankreich nach dem partiellen Zusammenbruch des Osmanischen Reichs und der Erstarkung der Balkanstaaten zu einer neuen Einschätzung der europäischen Machtverhältnisse gelangte.

In ihren Hoffnungen von der militärischen Auseinandersetzung beflügelt, die das Osmanische Reich und Italien seit dem September 1911 in Nordafrika führten, hatte sich im Laufe des Jahres 1912 eine Allianz von Balkanstaaten zusammengefunden, die dazu entschlossen war, die Gunst der Stunde zu nutzen. Nachdem am 17. Oktober 1912 dem Osmanischen Reich der Krieg erklärt wurde, kam der Vormarsch der Balkanstaaten erst vor den Toren Konstantinopels zum Stillstand. Mit diesem Erfolg hatte der Balkanbund bereits zu Beginn der militärischen Auseinandersetzung Fakten geschaffen, die eine Rückkehr zum Status quo ante unmöglich machten, und schon vor der Unterzeichnung des Präliminarfriedens von London, der den ersten Balkankrieg am 30. Mai 1913 beendete, stand fest, daß das Osmanische Reich den größten Teil seiner europäischen Besitzungen verlieren würde ${ }^{392}$.

Überblickt man die Untersuchungen, die der französische Generalstab der osteuropäischen Machtbalance in den letzten Jahren vor Ausbruch des Großen Krieges widmete, so wird deutlich, daß sich seine Kalkulationen nach dem partiellen Zusammenbruch des Osmanischen Reiches sichtlich optimistischer ausnahmen. Während man noch in der Entstehungsphase des Plan XVII angenommen hatte, daß das Deutsche Reich im Fall einer militärischen Auseinandersetzung nicht mehr als drei aktive Korps und mehrere Reservedivisionen gegen Rußland konzentrieren würde, neigte man nach dem $\mathrm{Zu}$ sammenbruch der Pforte dazu, diese Zahl in den entsprechenden Untersuchungen zu erhöhen ${ }^{393}$. Zwar schloß man schon in der Zeit vor dem Zusam-

392 Zu Ausbruch, Fortgang und Rückwirkungen der Balkankriege auf das europäische Staatensystem vgl. Ernest C. HelmREICH, The Diplomacy of the Balkan War, 19121913, New York 1969 [Nachdruck, zuerst 1938]; Andrew Rossos, Russia and the Balkans: Inter-Balkan Rivalries and Russian Foreign Policy, 1908-1914, Toronto 1981 und Richard G. HaLL, The Balkan Wars: 1912-1913. Prelude to the First World War, London 2000.

393 Als der Conseil supérieur de la défense nationale am 9. Januar 1912 zusammentrat, lag seinen Beratungen ein strategisches Exposé zugrunde, welches davon sprach, daß das Deutsche Reich im ungünstigsten Fall 22 oder 23 aktive Korps gegen Frankreich konzentrieren würde. Im Anhang des Exposés »Indication sur les forces militaires de l'Allemagne et de ses alliés « sprach der Generalstab von 23 Korps. Vgl. Note de présentation, CSDN, 9. 1. 1912, in: SHA 2N1, VI/36 und Indication sur les forces militaires de l'Allemagne et de ses alliés, CSDN, 9.1. 1912, in: ibid. Vor dem Hintergrund der Ausführungen in Oberstleutnant Janins Analyse der russischen Möglichkeiten aus dem November/Dezember 1911 erscheint der ungünstigste Fall als der tatsächliche. Vgl. Au 
menbruch des Osmanischen Reichs zuweilen nicht aus, daß das Deutsche Reich ein umfangreicheres Kontingent an aktiven Divisionen gegen Rußland zusammenziehen könnte ${ }^{394}$. Doch erst nach dem partiellen Zusammenbruch des Osmanischen Reichs, der das Siechtum der Habsburgermonarchie so dramatisch beschleunigte, sprach man davon, daß sich die strategische Gesamtsituation des Deutschen Reiches deutlich verschlechtert hatte ${ }^{395}$. So setzt beispielsweise die Betrachtung der außenpolitischen Lage im einleitenden Kapitel des Plan XVII mit der Bemerkung ein:

L'Allemagne ne peut plus escompter, avec le même degré de certitude, le concours que son principal allié avait été jusqu'ici en mesure de lui apporter. Le [sic] renaissance des États balkaniques aura, en effet, pour conséquence d'obliger l'Autriche à maintenir un plus grand nombre de corps d'armée sur sa frontière Sud, et à diminuer d'autant la puissance de ses efforts en Galicie ${ }^{396}$, um dann mit folgender Bilanz zu schließen: En résumé, la poussée des peuples balkaniques a modifié, dans une certaine mesure, l'équilibre européen ${ }^{397}$.

Daß sich die internationale Lage des Deutschen Reiches mit dem Zusammenbruch des Osmanischen Reiches deutlich verschlechtert hatte, erkannte man aber nicht nur innerhalb der militärischen, sondern auch innerhalb der poli-

sujet de la valeur de la coopération russe, Dezember 1911, in: SHA 7N1538. Vgl. ferner Comparaison des forces qui pourraient se trouver en présence sur le théâtre du nord-est en cas de conflit avec l'Allemagne, CSDN. 19. 10. 1912, in: SHA 2N1, VII. In dieser Übersicht, die den Ausführungen des Generalstabschefs am 12. Oktober 1912 zugrunde lag, kalkulierte man, daß das Deutsche Reich zwischen drei und fünf aktive Korps gegen Rußland einsetzen werde.

394 Vgl. Note sur l'action militaire de la Russie en Europe. Fascicule II, in: SHA 7N1538. In dieser Note, die als einziges Dokument eine kombinierte deutsch-österreichische Offensive annimmt, erachtete man es für wahrscheinlich, daß das Deutsche Reich im Zuge eines solchen Unterfangens vier oder fünf aktive Korps an seiner östlichen Grenze konzentrieren würde.

$395 \mathrm{Vgl}$. Situation sur le pied de guerre des principales armées européennes, 10. 11. 1913, in: SHA 7N1771. Dieser Übersicht kann man entnehmen, daß das Deutsche Reich seine östlichen Grenzen mit fünf aktiven Korps und dreizehn Reservedivisionen verteidigen würde. Eines der wichtigsten Ziele der »Étude relative à l'importance, à la répartition et à l'emploi des forces allemandes sur le théâtre d'opérations russo-allemandes « war dann im Mai 1914, den Umfang der Kontingente zu ermitteln, mit denen das Deutsche Reich einem russischen Angriff begegnen würde. Während man glaubte, mit Sicherheit nachweisen zu können, daß der Gegner zumindest drei aktive Korps zum Schutz seiner östlichen Territorien einsetzen werde, erachtete man es doch für wahrscheinlich, daß es fünf wären. Vgl. Étude relative à l'importance, à la répartition et à l'emploi des forces allemandes sur le théâtre d'opérations russo-allemandes, Mai 1914, in: SHA 7N1538. In einer unmittelbar vor Ausbruch des Großen Krieges entstandenen Übersicht zum deutschen Heer rechnete der Generalstab mit einer Zahl von drei bis sechs Korps. Vgl. Répartition possible des forces de l'Allemagne en cas de conflit européen, Juni 1914, in: SHA 7N1774. In der maschinenschriftlichen Fassung dieser Übersicht, die leicht vom handschriftlichen Original abweicht, ist von vier bis fünf Korps die Rede. Vgl. Répartitions des forces de l'Allemagne en cas de conflit européen, Juni 1914, in: SHA 7 N1785.

396 Zit. Bases du Plan, CSG, 18. 4. 1913, in: SHA 1N11, CXLIII, fol. 4.

397 Zit. ibid., fol. 6. 
tischen Führung Frankreichs. Angesichts des Machtverfalls der Habsburgermonarchie brachte man zuweilen gar Verständnis für die neuen Rüstungen des Deutschen Reiches auf. So erläuterte Kriegsminister Étienne im Militärausschuß der Assemblée nationale am 11. März 1913: Il [gemeint ist Wilhelm II., St. S.] a examiné les conséquences des troubles et bouleversements qui se sont produits dans l'est de l'Europe dans la péninsule balkanique. Il a constaté qu'un nouveau groupement, vigoureux, fort, ardent, doué de vertus guerrières, se constituait sur le flanc même de l'Autriche et il a estimé que l'Autriche serait toujours occupée à tourner ses regards vers l'est ${ }^{398}$. In Übereinstimmung mit diesen Ausführungen des Kriegsministers schrieb Poincaré einen Tag, nachdem Bethmann Hollweg in einer langen Rede den Reichstag von der Notwendigkeit erneuter Rüstungen zu überzeugen versucht hatte, in seinem Diarium einen Eintrag nieder, dem man um so größere Bedeutung wird zumessen müssen, als er zu den sehr seltenen Einträgen des Jahres 1913 zählt, in denen der Präsident sich nicht auf den Bericht von Fakten beschränkte, sondern an seine Beobachtungen zugleich eine längere Reflexion knüpfte.

La politique d'abaissement que l'Autriche poursuit [Lesart unsicher] à l'égard des États balkaniques, so notierte Poincaré unter dem Datum des 8. April 1913, se présente à mes yeux avec plus de clarté encore après les explications de Bethman [sic] Hollweg. Le chancelier allemand a constaté que des États doués d'une force de vie extraordinaire avaient dans les Balkans pris la place de la Turquie, et il a fait ressentir [Lesart unsicher] combien cette [unleserliches Wort] serait désavantageuse pour l'Allemagne dans un conflit qui mettrait face à face Slaves et Germains. L'Allemagne approuve donc son allié lorsqu'elle cherche à entraver le développement futur de ces royaumes slaves et grecs, lorsqu'elle veut les diviser par de multiples irrédentismes et des querelles de frontière. Et à la commission de budget du Reichstag le g[ouvernemen]t de Berlin a déclaré qu'il n'avait jamais paralysé l'énergie autrichienne dans la crise qui dure encore - c'est ainsi que s'expliquent la création d'un État albanais, l'effort pour en étendre les frontières, l'éloignement de la Serbie des côtes de l'Adriatique ${ }^{399}$.

Es wird im Rahmen der Untersuchung des Bildes, das sich Poincaré von der Außenpolitik des Deutschen Reiches machte, noch festzustellen sein, ob es sich bei dieser Einschätzung um einen momentanen Eindruck handelte, der

398 Zit. AN, C7421, Commission de l'Armée: procès-verbaux des séances, Bd. II, 11. 3. 1913, fol. 19f. Mit diesen Einlassungen machte der Kriegsminister gegenüber den Abgeordneten öffentlich, was der Außenminister am 19. Februar 1913 noch unter dem Siegel der Verschwiegenheit dem belgischen Gesandten anvertraut hatte. Vgl. Guillaume an Davignon, 19. 2. 1913, in: Belgische Aktenstücke, 115. Vgl. auch Note faisant ressortir l'effort fait par la France pour répondre aux armements de l'Allemagne, 25. 7. 1913, in: SHA 7N1535: Parmi les causes qui justifient l'effort considérable fait par l'Allemagne, il faut citer en première ligne la diminution de la puissance d'action de l'Autriche, à la suite des dernières évènements balkaniques. Obligée de se garder sur ces frontières du sud, doutant du loyalisme de ses sujets d'origine slave, l'Autriche bésitera sans doute, en cas de conflit général, à s'engager à fond et sans arrière pensée en Pologne.

399 Zit. Notes journalières, in: NL Poincaré, BNF, Nafr 16024, fol. 153 (Eintrag vom 8. 4. 1913). 
später von anderen Beobachtungen überlagert werden sollte, oder ob mit diesem Eintrag zum ersten Mal eine Einsicht formuliert wurde, die sich kontinuierlich verfestigte und schließlich zur Gewißheit wurde. Die Bedeutung dieser Gedanken für eine Untersuchung der Außenpolitik Frankreichs in der Julikrise 1914 liegt auf der Hand. Sollte Poincaré tatsächlich frühzeitig der Ansicht gewesen sein, daß das Deutsche Reich aus militärischen Motiven heraus eine Außenpolitik der systematischen Unterstützung seines habsburgischen Bündnispartners führte, so muß ihm schon am Tag der Übergabe des österreichischen Ultimatums an Serbien die ganze Brisanz der Situation schlagartig deutlich geworden sein. Für den im Rahmen dieses Kapitels zur Untersuchung stehenden Gegenstand genügt es aber zunächst, die wichtige Erkenntnis festzuhalten, daß sich nicht allein die militärische, sondern auch die politische Staatsführung des Machtverfalls der Habsburgermonarchie bewußt war und daß diese Einschätzung auch nicht grundlegend beeinträchtigt wurde, als der Balkanbund noch im Sommer 1913 zerfiel.

Entgegen früheren Annahmen konnte man in Paris zwar nun nicht mehr auf bulgarische Unterstützung in einem Krieg der Habsburgermonarchie gegen Serbien rechnen. Denn beide Staaten hatten nach ihrem gemeinsamen Krieg gegen das Osmanische Reich eine militärische Auseinandersetzung über die Aufteilung der Beute geführt. Doch die aus dem serbisch-bulgarischen Antagonismus resultierende Schwächung Serbiens wurde durch den neuen außenpolitischen Kurs Rumäniens kompensiert. Die rumänische Intervention im zweiten Balkankrieg, die es dem Land im Frieden von Bukarest ermöglichte, einen bulgarischen Grenzstreifen zu annektieren, und Serbien einen großen Teil der von Bulgarien beanspruchten Provinz Mazedonien eintrug, hatte Rumänien in einer Interessengemeinschaft mit Serbien verbunden. Zwar kündigte Rumänien seinen geheimen Freundschafts- und Beistandsvertrag mit der Habsburgermonarchie aus dem Jahre 1883 nicht auf, de facto war es aber aus seinem Bund mit den Mächten in der Mitte Europas ausgeschieden ${ }^{400}$. Hatten bislang alle Kalkulationen der militärischen Führung Frankreichs auf einer Kooperation der Habsburgermonarchie und Rumäniens beruht, so fand Österreich-Ungarn nun nach dem zweiten Balkankrieg Rumänien als potentiellen Gegner an seiner nicht befestigten östlichen Grenze wieder. Dieser konnte aber möglicherweise, so spekulierte man auch in Paris, in einem Großen Krieg zum Angriff übergehen, um sich der rumä-

400 Vgl. Étude sur le plan de concentration russe de 1913, Dezember 1913, in: SHA 7N1771. In dieser Analyse wird darauf aufmerksam gemacht, daß das Zarenreich durch die neue Ausrichtung Rumäniens, die Kontingente, die bislang im Fall einer militärischen Auseinandersetzung in Bessarabien konzentriert werden sollten, nunmehr an anderer Stelle einsetzen könne. Einschränkend gilt es jedoch hinzuzufügen, daß die strategischen Pläne Rußlands vorsahen, die rumänische Grenze ausschließlich mit einer Reihe von Reserveformationen zu sichern. Vgl. die Karten der Note sur le plan russe de 1913, in: SHA 7N1771. Vgl. auch Note pour le $3^{\mathrm{e}}$ Bureau (avant propos pour le plan), 12. 6. 1914, in: SHA 7N1771. 
nisch bevölkerten Territorien des Habsburger Reiches zu bemächtigen 401 . Hatte die militärische und politische Führung Frankreichs im Jahr 1912 Rumänien noch als sicheren Gegner eingestuft ${ }^{402}$, so kalkuliert man nun, daß im Kriegsfall die rumänische Neutralität kalmierend auf Bulgarien einwirken, das Handeln Österreich-Ungarns beschweren, das des Zarenreiches aber entlasten werde ${ }^{403}$. Dementsprechend zog Paléologue, nachdem sich im Spätsommer 1913 der Pulverdampf auf der Balkanhalbinsel gelichtet hatte, in seinem Diarium die für Österreich vernichtende Bilanz:

Tout ce que l'Autriche espérait et prévoyait, tout ce qu'elle a si obstinément poursuivi dans l'évolution de la crise balkanique l'a déçue. Elle voit aujourd'bui les Serbes élevés à un degré de puissance qu'ils n'ont jamais connu, les Monténégrins possesseurs du Sandjak, les Grecs installés à Salonique, la Bulgarie amoindrie et mortifié, la Roumanie se considérant comme affranchie désormais de la tutelle viennoise et commençant à tourner ses regards vers la Transylvanie, la Bukovine, le banat de Témesvar ... ${ }^{404}$.

War auch der Balkanbund zerfallen, in den Analysen des Generalstabs fuhr man fort, die gewandelte Machtbalance mit einem Hinweis auf den Machtverfall der Habsburgermonarchie zu begründen ${ }^{405}$. Noch in der letzten $\mathrm{Zu}$ -

$401 \mathrm{Vgl}$. SCHROEDER, Rumania. In diesem interessanten Aufsatz hat der amerikanische Historiker die These vertreten, daß das Abschwenken Rumäniens aus dem Lager der Mittelmächte eine bedeutende Ursache für den Ausbruch des Ersten Weltkrieges war. 402 Vgl. Indication sur les forces militaires de l'Allemagne et de ses alliés, CSDN, 9.1. 1912, in: SHA 2N1, VI/36. Schon in dem Memorandum, das der Besprechung zwischen dem Generalstabschef und dem Politischen Direktor des Außenministeriums am 16. Oktober 1911 zugrunde lag, hatte die rumänische Frage Beachtung gefunden. Ohne genauere Erkenntnisse über die vertraglichen Verpflichtungen zu besitzen, die Rumänien an die Habsburgermonarchie banden, glaubte der Generalstab doch über genügend Informationen zu verfügen, um auf eine Militärkonvention schließen zu können, in der Rumänien der Habsburgermonarchie militärische Unterstützung für den Fall einer russischen Intervention auf dem Balkan zugesichert hatte. Vgl. Note indiquant les points relatifs à la situation extérieure à élucider dans la Conférence du 16 octobre 1911, CSDN, in: SHA 2N1, V/32. In einer Note vom 20. Oktober 1911, mit der das Außenministerium das Memorandum des Generalstabs ergänzte, wurden insbesondere die guten Beziehungen zwischen den Monarchen des Deutschen Reiches und Rumäniens betont. Vgl. SHA 2N1, VI/34/2.

${ }^{403} \mathrm{Vgl}$. Situation sur le pied de guerre des principales armées européennes, 10.11.1913, in: 7N1771. Vgl. hierzu auch insbesondere die Aufzeichnung vom 25. 8. 1913, in: MAE, NS Turquie 283, fol. 253-259. In dieser Aufzeichnung des Außenministeriums, in der eine Einschätzung sowohl der aktuellen als auch der zukünftigen Entwicklung der Lage auf dem Balkan vorgenommen wurde, gelangte man zu der Ansicht, daß Rumänien in den vergangenen Monaten einen vergleichsweise hohen Grad an Autonomie gegenüber den Dreibundmächten erreicht und die öffentliche Meinung ihre Sympathie zunehmend Frankreich und seinem Bündnispartner zugewandt hatte. Dieser Entwicklung müsse auch der rumänische Monarch Rechnung tragen. Im Hinblick auf die zukünftige Entwicklung wurde konstatiert, daß Rumänien insbesondere an der Aufrechterhaltung des Bukarester Vertrages interessiert sei, deshalb an seiner Verbindung mit Serbien und Griechenland festhalten und sich der Triple Entente annähern werde.

404 Zit. PalÉOlOGUE, Journal, S. 195 (Eintrag vom 2. 9. 1913).

$405 \mathrm{Vgl}$. Répartition possible des forces de l'Allemagne en cas de conflit européen, Juni 1914, in: SHA 7N1771. 
sammenstellung des Generalstabs über den Zustand des deutschen Heeres aus dem Juni 1914 wird konstatiert: La situation militaire s'est [...] modifiée au détriment de l'Allemagne, und diese Feststellung dann unter anderem mit der réserve imposée à l'Autriche par la situation politique des Balkans ${ }^{406}$ begründet, die einen Angriff Rußlands gefährlicher mache als jemals zuvor.

Die Erkenntnisse der Untersuchungen über den Aufmarsch des Deutschen Reiches korrespondierten dabei mit den Resultaten der Analysen der strategischen Konzentration der Habsburgermonarchie, die der Generalstab in den letzten Jahren vor Ausbruch des Großen Krieges anstrengte ${ }^{407}$. Auch wenn die numerischen Angaben in den einzelnen Studien schwanken, die man zum Aufmarsch der österreichischen Armee erarbeitete, die zu Gunsten Rußlands und damit auch zu Gunsten Frankreichs gewandelte Lage tritt unverkennbar hervor ${ }^{408}$.

Der Gang der Untersuchung ist mit diesen Ausführungen an einen Punkt gelangt, an dem es scheint, als sei dem Historiker Isaac zuzustimmen, der in einer seiner späten Betrachtungen zum Gegenstand dieser Arbeit die Ansicht vertrat, daß Frankreich ein genuines Interesse am Fortbestand der Ordnung besaß, die durch den partiellen Zusammenbruch des Osmanischen Reiches geschaffen worden war, und der dieses Interesse gar in den Rang eines Motivs erhob, das die Außenpolitik Frankreichs in der Julikrise 1914 maßgeblich bestimmte.

406 Zit. ibid. Eine maschinenschriftliche Fassung dieser Note findet sich auch in: SHA 7N1785. Der Text dieses Dokumentes weicht an einzelnen Stellen von der in SHA 7N1771 aufbewahrten Note ab, ohne jedoch dessen Aussagen substantiell zu verändern.

407 Vgl. Note de présentation, CSDN, 9. 1. 1912, in: SHA 2N1, VI/36 und Indication sur les forces militaires de l'Allemagne et de ses alliés, in: ibid. Beide Noten gehen davon aus, daß die Habsburgermonarchie 14 aktive Korps an der russischen Grenze konzentrieren würde. Vgl. auch Action éventuelle de l'Autriche Hongrie dans les Balkans, in: CADN, Berlin A/224. In dieser Untersuchung aus dem September 1912 sprach man davon, daß das Kontingent der Habsburgermonarchie 13 Korps umfassen würde. Vgl. ferner Situation sur le pied de guerre des principales armées européennes, 10.11. 1913, in: SHA 7N1771. In dieser Übersicht glaubte man annehmen zu können, daß der Habsburgermonarchie im Konfliktfall nur noch ein zehn oder elf Korps umfassendes Kontingent gegen Rußland zur Verfügung stehe, während sie gleichzeitig gezwungen sei, gegen Serbien eine zwei oder drei aktive Korps umfassende Armee aufzustellen. Im Hinblick auf dieses Dokument gilt es allerdings zu bemerken, daß die in ihm genannte Gesamtzahl der Einheiten, die von der Habsburgermonarchie im Kriegsfalls mobilisiert werden würden, nicht mit der Summe der Korps übereinstimmt, die die Übersicht dann an den verschiedenen Fronten Österreich-Ungarns aufführt. Vgl. auch Résumé d'une note de février 1914 sur la concentration austro-hongroise en Galicie, in: SHA 7N1538: La nouvelle situation créée dans les Balkans par la dernière guerre a fatalement conduit l'État-major Général autrichien à augmenter sensiblement les forces maintenues en face de la Serbie. Während man im Jahr 1912 von 13 Korps in Galizien ausging, glaubte man im Februar 1914 dort nur noch mit elf Korps rechnen zu müssen.

$408 \mathrm{Vgl}$. Répartition possible des forces de l'Allemagne en cas de conflit européen, Juni 1914, in: SHA 7N1771. 
Sicherlich: Es ist deutlich geworden, daß durch ein System aufeinander abgestimmter Kriegspläne die ost- und westeuropäische Machtbalance zu einer Einheit verschmolzen wurden, und daß nach Ansicht der militärischen und politischen Führung Frankreichs das Gleichgewicht der Macht mit dem Verfall der Habsburgermonarchie einen Wandel erfahren hatte, der um so bedeutender sein mußte, als das neue Primat des uneingeschränkten Angriffs die Grande Nation in mehrfacher Hinsicht von den militärischen Möglichkeiten ihres russischen Bündnispartners abhängig machte. Ein Triumph der Habsburgermonarchie über Serbien mußte sich deshalb auch im Westen Europas merklich fühlbar machen, und in einem seiner letzten Berichte aus Wien sprach der Militärattaché Frankreichs dann im Juli 1914 auch offen aus, daß er aufgrund der zu befürchtenden Machtverschiebung eine Lokalisierung des Konflikts als dangereux erachte ${ }^{409}$.

Dennoch ist es fraglich, ob das Potential, das der Habsburgermonarchie aus einer Ausschaltung Serbiens erwachsen würde, nach französischer Auffassung die östliche Machtbalance bis zu jenem kritischen Punkt beeinträchtigen konnte, an dem eine militärische Intervention zwingend erforderlich schien. Denn der Machtverfall der Habsburgermonarchie war nur einer der Faktoren, die das sich in diesen Jahren dynamisch entwickelnde Gefüge der Macht beeinflußten. Neben dem Umstand, daß nach dem partiellen Zusammenbruch des Osmanischen Reiches die Habsburgermonarchie mehr und mehr einem gefesselten Gulliver denn einer handlungsfähigen Großmacht glich, gab es noch einen anderen für die Machtbalance konstitutiven Faktor, der in keinem direkten Zusammenhang mit der Entwicklung der Dinge auf Balkan stand und doch dieselbe Wirkung hatte: die von Frankreich tatkräftig geförderte Renaissance der militärischen Kraft Rußlands ${ }^{410}$.

Nach der empfindlichen Niederlage, die Rußland im Zuge seines fernöstlichen Abenteuers in den Jahren 1905/1906 erlitten hatte, war es dem Bündnispartner Frankreichs lange Zeit unmöglich gewesen, den raschen und machtvollen Angriff gegen das Deutsche Reich zu führen, zu dem er sich in der Militärkonvention verpflichtet hatte. Noch im Jahr 1911 hatte der russische Generalstabschef bekennen müssen, daß Rußland nicht auf eine militärische Auseinandersetzung der Großmächte vorbereitet war. Zwar sicherte er zu, daß man alle Anstrengungen unternehmen werde, um in Zukunft das Deutsche Reich frühzeitig angreifen zu können. Doch die erforderliche Reorganisation der Armee würde mindestens noch einen Zeitraum von zwei Jahren in Anspruch nehmen ${ }^{411}$.

409 Zit. Bericht Halliers, in: SHA 7N1132. Bei dem zitierten Dokument handelt es sich um den undatierten Entwurf eines Berichtes des Militärattachés.

410 Zur russischen Machtentfaltung vgl. die Ausführungen im Kapitel "Die französisch-russische Allianz - Eine bündnispolitische Zwangslage«.

$411 \mathrm{Vgl}$. Procès-verbal de l'entretien du 18/31 août 1911, entre les chefs d'état-major des armées française et russe, in: DDF 2, 14, 232. 
In demütigender Detailfülle mußte der Generalstabschef in einem Zusatzprotokoll zur Generalstabskonferenz von 1911 die Mängel der russischen Armee offenlegen ${ }^{412}$, die dann Dubail auf der Sitzung des Conseil supérieur de la défense nationale am 9. Januar 1912 abermals unterstrich ${ }^{413}$ und die auch Kriegsminister Millerand in der schon in anderem Zusammenhang behandelten Konferenz des 21. Februar 1912 feststellen ließen: La Russie a besoin de 2 années encore pour être capable de jouer son rôle avec la certitude de la victoire ${ }^{414}$. Bis zur Julikrise 1914 hatte aber die Reorganisation der russischen Armee bedeutende Fortschritte gemacht. Eine Untersuchung des Generalstabs vom 12. Juni 1914 konstatierte, daß die Periode der Regeneration abgeschlossen und der Bündnispartner durch seine gewaltige Aufrüstung nunmehr in die Phase der Verstärkung eingetreten seit15.

Betrachtet man unter diesem Blickwinkel noch einmal die Untersuchungen, die die militärische Führung Frankreichs hinsichtlich der strategischen Konzentration des Deutschen Reiches anstrengte, so stellt man fest, daß mitunter schon in den Analysen aus dem Jahr 1912, in zunehmenden Maße aber erst seit 1913 davon die Rede war, daß der Gegner durch die fortgeschrittene russische Erstarkung gezwungen sein werde, in bis zu diesem Zeitpunkt nicht gekanntem Maße Kontingente an seiner östlichen Front zu konzentrieren $^{416}$. Daß die Untersuchungen zur strategischen Konzentration des Deutschen Reiches die gewandelte Balance der Kräfte zuweilen in Rekurs auf den Machtverfall der Habsburgermonarchie, zuweilen auf den genuin russischen Kraftzuwachs und mitunter auf beide Faktoren gemeinsam zurückführen, macht es außerordentlich schwer, die Bedeutung des balkanischen Faktors

412 Vgl. Annexe au procès-verbal de l'entretien du 18/31 août 1911 entre les chefs d'état-major des armées française et russe à Krasnoe Celo, in: SHA $1 \mathrm{~K} 666$. Vgl. auch Annexe au procès-verbal de l'entretien du 6 juillet 1912 entre les chefs d'état-major des armées française et russe à Paris, in: ibid.

413 Vgl. Procès-verbal. CSDN, 9. 1. 1912, in: SHA 2N1, VI/38. In seinen Memoiren berichtet Caillaux, daß Dubail ihm im September 1911 einen Bericht vorgelegt habe, der zu dem Ergebnis gelangte, daß die Reorganisation des substantiellen Teils der russischen Armee noch zwei Jahre in Anspruch nehmen würde. Vgl. CaILLAUX, Mémoires, Bd. II, S. 144. Vgl. ferner die mit dieser Aussage übereinstimmenden Ausführungen im Manuskript "L'Accélération de l'offensive russe en août 1914«, in: NL Messimy, AN, 509 AP 6, fol. 3: En septembre, à son retour, Dubail me remet un rapport de mission très complet qui peut se résumer comme suit: En debors de la cavalerie, l'armée russe n'est pas véritablement prête.

${ }_{414}$ Zit. Conférence du 21 février 1912, in: NL Paléologue. Dokument im Besitz von Roger Lebon. Die Einlassung Millerands findet sich nicht im offiziellen Protokoll der Sitzung. Vgl. Conférence tenue au ministère des Affaires étrangères, Minute. CSDN, 21. 2. 1912, in: SHA $2 \mathrm{~N} 1, \mathrm{VI} / 39$.

$415 \mathrm{Vgl}$. Note pour le 3e Bureau (avant propos pour le plan), 12.6. 1914, in: SHA $7 \mathrm{~N} 1771$.

$416 \mathrm{Vgl}$. insbesondere die Ausführungen in: Étude relative à l'importance, à la répartition et à l'emploi des forces allemandes sur le théâtre d'opérations russo-allemandes, Mai 1914, in: SHA 7N1538. Vgl. ferner Répartition possible des forces de l'Allemagne en cas de conflit européen, Juni 1914, in: SHA 7N1771. 
einzuschätzen. Die Historiographie kann leider nicht über die Einrichtung des Experiments verfügen. Es ist ihr nicht gegeben, eine historische Konstellation unter Elimination eines Faktors, ceteris paribus, gleichsam noch einmal ablaufen zu lassen, um die Bedeutung eines anderen zu bestimmen. Aus diesem Grund sollte man nicht mit Jules Isaac oder Stephen Van Evera die Bewahrung des Status quo auf der Balkanhalbinsel in den Rang eines die französische Außenpolitik in der Julikrise maßgeblich bestimmenden Motivs erheben. Auch in den außenpolitischen Ausführungen in den Grundlagen des Plan XVII, die zu dem Ergebnis gelangten, daß durch den Machtverfall der Habsburgermonarchie die militärische Balance dans une certaine mesure $e^{417}$ einen Wandel zugunsten Frankreichs erfahren habe, heißt es dann doch weiter: Les événements d'Orient, la reconstitution des forces russes, la rivalité maritime de l'Angleterre et de l'Allemagne concourent à faire pencher la balance des forces du côté de la triple entente 418 .

Es sind diese letztgenannten Faktoren, die britische Intervention und die Renaissance der russischen Macht, die die Grenzen der Bedeutung einer balkanischen Auxiliarmacht markieren. Angesichts eines nicht auszuräumenden Restes an Unsicherheit, der sich stets mit der Frage der britischen Intervention verband, mußte insbesondere die russische Machtentfaltung den Einfluß der balkanischen Auxiliares kontinuierlich verringern und letztlich gar in der Bedeutungslosigkeit versinken lassen. Angesichts der russischen Machtentfaltung stellt sich gar die Frage, ob Frankreich unter militärischen Gesichtspunkten nicht mit Gelassenheit auf eine Auseinandersetzung zwischen der Habsburgermonarchie und Serbien blicken konnte. Doch ein solcher Gedanke beruht auf der Prämisse, daß das Deutsche Reich trotz einer sich kontinuierlich verschlechternden Gesamtlage nicht in einem ihm günstig scheinenden Augenblick zum militärischen Prävenire schritt. Er setzt kurzum voraus, daß eine Periode des Friedens und nicht der Krieg Europas Zukunft war.

Im Zusammenhang mit der Frage, ob das Deutsche Reich möglicherweise einen Präventivkrieg führen würde, gilt es zu nun zu bedenken, daß Frankreich seinerseits die Erfolgsaussichten für einen Koalitionskrieg, der seinen Ausgang von der Balkanhalbinsel nahm, als außerordentlich günstig erachtete. Diese Kalkulation beruhte zum einen auf der Annahme, daß in einer militärischen Auseinandersetzung, in die Frankreich zum Schutz russischer Interessen zog, der Bündnispartner anders als in einem Konflikt über französische Interessen die so dringend benötigte Entlastungsoffensive gegen das Deutsche Reich führen würde. Zum anderen lag ihr der Gedanke zugrunde, daß die Habsburgermonarchie im Rahmen eines Angriffs auf Serbien einen

417 Zit. Bases du Plan, CSG, 18. 4. 1913, in: SHA 1N11, CXLIII, fol. 6.

418 Zit. ibid. Vgl. ferner Les armées françaises dans la Grande Guerre, Bd. I/1, S. 18, 47. Es ist deutlich erkennbar, daß das Werk des Generalstabs diesen Sachverhalt zu verschleiern sucht. Mit Blick auf die Bases du Plan wird dort nur festgehalten, daß Serbien der militärischen Führung als appoint précieux galt. Zit. ibid., S. 18. 
substantiellen Teil ihrer Kontingente fern der russischen Front binden würde.

Die militärischen Auseinandersetzungen auf dem Balkan hatten in den letzen Jahren vor Ausbruch des Großen Krieges mehrfach Anlaß gegeben, die Erfolgsaussichten einer gründlichen Untersuchung zu unterziehen, die für Frankreich in einem Koalitionskrieg bestanden, der seinen Ausgang auf dem Balkan nahm. Nach seiner Rückkehr aus Sankt Petersburg hatte Poincaré eine entsprechende Untersuchung veranlaßt. Der Generalstab, der am 2. September 1912 ein umfangreiches Memorandum zu dieser Frage an den Ministerpräsidenten sandte, kam zu der Erkenntnis, daß ein Krieg, der aufgrund eines Angriffs der Habsburgermonarchie auf Serbien entstand, das Deutsche Reich und seinen Bündnispartner den Mächten der Triple Entente auf Gnade und Ungnade ausliefern werde ${ }^{419}$. Der Generalstab gründete sein Kalkül auf die Annahme, daß die Habsburgermonarchie im Rahmen einer Offensive gegen Serbien dazu gezwungen sein werde, vier ihrer Korps auf dem Balkan zu verwenden und ihr folglich für ihre Offensive gegen das Zarenreich nur ein reduzierter Teil ihrer Kräfte zu Verfügung stehe. In dem Geflecht der aufeinander abgestimmten Aufmarschpläne würde es diese Modifikation der östlichen Balance dem Bündnispartner ermöglichen, einen gefährlichen Angriff auf Berlin zu führen, oder aber sie würde eine Änderung des westlichen Kräfteverhältnisses nach sich ziehen, falls sich das Deutsche Reich gezwungen sah, einen Teil seiner Streitkräfte nach Ostpreußen zu verlegen, um die durch die Schwächung der Habsburgermonarchie gestärkte russische Offensive aufzuhalten:

En s'engageant dans les Balkans, l'Autriche risque de provoquer un affaiblissement considérable des forces de la Triple Alliance sur au moins un des théâtres principaux (Lorraine, Pologne). [...] Si elle se borne à l'occupation du Sandjak, elle diminue de 4 corps les forces de la Triple Alliance. Si, dans ce cas, l'Allemagne se contente de maintenir en Prusse orientale le même effectif minimum, la Russie peut prononcer une offensive très dangereuse dans la direction de Berlin. Si elle, l'Allemagne, maintient l'équilibre en Pologne, la France disposerait d'une supériorité en Lorraine ${ }^{420}$.

419 Wörtlich heißt es in dem Memorandum des Generalstabs: Quelles seraient les conséquences d'une intervention militaire de l'Autriche dans les Balkans au point de vue de l'équilibre des forces militaires de la Triple Alliance et de la Triple Entente? Il semble qu'une telle intervention pourrait risquer de mettre l'Alliance à la merci de l'Entente. Zit. Note de l'état-major de l'armée, 2. 9. 1912, in: DDF 3, 3, 359.

420 Zit. ibid. Vgl. auch Paul Cambon an Jules Cambon, 3. 9. 1912, in: DDF 3, 3, 366. Vgl. ferner Iswolski an Sasonow, 12. 9. 1912, in: STIEVE, Iswolski-Schriftwechsel II, 429: Ferner sagte mir H. Poincaré, daß im Hinblick auf die kritische Lage auf dem Balkan die höheren französischen Militärbehörden mit verstärkter Aufmerksamkeit alle militärischen Eventualitäten, die sich ergeben könnten, prüfen; er wisse, daß die eingeweibten und verantwortlichen Persönlichkeiten die Aussichten Rußlands und Frankreichs im Falle eines allgemeinen Zusammenstoßes sebr optimistisch beurteilten. Dieser Optimismus gründet sich unter anderem auch auf die Einschätzung der Kräfteablenkung, die die vereinigten Heere der Balkanstaaten (mit Ausnabme von Rumänien) be- 
In Kenntnis dieser Untersuchung hat Poincaré schon frühzeitig mit Gelassenheit auf eine mögliche militärische Eskalation der Spannungen geblickt ${ }^{421}$. So berichtete Iswolski im Oktober 1912 an Sasonow,

daß Herr Poincaré, wenngleich aufrichtig bestrebt, den Frieden zu erhalten, sich gleichzeitig nicht nur vor dem Gedanken nicht fürchtet, daß man sich unter gewissen Umständen zum Kriege werde entschließen müssen, sondern eine rubige Zuversicht bekundet, daß die gegenwärtige militärpolitische Konjunktur für die Mächte des Dreiverbandes durchaus günstig ist und daß die Mäcbte die größten Aussichten auf Erfolg auf ibrer Seite haben. Diese Zuversicht berubt auf eingebend ausgearbeiteten Erwägungen des französischen Generalstabs, der u.a. die Schwäche der Lage Österreichs in Betracht zieht, das genötigt ist, auf zwei Fronten mit Rußland und den Balkanstaaten zu kämpfen ${ }^{422}$.

Vor dem Hintergrund dieses Kalküls lassen sich dann auch die euphorischen Stimmen erklären, die unmittelbar vor und nach Ausbruch des Großen Krieges in Frankreich zu vernehmen waren. Zwar berichtet Joffre in seinen Memoiren, daß, als ihm am Tag nach der Übergabe des Ultimatums der Habsburgermonarchie an Serbien von Kriegsminister Messimy die Frage gestellt worden sei, welche Erfolgsaussichten für Frankreich nach Lage der Dinge im Juli 1914 in einem Krieg bestehen würden, er ausschließlich geantwortet habe: Eb bien! Monsieur le ministre, nous la ferons, s'il le faut ${ }^{423}$. Doch die Erinnerungen des Generalstabschefs lassen an dieser Stelle nur einen schwachen Abglanz der einzigartigen Erfolgschancen sichtbar werden, die sein Stab für einen solchen Koalitionskrieg kalkuliert hatte. Vielmehr ließ Castelnau seinen Sohn unter dem Datum des 30. Juli wissen: J'ai fait savoir aux plus bautes autorités que, au pont de vue stratégique, nous ne trouverions jamais une plus belle occasion ${ }^{424}$, und der russische Militärattaché telegraphierte unter demselben Datum über seine Eindrücke aus dem Generalstab nach Sankt Petersburg: Icb bewundere die allgemeine Rube, die Befriedigung über die eigene Arbeit [...] und die unverboblene Freude, die nach Ansicht der Franzosen günstige strategische Lage auszunutzen ${ }^{425}$. La lutte avec l'Allemagne, so stimmte der französische Militärattaché in Berlin am 31. Juli in diesen Chor ein, ne pouvait s'engager dans des conditions plus favorables pour

deuten würden, indem sie entsprechende Teile der österreich-ungarischen Streitkräfte auf sich ziehen würden.

421 Vgl. Paul Cambon an Jules Cambon, 20. 11. 1912, in: NL Jules Cambon, in: MAE, PA-AP 43/101, fol. 260f.: Millerand, un peu grisé par le commandement des armées, avait envisagé sans crainte un conflit général, il le désirait même. Poincaré, sans le désirer, $n$ 'en était pas effrayé.

422 Zit. Iswolski an Sasonow, 24. 10. 1912, in: IB III/4,1 46.

423 Zit. Joffre, Mémoires, Bd. I, S. $207 \mathrm{f}$.

424 Zit. Gras, Castelnau, S. 144. Unter Benutzung privaten Archivgutes. Mit Blick auf die Ausrüstung der Kontingente konstatierte Castelnau im selben Brief jedoch noch einige Mängel. Vgl. in diesem Zusammenhang auch Paul Cambon an Jules Cambon, 1. 10. 1913, in: Cambon-Correspondance III, S. 53.

425 Zit. Ignatjew an Suchomlinow, 30. 7. 1914, in: IB I/5 296. 
nous ${ }^{426}$. Nous somme pleins d'espoir, beschrieb Doulcet die Stimmungslage in der französischen Botschaft in Petersburg, dans l'issue de cette partie qui ne pouvait être engagée dans de meilleurs conditions ${ }^{427}$, und Poincaré schien gar im August ein Friedensschluß le plus grand malheur ${ }^{428}$ zu sein, das Frankreich widerfahren könne, würde es doch sein Land um die Früchte eines sicheren Sieges bringen.

$\mathrm{Da}$ eine solche Einschätzung der Erfolgsaussichten es Poincaré und $\mathrm{Pa}$ léologue ungemein erleichtert hat, dem Bündnispartner den uneingeschränkten Beistand Frankreichs zuzusichern, liegt auf der Hand. Doch kann ihr außenpolitischer Kurs im Juli 1914, der so unverkennbar das Risiko eines Krieges in sich barg und ihn als Möglichkeit bewußt einkalkulierte, als Ausdruck eines Kalküls interpretiert werden, in dem militärische Faktoren eine entscheidende Rolle spielten?

$\mathrm{Daß}$ zumindest der militärischen Führung der Gedanke nicht fern lag, die Auseinandersetzungen auf dem Balkan für einen Präventivschlag gegen das Deutsche Reich zu nutzen, da der Krieg auch unter weit ungünstigeren Umständen ausbrechen konnte, dokumentieren Quellen britischer Provenienz. Nach einer Unterredung mit Joffre und Castelnau notierte der Leiter der militärischen Operationsabteilung im britischen Stab Henry Wilson am 14. Februar 1913 in seinem Diarium: I was curious to find that Castelnau is in favour of a war now as being a good opportunity, France [and] Russia being ready, [and] Austria in a state of confusion. Germany unwilling. [...] I can't belp thinking that time is now on the side of the Entente ${ }^{429}$. Daß innerhalb der militärischen Führung Frankreichs nicht allein Castelnau die von Wilson überlieferte Ansicht vertrat, legt zudem der Brief nahe, den Nicolson nach einer Unterredung mit dem nach London zurückgekehrten Wilson an Außenminister Grey schrieb.

He tells me, that the soldiers are of the opinion that it would be far better for France if a conflict were not too long postponed. Their reasons are that if it would come now it would be in consequence of the Balkan difficulties, and therefore they would be able to secure the wholehearted support of Russia. Were a conflict to be postponed and eventually to arise over some difficulty between Germany and France alone, they had some

426 Zit. Manneville, Les derniers jours, S. 444.

427 Zit. Doulcet an de Manneville, 19. 8. 1914. Dokument im Besitz von André de Manneville.

428 Zit. Notes journalières, in: NL Poincaré BNF, Nafr. 16027, fol. $148 \mathrm{f}$. (Eintrag vom 6. 8. 1914). Der Eintrag lautet: On me prévient, en présence de Viviani et de Doumergue, que l'ambassadeur des États Unis désire me voir. Ce doit être, dis-je, une offre de médiation. La figure de Viviani s'illumine. Ça serait, ajoute-je immédiatement, le plus grand malbeur qui puisse nous arriver, si une médiation pouvait être acceptée aujourd'bui par l'Allemagne. Sans doute, la guerre immédiate n'aurait pas lieu, mais, comme nous ne sommes pas vainqueurs, la paix ne nous serait pas favorable, l'Allemagne resterait aussi puissante et nous serions exposés, avant peu, à de nouvelles menaces.

429 Zit. NL WILSON, Diaries, IWM, DS/MISC/80, fol. 45, 366 (Eintrag vom 13. 2. 1913). Der entsprechende Passus wurde getilgt in: WiLSON, Diaries, Bd. I, S. 122. 
doubts, treaty notwithstanding, whether Russia would go wholebeartedly on their side ${ }^{430}$.

Auch der britische Botschafter in Paris berichtet unter dem Datum des 3. März 1913: There are many Frenchmen who think that war is inevitable within the next two years and that it might be better for France to have it soon. The arguments in favour of an early war are the improbability of Austria on account of her Slavs being able to give much assistance to Germany and the hostile feeling against Austria in the Balkans ${ }^{431}$.

Einer solchen Spekulation aber trat der britische Außenminister umgehend entgegen. In einem Vermerk zu dem Brief Nicolsons hielt er fest, daß er vielmehr den Eindruck habe, daß Frankreich bemüht sei, eine friedliche Lösung des Balkankonflikts herbeizuführen ${ }^{432}$. Und in der Tat: Weder in den britischen und französischen Archiven noch in den publizierten russischen Akten lassen sich Hinweise darauf finden, daß die politische Führung im Sinne der Einlassungen Castelnaus im Juli 1914 die Absicht hatte, unter Ausnutzung einer strategisch ungemein günstigen Lage den als unvermeidlich erachteten Großen Krieg frühzeitig zu entscheiden. Läßt sich auch einerseits kein Denken in den Bahnen eines militärischen Prävenires nachweisen, so wird man andererseits doch zumindest festhalten können, daß die mit einem Triumph der Habsburgermonarchie für die osteuropäische Machtbalance verbundenen Konsequenzen - wenn sie auch angesichts der Möglichkeit einer britischen Intervention und der russischen Machtentfaltung Frankreichs Außenpolitik in der Julikrise nicht maßgeblich bestimmten - eine aus anderen Gründen getroffene Entscheidung zusätzlich bekräftigten. Denn wer wie nun im nächsten Kapitel im Zusammenhang mit einer Betrachtung des Deutschlandbildes der militärischen und politischen Führung zu zeigen sein wird - schwere Auseinandersetzungen, möglicherweise gar einen Krieg für die nahe oder doch nicht allzu ferne Zukunft befürchtet, der wird kaum dazu tendieren, einen militärischen Vorteil aus der Hand zu geben.

430 Zit. Nicolson an Grey, 24. 2. 1913, in: BD 9/2, 656. Aus dem zitierten Tagebucheintrag des Direktors der militärischen Operationsabteilung des britischen Stabes geht eindeutig hervor, daß mit der Formel the soldiers nicht allein Foch gemeint war, wie Cairns behauptet hat. Vgl. John C. CAIRNS, International Politics and the Military Mind. The Case of the French Republic. 1911-1914, in: JMH 25 (1953), S. 273-285, hier S. 276.

431 Zit. Bertie an Grey, 3. 3. 1913, in: NL Bertie, PRO, FO 800/166, fol. 16.

432 Vgl. die Annotation Greys zu Nicolson an Grey, 24. 2. 1913, in: BD 9/2, 656. Gleichzeitig ließ er aber den britischen Botschafter wissen: If France is aggressive to Germany there will be no support from Great Britain. Zit. Grey an Bertie, 4. 3. 1913, in: NL Bertie, PRO, FO 800/166, fol. 17. 


\section{Angst und Arroganz}

\section{Das ambivalente Deutschlandbild der Entscheidungsträger}

Beginnen mag man mit einer Untersuchung des Deutschlandbildes der Entscheidungsträger in Berlin, das heißt mit den Nachrichten, die dem französischen Außenministerium von seiner Botschaft in der Reichshauptstadt zugingen. Ein erster Blick auf die Korrespondenz Cambons macht dabei zunächst deutlich, daß auch noch nach der zweiten Marokkokrise, die das Klima zwischen beiden Staaten so nachhaltig belastet hatte, in seinen Berichten Meldungen enthalten waren, die Anlaß zu Optimismus geben konnten.

Aufgrund der Unterhaltungen, die der Botschafter mit dem Reichskanzler führte, war er sich sicher, daß Bethmann Hollweg den Frieden unter den europäischen Großmächten zu erhalten trachtete ${ }^{433}$. Die entsprechenden Versicherungen, die ihm der Kanzler in ihren Gesprächen gab, hatten mitunter einen Zug ins Grundsätzliche angenommen, wenn Bethmann Hollweg die Bewahrung des Friedens als eine zivilisatorische Pflicht bezeichnete ${ }^{434}$ oder wenn er, die Chancen und Risiken einer militärischen Konfrontation wägend, zu der Einsicht gelangte, daß es unter modernen Bedingungen in einem Krieg keine Sieger, sondern nur mehr Besiegte geben würde. Si la guerre éclatait en Europe, so überlegte der Kanzler im Januar 1913, elle serait un affreux désastre pour tout le monde excepté pour le Japon et les États-Unis, et la postérité nous traiterait les uns et les autres de fous si nous ne parvenions pas à l'éviter435.

Doch nicht allein dem Reichskanzler, auch dem deutschen Kaiser schrieb der Botschafter zu, prinzipiell um den politischen Ausgleich bemüht zu sein. In den Jahren bis zum Ausbruch des Großen Krieges berichtete Cambon mehrfach über die friedliche Disposition des Kaisers an sein Außenministerium $^{436}$, so daß er schließlich mit Recht unter dem Datum des 22. Juni 1914

433 Vgl. Jules Cambon an Poincaré, 27. 3. 1912, in: CADN, Berlin A 397. In diesem privaten Brief zitierte Cambon Bethmann Hollweg mit den Worten: Nos intentions sont absolument et résolument pacifiques. [...] Je vous assure qu'il n'y aura pas de guerre entre nous, si vous ne nous la déclarez pas [Hervorhebung im Original, St. S.], und der Botschafter fügte hinzu: Je crois à la sincérité $d u$ Chancelier. Vgl. ferner Ders. an Dens., 19. 9. 1912, in: DDF 3, 3, 432 und Ders. an Dens., 4. 1. 1913, in: DDF 3, 5, 172.

434 Il considérerait, so paraphrasierte der Botschafter die Einlassungen des Reichskanzlers, avec horreur les éventualités qui pourraient jeter le monde dans les périls de la guerre. 'Nous sommes, m'a-t-il dit, vous et nous, les deux peuples qui ont la plus baute culture intellectuelle et c'est vraiment un devoir d'bomme civilisé que d'éviter un conflit entre nouse. Zit. Jules Cambon an Poincaré, 28. 7. 1912, in: DDF 3, 3228 . In einem privaten Brief an Poincaré unterstrich der Botschafter noch einmal diese Ausführungen Bethmann Hollwegs. Vgl. Jules Cambon an Poincaré, 28. 7. 1912, in: NL Jules Cambon, MAE, PA-AP 43/58, fol. 46.

435 Zit. Jules Cambon an Jonnart, 29. 1. 1913, in: DDF 3, 5, 280.

436 Vgl. beispielsweise Jules Cambon an Poincaré, 4. 2. 1912, in: DDF 3, 1, 598; Ders. an Pichon, 28. 4. 1913, in: NL Pichon, BIF 4396, fol. 89 und Ders. an Doumergue, 16. 2. 1914, in: DDF 3, 9, 312. 
an den neuen Ministerpräsidenten und Außenminister René Viviani schreiben konnte: J'ai plus d'une fois entretenu vos prédécesseurs des sentiments pacifiques de l'Empereur. [...] L'Empereur aime et veut la paix, très sincèrement ${ }^{437}$. Gleichwohl gilt es zu bemerken, daß insbesondere Hinweise auf den Friedenswillen des Kaisers in den Berichten des Botschafters stets von einschränkenden Bemerkungen begleitet wurden. Zwar zweifelte Cambon nicht am prinzipiellen Friedenswillen des deutschen Monarchen, doch mehr als einmal warf er in seiner Korrespondenz die Frage auf, ob sich der leicht zu beeindruckende Kaiser im entscheidenden Moment nicht als zu schwach erweisen könnte, um die auf eine militärische Konfrontation bedachten Kräfte zu zähmen ${ }^{438}$.

Insbesondere in den letzten Monaten vor Ausbruch des Großen Krieges betonte der Botschafter dieses Motiv seiner Berichterstattung. $\mathrm{Zu}$ diesem Umstand trug nicht unwesentlich eine Unterredung bei, die der belgische Monarch in den ersten Novembertagen mit dem Kaiser und dessen Generalstabschef geführt und von der der belgische Botschafter dann Cambon in Kenntnis gesetzt hatte ${ }^{439}$. In diesem Gespräch hatten sowohl der Kaiser als auch der Generalstabschef mit einem Hinweis auf die Stimmungslage in Frankreich eine militärische Auseinandersetzung als inévitable bezeichnet, und Moltke hatte gar davon gesprochen, daß dieser Konflikt nécessaire ${ }^{440}$ sei. Obgleich sich der Botschafter nicht ganz sicher war, ob die Einlassungen des deutschen Kaisers nicht vielleicht taktischer Natur waren, maß er den Informationen große Bedeutung zu und bemerkte: il est bon de tenir compte de ce fait nouveau que l'Empereur se familiarise avec un ordre d'idées qui lui répugnait autrefois, [...] nous devons tenir notre poudre sèche $e^{441}$. Auch in den folgenden Monaten glaubte Cambon deutliche Anzeichen für einen Gesinnungswandel respektive die geschwächte Widerstandskraft des Kaisers zu erkennen ${ }^{442}$. So berichtete er beispielsweise unter dem Datum des 2. Januar

437 Zit. Jules Cambon an Viviani, 22. 6. 1914, in: DDF 3, 10, 424.

438 Vgl. Jules Cambon an Doumergue, 2. 1. 1914, in: DDF 3, 9, 6; Ders. an Dens., 16. 2. 1914, in: DDF 3, 9, 312 und Ders. an Viviani, 22. 6. 1914, in: DDF 3, 10, 424.

439 Der Inhalt dieses Gespräches war dem Botschafter von seinem belgischen Kollegen mitgeteilt worden. Vgl. Jules Cambon an Pichon, 22. 11. 1913, in: DDF 3, 8, 517. Vgl. auch Ders. an Dens., 24. 11. 1913, in: DDF 3, 8, 522. Zur Wirkung dieser Informationen auf die Staatsführung vgl. auch WILSBERG, Kooperative Momente und Konflikt, S. 157 und Jean STENGERS, Guillaume II et le roi Albert à Potsdam en novembre 1913, in: Bulletin de la classe des lettres et des sciences morales et politiques 7-12 (1993), S. 227-253, hier S. 246-249. Der belgische Historiker macht - unter Nutzung belgischen Archivmaterials - darauf aufmerksam, daß Cambon die Nachrichten nicht ganz authentisch wiedergab.

440 Zit. Jules Cambon an Pichon, 22. 11. 1913, in: DDF 3, 8, 517.

441 Zit. ibid.

442 Vgl. Jules Cambon an Doumergue, 16. 2. 1914, in: DDF 3, 9, 461 und Ders. an Viviani, 22. 6. 1914, in: DDF 3, 10, 424. Vgl. ferner VILLATE, République des diplomates, S. $305 \mathrm{f}$. 
1914 an den Außenminister: Il est incontestable qu'il se manifeste un certain changement dans l'état d'esprit de l'Empereur ${ }^{443}$.

Zeitgleich zu dieser beunruhigenden Entwicklung nahm der Botschafter auch ein Anwachsen der zum Krieg drängenden Kräfte wahr. Daß es im Deutschen Reich Gruppen gab, die unverhohlen den Krieg forderten, stand für den Botschafter außer Zweifel. Er erkannte sie in den Alldeutschen, deren Idol der Kronprinz zu sein schien, und nicht zuletzt auch in der unmittelbaren militärischen Umgebung des Kaisers. Sein Außenministerium machte Cambon gleich mehrfach, insbesondere im Gefolge der Zabern-Affaire, auf dieses Phänomen aufmerksam, das ihn sichtlich besorgte ${ }^{444}$.

Mochte ihm auch der Kanzler versichern, daß es sich bei den Alldeutschen um eine unbedeutende Minderheit handle, der Botschafter war nicht dieser Auffassung. Vielmehr galten ihm die Gruppen, die auf eine militärische Konfrontation bedacht waren, als puissants et babiles ${ }^{445}$, und gerade in den Alldeutschen erkannte er un mauvais levain dans une pâte qui pourrait lever malgré la volonté des hommes d'État ${ }^{446}$. Folgt man den Erinnerungen des Marineattachés, dann hatte sich die Zukunftserwartung des Botschafters im März 1914 schon soweit verdunkelt, daß er sowohl ihn als auch den Militärattaché nach Paris sandte, pour dire une fois encore que la paix $d u$ monde est menacée ${ }^{447}$. Faramonds Schilderung der Ereignisse dürfte wohl etwas überzeichnet sein, denn zumindest in den ersten Monaten des Jahres 1914 erkannte der Botschafter noch keine unmittelbare Kriegsgefahr ${ }^{448}$. Gleichwohl ist nicht zu verkennen, $\mathrm{da} ß$ sich die Berichterstattung des Botschafters in diesem Zeitraum deutlich pessimistischer ausnahm als noch in den Monaten zuvor $^{449}$. Man wird diesen Pessimismus sicherlich nicht allein vor dem Hinter-

443 Zit. Jules Cambon an Doumergue, 2. 1. 1914, in: DDF 3, 9, 6.

444 Vgl. Jules Cambon an Doumergue, 2. 1. 1914, in: DDF 3, 9, 6; Ders. an Dens., 19. 1. 1914, in: DDF 3, 9111 ; Ders. an Dens., 2. 2. 1914, in: DDF 3, 9205 und Ders. an Dens., 16. 2. 1914, in: DDF 3, 9 312. Die friedliche Disposition der Reichsleitung hatte Jules Cambon schon rund ein Jahr zuvor in einem privaten Brief an Pichon dem Treiben der Alldeutschen und des Kronprinzen gegenübergestellt. Vgl. Jules Cambon an Pichon, 28. 4. 1913, in: NL Pichon, BIF 4396, fol. 89.

445 Zit. Jules Cambon an Doumergue, 16. 2. 1914, in: DDF 3, 9, 312.

446 Zit. Jules Cambon an Viviani, 22. 6. 1914, in: DDF 3, 10, 424.

447 Zit. Gontran M. A. de FARAmOND, Souvenirs d'un attaché naval en Allemagne et en Autriche 1910-1914, Paris 1932, S. 152. Vgl. auch: Serret an Noulens, 20. 4. 1914, in: DDF 3, 10, 131.

448 Vgl. Jules Cambon an Doumergue, 16. 2. 1914, in: DDF 3, 9, 312; Ders. an Dens., 3. 5. 1914, in: DDF 3, 10, 194 und Ders. an Viviani, 22. 6. 1914, in: DDF 3, 10, 424.

449 Auch für Paul Cambon läßt sich in diesem Zeitraum ein merklicher Wandel konstatieren. Hatte der erfahrene Diplomat seinem Bruder noch unter dem Datum des 1 . Oktober 1913 geschrieben: Tu es très pessimiste, trop pessimiste à mon sens. [...] Tant que l'empereur Guillaume sera là, je ne crois pas à l'imminence d'un conflit. [...] Ni l'empereur, ni Bethmann-Holweg [sic] ni Jagow, ne paraissent bommes à nous chercher une mauvaise querelle. Zit. Paul Cambon an Jules Cambon, 1.10.1913, in: NL Paul Cambon, MAE, PA-AP 42/68, fol. 104. Die Passage wurde gestrichen in: Cambon-Correspondance III, S. 51 f. So fand er schon Ende November 1913 die Atmosphäre allzu an- 
grund der innerfranzösischen Auseinandersetzung um die loi des trois ans verstehen und mithin als taktisch motiviert deuten können. Denn auch in seiner privaten Korrespondenz lassen sich Hinweise darauf finden, daß dem erfahrenen Botschafter die Zukunft im Frühjahr 1914 nichts Gutes mehr zu verheißen schien. Unter dem Datum des 4. Januar 1914 schrieb er an einen alten Freund seines Bruders: Ce qui me frappe, c'est l'espèce de renouveau de l'esprit militaire et de passion chauvine qui apparaît en Allemagne, et particulièrement dans les milieux que nous fréquentions. On en veut à Bethmann et je me demande si l'Empereur n'aura pas plus de difficulté que dans le passé à maintenir sa ligne de conduite 450 .

Folgt man den Erinnerungen Chambruns, dann scheint es gar, als habe der Botschafter, der sich seit seinem Amtsantritt beharrlich für eine Politik des Ausgleichs eingesetzt hatte ${ }^{451}$, seine Bemühungen scheitern sehen, und als habe ausgerechnet er, der den Politischen Direktor des Außenministeriums noch im Mai 1912 vor den Konsequenzen eines Fatalismus warnte, dem die Unvermeidlichkeit des militärischen Konflikts zum Fluchtpunkt des außenpolitischen Denkens geworden war, letztlich resigniert ${ }^{452}$. Hatte Cambon damals noch gegenüber Paléologue darauf beharrt, qu'on s'amusât pas à jouer avec le feu en parlant de guerre inévitable. Il n'y a rien d'inévitable en ce monde ${ }^{453}$, so erklärte er dem Ersten Sekretär an der französischen Botschaft in Sankt Petersburg nun:

Ici, en Allemagne, l'opinion se laisse aller de plus en plus aux pensées belliqueuses [...]. Jusqu'à présent, Guillaume II demeure pacifique, mais combien de temps sa volonté de paix continuera-t-elle à prévaloir? Avec l'áge, elle devient fléchissante, tandis que s'affermit la volonté de guerre de son entourage. Celle-ci, dans la balance des forces finira par l'emporter. Nous avons assisté, l'année dernière, aux manifestations du centenaire de 1813; cette année, on en prépare de plus imposantes encore pour commémorer le centenaire de 1814. Le verrai-je? Je l'ignore. Mais quand on célébrera celui de 1815, je sais que je ne serai plus dans cette ambassade ${ }^{454}$.

Geteilt wurden diese Einschätzungen des Botschafters auch von Frankreichs militärischen Beobachtern in der Reichshauptstadt, deren Berichte

gespannt und bekannte im Februar 1914: Je commence à voir l'avenir en noir [...]. L'affaire de Saverne a donné au parti militaire une occasion de triomphe, et le chancelier, l'empereur lui-même, ont dîu baisser pavillon devant les porteurs de sabre. Vgl. Paul Cambon an Jules Cambon, 26.11. 1913, in: Cambon-Correspondance III, S. 55 und Ders. an Dens., 3. 2. 1914, in: ibid., S. 62.

450 Zit. Enrico SerRA, Lettres de Jules Cambon à Alberto Pansa, in: Revue d'historie diplomatique 116 (2002), S. 83-90, hier S. 87. Auch Paul Cambon hat den Pessimismus seines Bruders nicht als taktisch motiviert gedeutet. Vgl. Paul Cambon an Jules Cambon, 3. 2. 1914, in: Cambon-Correspondance III, S. 62. Zur gewandelten Lageeinschätzung Cambons vgl. auch VILlaTE, République des diplomates, S. 306.

$451 \mathrm{Vgl}$. hierzu insbesondere KeIGER, Jules Cambon.

452 Vgl. Jules Cambon an Paléologue, 20. 5. 1912, in: NL Jules Cambon, MAE, PA-AP 43/56, fol. 203. Ein Entwurf dieses Briefes findet sich auch in: CADN, Berlin A 397. 453 Zit. ibid.

454 Zit. Charles de Chambrun, L'Esprit de la diplomatie, Paris 1944, S. 61. 
um so weniger zu vernachlässigen sind, als sie zunächst stets an das Außenministerium gesandt, von dieser Stelle dann an das Kriegsministerium und mitunter auch an den Präsidenten weitergeleitet wurden und damit den politischen Entscheidungsträgern als zusätzliche Informationsquelle zur Verfügung standen.

Sowohl in seiner amtlichen als auch in seiner privaten Korrespondenz vertrat Militärattaché Pellé die Ansicht, daß die Reichsleitung nicht auf eine militärische Konfrontation bedacht, sondern um den politischen Ausgleich bemüht sei. Je suis absolument convaincu, so lautete seine kontinuierlich nach Paris übermittelte Einschätzung, que l'Empereur et le Chancelier sont pacifiques $^{455}$. [L]'Empereur et le Chancelier veulent la paix et non seulement qu'ils ne se sentent pas les plus forts en ce moment, mais d'une manière permanente 456 .

Nicht die Außenpolitik der Reichsleitung beunruhigte den Militärattaché, sondern es war die Stimmung, die er in Deutschland wahrnahm, die ihm sichtlich Sorgen machte und die ihn für die Zukunft eine militärische Konfrontation erwarten ließ. Wohlgemerkt: Nicht in dem Sinne, daß Pellé der Ansicht gewesen wäre, daß eine Mehrheit der Deutschen Krieg mit ihren Nachbarn zu führen wünschte ${ }^{457}$ - diese Absicht glaubte er nur innerhalb der kleinen, gleichwohl in seinen Augen nicht unbedeutenden Gruppe der Alldeutschen zu erkennen ${ }^{458}$. Doch was den Militärattaché mit Blick auf die Verhältnisse im Reich beunruhigte, war der Umstand, daß er eine große Mehrheit der Deutschen von Sehnsüchten getrieben sah, die weit über ihr angestammtes Territorium und Europa hinausgriffen.

455 Zit. Pellé an Messimy, 16. 12. 1911, in: DDF 3,1 351. Da Messimy im Kabinett Poincaré nicht mehr vertreten war, resümierte der Militärattaché unter dem Datum des 29. Januar 1912 in einem langen Brief an Joffre seine Berichterstattung. Vgl. Pellé an Joffre, 29. 1. 1912, in: NL Pellé, BIF 4405/11, fol. 268: J'ai dit dans mes rapports que l'Empereur et le Chancelier désiraient sincèrement la paix avec nous. C'est chez moi une croyance fondée sur de nombreux faits concordants [...] le gouvernement allemand est pacifique, je n'en doute pas.

456 Zit. Pellé an Joffre, 5. 4. 1912, in: NL Pellé, BIF 4405/11, fol. 302: Entsprechende Urteile lassen sich auch in folgenden Berichten finden: Pellé an Millerand, 21. 1., 3. 2. und 26. 5. 1912, in: SHA 7N1111 sowie DDF 3, 1, 588 und DDF 3, 3, 45. Aus der privaten Korrespondenz mit dem französischen Militärattaché in London vgl. in diesem Zusammenhang: Pellé an de la Panouse, 9. 2. 1912, in: NL Pellé, BIF 4405/11, fol. $281 \mathrm{f}$. Vgl. auch den Bericht, den der russische Militärattaché über eine Unterredung mit Pellé nach Sankt Petersburg sandte. Vgl. Basarow an Danilow, 1. 3. 1912, in: IB III/2,2 635. 457 Vielmehr war der Militärattaché durchaus überzeugt, daß eine Mehrheit der Deutschen friedlich gesinnt sei. Vgl. Pellé an Millerand, 3. 2. 1912, in: DDF 3, 1, 588; Ders. an Dens., 1. 4. 1912, in: DDF 2, 2, 285 und Ders. an Dens., 26. 5. 1912, in: DDF 3, 3, 45. Aus seiner privaten Korrespondenz mit dem Generalstabschef vgl. Pellé an Joffre, 29. 1. 1912, in: NL Pellé, BIF 4405/11, fol. 270 f., 275 sowie Ders. an Dens., 5. 4. 1912, in: NL Pellé, BIF 4405/11, fol. 303.

458 Vgl. Pellé an Millerand, 3. 2. 1912, in: DDF 3, 1, 588 und Ders. an Dens., 26. 5. 1912, in: $\mathrm{DDF} 3,3,45$. 
In seinen Briefen und Berichten entwarf Pellé das Bild einer Nation mit überschäumendem Kraftgefühl, die aus ihrer wirtschaftlichen Entfaltung, ihrer demographischen Entwicklung und ihrer militärischen Kraft ein gleichsam natürliches Recht auf Expansion ableitete und die dort, wo ihren Ambitionen die Interessen anderer Großmächte entgegentraten, diese als ungebührliche Zudringlichkeit empfand: Les allemands ont toujours besoin de débouchés, d'expansion économique et coloniale. Ils estiment qu'ils y ont droit, parce qu'ils grandissent tous les jours, parce que l'Avenir leur appartient 459 . Ausgestattet mit einer furchterregenden Macht glaubte sich das Deutsche Reich nicht allein in der Lage, sondern war nach Auffassung Pellés auch willens, Europa den Frieden auch ohne Krieg nach seinen Konditionen zu diktieren. Les allemands, so berichtete der Militärattaché, ont une manière à eux de concevoir la paix, qui est particulière; ils veulent être les maîtres ${ }^{460}$.

Die hochfahrenden Ambitionen des Deutschen Reiches hatten aber einen mächtigen Dämpfer und eine fast grausame Enttäuschung erlitten, als ihnen in der Marokkokrise eine Nation die Stirn geboten hatte, auf die man bislang verächtlich herabzublicken gewohnt war. Das Abkommen, mit dem das Deutsche Reich die Herrschaft Frankreichs in Marokko anerkannt hatte, wurde nach der Auffassung des Militärattachés von einer sehr großen Mehrheit der Deutschen - mochte es ihnen auch als Kompensation ein nicht unbeträchtliches Territorium in Mittelafrika eingetragen haben - als bittere Niederlage, gar als ein neues Olmütz empfunden ${ }^{461}$. In einer erneuten internationalen Krise würde das sich gedemütigt wähnende Reich deshalb jede Konzession als unerträglichen Prestigeverlust empfinden und keinen politischen Vergleich mehr hinnehmen: On ne veut plus de traité acbeté par des concessions $^{462}$.

In dieser Stimmungslage erkannte der Militärattaché das den Frieden bedrohende Faktum, zumal zu befürchten stand, daß die auf eine militärische Konfrontation drängenden Kräfte im Deutschen Reich sie im entscheidenden Augenblick zu nutzen wissen würden. On a l'impression, so bemerkte Pellé in einem seiner langen Briefe an den Militärattaché in London, que sous

459 Zit. Pellé an Joffre , 26. 5. 1912, in: DDF 3, 3, 45: Vgl. ferner Pellé an Millerand, 1. 4. 1912, in: DDF 3, 2, 285 und Ders. an de la Panouse, 24. 5. 1912, in: NL Pellé, BIF 4405/ 11 , fol. 324.

460 Zit. Pellé an Joffre, 5. 4. 1912, in: NL Pellé, BIF 4405/11, fol. 303. Mit ähnlichen Worten auch schon in Pellé an Joffre, 29. 1. 1912, in: NL Pellé, BIF 4405/11, fol. 271. Vgl. auch Pellé an de la Panouse, 9. 2. 1912, in: NL Pellé, BIF 4405/11, fol. 281: Les allemands en majorité ne comprennent qu'une paix imposée par eux où ils seront les mâे tres [Hervorhebung im Original, St. S.].

461 Vgl. insbesondere Pellé an Millerand, 26. 5. 1912, in: DDF 3, 3, 45. Vgl. ferner die übereinstimmenden Berichte Jules Cambons, der noch Monate später die Auswirkungen des Abkommens vom 4. November 1911 mit nahezu identischen Worten beschrieb. Vgl. Jules Cambon an Pichon, 30. 3. 1913, in: DDF 3, 6, 121 und Ders. an Doumergue, 3. 5. 1914, in: DDF 3, 10, 194.

462 Zit. Pellé an Joffre, 29. 1. 1912, in: NL Pellé, BIF 4405/11, fol. 271. 
La pression des sentiments que je te décrivais, ce petit parti pouvait à un moment donné brusquement entraîner la masse et que l'opinion forcerait la main à l'Empereur et conduirait l'Allemagne à la guerre ${ }^{463}$. Auch der Militärattaché warf mithin die Frage auf, ob sich der deutsche Kaiser in einer erneuten internationalen Krise nicht als zu schwach erweisen könnte, um die erhobenen Forderungen auf ein mit dem Frieden verträgliches $\mathrm{Maß}$ zu beschränken - zumal Wilhelm II. nach der Überzeugung Pellés in der letzten Marokkokrise einen großen Teil seiner moralischen Autorität verloren und damit beträchtlich an Einfluß eingebüßt hatte ${ }^{464}$.

Aus dem, was der Militärattaché im Deutschen Reich wahrnahm, zog er eine einfache Folgerung: Eine militärische Auseinandersetzung - mochte sie auch nicht unmittelbar bevorstehen und möglicherweise nicht einmal für die nahe Zukunft zu erwarten sein - war letztlich doch nur noch eine Frage der Zeit ${ }^{465}$. Denn als in den ersten Monaten des Jahres 1912 erste Nachrichten eine außergewöhnlich umfangreiche deutsche Aufrüstung erwarten ließen, empfahl er umgehend - aus Angst vor den durch Frankreich nicht zu konternden deutschen Anstrengungen - den Präventivkrieg 466.

Die Berichte, die seit 1913 aus der Feder seines Nachfolgers entstanden, waren nicht dazu angetan, das Bild in Frage zu stellen, das Pellé von der Lage der Dinge im Deutschen Reich entworfen hatte. Auch Serret betonte, daß die Reichsleitung nicht auf eine militärische Konfrontation bedacht sei ${ }^{467}$, und auch er gab mehr als einmal der Befürchtung Ausdruck, qu'en présence d'un très fort mouvement d'opinion le Gouvernement pourrait très bien se trouver débordét68. Daß es im Deutschen Reich unterschiedliche Gruppen gab, die unverhohlen den Krieg forderten, sei es, um genuin außenpolitische Interes-

463 Zit. Pellé an de la Panouse, 24. 5. 1912, in: NL Pellé, BIF 4405/11, fol. 325.

${ }^{464} \mathrm{Vgl}$. Pellé an Joffre, 29.1. 1912, in: NL Pellé, BIF 4405/11, fol. 269. Auf die geschwächte Stellung des Kaisers kam Pellé auch in seinem Brief vom 5. April 1912 zurück. Vgl. Ders. an Dens., 5. 4. 1912, in: NL Pellé, BIF 4405/11, fol. 303. Vgl. ferner Pellé an de la Panouse, 9.2. und 24. 5. 1912, in: NL Pellé, BIF 4405/11, fol. 281, 324. Was die amtliche Korrespondenz des Militärattachés betrifft, so findet man entsprechende Hinweise in den Berichten vom 3. Februar und 26. Mai 1912. Vgl. DDF 3, 1, 588 und DDF 3, 3, 45.

465 In einem Brief an den Generalstabschef gab der Militärattaché unter dem Datum des 26. Mai 1912 der Ansicht Ausdruck, daß man nach der Durchführung der deutschen Aufrüstung im Frühjahr 1913 in eine période critique eintreten werde, qui pourra se prolonger plus ou moins longtemps. Zit. Pellé an Joffre, 26. 5. 1912, in: NL Pellé, BIF 4405/11, fol. 330.

466 Vgl. Pellé an Joffre, 29. 1. 1912, in: NL Pellé, BIF 4405/11, fol. 275 f. und Pellé an de la Panouse, 9. 2. 1912, in: NL Pellé, BIF 4405/11, fol. $283 \mathrm{f}$.

$467 \mathrm{Vgl}$. Serret an Étienne, 1. 3. 1913, in: DDF 3, 5, 494 und Ders. an Dens., 15. 3. 1913 , in: DDF 3, 6, 12, Annexes I. Vgl. ferner Ders. an Dens., 25. 5. 1913, in: DDF 3, 6, 613; Ders. an Noulens, 15. 2. 1914, in: DDF 3, 9, 305 und Ders. an Dens., 20. 4. 1914, in: DDF 3, 10, 131.

468 Zit. Serret an Noulens, 15. 3. 1914, in: DDF 3, 9, 461. Vgl. auch Ders. an Dens., 20. 4. 1914, in: DDF 3, 10, 131. 
sen durchzusetzen, sei es, weil sie in der militärischen Konfrontation ein Mittel zur Bewahrung des gesellschaftlichen Status quo erkannten, war auch Serret eine Gewißheit ${ }^{469}$, und in noch deutlicheren Worten als sein Vorgänger beschrieb auch er jenes überschäumende Kraftgefühl der Nation ${ }^{470}$. In ihm glaubte der Militärattaché auch die treibende Kraft hinter der deutschen Aufrüstung im Jahr 1913 erkennen zu können ${ }^{471}$. Wohlgemerkt: Nicht in dem Sinne, daß er der Ansicht gewesen wäre, daß man im Deutschen Reich den Entschluß zur militärischen Konfrontation gefaßt hätte und mit Blick auf einen bestimmten Zeitpunkt sich einen militärischen Vorsprung anzueignen suchte. Zwar nahmen sowohl der französische Generalstab als auch Serret aufmerksam die ungewöhnliche Hast wahr, mit der das Deutsche Reich seine in den Jahren 1912 und 1913 beschlossenen Maßnahmen in die Realität umsetzte $^{472}$. Doch wenn der Verfasser dieser Untersuchung die Quellenlage vollständig zu überblicken vermag, dann kann die These, daß man in Frankreich der Überzeugung gewesen sei, die Aufrüstung des Reiches stehe im Dienst der Vorbereitung einer militärischen Konfrontation, auf keinen validen Beleg gestützt werden ${ }^{473}$.

Nicht mit dem Instrument des Krieges, wohl aber mit dem Mittel überlegener militärischer Drohung versuchte man, der Einschätzung Serrets zufolge, seine Ziele durchzusetzen. sDeutschland, Deutschland über alles/ Il faut que tout recule devant elle. Sans avoir d'intentions belliqueuses, elle est décidée à se constituer une force militaire d'une supériorité impressionnante. Elle veut, so berichtete der Militärattaché, que dans les conflits [...] le poids de

$469 \mathrm{Vgl}$. Serret an Etienne, 25. 5. 1913, in: DDF 3, 6, 613 und Ders. an Noulens, 15. 2. 1914, in: DDF 3, 9, 305.

470 Vgl. Serret an Millerand, 5. 12. 1912, in: DDF 3, 5, 5; Ders. an Dens., 23. 12. 1912, in: SHA 7N1111. Vgl. auch Ders. an Dens., 31. 1. 1913, in: DDF 3, 5, 302; Ders. an Dens., 1. 3. 1913, in: DDF 3, 5, 494; Ders. an Dens., 15. 3. 1913, in: DDF 3, 6, 12, Annexes I. Vgl. ferner Ders. an Dens., 25. 5. 1913, in: DDF 3, 6, 613; Ders. an Dens., 5. 7. 1913, in: DDF 3, 7, 292; Ders. an Noulens, 15. 3. 1914, in: DDF 3, 9, 461 und Ders. an Dens., 20. 4. 1914, in: DDF 3, 10, 131. In seinem Bericht von 20. April 1914 faßte Serret seine Lageeinschätzung mit folgenden Worten zusammen: Il y a ici deux courants très nets et distincts: celui de l'Empereur avec le Chancelier, tous deux sérieux et pacifiques. En face, le Kronprinz, belliqueux et très populaire. Et puis, il y a la masse de la nation, qui a été, comme je l'ai dit souvent, déçue et bumiliée par le traité marocain et qui, cette année, est chauffée et surexcitée par le centenaire des guerres de Délivrance. Il est impossible de prévoir quels remous pourront, le cas échéant, agiter cette masse et amener une tempête. Zit. Serret an Noulens, 20. 4. 1914, in: DDF 3, 10, 131.

471 Vgl. Serret an Étienne, 20.1. 1913, in: DDF 3, 5, 239. Vgl. auch Ders. an Dens., 1. 3. 1913, in: DDF 3, 5, 494 und Ders. an Dens., 15. 3. 1913, in: DDF 3, 5, 593, dort irrtümlich auf den 14. 3. 1913 datiert. Vgl. auch Serret an Étienne, 5. 7.1913, in: DDF 3, 7, 292. $472 \mathrm{Vgl}$. Serret an Étienne, 15. 2. 1913, in: DDF 3, 5, 404. Vgl. ferner Nouvelle loi militaire allemande, 21. 3. 1914, in: SHA 7N1784 und Situation militaire de l'Allemagne, Juni 1914, in: SHA 7N1771.

473 Allein Paléologue scheint dies an einer Stelle seines Tagebuches anzudeuten. Vgl. PALÉOLOGUE, Journal, S. 56 (Eintrag vom 21. 2. 1913). 
son épée fasse immédiatement pencher la balance sans même qu'il soit nécessaire de sortir la lame du fourreau ${ }^{474}$.

Das Bild, das die Militärattachés in ihrer amtlichen und persönlichen Korrespondenz von der Lage der Dinge im Deutschen Reich entwarfen, hatte folgenreiche Konsequenzen. Insbesondere Joffre hatte ein uneingeschränktes Vertrauen in die Urteilskraft Pellés, der schon in Afrika zum Kreis seiner Mitarbeiter gehört hatte und den er nach Ausbruch des Großen Krieges umgehend in seinen persönlichen Stab berufen sollte $e^{475}$. Auf der Grundlage seiner Berichte zeigte sich der Generalstabschef schon nach kurzer Zeit von der Unvermeidlichkeit einer militärischen Konfrontation mit dem Deutschen Reich überzeugt. In seinen Erinnerungen berichtet General Georges-René Alexandre ${ }^{476}$, daß Joffre ihm in den ersten Monaten des Jahres 1912 auf die Frage, ob er denn tatsächlich an die Schicksalhaftigkeit dieses Krieges glaube, geantwortet habe: Si, j'y pense, j'y pense même toujours: nous l'aurons, je la ferai, je la gagnerai ${ }^{477}$, und Anfang Juli 1914 vertraute Joffre auch seinem Kabinettschef Gamelin an: Le sort en est jeté, la guerre est probable, elle est proche, nous reprendrons l'Alsace et la Lorraine $e^{478}$.

Ähnliche Erwartungen lassen sich auch bei Castelnau nachweisen. So erinnerte sich die ehemalige Ordonnanz des Generals, Léon Zeller, nach dem Krieg an ein Gespräch, das im Herbst 1912 stattgefunden und in dem Castelnau im wesentlichen nur über ein Thema gesprochen hatte: L'imminence d'un inévitable conflit qui se généraliserait et mettrait le feu à l'Europe, à une échéance qui ne pouvait guère dépasser deux ou trois ans ${ }^{479}$. Bereits im Juni 1913 griff Castelnau gegenüber Zeller dieses Thema erneut auf und versicherte seinem Ordonnanzoffizier abermals: Deux années ne passeraient certainement pas avant la grande conflagration 480 .

474 Zit. Serret an Étienne, 1. 3. 1913, in: DDF 3, 5,494.

$475 \mathrm{Vgl}$. Georges-René AlEXANDRE, Avec Joffre d'Agadir à Verdun. Souvenirs 19111916, Paris 1932, S. 8 f.

476 Georges-René Alexandre war in den Jahren zwischen 1911 und 1914 Mitglied des Kabinetts des Generalstabschefs. Vgl. JofFrE, Mémoires, Bd. I, S. 166. Vgl. auch die Einleitung zu: ALEXANDRE, Avec Joffre, VIIf.

477 Zit. AleXANDre, Avec Joffre, S. 12. Im Jahr 1913 soll der Generalstabschef ihm diese Einsicht noch einmal ausdrücklich bestätigt haben. Vgl. ibid. Auch in den Erinnerungen Paul-Boncours findet sich ein entsprechender Hinweis. So erklärte der Generalstabschef dem Abgeordneten, der im Jahr 1913 einen alternativen Vorschlag zur Einführung der loi des trois ans gemacht hatte, rückblickend: La guerre était plus proche encore que nous ne le supposions, Messimy et moi, et, avec nous, ceux qui nous faisaient confiance. Zit. Joseph PAUL-BONCOUR, Entre deux guerres: souvenirs sur la III République, Bd. I: Les luttes républicaines 1877-1918, Paris 1945, S. 235.

$478 \mathrm{Zit}$. Louis GARRoS, L'armée de grand-papa: de Gallifet à Gamelin. 1871-1939, Paris 1965, S. 206. Garros erhielt diese Nachricht von Gamelin, der ein Freund des Historikers war. Vgl. GarRos, L'armée, S. 267.

479 Dieser Satz ist den Erinnerungen Zellers entnommen, die sich in privatem Besitz befinden, und wird hier zitiert nach GRAS, Castelnau, S. 132.

480 Zit. ibid., S. 138. Ähnlich pessimistische Urteile lassen sich auch in der privaten 
Doch nicht allein auf die militärische, auch auf die politische Führung Frankreichs haben die Berichte Wirkung gehabt, die aus dem Deutschen Reich eintrafen. Folgt man den Aufzeichnungen des Politischen Direktors des Quai d'Orsay, dann haben die Berichte Außenminister Stéphen Pichon sehr besorgt ${ }^{481}$ und ihn schließlich, als er im November 1913 von den Einlassungen des deutschen Kaisers gegenüber dem belgischen Monarchen erfuhr, die militärische Konfrontation für unvermeidlich erachten lassen. Pichon, so berichtet Paléologue, qui les lit précipitamment, d'un regard effaré, les mains tremblantes. Puis, après un long silence baletant, il me dit:-Maintenant, tous les voiles sont déchirés... Nous n'avons plus le droit de nous faire aucune illusion. [...] La guerre est désormais inévitable ${ }^{482}$. Der Außenminister brachte den Bericht des Botschafters umgehend sowohl dem Präsidenten als auch dem Ministerpräsidenten und dem Generalstabschef zur Kenntnis. Den Gedanken, daß es sich dabei möglicherweise um eine wohl kalkulierte Einlassung des Kaisers handeln könnte, verwarf Pichon im Gespräch mit diesen Personen ausdrücklich ${ }^{483}$. Nicht weniger pessimistisch nahm sich, derselben Quelle zufolge, die Erwartung von Pichons Nachfolger Viviani aus, dem die Zukunft sehr düster schien und in dessen Augen der große Krieg plötzlich ausbrechen konnte ${ }^{484}$.

Auch auf den Politischen Direktor haben die Berichte, die am Quai d'Orsay aus dem Deutschen Reich eintrafen, tiefen Eindruck gemacht und ihn außerordentlich beunruhigt, was seinen Grund nicht zuletzt in der charakterlichen Disposition Paléologues gehabt haben mag. Der für seine Nervosität, seine Phantasie und seinen Pessimismus ${ }^{485}$ bekannte Politische Direktor

Korrespondenz des Generals nachweisen. Vgl. unter Benutzung privaten Archivgutes: Gras, Castelnau, S. 144.

481 Vgl. PALÉlOGUe, Journal, S. $82 \mathrm{f}$. (Eintrag vom 22. 3. 1913).

482 Zit. PAlÉologue, Journal, S. 238 (Eintrag vom 25.11. 1913). Vgl. in diesem Zusammenhang auch PALÉOLOGUE, Journal, S. 242 f., 245 f., $251 \mathrm{f}$. (Einträge vom 28. 11., 1. 12. und 8. 12.1913).

$483 \mathrm{Vgl}$. Indications données par M. Stéphen Pichon à M. de Margerie, 18. 10. 1918, in: MAE, NS Allemagne 51, fol. 202. Seiner ernsten Besorgnis gab der Außenminister auch in einer Unterredung mit dem russischen Botschafter Ausdruck. Vgl. Iswolski an Sasonow, 4. 12. 1913, in: STIEVE, Iswolski-Schriftwechsel III, 1154: Nach ganz zuverlässigen Nachrichten, die er hat [gemeint ist Pichon, St. S.], beginnt gegenwärtig Kaiser Wilbelm, der sich bis jetzt persönlich durch überaus friedliebende Gefüble gegenüber Frankreich auszeichnete und sogar immer von einer Annäberung an Frankreich träumte, immer mebr der Ansicht derjenigen Personen aus seiner Umgebung, besonders aus militärischen Kreisen, zuzuneigen, die von der Unvermeidlichkeit eines französischdeutschen Krieges überzeugt sind, und deshalb glauben, daß ein solcher, je früber er ausbreche, desto günstiger für Deutschland sein werde.

484 Vgl. PalÉOlOGUE, Journal, S. 268 (Eintrag vom 7. 1. 1914). Vgl. ferner Jean Rives, Gaston Doumergue: du modèle républicain au sauveur suprême, Toulouse 1992, S. 133 und HAYNE, French Foreign Office, S. $251 \mathrm{f}$.

485 Zit. Sewastopoulo an Sasonow, 15. 1. 1914, in: IB I/1 16. Es war niemand geringeres als Paléologues Nachfolger im Amt des Politischen Direktors, Pierre de Margerie, der seinen ehemaligen Vorgesetzten mit diesen Worten beschrieb. 
wurde von seinen Kollegen oftmals als romancier ${ }^{486}$ und alarmiste ${ }^{487}$ charakterisiert, man attestierte ihm ein Talent, aus Mücken Elephanten zu fabrizieren ${ }^{488}$, glaubte, daß er excitable sei und inclined to spread sensational and alarmist rumours ${ }^{489}$.

Paléologue kam im Gespräch mit unterschiedlichen Personen bis zur Julikrise auf die Einlassungen des Kaisers aus dem November 1913 zurück. Gegenüber Lord Granville sprach er im Dezember von den very disquieting remarks ${ }^{490}$ des deutschen Kaisers und vertraute ihm im Geheimen an, that the Emperor had declared to His Majesty that war between France and Germany was inevitable, and the General von Moltke, the Chief of the Staff, has used the same expression to His Majesty and had added that it was even desirable and that ,dans un bref délai ${ }^{491}$. Ein taktisches Moment vermochte Paléologue - zumindest im Gespräch mit dem britischen Diplomaten - in den Einlassungen des Kaisers nicht zu erkennen ${ }^{492}$. Dem russischen Außenminister und dem britischen Botschafter berichtete Paléologue dann im Februar 1914 von der allgemeinen politischen Lage Europas, in der er the danger of our being surprised by some sudden move on the part of Germany erkannte und die der Triple Entente die Pflicht auferlege: We must not, therefore, allow ourselves to be taken unprepared. Seine Befürchtungen begründete er mit einem Hinweis auf die Einlassungen des deutschen Kaisers aus dem November 1913 und fügte darüber hinaus noch hinzu, daß sich angeblich auch der öster-

486 Zit. Jules Cambon an Paul Cambon, 16. 12. 1912, in: NL Jules Cambon, MAE, PAAP 43/100, fol. 83. Jules Cambon gab in seinem Schreiben das Urteil Daneffs, des bulgarischen Parlamentspräsidenten, wieder. Vgl. ferner Quelques-uns de mes anciens chefs, in: NL de Robien, AN, 427 AP 5, fol. 120.

487 Zit. Nicolson an Goschen, 18. 5. 1914, in: BD 10/2, 510. Vgl. auch Ders. an Buchanan, 18. 5. 1914, in: NL Nicolson, PRO, FO 800/374, fol. 47. Vgl. ferner Buchanan an Nicolson, 23. 12. 1914, in: NL Nicolson, PRO, FO 800/376, fol. 42.

488 Zit. Czernin an Berchtold, 17. 1. 1914, in: ÔUA 7, 9201.

489 Zit. Bertie an Grey, 26. 1. 1912, in: PRO, FO 371/1366, fol. 96. Der britische Botschafter gab das Urteil des britischen Kollegen Paléologues in Sofia wieder und fügte hinzu: I am inclined to believe from what I have beard of $M$. Paleologue bere that $M r$. Findlay's estimate of him was in no way exaggerated. Vgl. auch Bertie an Nicolson, 26. 1. 1912, in: NL Bertie, PRO, FO 800/165, fol. 133. Bertie schildert hier die Meinung des französischen Botschafters in Spanien.

490 Zit. Granville an Nicolson, 4. 12. 1913, in: BD 10/2, 430.

491 Zit. ibid.

492 Auch dem ehemaligen Ministerpräsidenten Alexandre Ribot berichtete Paléologue noch im Dezember von den Einlassungen des deutschen Kaisers; er bemerkte aber nun, daß die Frage erlaubt sei, si son langage n'était pas calculé. Zit. 28 déc[embre] 1913 conversation avec Paléologue, in: NL Ribot, AN, 563 AP 5. Der nicht ganz eindeutigen Notiz Ribots läßt sich nicht entnehmen, ob der Politische Direktor damit seine eigenen Gedanken, oder - wie noch in anderem Zusammenhang zu zeigen sein wird - diejenigen Poincarés ausgesprochen hatte. Die Informationen beschäftigten den ehemaligen Ministerpräsidenten jedenfalls noch in den folgenden Monaten. Vgl. Les carnets de Georges Louis. Directeur des affaires politiques au ministère des Affaires étrangères, ambassadeur en Russie (1908-1917), Bd. II, Paris 1926, S. 95 f. (Eintrag vom 25. 1. 1914). 
reichische Kaiser in einem Gespräch mit dem spanischen Monarchen sehr beunruhigt über die somewhat bellicose view of the Emperor William ${ }^{493}$ gezeigt habe.

Noch im Juli 1914 gab Paléologue seinem Pessimismus in einem Gespräch mit dem russischen Monarchen Ausdruck, der ihn auf seine düstere Analyse der Lage angesprochen hatte. Obgleich er im Moment keinen besonderen Anlaß habe, eine militärische Auseinandersetzung zu befürchten, glaube er doch, daß sich im Deutschen Reich eine Stimmung entwickelt habe, die es der Reichsleitung unmöglich mache, selbst anläßlich eines marginalen $\mathrm{Zwi}$ schenfalls eine konziliante Haltung einzunehmen. Doch nicht allein der oftmals formulierten Sorge, daß sich im entscheidenden Augenblick die Reichsleitung als zu schwach erweisen könnte, um die auf eine militärische Konfrontation bedachten Kräfte zu zähmen, gab Paléologue Ausdruck. Darüber hinaus warf er in diesem Gespräch auch die Frage auf, ob der deutsche Kaiser den Krieg überhaupt noch vermeiden wolle, und gab sich selbst und dem russischen Monarchen die Antwort: En toute sincérité, Sire, je ne le pense pas ${ }^{494}$.

Begreift man diese Ausführungen als einen authentischen Ausdruck der Befürchtungen, die Paléologue im Hinblick auf das Deutsche Reich umtrieben, dann läßt sich konstatieren, daß der ehemalige Politische Direktor des Außenministeriums die Erwartung einer militärischen Konfrontation interessanterweise nicht mit einem Hinweis auf einen fundamentalen oder gar akuten Interessensgegensatz zwischen dem Deutschen Reich und Frankreich verknüpfte. Mit dieser Beobachtung ordnet sich aber das Gespräch, das $\mathrm{Pa}$ léologue im Juli 1914 mit dem russischen Monarchen führte, in die Forschungsergebnisse der Historiker ein, die den Hinweis aufgegriffen haben, daß es gleichfalls lohnend sei, den in der Geschichte zwar stets vorhandenen, gleichwohl nicht zum Zuge gekommenen Möglichkeiten der historischen Entwicklung nachzugehen ${ }^{495}$, und die in diesem Zusammenhang eine Reihe von Untersuchungen publiziert haben, die sich den Elementen der Entspannung und Kooperation widmen, die vor 1914 auch in den Beziehungen zwischen Frankreich und dem Deutschen Reich enthalten waren ${ }^{496}$.

493 Zit. Buchanan an Grey, 18. 2. 1914, in: NL Grey, PRO, FO 800/74, fol. 265f. Vgl. in diesem Zusammenhang auch die entsprechenden Passagen im Tagebuch Paléologues, die an dieser Stelle durch die Parallelüberlieferung gedeckt sind. Vgl. PALÉOLOGUE, Journal, S. 230-241 (Einträge vom 12., 25., 26. und 27. 11. 1913). Auch dem russischen Monarchen teilte Paléologue die belliqueuses déclarations des deutschen Kaisers im Februar 1914 mit. Vgl. Paléologue an Doumergue, 17. 2. 1914, in: DDF 3, 9322.

494 Zit. Notes journalières, Visite du Président de la République à l'Empereur Nicolas, in: NL Poincaré, BNF, Nafr. 16027, fol. 133. Zur besonderen Überlieferungssituation dieses Eintrages vgl. die Ausführungen im Abschnitt "Quellenlage«. Bei der zitierten Aufzeichnung handelt es sich um ein Gespräch Paléologues mit dem Zaren und nicht wie Wilsberg irrtümlich annimmt - um eine Unterredung des Präsidenten mit dem russischen Monarchen. Vgl. Wilsberg, Kooperative Momente und Konflikt, S. 60.

495 Vgl. Hildebrand, Deutsche Außenpolitik, S. $120 \mathrm{f}$.

496 Vgl. LÖHR, Deutsch-französische Beziehungen und WILSBERG, Kooperative Momente und Konflikt. Vgl. ferner Gerhard KEIPER, Biographische Studien zu den Ver- 
Die im Rahmen dieser Forschungen unternommene Bestandsaufnahme macht deutlich, daß Frankreich und das Deutsche Reich in den letzten Jahren vor Ausbruch des Großen Krieges zahlreiche Streitfragen lösen oder doch zumindest entschärfen konnten. Was zunächst den marokkanischen Fall betrifft, so ist sicherlich zutreffend - und darauf ist im Rahmen der Untersuchung schon aufmerksam gemacht worden - daß die letzte große Krise um das Sultanat die Beziehungen beider Staaten außerordentlich belastet hatte. Gleichwohl hatte aber das Abkommen vom 4. November 1911, mit dem das Deutsche Reich das französische Protektorat anerkannte, in der Sache auch einen gefährlichen Konflikt ausgeräumt, der seit langer Zeit bestanden hatte ${ }^{497}$.

Hatten die beiden Großmächte ihre Rivalität in Marokko erst bis hart an den Rand einer militärischen Auseinandersetzung treiben müssen, um ihre gegensätzlichen Interessen zu vergleichen, so gelang es mit erfolgreichen Verhandlungen über den Bau von Bahnlinien relativ leicht, im Februar 1914 auch alte Streitfragen im Osmanischen Reich einer Klärung zuzuführen ${ }^{498}$. Mit Blick auf diesen Teil der europäischen Peripherie gilt es darüber hinaus ganz grundsätzlich festzuhalten, daß Frankreichs Außenpolitik dem Erhalt der Integrität des Osmanischen Reiches galt und daß in diesem Punkt seine Interessen mit denen des Deutschen Reiches koinzidierten. In dieser Hinsicht waren es nicht so sehr die Interessen des Deutschen Reiches als vielmehr die Ambitionen des Bündnispartners, die dem Außenministerium am Quai d'Orsay Sorge bereiteten ${ }^{499}$. So klagte Paléologue dem britischen Botschafter im August 1913 ausführlich über die außerordentlichen Schwierigkeiten, vor die Frankreich sich gestellt sehe, wenn es gelte, mit dem Zaren eine gemeinsame Politik in orientalischen Angelegenheiten zu führen, und ließ sich in

ständigungsversuchen zwischen Deutschland und Frankreich am Vorabend des Ersten Weltkrieges, Frankfurt am Main 1997. Im Mittelpunkt dieser Untersuchung stehen insbesondere das Handeln und Wirken des ersten Sekretärs an der deutschen Botschaft in Paris, Oscar Freiherr von der Lancken-Wakenitz, und Graf Abel Armands. Vgl. ferner den Abschnitt "Franco-German Détente and the Future of the Ottoman Empire in: KEIGER, France and the Origins, S. 130-135 und DERS., Jules Cambon, passim.

497 Auch die Regelung der von diesem Abkommen offen gelassen Detailfragen, die insbesondere den Austausch von Territorien in Zentralafrika betrafen, gelang in den folgenden Monaten oder zeichnete sich bis zum Ausbruch des Krieges doch zumindest ab. Vgl. WILSBERG, Kooperative Momente und Konflikt, S. 29-33.

${ }^{498}$ Vgl. ibid., S. 148-167 und Pierre GuILlEN, Questions coloniales dans les relations franco-allemandes à la veille de la Première Guerre mondiale, in RH 248 (1972), S. 87106, hier S. 100-102. Vgl. ferner LÖHR, Deutsch-französische Beziehungen, S. 143-145. 499 Das gemeinsame Interesse an der Integrität des Osmanischen Reiches gründete sich auf den Umstand, daß Frankreich und das Deutsche Reich im Besitz großer Teile der osmanischen Staatsschuld waren. Vgl. WILSBERG, Kooperative Momente und Konflikt, S. 139-142. Zu Frankreichs Interessen im Osmanischen Reich vgl. grundlegend Jacques THOBIE, Intérêts économiques, financiers et politiques français dans la partie asiatique de l'Empire ottoman, de 1895 à 1914, Diss. Paris 1973. Vgl. ferner Pierre GuILLEN, Les questions coloniales dans les relations franco-allemandes, S. $103 \mathrm{f}$., der die heftigen Invektiven des französischen Botschafters in Konstantinopel verzeichnet, die dieser zuweilen gegen den russischen Außenminister ausstieß. 
diesem Zusammenhang gar zu der Bemerkung hinreißen: Les Russes [...] sont insupportables 500 .

Daß sich Rußland in einen kolonialen Rivalen und das Deutsche Reich in einen kolonialen Partner verwandeln konnten, mußte man im Außenministerium am Quai d'Orsay auch erkennen, wenn der Blick von der Peripherie Europas an den fernen Rand des Staatensystems gelenkt wurde. Mutatis mutandis galt für die deutschen und französischen Ambitionen im Reich der Mitte nämlich das, was für ihre Politik im Osmanischen Reich zutraf: Beide Nationen besaßen hier ein gemeinsames Interesse an der Integrität des Staatsgebildes und lehnten seine Aufteilung in Einflußzonen ab. Im Fall Chinas trat zudem erleichternd hinzu, daß die Interessen Frankreichs im Süden, die Interessen des Deutschen Reiches jedoch im Nordosten des Landes konzentriert waren ${ }^{501}$. Dementsprechend kam Paléologue, als er im Februar 1912 dem deutschen Geschäftsträger von der Lancken in einem persönlichen $\mathrm{Ge}$ spräch vorschlug, daß man nach einem Betätigungsfeld Ausschau halten solle, auf dem das Deutsche Reich und Frankreich einem gleichen Ziel zustreben könnten, sogleich China als eine Möglichkeit in den Sinn ${ }^{502}$. Wie im Osmanischen Reich war es auch in diesem Teil der Welt eher die Politik des russischen Alliierten, die dem französischen Außenministerium Sorge bereitete.

Von grundlegender Natur, gleichwohl aber nicht unlösbar, gestaltete sich der deutsch-französische Interessenskonflikt auf einem anderen Feld kolonialer Expansion. Der Versuch des Deutschen Reiches, durch den Erwerb von Teilen der kolonialen Besitztümer Belgiens und Portugals ein mittelafrikanisches Kolonialreich zu schaffen, das sich vom Atlantischen bis zum Indischen Ozean erstrecken sollte, machte das französische Außenministerium um das koloniale Äquilibrium auf dem Schwarzen Kontinent fürchten, insbesondere um den Besitz Äquatorialafrikas. Doch ein genauerer Blick auf die Pläne, die man im Auswärtigen Amt und im französischen Außenministerium hinsichtlich des belgischen Kongos hegte, läßt auch in dieser Frage, deren Aktualität im Jahr 1914 ohnehin noch der Zukunft vorbehalten war, erkennen, daß ein Vergleich durchaus im Bereich des Möglichen lag503.

Was hier im Rahmen einer Arbeit zur Außenpolitik Frankreichs in der Julikrise nur konstatiert werden kann, was aber in den entsprechenden Spezial-

500 Zit. Bertie an Grey, 22. 8. 1913, in: NL Grey, PRO, FO 800/54, fol. 272.

$501 \mathrm{Vgl}$. GUILLEN, Questions coloniales dans les relations franco-allemandes, S. $93 \mathrm{f}$.

$502 \mathrm{Zu}$ einer peripheren Strategie, d. h. einer Außenpolitik, die durch eine Kooperation in thematisch oder geographisch sekundären Fragen Anknüpfungspunkte suchte, um verlorenes Vertrauen wieder herzustellen und mittelfristig gar die Beziehungen insgesamt zu verbessern, ist es in China dann aber nicht gekommen. Vgl. WILSBERG, Kooperative Momente und Konflikt, S. 135, 349. Zum Begriff "periphere Strategie « vgl. Gregor SCHÖLLGEN, Imperialismus und Gleichgewicht. Deutschland, England und die

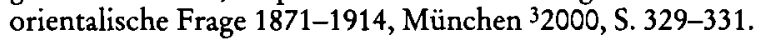

503 Vgl. GuILLEN, Questions coloniales dans les relations franco-allemandes, S. 95-97. Vgl. auch WILSBERG, Kooperative Momente und Konflikt, S. $32 \mathrm{f}$. 
untersuchungen detailreich untermauert wird, ist kurzum dieses: Beiden Staaten war es bis zum Ausbruch des Großen Krieges nicht allein mehrfach gelungen, ihre gegensätzlichen Interessen zu vergleichen und damit in zunehmendem Maße ihre Einflußsphären zu trennen. Darüber hinaus konnte ihr außenpolitischer Kurs mitunter auch in eine gemeinsame Richtung führen und damit Ansätze zur Kooperation und Entspannung bieten. Klaus Wilsberg ist in seiner Untersuchung dieses Sachverhalts zu dem Resultat gelangt, daß durch die zunehmende Trennung der Einflußzonen "Zum Zeitpunkt der Julikrise [...] zwischen dem Deutschen Reich und Frankreich kein wesentlicher politischer Streitpunkt mehr [bestand], der sich aus der Rivalität in den Kolonien oder an der Peripherie Europas ergeben hätte «504. Auf der Grundlage dieser Einsicht hat der Kölner Historiker dann die These formuliert, daß »ein wirklich gewichtiger Kriegsgrund [...] 1914 zwischen Deutschland und Frankreich nicht mehr [vorhanden war] «505. Ergänzt man diesen Befund um die Überlegung Paul W. Schroeders, daß weder die Interessengegensätze zwischen Großbritannien und dem Deutschen Reich, noch die zwischen Italien und der Habsburgermonarchie zum Gegenstand einer militärischen Auseinandersetzung werden konnten, so scheint die These des amerikanischen Historikers plausibel, daß "the only place World War One could have started was where it did, [...] over the fate of Central, Eastern, and South-eastern Europe «506. Dieser interessante Gedanke wird bei der Untersuchung des Bündnisses, das Frankreich und Rußland verband, im Auge zu behalten sein - liegt doch in seiner Fluchtlinie die Vermutung, daß Frankreich im Juli 1914 tatsächlich als victime de son alliance ${ }^{507}$ dem Zarenreich auf das europäische Schlachtfeld folgte. Doch gilt es vorerst folgendes festzuhalten: So plausibel sich das Urteil Paul W. Schroeders in der Retrospektive auch ausnehmen mag, die Untersuchung des Bildes, das sich die politische und militärische Führung Frankreichs von der Lage im Deutschen Reich machte, zeigt, das es mit der zeitgenössischen Bedrohungsanalyse nicht in Einklang zu bringen ist. Denn was man in Frankreich befürchtete und was auch Paléologue in seiner oben genannten Unterredung mit dem russischen Monarchen zu erkennen gab, war, daß die auf eine militärische Konfrontation bedachten Kräfte im Deutschen Reich letztlich die Oberhand erhalten würden und daß

504 Zit. WILSBERG, Kooperative Momente und Konflikt, S. 349. Zu einem ähnlichen Resultat gelangte 1972 auch schon Pierre Guillen. Vgl. GuILlEN, Questions coloniales dans les relations franco-allemandes, S. 105: $\AA$ la veille de la guerre il n'y avait pas entre le gouvernement français et le gouvernement allemand de conflits sérieux dans le domaine colonial. [...] On ne peut donc dire que les questions coloniales, dans les années 1912-1914 aient contribué sérieusement à l'aggravation de la tension franco-allemande«.

505 Zit. WILSBERG, Kooperative Momente und Konflikt, S. 355.

506 Zit. SCHroeder, Life and Death of a Long Peace, S. 41.

507 Zit. Beyens an Davignon, 26. 7. 1914, zit. nach STENGERS, July 1914: Some reflections, S. 120. Der belgische Botschafter gab in dieser Depesche eine Einlassung Jules Cambons wieder. 
sie mittels der Öffentlichkeit, deren Hoffnungen und Sehnsüchte weit über das angestammte deutsche Territorium hinausgingen, einen massiven Druck zu erzeugen vermochten, der es der prinzipiell friedlich gesinnten Reichsleitung dann unmöglich machen könnte, selbst über einen unbedeutenden Zwischenfall einen politischen Vergleich herbeizuführen. In dieser Hinsicht läßt sich tatsächlich davon sprechen, daß die Frage nach Krieg und Frieden unter den Bedingungen des politischen Massenmarktes nicht mehr, oder nur noch in sehr eingeschränktem Umfang, politischer Gestaltung verfügbar erschien - und dies in den Jahren bis zum Ausbruch des Großen Krieges in zunehmendem Maße. Que tout serait facile, so seufzte im Januar 1914 Frankreichs Botschafter im Deutschen Reich, s'il n'existait ni presse, ni opinion ${ }^{508}$.

Im Hinblick auf das Gespräch, das Paléologue und der russische Monarch am 20. Juli führten, gilt es aber noch ein wesentliches Detail zu ergänzen. Der Botschafter erlegte sich - zumindest was seine Erwartung für die Zukunft betraf - in dieser Unterredung mit Nikolaus II. ersichtlich größere Zurückhaltung auf, als er dies in den Gesprächen mit seinen Mitarbeitern tat. So erinnerte sich später der Attaché der Botschaft, daß Paléologue, annonçant chaque jour la guerre pour le lendemain, seine Zeit damit verbracht habe, $\grave{a}$ peindre le diable sur le mur ${ }^{509}$. Auch der Erste Sekretär der Botschaft berichtet in seinen Memoiren, der ehemalige Politische Direktor sei im Sommer 1914 von der imminence d'une guerre européenne $e^{510}$ überzeugt gewesen. $\mathrm{Pa}$ léologue hat diese Aussagen seiner Mitarbeiter post festum mit der Publikation seines Tagebuchs bestätigt ${ }^{511}$. Dem Ministerpräsidenten Briand erklärte er im Juni 1914: J'ai l'intime conviction que nous allons vers l'orage. Sur quel point de l'horizon, à quelle date éclatera-t-il? Je ne saurais le dire. Mais les symptômes objectifs, les signes prémonitoires sont désormais trop manifestes et trop concordantes: nous n'éviterons plus la guerre ${ }^{512}$. Mit ähnlichen Worten brachte er auch gegenüber dem Präsidenten seine Überzeugung zum Ausdruck $^{513}$, und Briands Nachfolger Viviani erklärte er auf eine direkte Frage: Oui, je crois que la guerre est désormais fatale, imminente même, et que nous devons nous y préparer ${ }^{514}$. Daß solch düstere Erwartungen das Handeln des

508 Zit. Jules Cambon an Pansa, 4. 1. 1914, in: Serra, Lettres de Jules Cambon, S. 88. 509 Zit. Quelques-uns de mes anciens chefs, in: NL de Robien, AN, 427 AP 5, fol. 121. Vgl. auch das Manuskript der Memoiren in: NL de Robien, AN, 427 AP 1, fol. 41.

510 Zit. Chambrun, L'Esprit de la diplomatie, S. 65. Eine ähnliche Andeutung läßt sich auch in einem privaten Brief Doulcets finden. Im August 1914 schrieb er an seinen Freund Henri de Manneville, daß sich Paléologue der neuen Situation in jeder Hinsicht gewachsen zeige, car il s'était toujours préparé et spécialisé dans la préparation de l'éventualité de la guerre. Zit. Doulcet an de Manneville, 19. 8. 1914. Dokument im Besitz von André de Manneville.

511 Vgl. Paléologue, Journal, S. 291 f, 303, 310f. (Einträge vom 5., 13. und 28.6. 1914). Vgl. auch HALFOND, Paléologue, S. 220, 275-277 sowie HAYNE, French Foreign Office, S. 294.

512 Zit. PALÉLOGUE, Journal, S. $291 \mathrm{f}$. (Eintrag vom 5. 6. 1913).

513 Zit. ibid., S. 303 (Eintrag vom 13. 6. 1914).

514 Zit. ibid., S. 310 f. (Eintrag vom 28. 6. 1914). 
Botschafters in der Julikrise beeinflußt haben müssen, liegt auf der Hand. Denn wem sich die Anzeichen für eine militärische Konfrontation in allernächster Zukunft in einem Maße verdichtet haben, daß er von der Unvermeidlichkeit eines Krieges überzeugt ist, der wird eine internationale Krise zunehmend unter militärischen Gesichtspunkten betrachten. Er wird dies nicht allein in dem Sinne tun, daß er sein persönliches Handeln weniger an den Anforderungen des politischen Ausgleichs als an den Bedingungen des militärischen Erfolges ausrichtet, und im Falle Paléologues wird genau dies im weiteren Fortgang der Untersuchung noch in Zusammenhang mit seiner Berichterstattung über die russische Generalmobilmachung zu beobachten sein. Weit darüber hinaus wird er möglicherweise auch der Versuchung erliegen, eine außerordentlich günstige strategische Lage zu nutzen, um die als unvermeidlich erachtete militärische Auseinandersetzung frühzeitig zu seinen Gunsten zu entscheiden.

Sehr viel mühsamer als der Eindruck Paléologues ist das Bild zu rekonstruieren, das sich der andere große Protagonist der französischen Außenpolitik in der Julikrise vom Deutschen Reich gemacht hatte. Der ehemalige Außenminister Stéphen Pichon erinnerte sich im April 1918 daran, daß sich Poincaré nicht sonderlich beunruhigt gezeigt hatte, als ihm das Gespräch zwischen dem deutschen Kaiser und dem belgischen Monarchen mitgeteilt worden war, und daß der Präsident die Äußerungen des Kaisers eher als taktische Einlassung denn als authentischen Ausdruck seiner Absichten verstand: [Monsieur le Président] exprima devant ses interlocuteurs l'opinion qu'il pouvait peut-être s'agir d'un >Bluff, de la part de l'Empereur d'Allema$g n e^{515}$. Poincaré hat nun in der Tat zu unterschiedlichen Gelegenheiten die deutsche Außenpolitik in den letzten Jahren vor Ausbruch des Großen Krieges im Gespräch mit diversen Personen direkt als Bluff oder bluffeuse ${ }^{516}$ bezeichnet, respektive sich in diesem Sinne ausgesprochen.

Folgt man den Erinnerungen des Chefredakteurs des »Matin «, Stéphane Lauzanne, dann war Poincaré schon in den ersten Monaten des Jahres 1912 bei der Durchsicht der Akten des Außenministeriums zu folgender Überzeugung gelangt: chaque fois que nous avons voulu nous montrer conciliants avec l'Allemagne, elle a abusé; chaque fois, au contraire, que nous nous sommes montrés fermes, elle a cédé ... l'Allemagne ne comprend pas le langage du droit; elle ne comprend que l'attitude de la force ${ }^{517}$. Einige Anzeichen sprechen dafür, daß sich dieses Urteil, das hier in den Quellen zum ersten Mal greifbar wird, durch die Erfahrungen, die Poincaré in den folgenden Jahren im Umgang mit dem Deutschen Reich sammelte, verfestigt hat und schließ-

515 Zit. Indications données par M. Stéphen Pichon à M. de Margerie, 18. 10. 1918, in: MAE, NS Allemagne 51, fol. 202.

516 Zit. Notes journalières, in: NL Poincaré, BNF, Nafr. 16027, fol. 85 (Eintrag vom 20.6. 1914).

517 Zit. LaUZanNe, Les hommes que j'ai vus, S. 55. 
lich zu einer Überzeugung gerann, die dann auch sein Handeln in der Julikrise 1914 beeinflussen sollte.

Rund ein Jahr nachdem er im Gespräch mit dem Chefredakteur des »Matin« die Außenpolitik des Deutschen Reiches als eine Politik des Bluffs charakterisiert hatte, sprach er sich auch gegenüber dem russischen Botschafter in diesem Sinne aus. Poincaré glaubte nun, das dem Journalisten beschriebene Muster der deutschen Außenpolitik in einem Zwischenfall zu erkennen, dessen Ursprung abermals in Marokko lag. Dieses Mal handelte es sich um die Reaktion des Auswärtigen Amtes auf die Gefangennahme des Kaiden El Glauli, dem Frankreich zur Last legte, einer der Protagonisten der Unruhen im südlichen Marokko zu sein. Der Fall des Kaiden hatte das deutsche und französische Außenministerium im Jahr 1912 schon mehrere Male beschäftigt, denn der Kaide gab an, daß er sich durch eine Kapitulation unter den diplomatischen Schutz des Deutschen Reiches begeben habe ${ }^{518}$. Der Zwischenfall schien im Februar 1913 zunächst beigelegt, als der Generalgouverneur, General Lyautey, und der Botschafter des Deutschen Reiches in Frankreich eine Aussprache über unterschiedliche Zwischenfälle führten, die sich in Marokko zugetragen hatten. Im Rahmen dieser Unterredung war die Sprache auch auf den Fall des Kaiden gekommen. Der Generalgouverneur machte darauf aufmerksam, daß nach dem Abkommen von Madrid jeder Marokkaner, der an militärischen Unruhen im Sultanat teilnehme, der Protektion durch eine ausländische Macht verlustig sei, und Baron von Schoen hatte in diesem Punkt nicht weiter insistiert ${ }^{519}$. Das Außenministerium, das ganz offensichtlich das Schweigen des deutschen Botschafters als Einverständnis gewertet hatte, mußte dann aber feststellen, daß es sich mit dieser Interpretation gröblich vergriffen hatte. Denn nur wenige Tage später wurde Schoen im Außenministerium vorstellig, um dem Politischen Direktor mitzuteilen, daß das Auswärtige Amt beabsichtige, von der Lancken als Emissär nach Marokko zu senden, um die Angelegenheiten vor Ort zu untersuchen. Folgt man den Notizen Paléologues, dann erachteten sowohl Ministerpräsident Briand als auch Außenminister Jonnart die Entsendung eines deutschen Emissärs als négation même de notre protectorat und als eine grave atteinte au prestige de la France au Maroc 520 , und dementsprechend energisch war dann das deutsche Ansinnen abgelehnt worden.

Es ist bemerkenswert, erklärte Poincaré daraufhin dem russischen Botschafter am 27. Februar, daß die deutsche Diplomatie es bei jedem Regierungswechsel in Frankreich für nötig findet, dem neuen Kabinett gegenüber die Politik der starken Hand (la ma-

518 Vgl. Poincaré an de Manneville, 29. 7. 1912, in: CADN, Berlin A 223; de Manneville an Poincaré, 30.7.12, in: CADN, Berlin A 397 und Ders. an Dens., 7. 9. 1912, in: CADN, Berlin A 397. Vgl. ferner Poincaré an Lyautey, 24. 10. 1912, in: CADN, Berlin A 224.

519 Vgl. Jonnart an Jules Cambon, 5. 2. 1913, in: CADN, Berlin B 1 und Jules Cambon an Jonnart, 16. 2. 1913, in: CADN, Berlin A 399.

${ }^{520}$ Zit. PALEOLOGUE, Journal, S. 40f. (Eintrag vom 13. 2. 1913). 
nière forte) zu erproben; so ist in der allerletzten Zeit die deutsche Regierung anläßlich des in Marokko entstandenen Zwischenfalls mit dem Kaiden El Glauli, der angeblich unter deutschem Schutze steht, mit Forderungen bervorgetreten, die durchaus unannebmbar und in eine äußerst schroffe Form gekleidet sind. Diese Forderungen sind von seiten des französischen Außenministeriums nachdrücklich abgelebnt worden, und die deutsche Regierung hat augenscheinlich darauf verzichtet, weitere Schritte in dieser Angelegenbeit $z$ tun ${ }^{521}$.

Daß eine Politik der Konzessionen nur zu neuen und vermehrten deutschen Forderungen führen werde, erklärte der Präsident dann im Juni 1914 auch dem Unterstaatssekretär im Außenministerium, Abel Ferry, als durch einen abermaligen Zwischenfall in Marokko die Frage auf die Agenda zurückzukehren drohte, ob die französische Militärgerichtsbarkeit ihre Anwendung auch auf Staatsbürger des Deutschen Reiches finden konnte ${ }^{522}$. Dem Unterstaatssekretär im Außenministerium, der die Absicht Vivianis, die Angelegenheit nicht weiter verfolgen zu wollen, als peu élégante befand, erläuterte Poincaré, daß er ein solches Handeln nicht allein für unbeholfen, sondern gar für gefährlich halte: Chaque fois qu'on fait preuve de faiblesse vis-à-vis de l'Allemagne, elle s'enhardit et devient provocante. Sans doute la question de droit est très délicate. [...] Mais, d'autre part, vis-à-vis de l'Allemagne, il conviendrait de prendre tout de suite position de demandeurs ${ }^{523}$. In diesem Sinne sprach sich Poincaré dann auch aus, als der Ministerpräsident ihn persönlich auf den Zwischenfall ansprach. Dem Diarium des Präsidenten läßt sich in diesem Zusammenhang entnehmen, daß Viviani gar eine militärische Konfrontation über diese Angelegenheit befürchtete ${ }^{524}$. Angesichts der Quellenlage kann man nur über die Gründe spekulieren, die den Ministerpräsidenten zu solch weitreichender Sorge veranlaßten. Möglicherweise teilte auch er die Befürchtung, daß sich eine unter den Druck der Öffentlichkeit geratene deutsche Reichsleitung als zu schwach erweisen könnte, um die auf eine militärische Konfrontation bedachten Kräfte zu zähmen, und möglicherweise zweifelte auch er, daß der Kaiser einen solchen Konflikt noch vermeiden wollte ${ }^{525}$. Welche Gründe den Ministerpräsidenten auch immer zu seinem

521 Zit. Iswolski an Sasonow, 27. 2. 1913, in: STIEvE, Iswolski-Schriftwechsel III, 747.

522 General Lyautey hatte das Außenministerium in dieser Frage konsultiert, da er zwei Staatsbürger des Deutschen Reiches vor ein Kriegsgericht bringen wollte, die unter dem Verdacht standen, die Desertion einiger Fremdenlegionäre begünstigt zu haben. Vgl. Notes journalières, in: NL Poincaré, BNF, Nafr. 16027, fol. $82 \mathrm{f}$. (Eintrag vom 18. 6. 1914).

523 Zit. Notes journalières, in: NL Poincaré, BNF, Nafr. 16027, fol. $82 \mathrm{f}$. (Eintrag vom 18.6. 1914).

524 Vgl. Notes journalières, in: NL Poincaré, BNF, Nafr. 16027, fol. 85 (Eintrag vom 20.6. 1914).

525 Die Quellenlage gestattet keine Rekonstruktion des Bildes, das sich René Viviani von der Außenpolitik des Deutschen Reiches machte. Die Erinnerungen des Ministerpräsidenten enthalten auch in dieser Hinsicht keine verwertbaren Informationen. Vgl. VIVIANI, Réponse au Kaiser. Paléologue berichtete post festum, daß der Ministerpräsident die Einlassungen Wilhelms II. aus dem November 1913 mit tiefem Entsetzen auf- 
vorsichtigen Handeln in diesem Fall bewogen haben mögen, zu konstatieren bleibt, daß Poincaré seine Bedenken zum Anlaß nahm, um dem in außenpolitischen Angelegenheiten Unerfahrenen seine Einsichten in die deutsche Außenpolitik zu erläutern: Je cherche à le rassurer et à lui démontrer qu'avec l'Allemagne, il faut toujours être ferme et résolu, que la diplomatie impériale est très bluffeuse et qu'elle nous tâte toujours pour voir, si nous sommes décidés à résister ou enclins à céder. Si nous ne donnons pas l'impression d'avoir une volonté claire et si nous semblons disposés à abandonner nos droits, on forcera sur nous ${ }^{526}$. Ob es dem Präsidenten tatsächlich gelungen war, dem Ministerpräsident die Richtigkeit seines Urteils zu ১beweisen «, kann man füglich bezweifeln, denn am 16. Juli 1914 nutzte er die langen Stunden der Reise nach Petersburg, um dem Ministerpräsidenten abermals die Maximen seiner Politik auseinanderzusetzen. Zu einem Zeitpunkt der Julikrise, an dem Poincaré weder Ausmaß noch Bedeutung dessen, was das Deutsche Reich und die Habsburgermonarchie im Geheimen vorbereiteten, bekannt war, erklärte er Viviani: je lui rapporte les incidents que j'ai eus à régler avec l'Allemagne, ferme de Reuschbausen, lettre de Jules Cambon à Bethmann Hollweg; je lui montre que je n'ai jamais eu de difficultés sérieuses avec l'Allemagne, parce que j'ai toujours usé vis-à-vis d'elle d'une grande fermetés27. Beide Zwischenfälle, die Poincaré im Gespräch mit dem Ministerpräsidenten erwähnte, sollen hier kurz eine genauere Betrachtung erfahren, da sie bislang in der Forschung keine Beachtung gefunden haben und auch in den publizierten Quellen nicht greifbar sind 528 .

Was zunächst den letztgenannten Fall betrifft, so handelt es sich um einen persönlichen Brief, den der Botschafter unter dem Datum des 8. August 1912 an den Reichskanzler gerichtet hatte ${ }^{529}$. In der Sache ging es um Verhandlungen, die zu diesem Zeitpunkt schon seit einigen Monaten zwischen Frankreich und Spanien über die Einrichtung einer Transitlinie in Marokko geführt wurden, die aber ins Stocken geraten waren, als das Auswärtige Amt am 28. Juli 1912 bekannt gab, daß es durch die Einrichtung einer solchen Linie die wirtschaftlichen Interessen des Deutschen Reiches beeinträchtigt und damit den im Abkommen vom 4. November 1911 niedergelegten Grundsatz

genommen habe, als sie ihm zu Beginn seiner Amtszeit mitgeteilt wurden. Vgl. Maurice PalÉlogue, Guillaume II et Nicolas II, Paris 1935, S. $212 \mathrm{f}$.

526 Zit. Notes journalières, in: NL Poincaré, BNF, Nafr. 16027, fol. 85 (Eintrag vom 20. 6. 1914).

527 Zit. Notes journalières, in: NL Poincaré, BNF, Nafr. 16027, fol. 98 (Eintrag vom 16.7. 1914).

528 Die Affäre um die ferme de Reuschbausen findet in der französischen Aktenpublikation nur in einer Fußnote, in der deutschen Sammlung keine Erwähnung. Vgl. DDF $3,3,361$.

529 Vgl. Jules Cambon an Bethmann Hollweg, 8. 8. 1912, in: DDF 3, 3, 361, Annexe. In der deutschen Aktenpublikation wird der Zwischenfall nur in einer Fußnote erwähnt. Vgl. von der Lancken an Bethmann Hollweg, 25. 9. 1912, in: GP 31, 11528. 
der ökonomischen Gleichbehandlung verletzt sah ${ }^{530}$. Um zu vermeiden, daß sich die gegensätzlichen Auffassungen zu einem Konflikt auswuchsen, hatte Cambon in seinem Brief an den Reichskanzler nochmals erläutert, daß keine Beeinträchtigung der deutschen Interessen vorliege, und den Kanzler gebeten, die Angelegenheit persönlich in die Hand zu nehmen ${ }^{531}$. Bethmann Hollweg hatte daraufhin in einem Antwortschreiben vom 16. August eine Prüfung des Falls zugesagt ${ }^{532}$.

Dieses Handeln des Reichskanzlers entfachte nun den Zorn des Staatssekretärs im Auswärtigen Amt, der in dem Brief des Botschafters einen beleidigende[n] Angriff 533 auf sein Ministerium erblickte, sich durch die Annahme der Beschwerde in seinem Ansehen sowie seiner Autorität herabgesetzt sah und Bethmann Hollweg mit Rücktritt drohte ${ }^{534}$. Der Staatssekretär leitete nun seinerseits ein Manöver ein, um Cambon zu desavouieren. Am 3. September wurde von der Lancken im Außenministerium vorstellig, um sich über den ton très singulier 535 des Briefs zu beschweren, der zudem mit folgendem Passus eine inakzeptable Passage enthalte: Vous savez, so hatte der Botschafter unter anderem an den Kanzler geschrieben, combien le sentiment public français est resté excitable dans tout ce qui touche au Maroc. Sa susceptibilité est avivée. Le moindre malentendu peut avoir des conséquences fâcheuses ${ }^{536}$. Von der Lancken bemühte sich ersichtlich, Poincaré in einen $\mathrm{Zu}$ sammenhang mit diesem Brief zu bringen und versuchte zudem, die ganze Angelegenheit zu einer Auseinandersetzung um großmächtliches Prestige zu machen, als er Poincaré fragte, ob er die Absicht gehabt habe, mit einem Hinweis auf die möglichen conséquences fâcheuses eine expression menaçante zu gebrauchen. Poincaré erklärte dem Diplomaten jedoch in schneidendem Ton, daß er den Brief des Botschafters für irréprochable halte und ihm darüber hinaus keine Erklärung schulde, da ihm das Schreiben Cambons unbekannt sei ${ }^{537}$. Am 7. September nahm dann von der Lancken letztere Erklärung zum Anlaß für die Feststellung, daß derart die Autorität des Botschafters vermindert worden sei. Poincaré bestritt auch dies energisch und insistierte gegen

530 Vgl. Jules Cambon an Bethmann Hollweg, 8. 8. 1912, in: DDF 3, 3, 361, Annexe. 531 Vgl. ibid. Der Botschafter war in dieser Angelegenheit persönlich engagiert, da er in einer Depesche vom 8. Mai 1912 Poincaré empfohlen hatte, daß Deutsche Reich weder über den Fortgang der Verhandlungen zu informieren noch sich seiner Zustimmung zu versichern. Vgl. Jules Cambon an Poincaré, 8. 5. 1912, in: CADN, Berlin A 397.

$532 \mathrm{Vgl}$. Bethmann Hollweg an Jules Cambon, 16. 8. 1912, in: DDF 3, 3, 361, Annexe. 533 Zit. Kiderlen-Wächter an Bethmann Hollweg, 20. 8. 1912, in: Ernst JÄCKH, Alfred von Kiderlen-Wächter, der Staatsmann und Mensch. Briefwechsel und Nachlaß, Bd. II, Stuttgart 1922, S. 147.

534 Vgl. ibid., S. 148.

535 Zit. Note du Ministre, 3. 9. 1912, in: DDF 3, 3, 361.

536 Zit. Jules Cambon an Bethmann Hollweg, 8. 8. 1912, in: DDF 3, 3, 361, Annexe.

537 Vgl. Note du Ministre, 3. 9. 1912, in: DDF 3, 3, 361. 
den Widerstand von der Lanckens, daß kein ungebührliches Verhalten vorliege ${ }^{538}$.

Nachdem dann dem Ministerpräsidenten die Antwort des Reichskanzlers zugegangen war, in der Bethmann Hollweg dem Botschafter für dessen freundlichen Brief gedankt hatte, stellte er am 12. September umgehend den deutschen Geschäftsträger zur Rede, erklärte aber gleichwohl den Zwischenfall für beendet ${ }^{539}$. In einem Brief vom 15. September 1912 berichtete daraufhin Cambon, daß der Staatssekretär, dem die Angelegenheit nun ersichtlich peinlich geworden war, gleichfalls die Sache nicht weiter zu verfolgen gedachte. Très certainement, so schloß er seinen Brief an Poincaré, dem dieser Zwischenfall noch rund zwei Jahre später lebhaft in Erinnerung sein sollte und der aus ihm offensichtlich dieselben Schlußfolgerungen wie Jules Cambon gezogen hatte, cette solution est due à la netteté et à la fermeté avec laquelle vous avez accueilli la réclamation de $M$. de Lancken. Votre Excellence me permettra de lui exprimer combien je lui en suis personnellement reconnaissant ${ }^{540}$.

Was darüber hinaus die affaire de Reuschbausen betrifft, so lag auch dieser Zwischenfall im Juli 1914 schon rund zwei Jahre zurück. Im Mai 1912 hatte die Botschaft des Deutschen Reiches das französische Außenministerium gebeten, die Untersuchung eines Vorgangs einzuleiten, der sich abermals in Marokko zugetragen hatte. Den Nachrichten zufolge, die das Auswärtige Amt von seinem Konsul in Tanger erhalten hatte, waren im April ein in der Nähe von Larache gelegener Besitz der Gesellschaft Reuschhausen von einer Einheit marokkanischer Soldaten unter französischem Befehl durchsucht und mehrere Landarbeiter verhaftet worden ${ }^{541}$. $\mathrm{Zu}$ einer gütlichen Regelung der Angelegenheit trug nicht gerade bei, daß die Botschaft in ihrer Note die Ansicht des deutschen Konsuls in Larache aufgriff, der in dem Zwischenfall nur einen neuerlichen Beweis für eine systematisch betriebene Kampagne erblickte, deren Ziel es sei, durch die Minderung des Prestiges der deutschen Protektion die ökonomischen Interessen des Deutschen Reiches in Marokko zu unterlaufen ${ }^{542}$. Eine weitere Schwelle war dann am 19. Mai überschritten worden, als der Staatssekretär des Auswärtigen Amtes in einer Rede vor dem Reichstag versicherte, daß sein Ministerium sorgsam über die Beachtung der deutschen Rechte in Marokko wache, und er sich in diesem Zusammenhang auch konkret auf den Zwischenfall in der Umgebung von Larache bezog ${ }^{543}$.

538 Vgl. Note du Ministre, 7. 9. 1912, in: DDF 3, 3, 382.

539 Vgl. Poincaré an Jules Cambon, 12. 9. 1912, in: NL Jules Cambon, MAE, PA-AP 43/56, fol. $229 \mathrm{f}$.

540 Zit. Jules Cambon an Poincaré, 15. 9. 1912, in: NL Jules Cambon, MAE, PA-AP 43/ 49, fol. 97. Vgl. auch Ders. an Paléologue, 15. 9. 1912, in: ibid., fol. 98-100.

$541 \mathrm{Vgl}$. Poincaré an Jules Cambon, 8. 5. 1912, in: CADN, Berlin A 222 und Ders. an Dens., 11. 5. 1912, in: ibid.

542 Vgl. Poincaré an Jules Cambon, 11. 5. 1912, in: CADN, Berlin A 222.

543 Vgl. Note du Ministre, 3. 9. 1912, in: DDF 3, 3, 361. 
$\mathrm{Zu}$ ersten Unstimmigkeiten war es aber schon gekommen, als von der Lancken unter dem Datum des 13. Mai einen Brief an den Politischen Direktor des Außenministeriums gerichtet hatte, in dem er zur Untersuchung und Regelung des Zwischenfalls die Bildung einer commission mixte forderte ${ }^{544}$. Der Politische Direktor sah darin nun seinerseits eine Beeinträchtigung der Rechte Frankreichs. Denn nach der Interpretation, die er dem Abkommen vom 4. November 1911 gab, konnten Zwischenfälle dieser Art durch eine Kommission, die aus dem französischen und dem deutschen Konsul in Tanger respektive deren Repräsentanten zu bilden war, zwar untersucht, nicht aber endgültig geregelt werden ${ }^{545}$. Die ganze Angelegenheit zog weitere Kreise, als es schließlich im Juni zum Abbruch der Arbeiten der Untersuchungskommission kam und sich nun auch der französische Generalgouverneur gezwungen sah, in dieser Sache Stellung zu beziehen.

In einem mehr als zehn Seiten umfassenden Bericht hatte zunächst der französische Konsul Klage über das Verhalten des deutschen Repräsentanten geführt. Dieser habe - was dem Konsul besonders schwerwiegend erschien auch in Gegenwart der marokkanischen >Eingeborenen< keine Gelegenheit ausgelassen, um ihn herabzusetzen und ihm während der notwendigen Untersuchungen vor Ort eine situation bumiliante ${ }^{546} \mathrm{zu}$ bereiten. Zum Eklat war es dann gekommen, als sich der Konsul gezwungen sah, bei der Befragung eines Leutnants durch den deutschen Repräsentanten einzuschreiten, um die Ehre des Franzosen zu wahren, und als daraufhin das deutsche Mitglied die Arbeit der Kommission für beendet erklärte und nach Larache zurückkehrte. Der ungebührliche Ton, den der deutsche Vertreter gegenüber dem Leutnant angeschlagen hatte, brachte auch den Generalgouverneur auf den Plan. In einem umfangreichen Bericht an den Ministerpräsidenten erklärte er, daß es mit der Ehre Frankreichs nicht zu vereinbaren sei, daß ein Repräsentant des Deutschen Reiches in Gegenwart von sEingeborenen، die Autorität eines seiner Offiziere in Frage stelle $e^{547}$.

Doch nicht durch den Abbruch der Untersuchungen wuchs sich der Zwischenfall in Marokko zur Affäre aus. Entscheidend war vielmehr, daß der deutsche Botschafter dem Außenministerium am 5. Juni ein Aide-mémoire übergeben hatte, in dem das von Frankreich beanspruchte Recht bestritten wurde, auch dann juristisch gegen Eingeborene vorgehen zu dürfen, wenn diese unter dem Schutz des Deutschen Reiches standen. Als Beweis des esprit de bonne entente - so lautete das Aide-mémoire weiter - wolle aber das Deutsche Reich seine 'Schutzbefohlenen

544 Vgl. Poincaré an Jules Cambon, 18. 5. 1912, in: CADN, Berlin A 222. 545 Vgl. ibid.

546 Zit. Rapport de M. Marchand, consul de France à Larache, 21. 6. 1912, in: CADN, Berlin A 223. Der Bericht findet sich als Anlage zu: Poincaré an de Manneville, 18. 7. 1913, in: ibid. Vgl. ferner Poincaré an Jules Cambon, 22. 6. 1912, in: CADN, Berlin A 222 und Ders. an Dens., 23.6. 1912, in: ibid.

547 Vgl. Lyautey an Poincaré, 28. 6. 1912, in: CADN, Berlin A 223. 
schen Protektion verlustig seien, wenn sie sich an bewaffneten Auseinandersetzungen beteiligten. Eine solche Mahnung machte das deutsche Außenministerium aber von mehreren Bedingungen abhängig. Zum einen sollten die Repräsentanten Frankreichs aufgefordert werden, die Rechte zu respektieren, die dem Deutschen Reich gemäß des Vertrages vom 4. November 1911 zustanden, zum anderen müsse es zu einem règlement satisfaisant des Zwischenfalles kommen, der sich auf dem Reuschhauser Landgut zugetragen hatte. Darüber hinaus begleitete das Reich seine Forderungen im Aide-mémoire noch mit dem Hinweis, daß man der in marokkanischen Fragen besonders sensiblen Stimmungslage in der deutschen Öffentlichkeit Rechnung tragen müsse ${ }^{548}$.

Stellt man sich auf den französischen Standpunkt, so mußten die Forderungen des Deutschen Reiches empörend sein. Denn das Deutsche Reich bot mit großzügiger Geste ein Handeln an, zu dem es nach französischer Auffassung ohnehin verpflichtet war, und machte ein solches Handeln auch noch abhängig von dem règlement satisfaisant einer Angelegenheit, in der Frankreich sich streng nach dem Abkommen vom 4. November 1911 gerichtet hatte. In seinem Antwortschreiben wies Poincaré die Forderungen zurück und schlug einen Ton an, der dem Auswärtigen Amt unmißverständlich zu erkennen gab, daß das Deutsche Reich in dieser Angelegenheit mit einer souveränen Großmacht sprach, die keine andere Regelung akzeptieren konnte, als eine solche, $\mathrm{zu}$ der sie sich vertraglich selbst verpflichtet hatte ${ }^{549}$. Das $\mathrm{Au}-$ ßenministerium in der Wilhelmstraße verfolgte die Angelegenheit zunächst nicht weiter, erklärte dann aber am 20. Juli in einer Note, daß man im Fall des Kaiden El Glauli dem Ministerium am Quai d'Orsay nicht entgegen kommen könne, da Frankreich die Forderung, die im Aide-mémoire vom 5. Juni formuliert worden waren, zurückgewiesen habe ${ }^{550}$. In einer Unterredung mit dem Unterstaatssekretär am 30. Juli bestritt dies der französische Geschäftsträger, und Zimmermann schien die Angelegenheit nicht mehr weiter verfolgen zu wollen, erklärte er doch de Manneville plötzlich, daß die Lage in Marokko zufriedenstellender sei als noch wenige Tage zuvor ${ }^{551}$.

548 Vgl. Poincaré an Jules Cambon, 8. 6. 1912, in: CADN, Berlin A 222, dort auch die Zitate. Vgl. ferner Ders. an Dens., 29. 7. 1912, in: CADN, Berlin A 223.

549 Vgl. Ders. an Dens., 13. 6. 1912, in: CADN, Berlin A 222.

550 Vgl. Poincaré an de Manneville, 29. 7. 1912, in: CADN, Berlin A 223 und de Manneville an Poincaré, 30. 7. 1912, in: CADN, Berlin A 397.

551 Vgl. de Manneville an Poincaré, 30. 7. 1912, in: CADN, Berlin A 397. Die Angelegenheit verlief schließlich im marokkanischen Sande. Im Herbst 1912 sandte Jules Cambon die Vernehmungsprotokolle mit der Bemerkung nach Paris zurück, daß die Wilhelmstraße ihn seit Juli nicht mehr auf den Zwischenfall angesprochen habe. Vgl. Jules Cambon an Poincaré, 30. 9. 1912, in: CADN, Berlin A 398. Vgl. ferner Jonnart an Jules Cambon, 5. 2. 1913, in: CADN, Berlin B 1. In seinen Erinnerungen erwähnt Poincaré die Affäre Reuschhausen nur in margine und gibt keinen Hinweis darauf, daß er aus ihrem Verlauf weitreichende Schlußfolgerungen hinsichtlich der deutschen Außenpolitik zog. Vgl. POINCARÉ, Au service de la France, Bd. I, S. 88. 
So unbedeutend dieser Zwischenfall in der Retrospektive auch anmuten mag: Für Poincaré, der sich noch zwei Jahre später an die Vorgänge um die ferme de Reuschbausen erinnerte, scheint u.a. diese Affaire zur Grundlage seines Deutschlandbildes geworden zu sein, und man wird mit Sicherheit annehmen können, daß er nicht erst während der Überfahrt nach Sankt Petersburg, sondern schon einige Wochen zuvor diesen Zwischenfall im Blick hatte, als er dem Ministerpräsidenten erklärte, qu'avec l'Allemagne il faut toujours être ferme et résolu, que la diplomatie impériale est très bluffeuse et qu'elle nous tâte toujours pour voir, si nous sommes décidés à résister ou enclins à céder. Si nous ne donnons pas l'impression d'avoir une volonté claire et si nous semblons disposés à abandonner nos droits, on forcera sur nous ${ }^{552}$. Paßt doch das Viviani mit diesen Worten beschriebene Verhaltensmuster sehr genau auf die Erfahrungen, die Poincaré im Jahr 1912 gesammelt hatte.

Folgt man den Aufzeichnungen des Präsidenten, dann war die damals gewonnene Einsicht auch für seine Beurteilung der deutschen Außenpolitik in der Julikrise 1914 maßgeblich. Als ihn am 22. Juli, daß heißt zu einem Zeitpunkt, als ihm bekannt war, daß die Habsburgermonarchie Forderungen an Serbien richten würde, die mit der Souveränität dieses Staates nicht zu vereinbaren waren, ein Bericht aus Berlin erreichte, in dem der Botschafter Frankreichs mitteilte, daß das Deutsche Reich sich dem Schritt der Habsburgermonarchie anschließen werde, erachtete er diese Nachricht zwar als fort inquiétante ${ }^{553}$. Gleichwohl vermerkte in seinem Tagebuch: Encore du bluff évidemment, dans le dessin d'intimider les autres puissances et d'abaisser la Serbie, par amitié pour l'Autriche 554 .

Obwohl sich dieser Eintrag nahtlos in das bislang entfaltete Bild reiht, fällt seine Beurteilung aus zwei Gründen nicht leicht. So existiert mit dem schon in anderem Zusammenhang behandelten Tagebucheintrag vom 8. April 1913 eine Quelle, in der der Präsident zu einer ganz anders gelagerten Einschätzung der Unterstützung gelangte, die das Deutsche Reich seinem Bündnispartner auf dem Balkan gewährte ${ }^{555}$. Was Poincaré in der Julikrise als »freundschaftliche Geste« des Deutschen Reichs verstand, war ihm damals Ausdruck kühl kalkulierender Staatsraison gewesen. Nachdem Bethmann Hollweg am 7. April die neuen Rüstungen des Deutschen Reiches unter anderem mit einem Hinweis auf die Macht begründet hatte, die durch den partiellen Zusammenbruch des Osmanischen Reiches entstanden war, hatte Poincaré nämlich in seinem Diarium notiert:

552 Zit. Notes journalières, in: NL Poincaré, BNF, Nafr. 16027, fol. 85 (Eintrag vom 20. 6. 1914).

553 Zit. Notes journalières, in: NL Poincaré, BNF, Nafr. 16027, fol. 106 (Eintrag vom 21. 7. 1914).

554 Zit. ibid.

555 Vgl. die Ausführungen im Abschnitt »Der habsburgische Gulliver im strategischen Konzept Frankreichs«. 
La politique d'abaissement que l'Autriche poursuit [Lesart unsicher] à l'égard des États balkaniques [...] se présente à mes yeux avec plus de clarté encore après les explications de Bethman [sic] Hollweg. Le chancelier allemand a constaté que des États doués d'une force de vie extraordinaire avaient dans les Balkans pris la place de la Turquie, et il a fait ressentir [Lesart unsicher] combien cette [unleserliches Wort] serait désavantageuse pour l'Allemagne dans un conflit qui mettrait face à face Slaves et Germains. L'Allemagne approuve donc son allié lorsqu'elle cherche à entraver le développement futur de ces royaumes slaves et grecs, lorsqu'elle veut les diviser par de multiples irrédentismes et des querelles de frontière. Et à la commission de budget du Reichstag le g[ouvernemen]t de Berlin a déclaré qu'il n'avait jamais paralysé l'énergie autrichienne dans la crise qui dure encore - C'est ainsi que s'expliquent la création d'un État albanais, l'effort pour en étendre les frontières, l'éloignement de la Serbie des côtes de l'Adriatique ${ }^{556}$.

Angesichts der Konstanz, mit der Poincaré die Außenpolitik des Deutschen Reiches in den letzten Jahren vor Ausbruch des Großen Krieges als eine Politik des Bluffs bezeichnete, könnte man geneigt sein, diesen Eintrag im Tagebuch des Präsidenten als eine Momentaufnahme zu interpretieren. Doch liegen nun sowohl mit zeitgenössischen als auch späteren Quellenzeugnissen eine ganze Reihe von Hinweisen vor, die darauf hindeuten, daß sich auch das Deutschlandbild Poincarés in den Bahnen bewegte, in denen die bereits behandelten Repräsentanten Frankreichs dachten.

So gibt der Chefredakteur des »Matin « in seinen Memoiren an, daß schon in den Gesprächen, die er in den letzten Monaten des Jahrs 1913 mit dem Präsidenten geführt habe, ein merklicher Stimmungsumschwung zu verzeichnen gewesen sei, und daß sich Poincarés Konflikterwartung zunehmend pessimistischer ausnahm. Le pangermanisme, so soll der Präsident ihm erklärt haben, est le maître incontesté de l'Allemagne: il veut la guerre et il la fera. L'empereur déclare de temps à l'autre: je suis le dernier pivot de résistancer. Mais c'est un pivot qui ne demande qu'à céder 557 . Obgleich in der Formulierung ersichtlich überspitzt, wird man Lauzannes Bericht in der Sache nicht als unglaubwürdig betrachten können, denn schon in einem anderen Fall hat sich der Chefredakteur des »Matin« als verläßlicher Zeuge erwiesen. Darüber hinaus gilt es zu bedenken, daß Lauzannes Erinnerungen noch zu Lebzeiten Poincarés publiziert wurden, so daß der Journalist im Fall einer bewußt falschen Überlieferung mit dem Widerspruch Poincarés hätte rechnen müssen. Dazu ist es aber offenbar nicht gekommen. Vielmehr hat Poincaré mit der

556 Zit. Notes journalières, in: NL Poincaré, BNF, Nafr. 16024, fol. 153 (Eintrag vom 8. 4. 1913.) Daß sich in den Aufzeichnungen unter dem Datum des 8. April ein Hinweis auf die Beratungen der Haushaltskommission des Reichstages findet, ist ein erstaunliches Faktum, denn die Sitzungen begannen erst am 24. und 25. April und zwar in geheimem Rahmen. Aus diesem Grund ist die Annahme naheliegend, daß Poincaré diesen Eintrag erst nachträglich unter das Datum des 8. April in sein Tagebuch schrieb und dort der Rede Bethmann Hollwegs hinzufügte - ein Umstand, der dem Eintrag zusätzliches Gewicht verleihen würde. Vgl. zu den Beratungen der Haushaltskommission: GROH, Die geheimen Sitzungen der Reichshaushaltskommission am 24. und 25. April 1913, in: Internationale wissenschaftliche Korrespondenz zur Geschichte der deutschen Arbeiterbewegung 11 (1971), S. 29-38.

557 Zit. LAUZANNE, Les hommes que j'ai vus, S. 56. 
Publikation seiner Memoiren die Erinnerungen Lauzannes direkt bestätigt. Im Rekurs auf die zu diesem Zeitpunkt noch nicht veröffentlichten Berichte der Militärattachés entwarf der ehemalige Präsident ein Bild deutscher Außenpolitik, deren bestimmender Zug die Arroganz gewesen sei: Tous les renseignements que nous recueillions concordaient avec les conclusions de notre attaché militaire. De plus en plus, l'Allemagne s'imaginait qu'elle était prédestinée à dominer le monde, que la prétendue supériorité de la race germanique, le nombre toujours croissant des habitants de l'Empire, la pression continue des nécessités économiques, lui créaient parmi les nations des droits exceptionnels ${ }^{558}$. Ebenso wie die militärischen Beobachter habe darüber hinaus auch ihn in den letzten Jahren vor Ausbruch des Großen Krieges in zunehmendem Maße die Frage beschäftigt, ob sich die deutsche Reichsleitung im entscheidenden Augenblick als stark genug erweisen würde, um die Forderungen der Öffentlichkeit auf ein mit dem Frieden verträgliches Maß zu beschränken. Je ne pouvais, so umschrieb Poincaré nachträglich seine Sorgen, me défendre de quelques apprébensions ${ }^{559}$. Entsprechende Befürchtungen lassen sich für den Präsidenten aber nicht allein post festum nachweisen. Mit einem Brief Nicolsons und einem kurzen Extrakt aus dem Tagebuch Paléologues liegen zumindest zwei zeitgenössische und zudem unabhängige Quellen vor, die diese Ausführungen in den Erinnerungen Poincarés bestätigen.

So berichtete in einem Schreiben an Lord Morely vom 15. April 1912 der Unterstaatssekretär im Foreign Office, daß ihm der französische Botschafter folgendes Bild entworfen habe:

The French Govt. were convinced that no [sic] opportunity would be seized, perbaps not this year, but possibly next year or the year after, by Germany to create some incident which would arouse public feeling on both sides of the frontier, and would, viewing the temper in both countries, very probably lead to war. The German Emperor and the German Chancellor were doubtless pacifically inclined, but they were not in reality the influential and deciding factors. The Pan-Germans, the Navy League, and other chauvinistic elements, the military etc were the factors which bad the greatest weight and influences ${ }^{560}$.

Auf der Linie dieser Ausführungen lagen dann auch die Erklärungen, die Paléologue dem russischen Monarchen im Juli 1914 über das Deutschlandbild Poincarés gab. Bereits in den einleitenden Passagen dieser Untersuchung ist darauf aufmerksam gemacht worden, daß Paléologue im Jahr 1918 - das heißt noch vor der Publikation der Erinnerungen Lauzannes und Poincarés - dem Präsidenten eine erste Fassung seines Diariums zur Lektüre übermittelte und daß Poincaré von dieser Fassung zumindest eine Abschrift des Eintrags vom 20. Juli 1914 anfertigte, die sich auf einigen in die Notes journalières eingelegten Blättern in seinem Nachlaß befindet. In dieser Aufzeichnung überliefert Paléologue das schon in anderem Zusammenhang behandelte Gespräch mit

558 Zit. POINCARÉ, Au service de la France, Bd. I, S. 144.

559 Zit. ibid., S. 145.

${ }^{560}$ Zit. Nicolson an Morely, 15. 4. 1912, in: NL Bertie, PRO, FO 800/165, fol. $142 \mathrm{f}$. 
dem russischen Monarchen, in dem er die Frage aufgeworfen hatte, ob der deutsche Kaiser in einer erneuten internationalen Krise die militärische Konfrontation noch vermeiden könne oder wolle. En toute sincérité, Sire, je ne le pense pas, so hatte der Botschafter seine Ausführungen beschlossen, um dann fortzufahren: $M$. le Président de la République exposera d'ailleurs à votre Majesté sa ferme conviction à cet égard...561.

Daß sich Poincarés Einschätzung der internationalen Lage in den letzten Monaten vor Ausbruch des Großen Krieges zunehmend pessimistischer ausnahm und dies in einem direktem Zusammenhang mit seinem Deutschlandbild stand, belegt auch ein Gespräch, das er in diesem Zeitraum mit dem Herausgeber des "Eclair « führte. Diesem soll Poincaré nach der Liman-von-Sanders-Krise erklärt haben: la Russie a un avenir immense. Sa force est en plein développement. Elle n'oubliera pas le coup que l'Allemagne vient de gagner à Constantinople. Dans deux ans, la guerre aura lieu. Tout mon effort va tendre à nous préparer ${ }^{562}$. Zwar verband dieses Mal der Präsident die Erwartung einer militärischen Auseinandersetzung nicht direkt mit einem Hinweis auf die Lage der Dinge im Deutschen Reich, und seine Begründung war somit anders gelagert. Gleichwohl setzte aber die Überzeugung, daß der Bündnispartner in einer neuerlichen Krise nicht mehr zurückweichen und es damit in einem absehbaren Zeitraum zum Großen Krieg kommen mußte, voraus, daß auch das Deutsche Reich in einer zukünftigen Krise keine Konzessionen mehr machen würde.

Ganz so sicher konnte sich der Präsident folglich nicht sein, als er unter dem Datum des 22. Juli 1914 in seinem Tagebuch notierte, daß es sich offen-

561 Zit. Notes journalières, Visite du Président de la République à l'Empereur Nicolas, in: NL Poincaré, BNF, Nafr. 16024, fol. 133.

562 Zit. LoUIS, Carnet II, S. 94 (Eintrag vom 12. 1. 1914). Judet kam noch bei anderen Gelegenheiten gegenüber Louis auf seine Unterredung mit dem Präsidenten aus dem Januar 1914 zurück. Beide Male wiederholte er die Auffassung Poincarés, wonach der Friede nicht länger als zwei Jahre gehalten werden könne. Vgl. Louss, Carnets II, S. 108, 119 (Einträge vom 18. 5. und 8.7. 1914). Der Bericht, den der Herausgeber des "Eclair« dem ehemaligen Botschafter gab, muß als durchaus glaubwürdig angesehen werden. Zum einen wird die pessimistische Zukunftserwartung Poincarés durch die Erinnerung Lauzannes bestätigt. Zum anderen wird das Gespräch zwischen Poincaré und Judet auch in den Erinnerungen Caillaux' erwähnt und dort durch den Verweis auf die Berichte des französischen Militärattachés in Petersburg mit einem Detail versehen, das Judet nur durch Poincaré erfahren haben kann: Ernest Judet, convoqué par lui pour une explication de détail dans les premiers mois de 1914, l'entend déclarer que la Russie vient de consentir pour la dernière fois une concession à l'Allemagne, mais que c'est fini, bien fini, qu'elle ne cédera plus, qu'elle a d'ailleurs une armée incomparable. Et, se montant, arpentant de long en large son cabinet, le chef de l'Etat explique que notre attaché militaire à Pétersbourg vient de parcourir la Russie de ,Varsovie au Kamtcharkar [sic], $q u$ 'il a trouvé partout des troupes merveilleusement entraînées, des approvisionnements surabondants, un matériel de premier ordre, etc. Zit. CaILlaUX, Mémoires, Bd. III, S. 45. Poincaré bezog sich in diesem Gespräch offensichtlich auf die Berichte de Laguiches über dessen Reise nach Sibirien vom 19., 20., 23. 11. und 3. 12. 1913. Vgl. SHA, 7N1478. 
sichtlich um einen neuerlichen Bluff des Deutschen Reiches handle, und als er dann am 27. Juli den Tag damit verbrachte, seinem Ministerpräsident zu erklären, que la faiblesse vis-à-vis de l'Allemagne était toujours mère de complications et que la seule manière d'écarter le danger était de montrer une fermeté persévérante et un impassible sang-froid ${ }^{563}$. Doch angesichts der Konstanz, mit der Poincaré die Außenpolitik des Deutschen Reiches als bluffeuse bezeichnete, wird man seine Erklärungen vom 27. Juli nicht als bloß taktische Einlassung deuten dürfen, die darauf zielte, das Risiko einer direkten Konfrontation der Blöcke geringer erscheinen zu lassen, als es tatsächlich war, um damit den schwankenden Ministerpräsidenten für seine Politik der $\mathrm{zu}$ allem entschlossenen Unterstützung Rußlands einzunehmen. Ohne daß nach seiner Auffassung eine direkte Konfrontation unmittelbar in eine militärische Auseinandersetzung einmünden würde, zeigt sich doch, daß auch Poincaré das Risiko einer solchen Politik beträchtlich erschienen sein muß, zumal sich für ihn - weit über den Zweifel hinaus, ob sich die Reichsleitung im entscheidenden Augenblick als stark genug erweisen würde, um gegen den Widerstand der öffentlichen Meinung den politischen Vergleich durchzusetzen - im Hinblick auf das Deutsche Reich noch ein weiterer Quell der Sorge nachweisen läßt. Denn nicht allein Hochmut und Arroganz erkannte er als einen bestimmenden Zug der deutschen Außenpolitik, sondern darüber hinaus auch einen Faktor, der sich kaum mit diesen beiden erstgenannten verbinden läßt: die Angst.

Abermals ist es der Chefredakteur des »Matin «, der in seinen Erinnerungen berichtet, daß Poincaré in den letzten Monaten des Jahres $1913 \mathrm{zu}$ der Erkenntnis gelangt sein soll: L'Empereur et l'Allemagne n'ont pas que la baine de la France: ils ont la crainte de la Russie. Ils savent que ce grand corps prend chaque jour de la cohésion; ils veulent l'attaquer et le détruire, avant qu'il ait atteint la plénitude de sa force ${ }^{564}$. Nach Wissen des Verfassers sind die Memoiren Lauzannes die einzige Quelle, die für Poincaré die Furcht überliefern, daß das Deutsche Reich aus Sorge vor der russischen Machtentfaltung zu einem militärischen Prävenire schreiten könnte. Gleichwohl macht dieses Faktum sie nicht von vornherein unglaubwürdig. Was an anderer Stelle zur Verteidigung dieser Memoiren angeführt worden ist, könnte hier wiederholt werden, und darüber hinaus läßt sich nachweisen, daß auch andere Repräsentanten der politischen Führung Frankreichs in diesen Bahnen dachten.

Über das Bild, das sich der Reichskanzler von der Zukunft Rußlands machte, hatte Jules Cambon Poincaré schon früh unterrichtet. In einem amtlichen Bericht unter dem Datum des 28. Juli 1912 hatte der Botschafter dem Ministerpräsidenten und Außenminister mitgeteilt: Il est revenu très frappé

563 Zit. Notes journalières, in: NL Poincaré, BNF, Nafr. 16027, fol. 122 (Eintrag vom 27. 7. 1914).

564 Zit. LaUZanNe, Les hommes que j'ai vus, S. 56. 
de la force latente de la Russie et convaincu qu'il y a dans ce pays une réserve de puissance politique, industrielle et économique qui dépasse de beaucoup celle du vieux monde: 'car, m'a-t-il dit, vous et nous, nous sommes de vieilles nations. La beauté de la race l'a frappé et il est convaincu que la Russie n'est

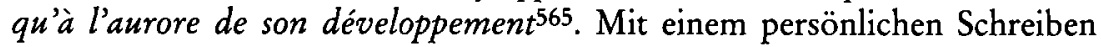
unterstrich Cambon dann noch unter demselben Datum diesen Eindruck des Kanzlers:

Je n'ai pas pu souligner dans cette lettre officielle ce qui m'a frappé; ce que je viendrai faire ici. [...] Le Chancelier a rapporté de Russie un sentiment d'admiration et d'étonnement si profond qu'il influera sur sa politique. La grandeur du pays, son étendue, sa richesse agricole l'ont impressionné, ainsi que la vigueur de la population encore dénuée, a-t-il remarqué de toute intellectualité. Il a comparé la jeunesse de la Russie à celle de l'Amérique, et il lui a semblé que celle de la Russie était pleine d'avenir tandis qu'il ne lui parait pas que l'Amérique apporte aucun élément nouveau au patrimoine commune de l'bumanité. A côté de la Russie, $m$ 'a dit le chancelier, l'Allemagne et la France sont des vieux pays, déjà un peu usés et nous représentons les uns et les autres la culture du passés66.

Rund ein Jahr später kam Cambon, dieses Mal in einem Brief an Außenminister Pichon, auf seinen Bericht aus dem vergangenen Sommer zurück. In der Rede, mit der der Kanzler am 7. April 1913 vor dem Reichstag die Notwendigkeit einer erneuten Aufrüstung zu begründen suchte, hatte er diese unter anderem mit einem Hinweis auf die Machtentfaltung Rußlands, dieses mit unerschöpflichen Naturschätzen ausgestatteten Riesenreiches ${ }^{567}$ verteidigt. Cambon erkannte in dieser dramatischen Beschreibung keinen rhetorischen Kunstgriff. Seiner Auffassung nach war Bethmann Hollweg weder Rhetor noch Diplomat, sondern hatte in seiner Rede einfach ausgesprochen, ce qu'il pense. Il m'a entretenu moi-même, de l'impression qu'il a rapportée de son dernier voyage en Russie; il croit ce pays destiné à un immense développe$m e n t^{568}$. Bethmann Hollwegs Einschätzung der zukünftigen Entwicklung Rußlands muß dabei den Verantwortlichen an der Seine um so glaubwürdiger erschienen sein, als - wie noch in anderem Zusammenhang darzulegen sein wird - auch die militärische und politische Führung Frankreichs von einer fast ungeheuer anmutenden Machtentfaltung ihres Bündnispartners ausging und diese Wahrnehmung wirkungsmächtige Konsequenzen für ihren eigenen außenpolitischen Kurs zeitigte.

Folgt man den Berichten des Botschafters, dann war das Erstarken des russischen Nachbarn nicht der einzige Faktor, der den Reichskanzler pessimistisch in die Zukunft blicken ließ. Glaubte Bethmann Hollweg schon die

565 Zit. Jules Cambon an Poincaré, 28. 7. 1912, in: DDF 3, 3, 228.

566 Zit. Jules Cambon an Poincaré, 28. 7. 1912, in: NL Jules Cambon, MAE, PA-AP 43/ 58 , fol. 45.

567 Zit. Verhandlungen des Reichstages. Stenographische Berichte, Bd. 289, 4512.

568 Zit. Jules Cambon an Pichon, 13. 4. 1913, in: DDF 3, 6, 289. Vgl. auch Jules Cambon an Jonnart, 6. 3. 1913, in: DDF 3, 5, 526. Vgl. damit übereinstimmend auch de Manneville an Pichon, 23. 10. 1913, in: DDF 3, 8, 376. 
Zukunft auf der Seite Rußlands, so fand er zudem auch die Gegenwart gegen sich. Denn mochte im 18. Jahrhundert die Herrschaft eines Monarchen über unterschiedliche Völker ein Diamant in seiner Krone gewesen sein, so hatte sich im Zeitalter des Nationalismus dieser Diamant in ein Stück Kohle verwandelt, das als schwarzer Fluch auf dem Haupt des Monarchen lastete.

Zeitgleich zur russischen Machtentfaltung und diese noch verstärkend trat der Reichsleitung mehr und mehr der habsburgische Machtverfall ins Bewußtsein, der mit dem partiellen Zusammenbruch des Osmanischen Reichs und dem Erstarken der Balkanstaaten die internationale Lage des Deutschen Reiches zunehmend prekärer werden ließ569. Auch über diese Entwicklung berichtet der französische Botschafter. In deutlich erkennbarem Gegensatz zu seinem Militärattaché Serret, der die Aufrüstung des Deutschen Reiches allein aus jenem bis zur Arroganz auftrumpfenden Selbstbewußtsein zu erklären suchte und der in dem partiellen Zusammenbruch des Osmanischen Reiches nur einen Vorwand zu erkennen vermochte, der es dem Deutschen Reich gestattete, seit langer Zeit Geplantes ins Werk zu setzen, entwarf der Botschafter ein differenziertes Bild ${ }^{570}$. Zwar erkannte auch er den von seinem Militärattaché geltend gemachten Grund als ein wichtiges Motiv der deutschen Politik, doch stellte er der deutschen "Arroganz« gleichwertig die durch den Zusammenbruch des Osmanischen Reiches nachteilig gewandelte Lage zur Seite. J'inclinerais cependant à penser, so berichtete Cambon gar einmal an seinen Dienstherrn, que la vraie raison du projet militaire se trouve dans le fait que, par suite de la guerre dans les Balkans, le Gouvernement impérial sent ses alliances affaiblies militairement, car les forces des jeunes États balkaniques occuperont suffisamment l'Autriche pour que le poids de la lutte avec la Triple Entente retombe sur l'Allemagne seule ${ }^{571}$.

Gleich mehrfach machte der Botschafter seine Außenminister in den Monaten bis zum Ausbruch des Großen Krieges darauf aufmerksam, daß maß-

569 Vgl. die Ausführungen im Kapitel „Der Sprung ins Dunkle«.

570 Nur in seinem ersten Bericht vom 20. Januar 1913 erwähnte Serret diesen Grund. Vgl. Serret an Étienne, 20.1. 1913, in: DDF 3, 5, 239. Vgl. auch Ders. an Dens., 1. 3. 1913, in: DDF 3, 5, 494 und Ders. an Dens., 15. 3. 1913, in: DDF 3, 5, 593, dort irrtümlich auf den 14. 3.1913 datiert. Vgl. auch Serret an Étienne, 5. 7. 1913, in: DDF 3, 7, 292: On ne parle plus de la rupture d'équilibre balkanique. Celle-ci, je n'ai cessé de le redire, a été le prétexte, permettant de réaliser d'un coup, à une date favorable, une situation, en face de laquelle nous nous serions trouvés quand même, quelques années plus tard. Le but principal, c'est sune politique mondiale productive - nous sommes encore à ses débuts.

571 Zit. Jules Cambon an Jonnart, 12. 2. 1913, in: DDF 3, 5, 380. Vgl. in diesem Zusammenhang auch Ders. an Dens., 27. 2. 1913, in: DDF 3, 5, 475 und Ders. an Dens., 6. 3. 1913, in: DDF 3, 5, 527 sowie Ders. an Pichon, 30. 3. 1913, in: DDF 3, 6, 121. Vgl. auch Cambons retrospektive Betrachtung, in deren Rahmen er einen doppelten Grund für die deutsche Aufrüstung verantwortlich machte: En premier lieu, l'Allemagne [...] a considéré comme un échec grave l'issue des négociations de 1911, qu'elle a appelée un Olmütz. En second lieu, la guerre des Balkans lui a owvert les yeux sur la faiblesse de l'Autriche. Zit. Jules Cambon an Doumergue, 3. 5. 1914, in: DDF 3, 10, 194. 
gebliche Repräsentanten des Reiches immer weniger Zutrauen in die Überlebensfähigkeit der Habsburgermonarchie hatten. So beispielsweise im Juli 1913, als er an Außenminister Pichon schrieb: on commence à trouver ici que l'Autriche est décidément un poids mort ${ }^{572}$ und so auch noch einmal im April 1914. Lange Zeit, nachdem der Balkanbund in einem Streit über die osmanische Beute zerfallen war, berichtete Cambon an Außenminister Doumergue: Ils considèrent l'Autriche, toute leur alliée, qu'elle soit comme à la veille de tomber en pièces ${ }^{573}$, und in einem privaten Brief an den Politischen Direktor de Margerie unterstrich der Botschafter diese Einschätzung noch einmal: Jagow a dit récemment à un de mes collègues qu'il croyait que l'Autriche s'écroulerait avant la Turquie ${ }^{574}$.

Folgt man den Memoiren des belgischen Botschafters, dann verstanden er und Cambon zumindest in den letzten Tagen der Julikrise das Ultimatum der Habsburgermonarchie an Serbien als ersten Zug in einem außenpolitischen Manöver, mit dem ein deutscher Präventivkrieg eingeleitet worden war ${ }^{575}$. $\mathrm{Zu}$ einem vergleichsweise frühen Zeitpunkt der Julikrise, das heißt noch vor dem 23. Juli, lassen sich solche Befürchtungen auch für den Marineattaché der französischen Botschaft nachweisen, wenn man dessen Erinnerungen Glauben schenken darf 576 .

Mit einer Eindeutigkeit, die nichts zu wünschen übrig läßt, können solche Befürchtungen jedoch für Delcassé nachgewiesen werden ${ }^{577}$. Der ehemalige Marineminister des Kabinetts Poincaré war schon im April 1913 convinced that Germany cannot afford to wait; that she will not be able to bear the strain; that her position will be worse in a few years' time than it is now; and that as she seems to have told the Italians the other day, if war cannot be averted she would sooner face it at once ${ }^{578}$. Nachgerade apodiktisch erklärte Del-

572 Zit. Jules Cambon an Pichon, 21. 7. 1913, in: NL Pichon, BIF 4396, fol. 93.

573 Zit. Jules Cambon an Doumergue, 13. 4. 1914, in: DDF 3, 10, 101.

574 Zit. Jules Cambon an de Margerie, 13. 4. 1914, in: NL de Margerie, MAE, PA-AP 113/9, fol. 295. Die Unterstreichungen im Original stammen von der Hand de Margeries. Vgl. den Entwurf in: NL Jules Cambon, MAE PA-AP 43/56, fol. $5 \mathrm{f}$. Jules Cambon hat diese Nachricht aller Wahrscheinlichkeit nach aus der Hand des britischen Botschafters erhalten. Vgl. Goschen an Nicolson, 27. 3. 1914, in: BD 10/2, 532. An dieser Stelle seien auch die Ausführungen des vorangegangenen Kapitels in Erinnerung gerufen, die deutlich gemacht haben, daß sich die Analysen des Generalstabs, die in den letzten Jahren vor Ausbruch des Großen Krieges der osteuropäischen Machtbalance gewidmet wurden, nach dem partiellen Zusammenbruch des Osmanischen Reichs ersichtlich optimistischer ausnahmen.

$575 \mathrm{Vgl}$. BEYENS, Deux années, S. 249.

576 Vgl. FARAMOND, Souvenirs, S. 100, 133, 164.

577 Vgl. auch einen Brief von unbekannter Hand, der unter dem Datum des 22. August 1914 an Delcassé gesandt wurde. Dort heißt es: Vous m'avez toujours dit que la guerre était inévitable et qu'elle éclaterait en 1914 ou en 1915, mais plus probablement en 1914. Zit. Anonymus an Delcassé, 22. 8. 1914, in: NL Delcassé, MAE, PA-AP 221/9, fol. 135. $578 \mathrm{Zit}$. Buchanan an Nicolson, 11.4. 1913, in: PRO NL Nicolson, FO 800/365, fol. $42 \mathrm{f}$. 
cassé dem britischen Botschafter, that Germany would strike before Russia was ready and discover a pretext for war whenever she found a weak place in Russia's armour. He assured me that be knew this as a fact ${ }^{579}$. Mit dieser Einsicht dürfte Delcassé auf die ungeteilte Zustimmung seines britischen Kollegen gestoßen sein. Denn in den letzten Monaten vor Kriegsausbruch erkannten auch zahlreiche britische Repräsentanten, unter ihnen insbesondere Buchanan, die Gefahr eines deutschen Prävenires, das aus Sorge vor den nicht zu konternden Rüstungen des Zarenreiches unternommen werden könnte ${ }^{580}$.

Es ist nicht ohne Ironie, daß ausgerechnet der Botschafter Frankreichs, dessen Mission primär darin bestanden hatte, den Ausbau der militärischen Infrastruktur des Bündnispartners in einem Maße zu fördern, daß dieser das Deutsche Reich mit einem tödlichen Angriff bedrohen konnte, ein militärisches Prävenire des Gegners prognostizierte. Doch in gewisser Hinsicht ist es bezeichnend. Denn obgleich maßgebliche Repräsentanten sowohl der militärischen als auch der politischen Führung Frankreichs erkannten, daß sich in den letzten Jahren vor Kriegsausbruch die Lage des Deutschen Reiches aufgrund der russischen Machtentfaltung und des habsburgischen Machtverfalls prekär ausnahm und daß wichtige Entscheidungsträger innerhalb der Reichsleitung diese Entwicklung mit zunehmender Sorge beobachteten und ihr möglicherweise mit militärischen Mitteln entgegentreten würden, zog man keine Konsequenzen aus dieser Einsicht. Statt in gesamtsystemischen Bahnen zu denken und etwa durch Konzessionen auf dem Rüstungssektor oder

579 Zit. ibid. Vgl. auch Ders. an Grey, 9. 4. 1913, in: BD 9/2, 820: $\mathrm{He}$ [gemeint ist Delcassé, St. S.] takes a very serious view of Germany's present attitude. He looked be said at the facts. Rate of taxation in Germany was far bigher than in France and her economic condition was not so good. She could not therefore bear for long the strain of the new taxes necessitated by ber increased armament. She knew moreover that in two or three years, the Balkan states would be far stronger that at present. She would therefore prefer not to postpone the evil days. Mit der Annahme, daß das Deutsche Reich aufgrund einer beschränkten Finanzkraft den Rüstungswettlauf der Großmächte verlieren und schließlich eine militärische Flucht nach vorn antreten würde, dürfte der Botschafter nicht auf die Zustimmung des Finanzministeriums getroffen sein. Unter dem Datum des 23. Juli 1912 sandte Finanzminister Klotz die Denkschrift "Au sujet de la situation financière de l'Allemagne» an Poincaré. In ihrem Rahmen sprach Klotz von einem prodigieux enrichissement de ce pays au cours des 20 dernières années und gelangte zu der Schlußfolgerung que les ressources qu'il [gemeint ist das Deutsche Reich, St. S.] se crée chaque jour en augmentation d'une richesse acquise déjà considérable, le mettent en mesure d'affronter tous les évènements dont dépendraient à ses yeux son avenir et sa prospérité. Zit. Klotz an Poincaré, 23. 7. 1912, in: CAEF, B 61035/2. Vgl. auch das Original des Schreibens in: MAE, NS Allemagne 115.

580 Vgl. Buchanan an Grey, 18. 3. 1914, in: BD 10/2, 528 und Ders. an Nicolson, 18. 3. 1914, in: BD 10/2, 529. Auch in den folgenden Monaten kam Buchanan immer wieder auf diesen Gedanken zurück, und noch am 21 . Juli sprach er gegenüber seinem italienischen Kollegen die Befürchtung aus, daß das Deutsche Reich die Krise nutzen werde, um einen Präventivkrieg gegen Rußland zu führen. Vgl. Carlotti an San Giuliano, 22. 7. 1914, in: DDI 4, 12, 406. 
durch eine Kooperation über bestehende Allianzen hinweg die Lage des Deutschen Reiches erträglich zu gestalten, förderte Frankreich mit allen verfügbaren Mitteln die Entfaltung der russischen Macht, war bestrebt, dem Deutschen Reich die Fähigkeit zum Angriff zu nehmen und vermied die geringste Distanz zu seinem Bündnispartner. Quant aux balivernes diplomatiques, aux vieilles calembredaines de l'équilibre européen, so ließ sich Delcassé vor seiner Abreise nach Sankt Petersburg gegenüber dem Politischen Direktor vernehmen, je m'en occuperai le moins possible: ce n'est plus que du verbiage $e^{581}$.

Einer der Gründe, die für den Verlust gesamtsystemischen Denkens verantwortlich zu machen sind, ist schon im letzten Kapitel dieser Untersuchung benannt worden, und ein weiterer mag auf ihren letzten Seiten deutlich geworden sein. Wird man einerseits in Rechnung stellen, daß Frankreich durch den Aufmarschplan seines Generalstabes in eine militärische Gesamtsituation geraten war, die unverkennbar die Züge der Überforderung trug und seinen außenpolitischen Entscheidungsträgern nur wenig Raum für Konzessionen gab, so wird man andererseits für den Verlust eines Handelns, das dem Abbau von Spannungen und damit dem Erhalt des gesamten Systems galt, eben auch jenes ambivalente Deutschlandbild verantwortlich machen müssen. Denn eine Politik, die sich dem Erhalt des Systems verpflichtete, wäre nur unter der Voraussetzung sinnvoll gewesen, daß auch der Gegner keinen revolutionären, das heißt das System sprengenden Absichten nachging. Zwar war man nun durchaus überzeugt, daß Kaiser und Kanzler, qui veulent concilier l'expansion de l'Empire avec le maintien de la paix ${ }^{582}$, prinzipiell friedlich gesinnt waren. Zugleich war man aber auch der Auffassung, daß sehr heterogene Kräfte auf die deutsche Außenpolitik einzuwirken vermochten, und hegte die Befürchtung, daß die Gruppen, die eine militärische Auseinandersetzung forderten, mittels einer von ausgreifenden Hoffnungen und Sehnsüchten getriebenen Öffentlichkeit einen Druck geltend machen könnten, der im entscheidenden Augenblick möglicherweise maßgeblich sein würde. Vor diesem Hintergrund mußten sich aber Konzessionen an das Deutsche Reich als gefährliche Beeinträchtigung der französischen Sicherheitsinteressen ausnehmen.

Doch selbst dort, wo Frankreichs Sicherheitsinteressen nicht unmittelbar berührt waren, ist es in den letzten Jahren vor Ausbruch des Großen Krieges nur sehr selten zu Einigungen gekommen, mit denen sich auf französischer Seite handlungsleitend die Absicht verband, einen Entspannungseffekt zu erzielen, und die möglicherweise die Position der Reichsleitung gegenüber der deutschen Öffentlichkeit hätten stärken können ${ }^{583}$. Das Abkommen, mit dem beide Nationen ihre widerstreitenden Interessen im Osmanischen Reich

581 Zit. PALÉologue, Journal, S. 79 (Eintrag vom 16. 3. 1913).

582 Zit. Pellé an Millerand, 26. 5. 1912, in: DDF 3, 3, 45.

$583 \mathrm{Vgl}$. WILSBERG, Kooperative Momente und Konflikt, S. $348 \mathrm{f}$. 
verglichen und an das insbesondere Außenminister Pichon weitergehende Hoffnungen geknüpft zu haben scheint - begründete er doch das Verhandlungsbegehren gegenüber dem deutschen Botschafter mit dem Wunsch, durch eine Einigung nicht nur örtliche Reibungsflächen zu beseitigen, sondern auch allgemein eine wobltuende erbebliche Entspannung der Beziebungen beider. Nationen ${ }^{584}$ herbeizuführen -, nimmt sich letztlich als ein Einzelfall aus. Auch die Fragen, die Cambon in einem Brief vom 8. Juli 1913 an den Außenminister aufwarf und die da lauteten:

Est-il raisonnable de croire qu'une nation de plus de soixante-dix millions d'habitants, qui s'accroît sans cesse et dont l'industrie se développe, peut se cantonner sur le territoire occupé il y a quelques années par trente-cinq millions d'bommes? A vouloir boucher toutes les issues d'une chaudière, ne la fait-on pas éclater? Et ne serait-il pas plus prudent de ne pas contrecarrer partout une expansion inévitable?, fanden keine Beachrung 585.

Zu einer kontinuierlich verfolgten Entspannungspolitik oder einer Kooperation, die dem Deutschen Reich ein Betätigungsfeld eröffnete, das ihm begrenztes, nicht jedoch systemsprengendes Wachstum ermöglicht hätte, ist es nie gekommen. Mit einem solchen Handeln begab man sich aber zugleich der Möglichkeit, den deutsch-französischen Antagonismus einzudämmen, was dann in der Folge - wie nun im Rahmen einer Untersuchung der französischrussischen Allianz zu zeigen sein wird - im Juli 1914 zu einer bündnispolitischen Zwangslage führte, die nach Auffassung Poincarés und Paléologues eine zu allem entschlossene Unterstützung Rußlands erforderlich machte.

\section{Die französisch-russische Allianz Eine bündnispolitische $\mathrm{Zwangslage}$}

Bei Ausbruch des Ersten Weltkrieges wurden die französisch-russischen Beziehungen durch ein politisches Abkommen aus dem Jahr 1891 und eine streng geheime Militärkonvention aus dem Jahr 1892 geregelt, deren genaue Bestimmungen bis zum Jahr 1914 mehrfach modifiziert worden waren ${ }^{586}$.

584 Zit. Schoen an Bethmann Hollweg, 6. 8. 1912, in: GP 37/2, 14935. Vgl. WILSBERG, Kooperative Momente und Konflikt, S. 340 f. Hingegen akzentuiert Löhr in seiner Miszelle für die Francia deutlich dieses Motiv und erblickt in dem entspannenden Effekt auf die europäische Politik die Grundlage der Deutschlandpolitik Pichons. Vgl. LÖHR, Deutsch-französische Beziehungen, S. $143 \mathrm{f}$. Vgl. ferner GUILLEN, Questions coloniales dans les relations franco-allemandes, S. $98 \mathrm{f}$. Vgl., allerdings mit starker Konzentration auf die deutsche Seite, KIESSLING, Entspannung, S. 193-206, hier insbesondere S. 194. Kießling urteilt in diesem Zusammenhang sehr zurückhaltend: »In Einzelfällen klang [...] auch die >Peripher-Strategie auf politischen Feldern an«. Zit. Ibid., S. 194. 585 Zit. Jules Cambon an Pichon, 8. 7. 1913, in: DDF 3, 7, 317.

586 Zum politischen Abkommen vgl. Mohrenheim an Ribot, 27. 8. 1891, in: DDF 1, 8, 514 und Ribot an Mohrenheim, 27. 8. 1891, in: DDF 1, 8, 517. Vgl. den Text der Militärkonvention von 1892 in: DDF 1, 9, 444 und DDF 1, 9, 461. Zur Ratifikation der Mi- 
Waren im politischen Abkommen Frankreich und Rußland zunächst darin übereingekommen, sich in allen Fragen abzustimmen, die zu einer Bedrohung des Friedens führen konnten, und hatten sie sich dann seit 1899 auch zur Abstimmung in Angelegenheiten verpflichtet, die das Gleichgewicht der Mächte in Europa berührten ${ }^{587}$, so legte erst die Militärkonvention, die von beiden Staaten an der Jahreswende 1893/1894 ratifiziert worden war, den casus foederis der Allianz fest. Mit ihr war am 27. Dezember 1893 und am 4. Januar 1894 vereinbart worden:

[Artikel I] Si la France est attaquée par l'Allemagne ou par l'Italie soutenue par l'Allemagne, la Russie emploiera toutes ses forces disponibles pour attaquer l'Allemagne. Si la Russie est attaquée par l'Allemagne ou par l'Autriche soutenue par l'Allemagne, la France emploiera toutes ses forces disponibles pour combattre l'Allemagne. [Artikel II] Dans le cas où les forces de la Triple Alliance ou d'une des Puissances qui en font partie viendraient à se mobiliser, la France et la Russie, à la première annonce de l'événement et sans qu'il soit besoin d'un concert préalable, mobiliseront immédiatement et simultanément la totalité de leurs forces et les porteront les plus près possibles de leurs frontières ${ }^{588}$.

In der historischen Forschung ist mehrfach darauf aufmerksam gemacht worden, daß zwischen diesen beiden Artikeln der Militärkonvention ein Ungleichgewicht bestand ${ }^{589}$, und mit George F. Kennan hat einer der besten Kenner der Verhandlungen, die zum Abschluß des Abkommens führten, gar davon gesprochen, daß Frankreich und Rußland durch die Gegenüberstellung dieser Klauseln "eine Unredlichkeit in gegenseitigem Einverständnis begingen ${ }^{590}$. Denn sicherte Frankreich dem Bündnispartner in Artikel I der Konvention seinen militärischen Beistand allein im Fall eines deutschen oder eines vom Deutschen Reich unterstützten Angriffs zu, sah Artikel II des Abkommens die Mobilmachung Frankreichs, die sich allein schon aufgrund der geographischen Gegebenheiten nur gegen das Deutsche Reich richten

litärkonvention vgl. Giers an Montelbello, 27. 12. 1893, in: DDF 1, 10, 488 (Annexe) und Montebello an Giers, 4. 1. 1894, in: DDF 1, 11, 7 (Annexe).

587 Zur Modifikation des politischen Abkommens im Jahr 1899 vgl. RENOUVIN, L'orientation de l'alliance franco-russe en 1900-1901, S. 312-319; ANDREW, Delcassé, S. 119-135, hier insbesondere S. 124-126 und DERS., German World Policy, S. $138 \mathrm{f}$. 588 Zit. Montebello an Ribot, 10. 8. 1892, in: DDF 1, 9, 444.

589 Vgl. Renouvin, Alliance, S. $312 \mathrm{f}$.; Ders., Les engagements de l'Alliance francorusse. Leur évolution de 1891 à 1914, in: RHGM 12 (1934), S. 297-311, hier S. 299 f. und DERS., Les relations franco-russes à la fin du XIX ${ }^{\mathrm{e}}$ et au début du XX $\mathrm{XX}^{\mathrm{e}}$ siècle, in: Cahiers du monde russe 1 (1959/1960), S. 128-147, hier S. 131 f. Bei dem letztgenannten Aufsatz handelt es sich um einen fast unveränderten Nachdruck der Arbeit "Les engagements de l'Alliance franco-russe. Leur évolution de 1891 à 1914«. Vgl. ferner KENNAN, Schicksalhafte Allianz, passim, hier insbesondere S. 240-250 und NOLDE, L'alliance franco-russe, S. 662f., 665, 668f., der nur mit einigen sehr knappen Bemerkungen auf diese wesentliche Tatsache eingeht.

590 Zit. KENNAN, Schicksalhafte Allianz, S. 249. Vgl. mit ähnlichem Urteil auch JAKOBS, Werden, S. $129 \mathrm{f}$. 
konnte, auch für den Fall einer Mobilmachung der Habsburgermonarchie vor.

Bedenkt man darüber hinaus, daß sich die Generalstabschefs beider Nationen darin einig waren, daß eine allgemeine Mobilmachung nicht mehr als friedlicher Akt gewertet werden konnte - hatte Boisdeffre doch in den Verhandlungen erklärt: la mobilisation, c'était la déclaration de guerre [... $]^{591}$ so wird deutlich, daß durch den Artikel II der Militärkonvention der casus foederis der Allianz eine bedenkliche Ausdehnung erfahren konnte, zumal in seiner ursprünglichen Fassung weder zwischen einer partiellen noch einer allgemeinen und damit weder zwischen einer gegen Rußland noch gegen einen Balkanstaat gerichteten Mobilmachung der Habsburgermonarchie unterschieden worden war.

Der kleine Kreis der wichtigsten Entscheidungsträger, der auf seiten Frankreichs die Verhandlungen geführt hatte, war sich dieser Tatsache durchaus bewußt. Ein von ihnen im Juli 1892 ausgearbeiteter erster Entwurf des Abkommens hätte deshalb Frankreich allein für den Fall einer Mobilmachung des Deutschen Reiches oder des gesamten Dreibundes zu einem entsprechenden Schritt verpflichtet ${ }^{592}$. Doch gegen den russischen Widerstand hatten sie keine Fassung durchzusetzen können, in der der Automatismus zwischen der österreichischen und französischen Mobilmachung aufgehoben worden wäre ${ }^{593}$. Aus Sicht des russischen Generalstabschefs Obrutchew galt es, sich insbesondere für eine militärische Auseinandersetzung mit der Habsburgermonarchie die erforderliche Rückenfreiheit zu verschaffen, und deshalb sollte Frankreich eine Generalmobilmachung der Doppelmonarchie umgehend mit einem entsprechenden Schritt beantworten ${ }^{594}$. Letztlich lag damit schon der Konvention in ihrer Fassung von 1892 eine Divergenz der strategischen Absichten zugrunde, die in ähnlicher Form auch noch die Unterredungen zwischen den militärischen Führungen beider Staaten in den letzten Jahren vor Ausbruch des Großen Krieges bestimmen sollte. Während Frankreich den Bündnispartner auf einen sowohl umgehenden als auch umfassenden Angriff gegen das Deutsche Reich zu verpflichten suchte, beabsichtigte Rußland in der ersten Phase der Auseinandersetzungen, zunächst den habsburgischen Rivalen anzugreifen und erst in einem fortgeschrittenen Stadium gegen das dann geschwächte und isolierte Deutsche Reich vorzugehen.

Doch bei diesen unterschiedlichen militärischen Prioritäten handelte es sich um Bedeutenderes als einen Disput über eine strategische Frage. Vielmehr lagen den divergenten Auffassungen über das richtige Handeln im Kriegsfall auch gegensätzliche politische Interessen zugrunde. So fand sich weder Frankreich dazu bereit, zur Durchsetzung russischer Interessen auf

591 Zit. Boisdeffre an Freycinet, 18. 8. 1892, in: DDF 1, 9, 461 (Annexe).

592 Vgl. Ribot an Montebello, 28. 7. 1892, in: DDF 1, 9, 421.

593 Vgl. KenNAN, Schicksalhafte Allianz, S. 207-209, 240-242.

594 Vgl. ibid., S. 138-142, 222-233. 
dem Balkan eine militärische Auseinandersetzung zu führen, noch Rußland dem Bündnispartner seine Hand für eine militärische Revision des Frankfurter Friedens zu leihen 595 . Aus diesem Grund mag man möglicherweise George F. Kennan in juristischer, nicht aber in politischer Hinsicht zustimmen, wenn der amerikanische Diplomat und Historiker konstatiert, daß durch den Artikel II der Militärkonvention, der de facto den casus foederis nicht an die Bedingung eines Angriffs, sondern an die Mobilmachung einer Macht des Dreibundes knüpfte, eine "merkwürdige und befremdliche Besonderheit « entstanden war, "dank derer die Russen die Möglichkeit hatten, einen großen europäischen Krieg zu entfesseln, wann immer es ihnen in den Kram paßte ${ }^{596}$.

Gemäß seiner politischen Interessen hatte Frankreich in den folgenden Jahren dann auch mehrfach dem casus foederis der Allianz eine restriktive Interpretation geben. So zunächst im Jahr 1895, als der armenische Greuel die Großmächte entzweite, und dann auch im Jahr 1897, als das Osmanische Reich mit Griechenland im Krieg lag und Außenminister Hanotaux dem Bündnispartner erklärte, daß im Fall einer militärischen Intervention der Habsburgermonarchie die Militärkonvention keine Anwendung finden könne ${ }^{597}$. Ganz ähnlich war die Reaktion Frankreichs noch im Rahmen der bosnischen Annexionskrise von 1908 ausgefallen ${ }^{598}$. Als der damalige russische Außenminister Iswolski anfragte, ob Rußland im Fall einer militärischen Aktion der Habsburgermonarchie gegen Serbien auf den uneingeschränkten Beistand des Bündnispartners rechnen könne ${ }^{599}$, hatte Außenminister Pichon zur sichtlichen Enttäuschung des Bündnispartners in Petersburg erklären lassen, daß tous les intérêts primordiaux de la Russie ne sont pas engagés. Frankreich werde die ihm obliegenden Verpflichtungen aber nur dann erfüllen, lorsque les intérêts vitaux de la France et de la Russie sont menacés 600 . Überblickt man die Periode zwischen dem Abschluß der Allianz und dem Jahr 1911, so wird deutlich, daß Frankreich seinem Bündnispartner mehrfach zu verstehen gab, daß man für die Durchsetzung rein russischer Interessen auf der Balkanhalbinsel keinen Krieg führen werde, und diese defen-

$595 \mathrm{Vgl}$. RenOUVIN, Alliance franco-russe, S. $307 \mathrm{f}$. und insbesondere DerS., Engagements, passim. Vgl. ferner JAKOBS, Werden, S. $130 \mathrm{f}$.

596 Zit. KENNAN, Schicksalhafte Allianz, S. 337.

597 Vgl. Hanotaux an Montebello, 10. 4. 1897, in: DDF 1, 13, 193.

598 Zur Bosnischen Annexionskrise vgl. DülfFER, Vermiedene Kriege, S. 603-614.

599 Vgl. Touchard an Pichon, 14. 2. 1909, in: DDF 2, 12, 13; Ders. an Dens., 16. 2. 1909, in: DDF 2, 12, 19; Ders. an Dens., 18. 2. 1909, in: DDF 2, 12, 23 und insbesondere Ders. an Dens., 19. 2. 1909, in: DDF 2, 12, 29. In der letztgenannten Depesche zitierte der Botschafter Iswolski mit den Worten: Si les appuis sur lesquels nous sommes en droit de compter venaient à nous faire défaut, nous serions obligé sans doute de dévorer l'affront; mais soyez bien assurés que, dans ce cas, nous serions amenés [...] à changer complètement le système de nos alliances et de nos amitiés.

600 Zit. Pichon an Touchard, 25. 2. 1909, in: DDF 2, 12, 55. Dort auch das vorhergehende Zitat. 
sive Interpretation des casus foederis schlug sich schließlich auch in den vertraglichen Bestimmungen der Militärkonvention nieder. So wurde in der Fassung der Militärkonvention von 1911 für beide Staaten erstmals rechtlich verbindlich zwischen dem Fall einer partiellen und dem Fall einer allgemeinen Mobilmachung der Habsburgermonarchie unterschieden und zudem der seit rund zwei Jahrzehnten bestehende Automatismus zwischen einer Mobilmachung Österreich-Ungarns und Frankreichs aufgehoben ${ }^{601}$. Während sich beide Nationen im Fall einer deutschen Mobilmachung weiterhin verpflichteten, diese umgehend mit einem entsprechenden Schritt zu beantworten, sollte zukünftig im Fall einer Mobilmachung der Donaumonarchie zunächst eine Abstimmung zwischen Frankreich und Rußland erfolgen ${ }^{602}$.

Diese Entwicklung sollte sich erst umkehren, als Poincaré in den Monaten nach seiner Ernennung zum Ministerpräsidenten und Außenminister der Republik dem casus foederis eine extensive Interpretation gab, indem er eine militärische Unterstützung des russischen Bündnispartners nicht mehr von den spezifischen Umständen abhängig machte, unter denen der große Krieg ausbrechen würde, sondern diese allein mit der Intervention des Deutschen Reiches verknüpfte und damit die Allianz von einem defensiven Arrangement in ein Abkommen umdeutete, das für eine offensive Politik benutzt werden konnte.

In der historischen Forschung besteht über diese neue Wendung in der Geschichte der französisch-russischen Allianz weitgehender Konsens ${ }^{603}$, und selbst Renouvin hat in diesem Zusammenhang konstatiert, daß unter dem neuen Ministerpräsidenten »des nouvelles tendances« erkennbar geworden seien $^{604}$. Eine von dieser Meinung abweichende Auffassung vertreten aller-

601 Schon die Fassungen der Militärkonvention von 1900 und 1906 machten erstmals diesen Unterschied. Vgl. Résumé de l'entretien du 2 juillet/19 juin 1900 entre les chefs d'état-major généraux des armées russe et française par application de l'article 4 de la Convention militaire de 1892, in: DDF 1, 16, 208. Vgl. ferner Procès-verbal de l'entretien du 8/21 avril 1906 entre les chefs d'état-major généraux des armées russe et française, 21. 4. 1906, in: DDF 2, 10, 119 (Annexe). Doch im Gegensatz zum Protokoll der Unterredungen von 1911 wurden diese Fassungen nicht von beiden Staaten ratifiziert und blieben damit rechtlich unverbindlich. Vgl. WILCOX, Franco-Russian Alliance, S. 186f. und Murielle AVICE-HANOUN, L'Alliance franco-russe (1892-1914), in: Ijla MIECK, Pierre Guillen (Hg.), Deutschland - Frankreich - Rußland. Begegnungen und Konfrontationen. La France et l'Allemagne face à la Russie, München 2000, S. 109-124, hier S. $113 \mathrm{f}$.

602 Vgl. Procès-verbal de l'entretien du 18/31 août 1911, entre les chefs d'état-major des armées française et russe, in: DDF 2, 14, 232. Vgl. ferner Procès verbal d'une conférence tenue chez M. le Président de la République, 13. 2. 1911, in: DDF 2, 13, 152.

603 Vgl. MiCHON, Alliance, S. 194-197; IsAAC, Paradoxe, S. 229-234; Constantin de GRUNWALD, Les alliances franco-russes. Neuf siècles de malentendus, Paris 1965, S. 342 f.; AlBerTiNi, Origins, Bd. I, S. 402-416; KrUMEICH, Aufrüstung und Innenpolitik, S. $25 \mathrm{f}$. und MATHIEU, Role of Russia, S. $118 \mathrm{f}$.

604 Zit. RENOUVIN, Engagements, S. 308. In der historischen Forschung wird diese These mitunter auf Berichte des russischen Botschafters gestützt, die dieser unter dem Datum des 4. und 7. November an sein Außenministerium sandte. Vgl. Iswolski an Sa- 
dings John F. Keiger und Mark B. Hayne. So gelangt der britische Historiker in seiner Untersuchung der Außenpolitik Frankreichs in den letzten Jahren vor Ausbruch des Großen Krieges zu der These, daß Poincarés Haltung gegenüber dem Bündnispartner in einer Politik der »cohesion and restraint «605 bestanden habe und es dem Ministerpräsidenten auch unter den ungünstigen Bedingungen des "alliance security dilemma" gelungen sei, die feine Balance zwischen den gleichermaßen fatalen Möglichkeiten des »entrapment« und des »abandonment « ${ }^{606} \mathrm{zu}$ wahren. Ohne diese Interpretation in allen Einzelheiten zu teilen, kommt auch Mark B. Hayne zu einem vergleichbaren $\mathrm{Er}-$ gebnis ${ }^{607}$.

sonow, 4. 11. 1912, in: IB III/4,1 143 und Ders. an Dens., 7. 11. 1912, in: IB III/4, 1176. Vgl. ferner Poincaré an Iswolski, 4. 11. 1912, in: DDF 3, 3, 46. In diesem Zusammenhang gerät aber aus dem Blick, daß sich in den Unterredungen, die Poincaré und Iswolski im November 1912 führten, zwei unterschiedliche Fragestellungen überlagerten. Bei ihnen handelte es sich zum einen um die Antwort, die Frankreich einer Annexion osmanischen Territoriums durch Österreich-Ungarn erteilen und zum anderen um die Frage, welche Art von Beistand Frankreich seinem Bündnispartner im Fall eines militärischen Angriffs der Habsburgermonarchie auf Serbien gewähren würde. Die genannten Berichte des russischen Botschafters nehmen allein auf den erstgenannten Problemkreis Bezug, und das Kabinett war in diesem Fall tatsächlich entschlossen, einem solchen Schritt der Donaumonarchie auch mit militärischen Mitteln entgegenzutreten. In den Berichten des Botschafters klingt an, daß Poincaré in einer Annexion osmanischen Territoriums das Fanal zur endgültigen Aufteilung des kranken Mannes am Bosporus erblickte und aus diesem Grund entschlossen war, der Habsburgermonarchie notfalls mit einer militärischen Intervention zu drohen. Im Gespräch mit seinem Botschafter in London benannte er jedoch andere Gründe: $I l$ m'avait répondu nettement, so berichtete Paul Cambon an seinen Bruder in Berlin, [...] que cela soulèverait l'opinion en France et constitueraient un échec pour la triple entente! que nous serions obligés, nous qui avions tant fait depuis le commencement de la guerre (!) de demander aussi des avantages, une île dans la mer Egée par exemple. Zit. Paul Cambon an Jules Camon, 5. 11. 1912, in: NL Jules Cambon, MAE, PA-AP 43/101, fol. 251.

$\mathrm{Daß}$ die öffentliche Meinung in dieser Angelegenheit ein Faktor von bestimmendem Gewicht gewesen sei, mutet eher unwahrscheinlich an. Als Paul Cambon den Präsidenten der Republik darauf ansprach, brach dieser in einen Wutanfall aus: sûr, j'en ai causé avec P[oincaré]. Ils ont pris dans un conseil que je ne présidais pas une résolution pour s'opposer à toute session du Sandjak - qu'est ce que cela nous fait le Sandjak! Ils parlent de l'opinion, ils ne la connaissent pas, je la connais mieux qu'eux, l'opinion ne sait pas ce que c'est ce sandjak. En tous cas, l'opinion se soulèverait si elle savait que nous ne faisons pas la guerre pour reprendre l'Alsace-Lorraine mais que nous sommes prêts à l'affronter pour le Sandjak! Zit. ibid. Vgl. auch Ders. an Dens., 20. November 1912, in: NL Jules Cambon, MAE, PA-AP 43/101, fol. 259: Dans un conciliabule entre Poincaré, Millerand, Briand et Bourgeois il a été décidé qu'on prendrait une attitude intransigeante sur cette question du Sandjak; Millerand, un peu grisé par le commandement des armées, aurait envisagé sans crainte un conflit général, il le désirait même. Poincaré, sans le désirer, $n$ 'en était pas effrayé.

605 Zit. KeIGER, France and the Origins, S. 96. Vgl. ferner ibid., S. 99-101. Vgl. auch die damit übereinstimmenden Ausführungen in: DERS., Poincaré, S. $138 \mathrm{f}$.

606 Zit. SNYDER, Alliance Politics, S. $19 \mathrm{f}$.

$607 \mathrm{Vgl}$. HAYNE, French Foreign Office, S. 244-246. 
Eine Stellung von herausgehobener Bedeutung nimmt in dieser Diskussion für beide Seiten eine Reihe von Gesprächen ein, die der französische Ministerpräsident und der russische Botschafter im November 1912 führten. Unmittelbarer Anlaß dieser Unterredungen war der Vormarsch serbischer Kontingente zur Adria, durch den das kleine Königreich - trotz des hartnäkkigen Widerstandes der Habsburgermonarchie - bei einem Friedensschluß mit dem Osmanischen Reich sein Territorium um einen Zugang zum Mittelmeer zu erweitern hoffte ${ }^{608}$.

Im weiteren Fortgang der Krise hatte der russische Außenminister Frankreich dann am 11. November zwei Noten überreichen lassen ${ }^{609}$. Mit ihnen wurde zum einen ein nach Belgrad übersandtes Telegramm übermittelt, in dem Sasonow erklärte, daß Rußland für einen serbischen Hafen keinen Krieg führen werde und seine Haltung unter anderem mit dem Hinweis begründete: la France et l'Angleterre déclarent ouvertement qu'elles ne sont absolument pas disposées à laisser s'envenimer le conflit avec la Triple Alliance au sujet de cette affaire ${ }^{610}$. Zum anderen konfrontierten diese Noten Frankreich aber auch mit der Frage, welche Haltung der Bündnispartner im Fall eines militärischen Vorgehens der Habsburgermonarchie gegen Serbien einnehmen werde 611 .

Hatte Poincaré zunächst eine ausweichende Haltung gegenüber diesem Sondierungsversuch eingenommen, indem er erklärte, daß Frankreich zuerst der Standpunkt des Bündnispartners zur Kenntnis gebracht werden müsse ${ }^{612}$, so erteilte er dann am 16. November doch Iswolski eine Antwort in der Form eines geheimen Briefes. In diesem begrüßte er einerseits die Instruktionen Sasonows an den russischen Gesandten in Belgrad, stellte aber andererseits mit einem Hinweis auf die Passage, in der der Außenminister des Zaren davon gesprochen hatte, daß Frankreich und Großbritannien keine Eskalation der Krise wünschten, fest: Quant au Gouvernement de la République [...] il n'a [...] rien dit, ni rien laissé supposer qui puisse impliquer de sa part une défaillance de concours ${ }^{613}$. Deutlicher waren Poincarés Worte noch in seinem Schreiben an den französischen Botschafter ausgefallen:

$608 \mathrm{Vgl}$. ZECHLIN, Adriakrise, S. 115-159, hier insbesondere S. $118 \mathrm{f}$. und DULfFER, Vermiedene Kriege, S. 641-655, hier insbesondere S. $647 \mathrm{f}$.

$609 \mathrm{Vgl}$. Sasonow an Iswolski und Benckendorff, 11. 11. 1912, in: IB III/4,1 215. Vgl. Note de l'ambassade de Russie, 12. 11. 1912, in: DDF 3, 3, 431 und Note de l'ambassade de Russie, 12. 11. 1912, in: DDF 3, 4, 432. Zur gleichen Zeit waren dieselben Eröffnungen auch von Benckendorff dem britischen Außenminister gemacht worden. Vgl. Paul Cambon an Poincaré, 12. 11. 1912, in: DDF 3, 4, 434.

610 Zit. Note de l'ambassade de Russie, 12.11. 1914, in: DDF 3, 4, 431. Vgl. ferner Sasonow an Hartwig, 11. 12. 1912, in: IB III/4,1 214.

611 Vgl. Note de l'ambassade de Russie, 12.11. 1914, in: DDF 3, 4, 432.

612 Vgl. Poincaré an Louis, 13. 11. 1912, in: DDF 3, 4, 433 und Ders. an Dens., 16. 11. 1912, in: DDF 3, 4, 468. Vgl. ferner Iswolski an Sasonow, 13. 11. 1912, in: IB III/4,1 235. 613 Zit. Poincaré an Iswolski, 16. 11. 1912, in: DDF 3, 4, 468. 
Quant à la France, so telegraphierte er am selben Tag an Louis, elle s'est soigneusement abstenue de toute attitude et de tout langage que le Gouvernement impérial pourrait interpréter comme une défaillance de concours. Je sais qu'en 1908-1909 M. Isvolsky a cru pouvoir attribuer les échecs de sa politique aux bésitations de la France. Je tiens essentiellement à ce que des reproches de cette sorte ne puissent pas nous être adressés et à ce $q u$ 'on ne nous prête pas des responsabilités qui ne sont pas les nôtres ${ }^{614}$.

Folgt man einem Bericht des russischen Botschafters vom 17. November, so hat es der Ministerpräsident bei diesem geheimen Brief jedoch nicht bewenden lassen, sondern seine schriftlichen Ausführungen in dem sich anschließenden Gespräch um folgenden mündlichen Kommentar ergänzt: Mit einem Worte, fügte Herr Poincaré hinzu, alles dieses kommt darauf heraus, zu sagen, daß wenn Rußland Krieg fübrt, Frankreich ibn auch führen wird, da wir wissen, daß in dieser Frage Deutschland hinter Österreich stehen wird ${ }^{615}$.

In seinen Erinnerungen hat Poincaré später glauben machen wollen, daß er gegen diese Interpretation seiner Einlassungen heftig protestiert habe, als ihm der russische Botschafter sein in französischer Sprache abgefaßtes Telegramm am folgenden Tag zur Kenntnis brachte ${ }^{616}$. Doch mutet es unwahrscheinlich an, daß Iswolski - sollte es sich tatsächlich um eine bewußte Deformation der Einlassungen Poincarés gehandelt haben - dem Ministerpräsidenten und Außenminister umgehend Gelegenheit bot, diese zu korrigieren, und so lassen sich in der zeitgenössischen Parallelüberlieferung denn auch keine Hinweise auf einen solchen Protest des französischen Außenministers finden ${ }^{617}$. In einem Telegramm an den Botschafter in Petersburg vermerkte

614 Zit. Poincaré an Louis, 16. 11. 1912, in: DDF 3, 4, 469.

615 Zit. Iswolski an Sasonow, 17. 11. 1912, in: IB III/4,1 268. Vgl. auch das Telegramm, mit dem der Botschafter den geheimen Brief an seinen Außenminister übermittelte. Vgl. Ders. an Dens., 17. 11. 1912, in: IB III/4,1 267. Vgl. auch den Brief vom 21. November 1912, in dem der russische Botschafter die Angelegenheit noch einmal resümierte und vermerkte, daß Poincaré nunmehr genau den Zeitpunkt der Intervention festgelegt habe: dieser Augenblick ist festgelegt durch den Text der russisch-französischen Militärkonvention, kraft deren Frankreich Rußland in einem österreich-russischen Konflikt in dem Falle bewaffnete Unterstützung erweisen muß, wenn Österreich durch Deutschland unterstützt wird; und da im vorliegenden Falle bekannt ist, daß Deutschland entschlossen ist, die österreichischen Forderungen zu unterstützen, erkennt Herr Poincaré, und in seiner Person die französische Regierung an, daß ein aktives Vorgehen Österreichs automatisch das bewaffnete Eingreifen auch Frankreichs zur Folge haben kann. Zit. Iswolski an Sasonow, 21. 11. 1912, in: IB III/4,1 310. Mit ähnlichem Wortlaut auch noch einmal in: Ders. an Dens., 5. 12. 1912, in: STIEVE, Iswolski-Schriftwechsel II, 608.

616 Vgl. POINCARE, Au service de la France, Bd. II, S. 339: J'ai vivement protesté. Je lui ai déclaré que je ne lui avais jamais tenu pareil propos, qu'il n'avait aucun commentaire à ajouter à ma lettre, et que, s'il ne rectifiait pas lui-même, j'allais démentir à Saint-Pétersbourg le langage qu'il me prêtait.

617 Ganz im Gegenteil scheint Poincaré im November 1912 der Überzeugung gewesen zu sein, daß Sasonows Hinweis: que la France et l'Angleterre déclarent ouvertement qu'elles ne sont absolument pas disposées à laisser s'envenimer le conflit avec la Triple Alliance au sujet de cette affaire auf die Berichterstattung Iswolskis zurückzuführen sei. 
Poincaré ausschließlich: Je lui ai fait remarquer que cette formule était trop générale et que j'avais uniquement dit que la France respecterait le traité d'alliance et soutiendrait même militairement la Russie au cas où jouerait le casus foederis ${ }^{618}$.

Weit davon entfernt »heftig « zu protestieren, befand Poincaré die von Iswolski übermittelten Worte also nur als "zu allgemein«. Konnte doch das Telegramm des russischen Botschafters auch in dem Sinne verstanden werden, daß Frankreich sich im Fall einer militärischen Auseinandersetzung zwischen Rußland und Österreich-Ungarn umgehend, und das heißt, noch vor einem Eingreifen des Deutschen Reiches, zur Intervention entschließen würde. Unter diesen Bedingungen würde Poincaré aber nicht in der Lage sein, vom Parlament die erforderliche Zustimmung für eine bewaffnete Intervention zu erhalten ${ }^{619}$.

Was besagte nun aber die Feststellung, que la France respecterait le traité d'alliance et soutiendrait même militairement la Russie au cas où jouerait le casus foederis? Sollte Poincaré mit ihr Iswolski nur die vertraglichen Bestimmungen der Militärkonvention in Erinnerung gerufen haben, so wäre er einer Antwort auf die entscheidende Frage ausgewichen, ob Frankreich auch im Falle einer großen militärischen Auseinandersetzung, die aus einem österreichischen Angriff auf Serbien und einer anschließenden russischen Intervention entstand, zum Beistand verpflichtet war. Denn anhand der Bestimmungen des Abkommens konnte genau dieser Fall nicht eindeutig geklärt werden und bedurfte damit letztlich einer politischen Entscheidung. Schon in einem Bericht vom 24. Oktober hatte der russische Botschafter die Militärkonvention auf diesen Fall angewandt und die Schlußfolgerung gezogen: In diesem Falle wird Rußland der Angreifer sein, und in der Theorie entbindet das Frankreich von der Verpflichtung eines bewaffneten Eingreifens ${ }^{620}$.

Vor dem Hintergrund der Ausführungen, die ihm der Ministerpräsident im Laufe des Jahres 1912 gemacht hatte, hatte Iswolski aber schon im selben Bericht konstatiert: Tatsächlich wird aber eine derartige Konjunktur unvermeidlich Frankreich in den Krieg verwickeln, denn ein Angriff Rußlands auf Österreich ist für Österreich und Deutschland casus foederis, und das wird wiederum ganz von selbst den casus foederis auch für Rußland und Frankreich aufstellen ${ }^{621}$. Ganz ähnlich berichtete der Botschafter nun aber auch am 18. November 1912, als er Sasonow mitteilte, daß Poincaré den Wortlaut seines Telegramms vollkommen gebilligt und ihn nur zu präzisieren gebeten

Vgl. Poincarés Randbemerkung zu: Note de l'ambassade de Russie, 12.11. 1912, in: DDF 3, 4, 431 und insbesondere Ders. an Louis, 16. 11. 1912, in: DDF 3, 4, 469.

618 Zit. Poincaré an Louis, 19. 11. 1912, in: DDF 3, 4, 494.

${ }^{619} \mathrm{Vgl}$. Bericht des russischen Außenministers an den Zaren über die Unterredungen mit Poincaré während dessen Aufenthalt in St. Petersburg, 17.8. 1912, in: STIEVE, Iswolski-Schriftwechsel II, 401.

620 Zit. Iswolski an Sasonow, 24. 10. 1912, in: IB III/4,1 46.

621 Zit. ibid. 
habe, daß Frankreich in dem bestimmten Falle marschieren wird, wenn der durch das Bündnis vorgesebene casus foederis eintreten würde, d.h. wenn Deutschland Österreich mit den Waffen gegen Rußland unterstützt ${ }^{622}$. Dieser Fall war aber in dieser Allgemeinheit - und der Bericht des Botschafters vom 24. Oktober macht deutlich, daß er sich dieser Tatsache vollkommen bewußt gewesen ist - durch die Bestimmungen der Militärkonvention gar nicht vorgesehen und bedeutete letztlich eine substantielle Ausdehnung des casus foederis durch Poincaré, der mit seiner Einlassung den Artikel II des geheimen Abkommens gleichsam absolut setzte und ungeachtet der in Artikel I gemachten Einschränkung, daß es sich um einen "Angriff « Österreich-Ungarns handeln müsse, die Intervention Frankreichs allein an die Mobilmachung des Deutschen Reiches knüpfte.

Der Brief des Botschafters aus dem Oktober 1912 deutet schon darauf hin, daß von einer bewußten Entstellung der Einlassungen Poincarés um so weniger die Rede sein kann, als der Ministerpräsident und Außenminister sowohl zu früheren als auch späteren Gelegenheiten und im Gespräch mit unterschiedlichen Personen dem casus foederis eben jene extensive Auslegung gab, von der Iswolski am 17. November berichtete. Denn nur wenige Tage später erklärte Poincaré auch dem italienischen Botschafter, wenn der österreichserbische Konflikt $z u$ einem allgemeinen Kriege fübren werde, könne Rußland ganz und gar auf die bewaffnete Unterstïtzung Frankreichs rechnen ${ }^{623}$. Schon in seinem Brief vom 24. Oktober hatte der russische Botschafter zudem - allerdings ohne dies im einzelnen kenntlich zu machen - lange Passagen aus Schreiben zitiert, die er über Unterredungen mit Poincaré am 28. März und 12. September 1912 an Sasonow gesandt hatte. Hatte Poincaré in den Unterredungen, die er im März mit Iswolski führte, einerseits noch zwischen "lokalen " und solchen Ereignissen unterschieden, die unter die Abkommen von 1891 und 1892 fielen ${ }^{624}$, so hatte er ihm andererseits schon damals erklärt:

dieser Unterschied habe seiner Überzengung nach keine praktische Bedeutung; bei dem jetzigen System der europäischen Bündnisse und Gruppierung falle es sebr schwer, sich ein Ereignis im Naben Osten vorzustellen, das nicht das allgemeine Gleichgewicht Europas berübren würde. So werde [...] jeder bewaffnete Zusammenstoß zwischen Rußland und Österreich-Ungarn wegen Balkanangelegenheiten zweifellos einen casus foederis zwischen Österreich-Ungarn und Deutschland bilden; das aber werde seinerseits die Anwendung des französisch-russischen Bündnisses nach sich zieben ${ }^{625}$.

Noch deutlicher war Poincaré gegenüber dem russischen Botschafter dann im September 1912 geworden. Welche Umstände der Ministerpräsident und Außenminister Frankreichs auch immer im Blick gehabt haben mochte, als er

622 Zit. Iswolski an Sasonow, 18. 11. 1912, in: IB III/4,1 280.

$623 \mathrm{Vgl}$. Iswolski an Sasonow, 20. 11. 1912, in: IB III/4,1 298 und Ders. an Dens., 20. 11.

1912, in: IB III $/ 4,1300$.

624 Vgl. Iswolski an Sasonow, 28. 3. 1912, in: IB III/2,2 699.

625 Zit. ibid. 
im März gegenüber Iswolski davon gesprochen hatte, daß eine militärische Auseinandersetzung zwischen der Habsburgermonarchie und Rußland bei einer Intervention des Deutschen Reiches für sein Land den casus foederis bedeute, dieses Mal faßte er konkret den Fall eines militärischen Konfliktes zwischen der Habsburgermonarchie und Serbien ins Auge. Ein solcher, so sagte er dem Botschafter

könne selbstverständlich Rußland nicht gleichgültig lassen und werde wabrscheinlich zu einem allgemeinen Krieg fübren ${ }^{626}$. Er gebe sich vollste Rechenschaft darüber, daß das eine oder andere Ereignis, zum Beispiel die Zertrümmerung Bulgariens durch die Türkei oder ein Angriff Osterreich-Ungarns auf Serbien, Rußland zwingen könnte, seine passive Rolle aufzugeben und zunächst seine Zuflucht zu einer diplomatischen Aktion und dann zu einer militärischen Intervention gegen die Türkei oder Österreich zu nehmen. [...] Wenn aber der Konflikt mit Österreich ein bewaffnetes Eingreifen Deutschlands nach sich zieben würde, so erkenne die französische Regierung dies im voraus als casus foederis an und würde nicht einen Augenblick zögern, die Verpflichtungen, die sie Rußland gegenüber auf sich genommen bat, zu erfüllen ${ }^{627}$.

In seinen Erinnerungen hat Poincaré diese eindeutigen Einlassungen abermals hartnäckig bestritten ${ }^{628}$. Doch seine Ausführungen sind an dieser Stelle um so unglaubwürdiger, als Iswolski in seinem Bericht an Sasonow noch eine bedeutende Information hinzufügte, die er nur aus Poincarés Hand erhalten haben kann und die der Ministerpräsident und Außenminister deshalb später auch in seinen Memoiren geflissentlich unerwähnt ließ. Hatte Poincaré doch dem Bericht Iswolskis zufolge sein Beistandsversprechen zusätzlich noch durch den Hinweis unterstrichen, daß nach Ansicht der militärischen Führung Frankreichs in einem Großen Krieg, der seinen Ausgang von den genannten Umständen nahm, glänzende Erfolgsaussichten bestanden, da die Habsburgermonarchie in diesem Fall gezwungen sein würde, einen nicht unbeträchtlichen Teil ihrer Kontingente auf dem Balkan zu binden ${ }^{629}$. Mit dieser Argumentation bezog sich Poincaré aber zweifellos auf das schon in anderem Zusammenhang behandelte Memorandum des Generalstabs vom 2. September, das dem russischen Botschafter gar nicht bekannt gewesen sein konnte ${ }^{630}$. Iswolskis Bericht vom 12. September läßt damit nur die Schlußfolgerung zu, daß Poincaré zu einem Zeitpunkt, an dem ihm der serbisch-

626 Zit. Iswolski an Sasonow, 12. 9. 1912, in: STIEVE, Iswolski-Schriftwechsel II, 429. 627 Zit. ibid.

628 Vgl. POINCARE, Au service de la France, Bd. II, S. 198-206.

629 Ferner sagte mir H. Poincaré, daß im Hinblick auf den Balkan die höheren französischen Militärbebörden mit verstärkter Aufmerksamkeit alle militärischen Eventualitäten, die sich ergeben könnten, prüfen; er wisse, daß die eingeweibten und verantwortlichen Persönlicbkeiten die Aussichten Rußlands und Frankreichs im Falle eines allgemeinen Zusammenstoßes sehr optimistisch beurteilten. Zit. Iswolski an Sasonow, 12. 9. 1912, in: STIEVE, Iswolski-Schriftwechsel II, 429. Auf diese Einlassung Poincarés kam der Botschafter auch in einem späteren Schreiben zurück. Vgl. Iswolski an Sasonow, 24. 10. 1912, in: IB III/4,1 46.

630 Vgl. Note de l'état-major de l'armée, 2. 9. 1912, in: DDF 3, 3, 359. 
bulgarische Vertrag in seinem ganzen Umfang bereits bekannt war und er annahm, daß dieser nicht allein zu einen Krieg mit dem Osmanischen Reich führen werde, sondern darüber hinaus »im Keim « auch eine militärische Auseinandersetzung mit der Habsburgermonarchie enthalte, sich grundsätzlich dazu bereit gefunden hatte, den casus foederis der Allianz auszudeh$n^{6}{ }^{631}$. Gestützt wird diese Interpretation durch einige von der Forschung bislang unbeachtete Aufzeichnungen, die Alexandre Ribot über Unterredungen anfertigte, die er in den letzten Monaten des Jahres 1912 mit Poincaré führte ${ }^{632}$. Als schon bald nach Beginn des Balkankrieges durch die raschen Niederlagen des Osmanischen Reiches eine Rückkehr zum Status quo ante ausgeschlossen schien und nunmehr die Frage in das Blickfeld rückte, mit welchen Mitteln die Habsburgermonarchie auf einen beträchtlichen territorialen Zuwachs Serbiens antworten würde, fand sich Poincaré nach den Aufzeichnungen Ribots grundsätzlich dazu bereit, den Casus foederis auch auf eine militärische Intervention Österreich-Ungarns auszudehnen.

Waren der ehemalige Außenminister und auch der ehemalige Ministerpräsident und Kriegsminister Freycinet ${ }^{633}$, die 1892 die Militärkonvention mit Rußland ausgehandelt hatten, der Auffassung: Nous ne sommes tenus de marcher que si l'Allemagne ou l'Autriche soutenue par l'Allemagne attaque la Russie. Dans l'bypothèse où la Russie déclarerait la guerre à l'Autriche à la suite d'une intervention de l'Autriche en Serbie, nous ne serions pas engagés par les termes du traité6 $e^{634}$, so mochte Poincaré diese Sicht der Dinge nicht teilen. Poincaré pense, so hielt Ribot in einer Aufzeichnung unter dem Datum des 31 . Oktober 1912 fest, que la Serbie ne pourra pas évacuer Uskub et que si l'Autriche intervient, la Russie ne pourra pas ne pas intervenir. L'Allemagne et la France seraient obligées par leurs traités d'entrer en scène. Le conseil des Ministres en a délibéré et a décidé que la France devrait tenir ses engagements. Il n'y a pas eu de résistance dans le Conseil635.

631 Le traité contient donc, en germe, non seulement une guerre contre la Turquie, mais une guerre contre l'Autriche. Zit. Notes de M. Poincaré sur ses entretiens de Saint-Pétersburg, August 1912, in: DDF 3, 3, 264.

632 Weder läßt sich in den Erinnerungen Ribots noch in den post festum von seinem Sohn herausgegebenen und als Tagebuch arrangierten Notizen ein Hinweis auf diese Gespräche finden. Vgl. Alexandre Ribot, Journal d'Alexandre Ribot et correspondances inédites. 1914-1922. Hg. von Alexandre RIBOT, Paris 1936 und DERS., Lettres à un ami. Souvenirs de ma vie politique, Paris 1924.

633 Daß Freycinet die Auffassung des ehemaligen Außenministers teilte, geht aus zwei Aufzeichnungen vom 7. und 9. November 1912 hervor. Freycinet, à qui j'ai fait part à l'Académie de ce que j'ai dit à Poincaré au sujet du casus foederis, m'approuve complètement. Zit. 7 nov[embre] 1912, in: NL Ribot, AN, 563 AP 5. Vgl. auch 12 nov[embre] 1912, in: NL Ribot, AN, 563 AP 5: Poincaré verra demain Freycinet. Il sait par Clemenceau que Freycinet est surtout préoccupé de démontrer que le casus foederis ne saurait être invoqué par la Russie dans les circonstances actuelles.

634 Zit. 1 nov[embre] 1912, in: NL Ribot, AN, 563 AP 5.

635 Zit. 31 oct[obre] 1912, in: NL Ribot, AN, 563 AP 5. 
Wohlgemerkt: Das Gesagte darf nicht dahingehend mißverstanden werden, daß Poincaré im Herbst des Jahres 1912 zum Krieg der großen Mächte drängte, denn in den Wochen bis zum Ausbruch des ersten Balkankrieges unternahm er im Sinne einer Politik, die der Integrität des Osmanischen Reiches verpflichtet war, beträchtliche Anstrengungen, um den Ausbruch der militärischen Auseinandersetzung zu verhindern ${ }^{636}$. Nicht zu verkennen ist aber auch, daß ein Kurs, der die militärische Intervention Frankreichs allein an die Mobilmachung des Deutschen Reiches band, weniger einer Politik der cobesion and restraint als einer Politik der letztlich zu allem entschlossenen Unterstützung und damit einem Kurs hart am Rand des Abgrundes glich.

Besonders deutlich wird dies in Zusammenhang mit der schon an anderer Stelle behandelten Episode aus dem Dezember 1912, als Österreich-Ungarn zu einer partiellen Mobilmachung schritt, Frankreich diese nicht in erster Linie als eine militärische Drohung, sondern als Vorbereitung auf den Krieg gegen Serbien verstand und das Zarenreich zu umfangreichen militärischen Vorbereitungen drängte ${ }^{637}$. Gegenstand der Unterredungen, die Poincaré in diesem Zusammenhang mit dem russischen Botschafter führte, war daraufhin nicht mehr die Frage, welche Art des Beistands Frankreich seinem Bündnispartner gewähren würde, sondern in ihnen ging es insbesondere darum, daß Rußland nach französischer Einschätzung sich durch unzureichende militärische Maßnahmen in eine ungünstige Ausgangsposition zu manövrieren begann, sollte es zu einem Angriff der Habsburgermonarchie auf Serbien kommen. Ein solcher könnte, so berichtete Iswolski, wie man hier annimmt, eine Abwehr von seiten Rußlands nach sich zieben, was seinerseits unvermeidlich und automatisch zunächst Deutschland und dann Frankreich in den Krieg bineinzieben würde. Die französische Regierung siebt dieser Möglichkeit mit vollkommener Rube, bewußt und mit der festen Entschlossenbeit entgegen, ibre Bündnispflichten zu erfüllen ${ }^{638}$.

Daß Frankreich fest entschlossen war, seinen Bündnispartner militärisch zu unterstützen, unterstrich damals auch Kriegsminister Milllerand in einer Unterredung mit dem russischen Militärattaché. Als dieser Millerand am 18. Dezember anzudeuten schien, daß man sich auch für den Fall eines militärischen Handelns der Habsburgermonarchie nicht schützend vor den serbischen Protegé stellen werde, entgegnete Millerand dem Repräsentanten des Generalstabs: Folglich werden Sie Serbien seinem Schicksal überlassen müssen. Das ist natürlich ibre Sache, man muß aber nur wissen, daß dies nicht durch unsere Schuld geschiebt: Wir sind bereit, und das muß in Rechnung gestellt werden ${ }^{639}$.

636 Vgl. KeIGer, France and the Origins, S. 73 f. und DerS., Poincaré, S. 138-140 sowie 142.

637 Vgl. die Ausführungen im Abschnitt »Der habsburgische Gulliver im strategischen Konzept Frankreichs «.

638 Zit. Iswoslki an Sasonow, 18. 12. 1912, in: STIEVE, Iswolski-Schriftwechsel II, 639. 639 Zit. nach STIEVE, Iswolski und der Weltkrieg, 118. Stieve gibt eine deutsche Über- 
Daß Poincaré sich schon in seiner Zeit als Ministerpräsident und Außenminister grundsätzlich dazu bereit fand, eine militärische Intervention der Habsburgermonarchie auf dem Balkan zum Bündnisfall zu machen, bestätigt noch einmal die schon in anderem Zusammenhang vorgetragene Kritik an der These Jules Isaacs. Denn offensichtlich war Poincaré zu dieser Ausdehnung des casus foederis bereit, noch bevor die säkulare Tendenz des osmanischen Machtverfalls durch den Aufstieg der Balkanstaaten Rußland und damit auch Frankreich begünstigte. Die Konsequenzen, die mit einer militärischen Ausschaltung Serbiens für die osteuropäische Machtbalance verbunden gewesen wären, konnten deshalb im Juli 1914 allenfalls ein zusätzliches, nicht aber ein handlungsleitendes Motiv der Außenpolitik Frankreichs sein.

Fragt man nun im einzelnen nach den Gründen, die für diese Ausdehnung des casus foederis konstitutiv waren, so wird man zunächst konstatieren müssen, daß die französische Staatsführung in den letzten Jahren vor Ausbruch des Großen Krieges die außenpolitischen Optionen ihres Bündnispartners ersichtlich überschätzte und die Möglichkeit einer deutsch-russischen Annäherung selbst dann nicht für ausgeschlossen hielt, als im Rahmen der Auseinandersetzungen um die deutsche Militärmission unter Liman von Sanders die Beziehungen beider Staaten an der Jahreswende 1913/1914 einen "Tiefpunkt ${ }^{640}$ erreicht hatten und sich auch in den folgenden Monaten nicht deutlich verbessern sollten.

Ausgelöst worden war die Krise, die die deutsch-russischen Beziehungen so schwer belastete, durch die Ernennung des Generalleutnants Otto Liman von Sanders zum Chef der deutschen Militärmission in Konstantinopel durch den Kaiser am 30. Juni, der dann am 27. November 1913 die Unterzeichnung des Vertrages durch den türkischen Kriegsminister gefolgt war ${ }^{641}$. Betrachtete die politische Führung Rußlands das militärische Engagement Deutschlands im Osmanischen Reich ohnehin mit deutlichem Mißtrauen, da allein schon aus geographischen Gründen die Kräfte des Osmanischen Reiches nur entweder direkt gegen Rußland oder aber gegen die Balkanstaaten eingesetzt werden konnten ${ }^{642}$, so war es insbesondere die Ernennung des deutschen Generals zum Befehlshaber des I. Armeekorps, das in Konstantinopel und damit in unmittelbarer Nähe zu den Meerengen stand, die das $\mathrm{Za}-$ renreich empfindlich traf.

Denn gerade die Meerengenfrage nahm seit geraumer Zeit eine Schlüsselstellung in der russischen Politik ein ${ }^{643}$. Abgesehen von der militärisch-stra-

setzung des russischen Orginialdokuments, das von Adamow in einem Artikel für die »Iswestija « vom 29.6. 1924 zitiert wurde.

640 Zit. Hildebrand, Reich, S. 298.

641 Zur Liman-von-Sanders-Krise vgl. Hans HerzFeld, Die Liman-Krise und die Politik der Großmächte in der Jahreswende 1913/1914, in: BM 11 (1933), S. 837-858, S. 973-993 sowie DÜLFFER, Vermiedene Kriege, S. 657-671.

$642 \mathrm{Vgl}$. Buchanan, My Mission, Bd. I, S. $179 \mathrm{f}$.

643 Zur Bedeutung der russischen Meerengen für die russische Außenpolitik vgl. Eg- 
tegischen Bedeutung, die mit der Kontrolle der Zufahrt zum Schwarzen Meer verbunden war, hatte die empfindliche Reaktion des Zarenreiches vor allem ökonomische Gründe. Stellten doch die Meerengen die wichtigste Handelsader ${ }^{644}$ des Landes dar. Rund 37 Prozent seines gesamten Exportes und drei Viertel der für die russische Handelsbilanz besonders wichtigen Ausfuhr agraischer Erzeugnisse wickelte Rußland in den Jahren zwischen 1903 und 1913 durchschnittlich durch die Wasserstraße ab ${ }^{645}$. Als das Osmanische Reich im Rahmen seiner militärischen Auseinandersetzungen mit Italien und dann mit den Balkanstaaten die Meerengen 1912 und 1913 zweimal für einen kurzen Zeitraum geschlossen hatte, war dies mit merklichen Folgen für den russischen Handel verbunden gewesen ${ }^{646}$. In seinem Bericht an den Monarchen hatte der russische Außenminister deshalb im Dezember 1913 nicht zu Unrecht davon gesprochen, daß die Meerengen einem mächtigen Staat $z$ ü überlassen, [...] gleichbedeutend damit [wäre], die ganze wirtschaftliche Entwicklung des südlichen Rußlands diesem Staat zu unterwerfen ${ }^{647}$.

Nicht zuletzt aus diesem Grund war es eine Konstante der russischen Außenpolitik, die Meerengen nicht unter die Kontrolle einer anderen europäischen Großmacht geraten zu lassen ${ }^{648}$, und folglich hatte Berlin seinen östlichen Nachbarn mit der Militärmission Liman von Sanders zweifellos an einem seiner »wundesten Punkte ${ }^{649}$ getroffen. Entsprechend stürmisch war auch die russische Reaktion ausgefallen, hatte doch Sasonow im Verlauf der Krise gar davon gesprochen unsere Interessen entschlossen bis ans Ende $z u$ verteidigen ${ }^{650}$, was letztlich nichts anderes bedeutete, als daß Rußland sich in diesem Fall notfalls auch bereit finden würde, den Großen Krieg zu führen.

mont ZECHLIN, Die türkischen Meerengen - Brennpunkt der Weltgeschichte, in: GWU 17 (1966), S. 9-31; LIEVEN, Russia and the Origins, S. 45-47 und Derek W. SPRING, Russian Foreign Policy, Economic Interest and the Straits Question, 1905-1914, in: Robert B. MCKEAN (Hg.), New Perspectives in modern Russian History, Basingtoke 1992, S. 203-221.

644 Zit. Über unsere Ziele in den Meerengen, November 1914, in: ADAMOw, Konstantinopel und die Meerengen II, 2. Bei dem Memorandum handelt es sich um eine Denkschrift des stellvertretenden Direktors der Kanzlei des russischen Außenministeriums, Nikolai Basili.

645 Zur ökonomischen Bedeutung der Meerengen vgl. insbesondere SPRING, Russian Foreign Policy. Economic Interests, S. 207-209, S. 216.

646 Vgl. Über unsere Ziele in den Meerengen, November 1914, in: ADAmow, Konstantinopel und die Meerengen II, 2. Vgl. im Gegensatz dazu SPRING, Russian Foreign Policy. Economic interests, S. 219, der die Auswirkungen der osmanischen Blockade geringer einschätzt, gleichwohl aber die - auch gegenüber den strategischen Interessen herausgehobene ökonomische Bedeutung der Meerengen für das Zarenreich betont.

647 Zit. Bericht Sasonows an den Zaren, 6. 12. 1913, in: HÖLZLE, Quellen 72.

$648 \mathrm{Vgl}$. Louis an Poincaré, 21. 12. 1912, in: DDF 3, 5, 105 und Journal einer Sonderkonferenz, 21. 2. 1914, in: IB I/1,1 295. Vgl. LIEveN, Russia and the Origins, S. 45 f.

649 Zit. SCHÖLlGEN, Imperialismus, S. 367.

650 Zit. Bericht Sasonows an den Zaren, 5. 1. 1914, in: ADAMOw, Konstantinopel und die Meerengen I, 80. 
Obgleich die Krise um die Ernennung Liman von Sanders letztlich beigelegt werden konnte ${ }^{651}$, sollte die deutsche Außenpolitik durch den Zaren, insbesondere aber auch durch Sasonow in ihrer Folge merklich kritischer beurteilt werden. Zwar waren die deutsch-russischen Beziehungen schon im Vorfeld dieses »letzte[n] Konflikt[s] vor der Katastrophe «652 nicht entspannt gewesen: Warf man doch an der Newa der deutschen Reichsleitung vor, den habsburgischen Rivalen allzu bereitwillig zu unterstützen. Doch trotz dieser unbestreitbaren Spannungsmomente begann die eigentliche Krisenperiode im bilateralen Verhältnis erst mit der Liman-von-Sanders-Krise.

It was commonly supposed, so paraphrasierte der britische Botschafter die Ausführungen, die ihm der russische Monarch im April 1914 machte, that there was notbing to keep Germany and Russia apart. This was, however, not the case. There was the question of the Dardanelles. Twice in the last years the Straits had been closed for a short period with the result that the Russian Grain industry had suffered very serious loss. From information which had been reached Him from a secret source through Vienna He had reason to believe that Germany was aiming at acquiring such a position at Constantinople as would enable her to shut in Russia altogether in the Black Sea. Should she attempt to carry out this policy He would have to resist it with all His power, even should war be the only alternative 653 .

In ganz ähnlichen Bahnen dachte im selben Zeitraum auch der russische Außenminister über die Politik des Deutschen Reiches. So erklärte er dem britischen Botschafter nur wenige Tage nach dessen Audienz mit dem Zaren, that Germany aimed at acquiring a moral protectorate over Turkey and, if she succeeded in this, she would one day convert it into an effective one. Russia would never take any aggressive action against Turkey so long as she remained an independent State but she would never permit her to become the dependency of another Power654, und in der Folgezeit scheint Sasonow dann gar der Ansicht gewesen zu sein, daß die Außenpolitik des Deutschen Reiches nicht nur von Fall zu Fall, sondern »planmäßig «655 zum Schaden Rußlands betrieben werde. So leitete er die Ministerratsitzung, in der am 24. Juli 1914 der Beschluß gefaßt wurde, die territoriale Integrität und politische Souveränität Serbiens notfalls durch eine militärische Intervention zu schüt-

651 Der Chef der deutschen Militärmission wurde mit Wirkung zum 10. respektive 14. Januar vom deutschen Kaiser zum Marschall befördert und verlor damit sein Kommando über das I. Armeekorps. Vgl. Jehuda D. WALLACH, Anatomie einer Militärhilfe: die preußisch-deutschen Militärmissionen in der Türkei 1835-1919, Düsseldorf 1976, S. $142 \mathrm{f}$.

652 Zit. DÜLFFER, Vermiedene Kriege, S. 657.

${ }^{653}$ Zit. Buchanan an Grey, 3. 4. 1914, in: BD 10/2, 537. Vgl. ferner Dominic C. B. LIEVEN, Nicholas II. Twilight of the Empire, New York 1994, S. $196 \mathrm{f}$., der das besondere Interesse des Zaren an der Meerengenfrage betont.

${ }^{654} \mathrm{Zit}$. ibid. Mit ähnlichen Worten wurde der Außenminister des russischen Monarchen auch in einem Bericht des britischen Botschafters vom 16. April 1914 zitiert. Vgl. Buchanan an Nicolson, 16. 4. 1914, in: BD 10/2, 538.

655 Zit. Horst Günter LiNKE, Das zarische Russland und der Erste Weltkrieg. Diplomatie und Kriegsziele 1914-1917, München 1972, S. 19. 
zen, mit einem Exposé der internationalen Gesamtlage ein, in dem kaum mehr von Österreich, sondern ausschließlich von Germany's systematic preparations die Rede war, which were calculated to increase ber power in Central Europe in order to enable ber to carry out ber wishes, not only as regards matters in the Near East, but in all international questions, without taking into consideration the opinion and influence of the Powers not included in the Triple Alliance ${ }^{656}$. Diese Einschätzungen des Außenministers verweisen auf die markanten Gegensätze, die zwischen Deutschland und Rußland gerade in den ersten Monaten des Jahres 1914 sichtbar geworden waren, und machen darauf aufmerksam, daß zumindest in der rückschauenden Betrachtung des Historikers an eine deutsch-russische Annäherung oder gar an ein Bündnis nach der Krise um die deutsche Militärmission noch weniger zu denken war als in den Monaten zuvor.

Der außenpolitischen Führung Frankreichs war diese Entwicklung durchaus nicht verborgen geblieben. An der Jahreswende 1913/1914 war es zunächst Delcassé, der die aus dem deutsch-russischen Gegensatz im Osmanischen Reich resultierende Verschlechterung der Beziehungen beschrieb ${ }^{657}$. Aus seiner letzten Audienz mit dem Zaren berichtete er:

L'affaire Sanders a rendu manifeste la menace allemande aux intérêts essentiels de la Russie: Il nous faut la mer libre, m'a dit l'Empereur; il nous la faut ouverte au moins au Sud, bien que la fermeture de nos ports $d u$ Nord pendant l'biver, qui s'étend cette année jusqu'à Riga, gêne considérablement et même immobilise notre commerce. [...] Nous ne visons nullement Constantinople, mais il faut la garantie que les détroits ne nous seront pas fermés 658 .

Delcassé, der die Gelegenheit sogleich hastig ergriff, um dem Monarchen deutlich zu machen, daß die Habsburgermonarchie letztlich nur ein gehorsamer Vasall des Deutschen Reiches sei ${ }^{659}$, antwortete der Zar: Alors [...] nous parlerons à Berlin. Nous ne nous laisserons pas marcher sur les pieds et, cette fois, ce ne sera pas comme pour la guerre d'Extrême-Orient: le sentiment national nous soutiendra660.

Ganz ähnlich berichtete Botschaftsrat Doulcet, der bis zur Ernennung Paléologues und zeitweilig auch darüber hinaus die Geschäfte der französischen Auslandsvertretung führte 661 . In einer ausführlichen, die Entwicklung

656 Zit. Bark's Memoirs, in: NL Bark, Rare Book and Manuscript Library. Columbia University, 1/7, S. $7 \mathrm{f}$.

$657 \mathrm{Vgl}$. Delcassés Bericht über seine Unterredung mit Benckendorff. Vgl. Delcassé an Doumergue, 1. 12. 1913, in: DDF 3, 8, 565; Ders. an Dens., 4. 1. 1914, in: DDF 3, 9,12 und Ders. an Dens., 29. 1. 1914, in: DDF 3, 9, 189.

658 Zit. Delcassé an Doumergue, 29. 1. 1914, in: DDF 3, 9, 189.

$659 \mathrm{Vgl}$. in diesem Zusammenhang auch O'Beirne an Nicolson, 11. 12. 1913, in: BD 10/ 1,418 .

660 Zit. Delcassé an Doumergue, 29. 1. 1914, in: DDF 3, 9, 189.

$661 \mathrm{Vgl}$. Doulcet an Doumergue, 14. 3. 1914, in: DDF 3, 9, 458: L'antagonisme russoallemande s'accentue avec une rapidité surprenante. Vgl. auch Ders. an Dens., 21.3. 1914, in: DDF 3, 10, 13. Auf die Verschlechterung der deutsch-russischen Beziehungen 
der deutsch-russischen Beziehungen seit 1912 gründlich beleuchtenden Depesche sprach Doulcet davon, daß der deutsch-russische Antagonismus rasch an Schärfe gewinne, et je puis dire qu'en deux ans j'aurai assisté à une véritable transformation des sentiments de la Russie officielle par rapport à l'Allemagne ${ }^{662}$. Die Ursachen für diese Entwicklung fand der Botschaftsrat zum einen in einer - so mutete es ihm an - unbegrenzten deutschen Unterstützung der habsburgischen Politik auf dem Balkan und zum anderen in eben jenem, durch die Liman-von-Sanders-Krise manifest gewordenen Vordringen des deutschen Imperialismus im Osmanischen Reich ${ }^{663}$.

Doch obgleich sich nach Auffassung der französischen Beobachter insbesondere im Gefolge der Liman-von-Sanders-Krise das deutsch-russische Verhältnis beträchtlich verschlechtert hatte, barg ihrer Einschätzung nach die internationale Konstellation auch in den letzten Monaten vor Ausbruch des Krieges noch immer beträchtliche Entwicklungsmöglichkeiten in sich.

Deutlich erkennbar wird diese Auffassung in den Berichten, die Paléologue beispielsweise über die Personen an sein Außenministerium sandte, die in Sankt Petersburg für einen umfassenden deutsch-russischen Ausgleich warben. Vertreten waren die sogenannten »Pro-Germans «664 in unterschiedlichen Bereichen der russischen Politik und zwar insbesondere in rechtskonservativen Kreisen. Darüber hinaus zählten zu ihnen aber auch einige hochrangige Beamte, Politiker und Diplomaten, bei denen der Gedanke an eine deutsch-russische Annäherung mit einer vergleichsweise liberalen Gesinnung einherging. Insgesamt betrachtet bildeten die »Pro-Germans« eine heterogene Gruppe, deren außenpolitischem Denken aber die Auffassung gemein war, daß kein fundamentaler Interessensgegensatz zwischen dem Deut-

wies auch der französische Gesandte in München hin. Vgl. Allizé an Doumergue, 11. 3. 1914, in: DDF 3, 9, 437. Auch Jules Cambons Depesche vom 30. März deutet in diese Richtung. Vgl. Jules Cambon an Doumergue, 30. 3. 1914, in: DDF 3, 10, 46. Vgl. auch de Manneville an Doumerge, 5. 3. 1914, in: DDF 3, 9, 402.

662 Zit. Doulcet an Doumergue, 14. 3. 1914, in: DDF, 3, 9, 458. Auch der Militärattaché sprach im Gefolge der Liman-von-Sanders-Krise davon, que la baine contre l'Allemagne s'est vraiment établie et que, par suite, on a le désir plus net que jamais d'affirmer l'alliance. Zit. de Laguiche an Brissaud, 18. 7. 1914, in: MAE, Publications de la Commission des origines de la guerre de 1914-1918, 73/D.6.F.4. Notes divers. Pièces retrouvées dans les papiers du doyen Renouvin. Gleichwohl vergaß de Laguiche nicht warnend hinzuzufügen, daß dieser Wunsch nur in dem Maße erhalten bleiben werde, wie Frankreich sich dazu bereit fand, den außenpolitischen Kurs des Bündnispartners zu unterstützen. Vgl. ibid.

${ }^{663}$ Neue Komplikationen in den deutsch-russischen Beziehungen - und auch dies erkannte man auf seiten Frankreichs - standen darüber hinaus für die Zukunft in Zusammenhang mit den Verhandlungen über die Revision des 1917 auslaufenden Handelsvertrages zu erwarten, den das Deutsche Reich in einer russischen Schwächeperiode zu günstigen Konditionen hatte abschließen können. Zur französischen Einschätzung der Komplikationen vgl. Doulcet an Doumergue, 13. 3. 1913, in: DDF 3, 9, 453.

664 Vgl. Lieven, Russia and the Origins, S. 73-83 und insbesondere Ders., Pro-Germans and Russian Foreign Policy 1890-1914, in: The International History Review 2 (1980), S. 34-54, hier S. 43. 
schen Reich und Rußland bestehe und daß vielmehr die Annäherung an Großbritannien die Gefahr in sich berge, über den deutsch-britischen Gegensatz in eine militärische Auseinandersetzung verwickelt zu werden, an deren Ende für Rußland die Revolution stehen werde.

Innerhalb dieses Personenkreises divergierten die Ansichten über die grundsätzliche Ausrichtung der russischen Außenpolitik beträchtlich. So war der ehemalige Botschafter des Zaren in Washington, Baron Rosen, der Auffassung, daß Rußlands primäres Interesse in der Entwicklung seiner asiatischen Besitzungen lag, und er verband mit einem deutsch-russischen Kondominium in Europa den Gedanken an eine glanzvolle Zukunft Rußlands in Asien ${ }^{665}$. Die Gefahren, die sich mit einer solchen Politik für Frankreich verbinden konnten, lagen auf der Hand. Mußte doch eine aktive Politik des Bündnispartners in Asien letztlich zu einer Interessenkollision mit der britischen Weltmacht führen, die Frankreich unter Umständen mit dem Dilemma konfrontieren konnte, zwischen beiden Mächten optieren zu müssen.

$\mathrm{Da}$ der Bündnispartner eine hemisphärische Macht darstellte, deren Interessen auch den asiatischen Kontinent umspannten, war Frankreich durchaus bewußt ${ }^{666}$. So hatte der Militärattaché Frankreichs im November 1913 schon in seinem ersten Bericht, den er über seine Reise nach Sibirien verfaßte, davon gesprochen, daß in "gewissen Kreisen ${ }^{667}$ ein weit größeres Interesse an Asien als an Europa bestehe, um dann in seinem letzten Reisebericht die Frage aufzuwerfen, ob der Bündnispartner sich in absehbarer Zukunft nicht erneut seiner anderen großen außenpolitischen Option zuwenden würde ${ }^{668}$. Zwar erwartete de Laguiche einen solchen Schritt Rußlands nicht für die nahe Zukunft - und darunter verstand der Militärattaché einen Zeitraum von ein oder zwei Jahren. Doch daß der Bündnispartner sich nach dem Ausbau seiner militärischen Infrastruktur in Asien erneut dem fernen Kontinent zuwenden würde, glaubte er mit Sicherheit annehmen zu können.

Alors [...] elle accentuera sa marche en avant qu'elle a déjà reprise. La guerre de 1904 a été, pour cette puissance sans limite, une simple chiquenaude; [...] et comme un rouleau compresseur qui écrase tout, le mouvement russe, lent, insaisissable, pousse droit devant lui. Une grande partie de son attention est dirigée vers ces pays trop lointains pour nos intérêts, vers des buts étrangers à notre propre destinée et cela mérite d'être examiné. Je crains, so schloß de Laguiche seinen Bericht, que la frontière de l'ouest ne soit celle quile préoccupe le moins ${ }^{669}$.

665 Zur außenpolitischen Gedankenbildung Rosens vgl. LIEvEN, Russia and the Origins, S. 89 f. und Ders., Pro Germans, S. $46 \mathrm{f}$.

666 So entstand noch im Juni 1914 eine lange Abhandlung zur Geschichte der Allianz im Außenministerium, die insbesondere die Probleme berücksichtigte, die aus einer aktiven russischen Politik in Asien resultierten. Vgl. Note sur l'alliance franco-russe, 17. 3. 1914, in: MAE, NS Russie 42, fol. 237-254.

667 Zit. de Laguiche an Noulens, 3. 12. 1913, in: SHA 7N1478.

$668 \mathrm{Zu}$ den grundsätzlichen Möglichkeiten der russischen Außenpolitik vgl. LIEVEN, Russia and the Origins, passim, hier insbesondere S. 5-7, $89 \mathrm{f}$.

669 Zit. de Laguiche an Noulens, 3. 12. 1913, in: SHA 7N1478. 
Überblickt man jedoch die Quellenlage in ihrer Gänze, so handelte es sich bei dieser Befürchtung des Militärattachés um einen Einzelfall, der in den Berichten der französischen Botschafter keine Entsprechung fand. Sie erkannten vielmehr, daß der Zar - zumindest nach 1905/1906 - und auch sein Außenminister Sasonow in Rußland eine europäische Macht sahen ${ }^{670}$, deren Zukunft nicht im Fernen Osten lag671. Aufmerksam hatte man wahrgenommen, daß Sasonow im April 1912 in der Duma erklärte: one must not forget that Russia is a European power, that the state was formed not on the banks of the Black Irytch but on the banks of the Dnieper and of the river Moskva. Increasing Russian possessions in Asia cannot be a goal of our foreign policy; this would lead to an undesirable shift in the state's centre of gravity and consequently weakening of our position in Europe and in the Middle East ${ }^{672}$.

Gefährlicher als die "Pro-Germans", die sich mit einem umfassenden deutsch-russischen Ausgleich die erforderliche Rückenfreiheit für eine ostasiatische Mission des Zarenreiches verschaffen wollten, erachteten die französischen Beobachter vielmehr die Personen, deren Interesse Europa galt und die gleichwohl über eine weitgehende Umgestaltung der internationalen Konstellation nachdachten. Zu diesem Kreis gehörte beispielsweise Prinz Meshchersky, der Herausgeber des $\gg$ Grazhdanin «, der in seinem Journal, das vom russischen Monarchen finanziell gefördert wurde, offen für eine Restitution des Dreikaiserbundes warb673. Darüber hinaus zählten zu diesem Personenkreis mit dem ehemaligen Innenminister und Mitglied des Staatsrates Peter Durnovo und dem ehemaligen Ministerpräsidenten Graf Witte auch die herausragendsten Repräsentanten der »Pro-Germans«, die anders als Meshchersky das Bündnis mit Frankreich zwar nicht aufgeben, es wohl aber um das Deutsche Reich zu einer Kontinentalallianz ergänzen wollten ${ }^{674}$.

Mochte es sich bei dieser Gruppe in den letzten Jahren vor Ausbruch des Großen Krieges auch um eine "small minority« handeln und die Ansichten Prinz Meshcherskys selbst in Rußland als »eccentric « ${ }^{675}$ gelten, allein die Existenz dieser Gruppe führte Frankreich die diversen außenpolitischen Optionen seines Bündnispartners vor Augen und erfüllte seine Entscheidungs-

$670 \mathrm{Vgl}$. Louis an Poincaré, 12. 2. 1912, in: DDF 3, 2, 71: Pour Sazonoff, comme pour M. Isvolsky, ce n'est ni en Chine ni en Perse, c'est dans les Balkans que la Russie doit porter actuellement les principaux efforts de sa politique. Zur Rede des russischen Außenministers im Parlament vgl. Louis an Poincaré, 26. 4. 1912, in: DDF 3, 2, 287.

671 Vgl. Lieven, Russia and the Origins, S. 89f. und Fiona K. TOMASZEwSKI, A Great Russia. Russia and the Triple Entente, 1905 to 1914, Westport, London 2002, S. $79 \mathrm{f}$.

672 Die Einlassungen des russischen Außenministers werden zitiert nach LIEVEN, Russia and the Origins, S. 90, mit gleichlautender Übersetzung bei TOMASZEwSKI, Great Russia, S. 79.

673 Zum außenpolitischen Denken Meshcherskys vgl. LIEvEN, Russia and the Origins, S. 73 f., dort auch zu seinem Einfluß auf den Zaren. Vgl. ferner DERS., Pro-Germans, S. 44.

674 Vgl. Lieven, Russia and the Origins, S. 75 und DerS., Pro-Germans, S. 45 sowie S. 47-50.

675 Zit. ibid., S. 73. 
träger mit Besorgnis. So war es in den ersten Monaten des Jahres 1914 die "Kampagne «676 des ehemaligen Ministerpräsidenten Witte, die die außenpolitische Führung beunruhigte, und insbesondere Paléologue glaubte in diesem Zeitraum deutliche Anzeichen einer deutsch-russischen Annäherung oder - besser gesagt - in diese Richtung zielende Bemühungen wahrnehmen zu können ${ }^{677}$.

Im März 1914 berichtete Paléologue gleich mehrfach, daß der ehemalige Ministerpräsident, der nach der Auffassung des Botschafters in seinen Bemühungen auch durch den deutschen Kaiser unterstützt wurde, auf den russischen Monarchen im Sinne einer Kontinentalallianz oder doch zumindest einer deutsch-russischen Annäherung einzuwirken suchte ${ }^{678}$. Als am 24. März zum zweiten Mal binnen kurzer Zeit ein Artikel in der russischen Presse publiziert wurde, der zweifellos auf Witte zurückging, telegraphierte der Botschafter an Doumergue: Le comte Witte poursuit sa campagne en faveur d'une alliance russo-franco-allemande. Il y serait incité par l'Empereur Guillaume qui lui aurait récemment adressé une lettre personnelle en lui rappelant un entretien qu'ils ont eu ensemble sur le même sujet au mois de septembre 1905679 . Zwar versicherte ihm Sasonow, den er umgehend auf den ehemaligen Ministerpräsidenten angesprochen hatte, qu'aucun changement n'est à prévoir dans la politique extérieure de l'Empire ${ }^{680}$. Doch Paléologue war sich zu dieser Zeit nicht sicher, ob Sasonow noch lange Zeit im Amt bleiben würde ${ }^{681}$. Schon im Gefolge der Ernennung Goremykins zum Ministerpräsidenten hatte er von den Aktivitäten reaktionärer Kreise und des Grafen Witte berichtet und weitere Veränderungen im Kabinett sowie eine Entlassung des

676 Zit. Paléologue an Doumergue, 24. 3. 1914, in: DDF 3, 10, 20.

677 Es waren aber nicht allein die Bemühungen des ehemaligen Ministerpräsidenten, die dem Botschafter Anlaß zur Sorge gaben. So glaubte Paléologue in der unmittelbaren Umgebung des Monarchen zahlreiche Anhänger einer deutsch-russischen Annäherung ausmachen zu können. Vgl. Paléologue an Doumergue, 4. 4. 1914, in: DDF 3, 10, 69. Im einzelnen ist schwer festzustellen, welche Personen der Botschafter mit dieser Aussage im Blick gehabt haben könnte. Das familiäre Umfeld des Monarchen hegte ausgesprochene Antipathien gegen das Deutsche Reich - vgl. Lamar CECIL, William II. and his Russian »Colleagues «, in: Carole FINK u. a. (Hg.), German Nationalism and European Responses, 1890-1914, Norman 1985, S. 95-134, hier S. 127-129 - und der Leiter der Militärkanzlei Nikolaus II. war ohne politischen Einfluß auf den Zaren. Vgl. LIEvEN, Russia and the Origins, S. $69 \mathrm{f}$.

678 Vgl. ibid. Vgl. ferner Paléologue an Doumergue, 25. 3. 1914, in: DDF 3, 10, 26. Zu den Bemühungen um eine deutsch-russische Annäherung vgl. auch Ders. an Dens., 25. 3. 1914, in: DDF 3, 10, 23; Ders. an Dens., 4. 4. 1914, in: DDF 3, 10, 69; Ders. an Dens., 13. 4. 1914, in: DDF 3, 10, 100 und Ders. an Dens., 12. 5. 1914, in: DDF 3, 10, 224.

679 Zit. Paléologue an Doumergue, 24. 3. 1914, in: DDF, 3, 10, 20.

680 Zit. Paléologue an Doumergue, 25. 3. 1914, in: DDF, 3, 10, 26.

681 Vgl. Note sur le comte Witte, 12. 7. 1914, in: MAE, NS Russie 42, fol. 270-272. Von ersten Gerüchten über eine mögliche Entlassung Sasonows berichtete der Botschafter schon im Februar 1914. Vgl. Paléologue an Doumergue, 13. 2. 1914, in: DDF 3, 9, 290. 
Außenministers für möglich gehalten ${ }^{682}$. Auch in den folgenden Monaten schätzte Paléologue die Stellung Sasonows nicht als gesichert ein, und im Mai scheint er im Zuge personeller Veränderungen sogar eine Ernennung Wittes zum persönlichen Berater des Zaren für möglich gehalten zu haben ${ }^{633}$.

Von den intensiven Bemühungen um eine umfassende Annäherung der Kaiserreiche, mit denen sich alsbald auch das Gerücht einer Zusammenkunft zwischen dem deutschen und dem russischen Monarchen verband ${ }^{684}$, berichtete Paléologue jedenfalls in den folgenden Monaten gleich mehrfach. Zwar mutet seine Berichterstattung in diesem Zusammenhang zuweilen recht unrealistisch an, wenn er selbst im Zeitalter des politischen Massenmarktes der Überzeugung war, daß Gegensätze in der öffentlichen Meinung und die Streitigkeiten zwischen den Regierungen von geringerer Bedeutung seien, car jusqu'au dernier moment, il y a possibilité d'un arrangement direct entre les Monarques ${ }^{685}$. Doch im Zaren erblickte nicht allein der Botschafter den maßgeblichen Bestimmungsfaktor der russischen Außenpolitik ${ }^{686}$, und vor dem Hintergrund dieser Einschätzung wird verständlich, warum Frankreich schon bei geringen Anzeichen einer Einflußnahme auf Nikolaus II. beunruhigt reagierte, zumal der Monarch nach allgemein geteilter Auffassung als beeinflußbar galt 687 .

Die Berichte Paléologues haben deshalb auch auf den Ministerpräsidenten und Außenminister Doumergue Eindruck gemacht. Im Rahmen seiner Un-

682 Vgl. Paléologue an Doumergue, 14. 2. 1914, in: DDF 3, 9, 299. Vgl. auch Ders. an Dens., 24. 2. 1914, in: DDF 3, 9, 351; Ders. an Dens., 12. 5. 1914, in: DDF 3, 10, 224 und Ders. an Dens., 22. 5. 1914, in: DDF 3, 10, 273.

${ }^{683} \mathrm{Vgl}$. Paléologue an Doumergue, 12. 5. 1914, in: DDF 3, 10, 224 und seine Einlassungen gegenüber Buchanan in: Buchanan an Nicolson, 14. 5. 1914, in: NL Nicolson, PRO, FO 800/374, fol. 41. Einige Monate zuvor hatte auch der Militärattaché von dem Gerücht berichtet, daß Goremykin alsbald durch Witte abgelöst werden könnte. Vgl. de Laguiche an Dupont, 12. 2. 1914, in: SHA 7N1478.

684 Vgl. Paléologue an Doumergue, 14. 4. 1914, in: DDF 3, 10, 105. Von ähnlichen Gerüchten berichtete auch der Botschafter in Berlin. Vgl. Jules Cambon an Dens., 16. 4. 1914, in: DDF 3, 10, 109.

685 Zit. Paléologue an Doumergue, 14. 4. 1914, in: DDF 3, 10, 105. Auch die Bedeutung des privaten Briefwechsels, den der deutsche und der russische Monarch führten, ist in diesem Zusammenhang von Paléologue erheblich überschätzt worden. So hatte sich diese Korrespondenz nicht allein in ihrem Umfang nach 1905 beträchtlich veringert, sondern auch in ihrem Inhalt gewandelt und kreiste in zunehmendem Maße um Banalitäten. Vgl. CECIL, William II., S. 131-133.

686 Vgl. ibid. Vgl. ferner Louis an Poincaré, 21. 12. 1912, in: DDF 3, 5, 105 und Ders. an Dens., 30. 12. 1912, in: DDF 3, 5, 150. Eine entsprechende Einschätzung wird für Delcassé überliefert durch: Memorandum, 20.10. 1913, in: NL Bertie, PRO, FO 800/177, fol. 111. Bei diesem Memorandum handelt es sich um eine Aufzeichnung, die der britische Botschafter über ein Gespräch mit Delcassé anfertigte. Für Poincaré ist sie bezeugt durch POINCARÉ, Au service de la France, Bd. I, S. $285 \mathrm{f}$.

687 Vgl. Paléologue an Doumergue, 22. 5. 1914, in: DDF 3, 10, 270. Vgl. auch die Einlassungen Doumergues gegenüber dem britischen Botschafter in: Bertie an Grey, 18. 12. 1912, in: NL Bertie, PRO, FO 800/166, fol. 54 und Ders. an Dens., 28. 5. 1914, in: NL Bertie, PRO, FO 800/166, fol. 74. 
terredung mit Grey führte Doumergue am 23. April dem Außenminister die Möglichkeit einer deutsch-russischen Annäherung eindringlich vor Augen, so daß der Brite in seiner Korrespondenz mit dem Botschafter in Paris vermerkte: He evidently assumed that Germany would make great efforts to detach Russia from the French Alliance, and might possibly be successful688. Man wird diese Einlassung nicht als ein taktisches Manöver deuten können, mit dem Frankreich im April 1914 Großbritannien zur Aufnahme von Verhandlungen über eine Marinekonvention mit dem russischen Bündnispartner zu bestimmen suchte. Kehrte doch Doumergue rund einen Monat später, und das heißt, nachdem Großbritannien seine grundsätzliche Zustimmung zu den gewünschten Verhandlungen ausgesprochen hatte, auf seine Sorgen zurück und bemerkte, dieses $\mathrm{Mal}$ in einer Unterredung mit dem britischen Botschafter: The Emperor is changeable and the Ministry is not stable. There has always been a party at court in favour of an understanding with Germany ${ }^{689}$.

Auch für den Präsidenten der Republik läßt sich im Gefolge der Nachrichten seines Botschafters eine gewisse Beunruhigung nachweisen. Als das Außenministerium ihm die entsprechenden Telegramme Paléologues zur Kenntnis brachte, übertrug er diese umgehend in seine Aufzeichnungen und versah die Berichte mit einigen Annotationen ${ }^{690}$. So erachtete Poincaré das Telegramm des Botschafters vom 24. März 1914, in dem dieser ausführlich von den Bemühungen des ehemaligen Ministerpräsidenten und den Anstrengungen des deutschen Kaisers berichtet hatte, als important ${ }^{691}$, und kurze Zeit später notierte er in seinem Diarium, daß er, préoccupé du côté de Witte, den russischen Botschafter auf den ehemaligen Ministerpräsidenten angesprochen habe. Dieser hatte ihm zwar versichert, Witte werde keinen entscheidenden Einfluß mehr auf die russische Außenpolitik nehmen können. Doch Poincaré zeigte sich mißtrauisch und vermerkte, daß es dem Treiben Wittes, der ihm außerordentlich suspekt schien, umgehend entgegenzutreten gelte: Il va falloir chercher immédiatement à dénouer ces intrigues ${ }^{692}$.

688 Zit. Grey an Bertie, 1. 5. 1914, in: BD 10/2, 541. Vgl. auch die damit übereinstimmenden Bemerkungen Doumergues in seiner Aufzeichnung über die Unterredung mit dem britischen Außenminister. Vgl. Note du Ministre. Conversation, au ministère des Affaires étrangères entre Sir Edward Grey et M. Gaston Doumergue, en présence de M. Paul Cambon, Sir William Tyrell, M. de Margerie, 24. 4. 1914, in: DDF 3, 10, 155.

689 Zit. Bertie an Grey, 28. 5. 1914, in: NL Bertie, PRO, FO 800/166, fol. 74. Über die unstete russische Politik hatte Doumergue dem britischen Botschafter auch schon im Dezember 1913 geklagt. Vgl. Bertie an Grey, 18. 12. 1913, in: NL Bertie, PRO, FO 800/ 166 , fol. 54 .

690 Vgl. Notes journalières, in: NL Poincaré, BNF, Nafr. 16027, fol. 32-34 (Eintrag vom 26. 3. 1914).

691 Zit. ibid., fol. 33.

692 Zit. ibid. In der Korrespondenz des russischen Botschafters findet sich kein Hinweis auf dieses Gespräch. Poincaré dachte in diesem Zusammenhang an seinen Aufenthalt in Petersburg, den er dann auch nutzen sollte, um in einer Unterredung mit dem russischen Monarchen das Gespräch auf den ehemaligen Ministerpräsidenten zu lenken. Vgl. Notes journalières, in: NL Poincaré, BNF, Nafr. 16027, fol. 100 f. (Eintrag 
Alles in allem mag aus der Beunruhigung, die sich im Gefolge von Nachrichten einstellte, die von einer deutsch-russischen Annäherung oder auch nur von einem Bemühen um einen solchen Ausgleich berichteten, deutlich geworden sein, daß aus der Sicht Frankreichs die internationale Konstellation auch noch in den letzten Monaten vor Kriegsausbruch beträchtliche Entwicklungsmöglichkeiten in sich barg. Ganz offensichtlich unterschätzte man auf französischer Seite, wie fest letztlich der Zar und sein Außenminister im Lager der Allianz standen. Mochte der russische Monarch auch zu unterschiedlichen Gelegenheiten betonen, daß das Bündnis eine unverrückbare Konstante seiner Außenpolitik sei ${ }^{693}$, bestimmend für Frankreichs Wahrnehmung der deutsch-russischen Beziehungen war vielmehr das, was Sasonow einmal dem britischen Geschäftsträger klagte, daß nämlich nothing he can say or do can dispel French mistrust ${ }^{694}$. Im Zusammenhang mit der Möglichkeit eines deutsch-russischen Ausgleichs sollte man deshalb nicht von einer »absurde[n] Furcht « ${ }^{695}$ der französischen Staatsmänner sprechen, sondern vielmehr dem Historiker Thomas Nipperdey zustimmen, der in seinem Opus magnum konstatierte, daß den Zeitgenossen "wichtige Allianzen nicht so fest [... schienen], wie den Historikern es im nachhinein vorkommt «696.

Diese Feststellung darf nun allerdings nicht in dem Sinne mißverstanden werden, daß Frankreich in der Julikrise mit einer Politik der uneingeschränkten Unterstützung des Bündnispartners auf eine als akut eingeschätzte $\mathrm{Ge}$ fahr eines russischen Abschwenkens in das deutsche Lager reagierte hätte. Wohl aber wird deutlich, daß Frankreich die außenpolitischen Optionen und den Handlungsspielraum seines Bündnispartners überschätzte und dies selbst dann noch tat, als das deutsch-russische Verhältnis im Gefolge der Liman-von-Sanders-Krise einen Tiefpunkt erreicht und Wilhelm II. die Bezie-

vom 20. 7. 1914). Im Hinblick auf diesen Staatsbesuch dürfte auch das immerhin sechs Seiten umfassende, maschinenschriftliche Memorandum über Witte entstanden sein, das sich in den Archiven des Außenministeriums findet. Vgl. Note sur le Comte Witte, 12. 7. 1914, in: MAE, NS Russie 42, fol. 270-272.

693 Vgl. Louis an Poincaré, 27. 6. 1912, in: DDF 3, 3, 143; Ders. an Dens., 27. 6. 1912, in: DDF 3, 3, 147; Notes de M. Poincaré sur ses entretiens de Saint-Pétersburg, August 1912, in: DDF 3, 3, 264. Vgl. ferner die Aussagen Delcassés gegenüber dem britischen Botschafter in: Memorandum, 20. 10. 1913, in: NL Bertie, PRO, FO 800/177, fol. 111. Vgl. auch Notes journalières, in: NL Poincaré, BNF, Nafr. 16027, fol. 100f. (Eintrag vom 20. 7. 1914). Für Sasonow vgl. Louis an Poincaré, 19.6. 1912, in: DDF 3, 3, 121 und Ders. an Dens., 21. 6. 1912, in: MAE, NS Allemagne 62, fol. 81.

694 Zit. O'Beirne an Grey, 24. 6. 1912, in: BD 9/2, 579. Vgl. in diesem Zusammenhang auch das Schreiben des russischen Botschafters in Paris vom 18. Juni 1913, in dem dieser davon sprach, daß man in Frankreich die Beziehungen Rußlands zum Deutschen Reich stets mit krankhafter Empfindlichkeit verfolge. Zit. Iswolski an Sasonow, 18. 6. 1913, in: STIEVE, Iswolski-Schriftwechsel III, 928.

695 Zit. NEITZEL, Kriegsausbruch, S. 159.

696 Zit. Thomas NIPPERDEY, Deutsche Geschichte 1866-1918, Bd. II: Machtstaat vor der Demokratie, München 1992, S. 697. 
hungen zum östlichen Nachbarn gar schon für todt ${ }^{697}$ erklärt hatte. Denn der deutsch-russische Interessensgegensatz resultierte nach der überwiegenden Einschätzung der französischen Beobachter nicht primär aus den sich überkreuzenden Interessen im Osmanischen Reich, sondern war in ganz entscheidendem Maße von der Unterstützung bestimmt, die das Deutsche Reich dem traditionellen Rivalen Rußlands, der Habsburgermonarchie, gewährte ${ }^{698}$. La Russie, so erklärte Ministerpräsident und Außenminister Poincaré im Oktober 1912 seinem Botschafter in Sankt Petersburg, s'est alliée à nous pour contenir l'Autriche comme nous nous sommes alliés aux Russes pour contenir l'Allemagne [...]. À Pétersbourg, on parle sans cesse de l'amitié traditionnelle de l'Allemagne et de la Russie ${ }^{699}$. War dies aber der Fall, so war der deutsch-russische Gegensatz der Berliner Kontrolle unterworfen und eine deutsch-russische Verständigung auf dem Rücken der Habsburgermonarchie nicht ausgeschlossen, zumal angesichts des rapide voranschreitenden Machtverfalls Österreich-Ungarns der Bündniswert der Donaumonarchie ohnehin in Zweifel stand. Ganz auf der Linie der Erklärungen Poincarés lag es deshalb, wenn Jules Cambon im April 1914 in einem Brief an den Politischen Direktor des Außenministeriums darüber nachdachte: Il faut bien en arriver à cette conclusion, paradoxale en apparence, que nous sommes plus intéressés à l'existence de l'Autriche que ne l'est l'Allemagne elle même, puisque toute l'amitié que la Russie nous manifeste repose sur l'inimitié qu'elle nourrit contre l'Autriche ${ }^{700}$. Der deutsch-russische Gegensatz galt Frankreich eben nicht als unüberbrückbar, und noch einen Monat vor Ausbruch des Großen Krieges erklärte Paléologue dem belgischen Botschafter: je ne vois aucune question qui puisse diviser gravement les deux pays ${ }^{701}$.

Im Fall eines umfassenden deutsch-russischen Ausgleichs hätte sich Frankreich aber entweder als das zweifellos schwächste Glied den beiden weltanschaulich fremden Giganten anschließen und im Sinne Wittes eine Kontinentalallianz bilden müssen, oder aber sich ihm ein übermächtiger deutsch-russischer Block entgegengestellt. Ce serait épouvantable!, so soll angesichts dieser beiden Möglichkeiten Viviani im Juni 1914 ausgerufen ha-

${ }^{697}$ Zit. Randmerkung Wilhelms II. zu Pourtalès an Bethmann Hollweg, 25. 2. 1914, in: GP 3915481.

698 In diesem Zusammenhang sei auch an die schon an anderer Stelle ausführlich behandelte Furcht erinnert, die gleichsam das militärische Pendant zu der hier erörterten Sorge darstellte und darin bestand, daß der russische Bündnispartner sich im Kriegsfall primär gegen Österreich-Ungarn richten könnte. Vgl. die Ausführungen im Abschnitt »Frankreichs Forderungen - Der Verlust gesamtsystemischen Denkens«.

699 Zit. LOUIS, Carnet II, S. 34 (Eintrag vom 8. 10. 1912).

700 Zit. Jules Cambon an de Margerie, 13. 4. 1914, in: NL Jules Cambon, MAE, PA-AP 43/56, fol. 6. De Margerie unterstrich im Brief des Botschafters die Passage nous manifeste repose sur l'inimitié qu'elle nourrit contre l'Autriche. Vgl. Ders. an Dens., 13. 4. 1914, in: NL de Margerie, MAE, PA-AP113/9, fol. 295. Vgl. auch Jules Cambon an Doumergue, 13. 4. 1914, in: DDF 3, 10, 101.

701 Zit. Paléologue an Doumergue, 30. 4. 1914, in: DDF 3, 10, 186. 
ben, nous y perdrions notre indépendance nationale! ... Ce ne serait pas seulement la fin de la République, ce serait la fin de la France?02. Mag man diese Einlassung des Ministerpräsidenten und Außenministers, die Paléologue in seinem Diarium überliefert, zumindest in ihrer zugespitzten Form auch nicht für authentisch halten, was den Kern der Sache angeht, dürfte der ehemalige Botschafter nichts Falsches berichtet haben. Notierte doch auch Doulcet nach einem Gespräch mit Paléologue, daß auch Poincaré in den ersten Monaten des Jahres 1914 in einer Kontinentallianz le piège le plus dangereux erblickte, que nos ennemis puissent nous tendre ${ }^{703}$.

Daß Frankreich bei Ausbruch des Großen Krieges den außenpolitischen Handlungsspielraum seines Bündnispartners überschätzte, hatte seinen Grund aber nicht allein in der stets vorhandenen Möglichkeit eines renversement des alliances, sondern darüber hinaus mit der russischen Machtentfaltung auch in der vergleichsweise neuen Entwicklung. Von ihr ist einmal sicherlich zu Recht durch den britischen Historiker Michael Ekstein bemerkt worden, daß es sich dabei um "the major development in international relations in the year or so before the outbreak of war ${ }^{704}$ gehandelt habe, und in der historischen Forschung ist deshalb auch mehrfach auf die Bedeutung dieses Phänomens für die Außenpolitik der europäischen Großmächte aufmerksam worden - allerdings nur unter einer sehr ungleichmäßigen Berücksichtigung der einzelnen Staaten ${ }^{705}$. So ist man selbst in den neueren Arbeiten zur Außenpolitik Frankreichs der Wahrnehmung der russischen Machtentfaltung nicht gründlich nachgegangen ${ }^{706}$, und auch in den Untersuchungen, die sich der Einschätzung dieser Entwicklung im Rahmen einer vergleichenden europäischen Betrachtung nähern, wird der Fall Frankreichs nur am Rande behandelt ${ }^{707}$. Dieser Befund mutet um so überraschender an, als die Machtentfaltung Rußlands die Grande Nation vor ganz neue Herausforderungen stellte. Ging doch mit dem sich wandelnden Urteil über die russischen Mög-

702 Zit. PALÉologue, Journal, S. 318 (Eintrag vom 23. Juni 1914).

703 Zit. Paléo[logue], juillet 1916, in: NL Doulcet, MAE, PA-AP 240/23, fol. 158.

704 Zit. EKSTEIN, Great Britain, S. 342.

705 Zur britischen Perzeption der russischen Machtentfaltung vgl. insbesondere RoPPONEN, Kraft, S. 285-289; WOHLFORTH, Perception, S. 355-358 und Keith NeILSON, »Watching the Steamroller «: British Observers and the Russian Army before 1914, in: Journal of Strategic Studies 8 (1985), S. 199-217; letzterer unter besonderer Berücksichtigung der Wahrnehmung der militärischen Beobachter. Vgl. ferner die Bemerkungen bei Steiner, NeILson, Britain and the Origins, S. 114f.; STEINER, Foreign Office, S. 136f. und NEILSON, Britain and the Last Tsar, S. 136-140. Zur deutschen Perzeption vgl. Ropponen, Kraft, S. 245-250; WoHlforth, Perception of Power, S. 360-363 und LINDEMANN, Macht, S. 234f., 237-239, S. 248 f.; letzterer unter besonderer Berücksichtigung der Person Bethmann Hollwegs.

706 Vgl. beispielsweise KeIger, France and the Origins; DERs., Poincaré und HaYne, French Foreign Office.

707 Vgl. Ropponen, Kraft, S. 168-170 und Wohlforth, Perception of Power, S. 357359. Einige Bemerkungen zur Wahrnehmung der russischen Machtentfaltung in der französischen Öffentlichkeit finden sich auch in MATHIEU, Role of Russia, S. 153-160. 
lichkeiten auch die Erkenntnis einher, daß sich innerhalb des Bündnisses die Gewichte zu Ungunsten Frankreichs verschoben und daß dies nicht ohne Auswirkungen auf den außenpolitischen Kurs des Landes bleiben konnte.

Grundsätzlich kann in diesem Zusammenhang zunächst konstatiert werden, daß sich die schon an anderer Stelle erkennbar gewordene Wahrnehmung, daß der Bündnispartner in den Jahren nach der militärischen Niederlage und politischen Revolution von 1905 beträchtlich an Macht gewonnen hatte, auch bis zum Kriegsausbruch fortsetzte ${ }^{708}$. Schon zu einem vergleichsweise frühen Zeitpunkt läßt sich dann in den Quellen für die französischen Beobachter die Auffassung nachweisen, daß das Zarenreich im Begriff stehe, eine bislang unbekannte Macht zu entfalten, und nicht zu verkennen ist, daß diese Ansicht bis zur Julikrise in ein nahezu unheimliches Urteil über die russischen Möglichkeiten einmündete.

Deutlich wird diese letzte Wendung beispielsweise in einer Reihe von Berichten, die der Militärattaché Frankreichs im November und Dezember 1913 an den Kriegsminister richtete, nachdem er von einer längeren Reise durch die asiatischen Provinzen Rußlands zurückgekehrt war ${ }^{709}$. GleichmäBig beleuchtete er in ihnen die ökonomische und militärische Entwicklung des Landes, um dann in einem letzten, abschließenden Bericht auch auf die außenpolitischen Konsequenzen der russischen Machtentfaltung aufmerksam zu machen.

In seinen Berichten entwarf der Militärattaché das Bild eines märchenhaft reichen Landes, dessen Anblick ihn in den erstaunten Ausruf verfallen ließ: Je ne pouvais y croire $?^{710}$. Sollte ihm die Einschätzung des deutschen Kanzlers, der im Hinblick auf Rußland von einem mit unerschöpflichen Naturschätzen ausgestatteten Riesenreich ${ }^{711}$ sprach, bekannt gewesen sein, so hätte sie sicherlich seine uneingeschränkte Zustimmung gefunden. Denn es waren insbesondere die Fruchtbarkeit des Landes, der außergewöhnliche Reichtum an Bodenschätzen und Edelmetallen und die rasante demographische Entwicklung ${ }^{712}$, die de Laguiche tief beeindruckten und ihn in seinem Reisebericht zu dem Urteil führten, daß der Bündnispartner ein colosse, gar eine puissance sans limite sei, dessen Entwicklung à pas de géant ${ }^{713}$ voranschreite.

708 Vgl. die Ausführungen im Abschnitt "Der habsburgische Gulliver im strategischen Konzept Frankreichs".

709 Vgl. de Laguiche an Noulens, 19. 11. 1913; Ders. an Dens., 20. 11. 1913; Ders. an Dens., 23. 11. 1913 und Ders. an Dens., 3. 12. 1913, in: SHA 7N1478.

710 Zit. Ders. an. Dens., 20. 11. 1913, in: SHA 7N1478.

711 Zit. Verhandlungen des Reichstages. Stenographische Berichte, Bd. 289, 4512.

712 Von einer rasanten demographischen Entwicklung des Bündnispartners hatte der Militärattaché auch schon im Sommer 1913 in Zusammenhang mit der russischen Aufrüstung gesprochen. Vgl. de Laguiche an Etienne, 26. 6. 1913, in: DDF 3, 7, 216.

713 Zit. de Laguiche an Noulens, 3. 12. 1913, in: SHA 7N1478. L'ensemble de l'impression, so hatte der Militärattaché gleich im ersten Bericht seine Eindrücke zusammenge$\mathrm{faßt}$, se résume en peu de mots: admiration de l'avenir de ce pays, émerveillement de l'activité russe et des résultats obtenus par elle, surtout en Sibérie Orientale. Tout se réu- 
Der Militärattaché war von der russischen Entwicklung im Fernen Osten so beeindruckt, daß er noch Monate später in seiner Korrespondenz auf seine Beobachtungen zurückkam. Als ihm Kriegsminister Suchomlinow im Juli 1914 mit Begeisterung von den außergewöhnlichen Fortschritten berichtete, die Rußland in Asien mache, gestand de Laguiche: J'ai dî̀ entamer le même ton, tellement je reste sous l'impression de ma visite de l'an dernier ${ }^{714}$. Doch nicht allein von der ökonomischen Entwicklung, auch von der militärischen Kraft des Bündnispartners hatte der Militärattaché schon kurze Zeit nach seiner Entsendung einen überaus günstigen Eindruck gewonnen ${ }^{715}$. Hatte er in seinem Bericht über die militärische Entwicklung im Jahr 1913 bemerkt, daß der russische Soldat ein élément de tout premier ordre, möglicherweise gar le meilleur de ce qui peut se trouver ${ }^{716}$ sei, so schlug er wenige Monate später einen Ton offener Bewunderung an. En resumé, so schloß er im April 1914 einen Bericht über die russischen Manöver, $p l u s$ je vais, plus j'admire ce matériel, l'homme russe [...] est supérieur à tout ce que je connais. Il y a là une origine de force et de puissance que je n'ai retrouvée dans aucune armée ${ }^{717}$. Mochte auch nach seiner Einschätzung das Offizierskorps an Qualität zu wünschen übrig lassen, für de Laguiche, der schon als Militärattaché in der Habsburgermonarchie und im Deutschen Reich die militärische Lage anderer Staaten beobachtet hatte, stand fest, daß die russischen Kontingente auch im europäischen Vergleich exzellent waren ${ }^{718}$.

Das Bild, das der Militärattaché von der Entfaltung der russischen Macht nach Paris übermittelte und von dem auch Poincaré Kenntnis erhielt, fand in den Berichten der Diplomaten zahlreiche Entsprechungen ${ }^{719}$. Den insbesondere von den Gegnern der Allianz vorgebrachten Einwand, daß der Bündnispartner innenpolitisch auf tönernen Füßen stehe, da die allgemeine Mobil-

nit dans ce pays pour en faire l'un des plus riches que l'on puisse imaginer, sans même que l'on ait une idée des trésors qu'il renferme. Zit. Ders. an Dens., 20. 11. 1913, in: SHA $7 \mathrm{~N} 1478$.

714 Zit. de Laguiche an Messimy, 9. 7. 1914, in: SHA 7N1478.

715 Vgl. die Ausführungen des Militärattachés gegenüber Millerand, die aus dem Dezember 1912 stammen und mit den nachfolgend zitierten Einschätzungen grundsätzlich übereinstimmen. Vgl. die Aufzeichnung: G[éneral] Laguiche, 23. 12. 1912, in: NL Millerand, AN, 470 AP 9.

716 Zit. de Laguiche an Noulens, 10. 12. 1913, in: SHA 7N1478.

717 Zit. Ders. an Dens., 22. 4. 1914, in: SHA 7N1478.

718 Vgl. Russie: Ancien Régime, 1914, in: NL de Robien, AN, 427 AP 1, fol. 32. Das Bild, das sich der Militärattaché von der russischen Armee gemacht hatte, entsprach nicht allein sehr genau der Einschätzung des Generalstabs, sondern darüber hinaus auch der der britischen Beobachter. Vgl. L'Accélération de l'offensive russe, in: NL Messimy, AN, 509 AP 6, fol. 1; Conférence sur l'armée russe. École supérieure de guerre, 1912, in: SHA 7N1535 und Physionomie de l'armée russe, 1913, in: ibid. Zur britischen Wahrnehmung vgl. NEILSON, Steamroller, passim.

719 Im Diarium Paléologues, das für den Zeitraum zwischen seiner Ernennung zum Botschafter in Petersburg und der Julikrise nur wenige Einträge enthält, findet sich keine Einschätzung der russischen Machtentfaltung. Vgl. PALÉOLOGUE, La Russie des tsars, Bd. I. 
machung zugleich das Fanal für den politischen Umsturz sein werde, mochte Paléologue nicht gelten lassen. Vielmehr glaubte er, überall in Rußland eine prodigeuse manifestation de vitalite 720 wahrnehmen zu können, und die Machtentfaltung des Landes beschrieb er mit den Worten:

Depuis quelques années, la Russie accuse un développement de population et de richesse dont les États-Unis seuls ont parfois offert l'exemple; le nombre des habitants, qui a déjà dépassé 180 millions, augmente de deux millions par an; l'excédent des recettes budgétaires s'élevè à 1250 millions de francs; l'effectif de l'armée qui était jusqu'ici de 1200000 bommes atteindra bientôt $1600000^{721}$.

Welche Relationen für den Botschafter mit diesen Zahlen verbunden waren, macht ein Artikel deutlich, den ein nach Petersburg entsandter Sonderkorrespondent des »Matin« am 18. Juli 1914 publizierte und der ohne Zweifel auf ein Gespräch mit Paléologue zurückzuführen ist, denn in seinem Bericht hatte sich der Korrespondent des »Matin « nicht allein ausdrücklich auf einen "diplomate français « berufen, sondern zitierte fast wörtlich aus Depeschen, die Paléologue am 17. Februar und 21. März 1914 an sein Außenministerium gesandte hatte ${ }^{722}$. Ausführlich wurde in diesem Artikel die Entfaltung der militärischen Macht Rußlands behandelt, die schon in naher Zukunft nach Einschätzung des Korrespondenten zu einer supériorité écrasante sur toutes les armées européennes ${ }^{723}$ führen müsse. Mag man diese letzte Formulierung

720 Zit. Paléologue an Doumergue, 21. 3. 1914, in: DDF 3, 10, 52. Vgl. in diesem Zusammenhang auch Ders. an Dens., 23. 4. 1914, in: DDF 3, 10, 149. In diesem Bericht machte der Botschafter zugleich darauf aufmerksam, daß aufgrund der russischen Machtentfaltung in Zukunft auch mit einer aktiveren Außenpolitik des Alliierten zu rechnen sei. Ein Hinweis auf die glänzende Lage der russischen Staatsfinanzen findet sich in PALÉlogue, Journal, S. 216 (Eintrag vom 26. 10. 1913).

721 Zit. Paléologue an Doumergue, 21. 3. 1914, in: DDF, 3, 10, 52. De Robien berichtet in seinen Erinnerungen, daß Paléologue anläßlich der Manöver, denen er am 23. Juli 1914 in Zarskoje Selo beiwohnen konnte, in einen nahezu verzückten Ton der Bewunderung ausgebrochen sei. Vgl. Russie: Ancien Régime, 1914, in: NL de Robien, AN, 427 AP 1, fol. 59.

722 Vgl. Paléologue an Doumerge, 17. 2. 1914, in: DDF 3, 9, 322 und Ders. an Dens., 21. 3. 1914, in: DDF 3, 10, 52. Vgl. auch das Schreiben der britischen Botschaft, mit dem der Inhalt dieses Artikels nach London übermittelt wurde. Vgl. Graneville an Grey, 18. 7. 1914, in: BD 11, 66.

723 Zit. HeDEMAN, Le président Poincaré arrivera à Cronstadt, in: »Le Matin« vom 18. 7. 1914, 1. Vgl. ferner die Bemerkung mit der der österreichische Botschafter den Artikel des Sonderkorrespondenten an sein Außenministerium übermittelte: Eine jetzt viel erörterte Theorie ist, daß die Bevölkerung, der Volkswoblstand, die militärische Macht Rußlands alljährlich dermassen zunehmen, daß das Czarenreich binnen wenigen Jabren, gewissermassen automatisch, eine derartige Superiorität erlangt baben wird, daß es dann auch obne Krieg seinen Willen Europa wird dictieren können. Zit. Szécsen an Berchtold, 18. 7. 1914, in: ÖUA 8, 10358. Daß der "Matin « einen solchen Artikel publizierte, war kein Zufall. Sein Chefredakteur, Stéphanne Lauzanne, hatte das Zarenreich an der Jahreswende 1913/1914 bereist und daraufhin eine Artikelserie veröffentlicht, in der die demographische, ökonomische und militärische Entwicklung des Landes beschrieben wurde und die in immer neuen Wendungen zu der immer gleichen Schlußfolgerung gelangte: La Russie est un colosse qui, s'il abattait son poing sur le 
auch für eine journalistische Übertreibung halten, in seinen Berichten an das Außenministerium unterstrich auch Paléologue die rasante russische Entwicklung gleich mehrfach und gelangte zu dem Urteil, daß der Bündnispartner täglich an Macht und Stärke zulege ${ }^{724}$.

Es waren aber nicht allein Frankreichs Repräsentanten im Zarenreich, die sich in den letzten Monaten vor Ausbruch des Krieges sehr beeindruckt von der russischen Machtentfaltung zeigten. In seinen Aufzeichnungen über die Unterredungen, die er im April 1914 mit der politischen Führung Frankreichs geführt hatte, notierte der britische Außenminister: $I$ found that everyone conversant with politics, both those in office and such men as $M M$. Clemenceau and Delcassé, were immensely impressed by the growing strength of Russia and her tremendous resources and potential power and wealth ${ }^{725}$.

Unter den von Grey benannten Personen befand sich aber - und dies ist im Zusammenhang mit dem Gegenstand dieser Untersuchung von besonderer Bedeutung - niemand geringerer als Poincaré. Sich ausdrücklich auf die Berichte des Militärattachés berufend erklärte der französische Präsident dem Herausgeber des »Eclair« im Januar 1914, daß der Bündnispartner eine armée incomparable ${ }^{726}$ besitze, und fügte, sein Urteil ins Allgemeine wendend und nicht allein den militärischen Parameter der russischen Machtentfaltung berücksichtigend, hinzu: la Russie a un avenir immense. Sa force est en plein développement ${ }^{727}$. Für Poincaré schritt die russische Entwicklung dabei in einem solchem Maße voran, daß mit ihr ganz beträchtliche Auswirkungen auf das Gleichgewicht der Kräfte im europäischen Staatensystem verbunden waren, hatte er doch wenige Monate zuvor schon dem Chefredakteur des »Matin« erklärt, daß man im Deutschen Reich die kontinuierlich wachsende Macht Rußlands mit zunehmender Sorge wahrnehme und möglicherweise zu einem spezifisch verstandenen, militärischen Prävenire schreiten werde.

globe, le ferait éclater. Zit. LAUZANNE, La plus grande Russie, in: »Le Matin« vom 8. 1. 1914, S. 1. Vgl. auch die Artikel vom 2., 4., 6. und 10.1. 1914, in: ibid., S. 1. Vgl. MATHIEU, Role of Russia, S. 153-155.

$724 \mathrm{Vgl}$. Paléologue an Doumergue, 30.4. 1914, in: DDF 3, 10, 186. Von der pression formidable, die die puissance économique de la Russie ausübe, sprach Paléologue dann im Mai. Vgl. Paléologue an Doumergue, 27. 5. 1914, in: DDF 3, 10, 293.

725 Zit. Grey an Bertie, 1. 5. 1914, in: BD 10/2, 541. Vgl. auch die damit übereinstimmende Aufzeichnung des britischen Botschafters in: Memorandum, 24. 4. 1914, in: NL Bertie, PRO, FO 800/166, fol. 69.

726 Zit. CaIllaUX, Mémoires, Bd. III, S. 45: Le chef de l'État explique que notre attaché militaire à Pétersbourg vint de parcourir la Russie `de Varsovie au Kamtcharka< [sic], $q u ' i l$ a trouve partout des troupes merveilleusement entraînées, des approvisionnements surabondants, un matériel de premier ordre, etc. Die Erinnerungen des ehemaligen Ministerpräsidenten sind an dieser Stelle durch die zeitgenössische Parallelüberlieferung gedeckt. Vgl. LoUIS, Carnet II, S. 94 (Eintrag vom 12.1. 1914). Im Juli 1914 soll Poincaré auch gegenüber Innenminister Malvy von der armée admirable des Bündnispartners gesprochen haben. Vgl. CaIllaux, Mémoires, Bd. III, S. 45.

727 Zit. LoUIS, Carnet II, S. 94 (Eintrag vom 12. 1. 1914). 
L'Empereur et l'Allemagne, so ließ sich der Präsident gegenüber dem Journalisten Lauzanne vernehmen, $n$ 'ont pas que la baine de la France: Ils ont la crainte de la Russie. Ils savent que ce grand corps prend chaque jour de la cobésion; ils veulent l'attaquer et le détruire, avant qu'il ait atteint la plénitude de sa force 728 .

Man mag sich mit Paul Kennedy verwundert fragen, warum die Macht Rußlands - eines »militärischen Kolosses «, der trotz fortschreitender Industrialisierung im europäischen Vergleich unter den großen Mächten noch ein "ökonomischer Pygmäe « war - so "absurd überschätzt « ${ }^{729}$ worden ist. Doch eine solche Frage zu stellen, bedeutet, in rückschauender Betrachtung die Maßstäbe des Zeitalters zu verkennen ${ }^{730}$. Denn der Machtbegriff der französischen Staatsführung beruhte eben noch nicht primär auf der Kraft des Ökonomischen, sondern auf geographischen, demographischen und militärischen Elementen.

Mit dieser Feststellung soll nicht gesagt sein, daß die ökonomische Entwicklung und insbesondere die fiskalische Lage Rußlands keine Beachtung fanden ${ }^{731}$. So berichtete die Petersburger Botschaft in den Jahren 1913 und 1914 gleich mehrfach über beachtliche Fortschritte auf diesem Feld ${ }^{732}$. Darüber hinaus gingen auch eine Reihe von Finanzexperten, die sich in direktem oder indirektem Kontakt mit dem Außenministerium am Quai d'Orsay befanden, von einer glänzenden ökonomischen Zukunft des Bündnispartners aus, wenn auch in diesem Zusammenhang nicht zu verkennen ist, daß sie im Vergleich zur militärischen und politischen Führung in sehr viel längeren Zeiträumen dachten. So sprach beispielsweise der Syndikus der Pariser Börsenaufsicht de Verneuil in einem Brief an Pichon von der situation financière et économique tout à fait extraordinaire ${ }^{733}$ des Bündnispartners. Hatte der mit den ersten Verhandlungen über eine Anleihe betraute Syndikus schon

728 Zit. LaUZanNe, Les hommes que j'ai vus, S. 56.

729 Zit. KenNeDY, First World War, S. 28. Zum Ausmaß der russischen Industrialisierung vgl. auch TOMASZEWSKI, Great Russia, S. 2 f.

730 Vgl. auch die Kritik Neilsons an Kennedy, in: NeILSON, Steamroller, S. 213 f. Zum Ausgangspunkt seiner Kritik macht der britische Historiker den Gedanken, daß sich nach allgemein geteilter Einschätzung, eine militärische Auseinandersetzung der Großmächte nicht über einen längeren Zeitraum erstrecken würde. Folglich habe im Jahr 1914 niemand erkannt, daß der zukünftige Krieg nicht mit den kurzfristig zur Disposition stehenden Mitteln, sondern aufgrund der gesellschaftlichen und ökonomischen Belastbarkeit der Staaten entschieden werden würde. Ähnliche Überlegungen finden sich schon bei WILCOX, Franco-Russian Alliance, S. $220 \mathrm{f}$.

731 Vgl. Calllaux, Mémoires, Bd. I, S. 163. Der Finanzminister des Kabinetts Doumergue berichtet, daß man in den französischen Finanzkreisen schon im Jahr 1913 von nichts anderem mehr gesprochen habe als der glanzvollen ökonomischen Entwicklung des russischen Bündnispartners.

732 Vgl. beispielsweise Doulcet an Pichon, 11. 10. 1913, in: DDF 3, 8, 307 und Paléologue an Doumergue, 31.3. 1914, in: DDF 3, 10, 54. Vgl. ferner GIRAULT, Emprunts russes, Bd. II, S. $996 \mathrm{f}$.

733 Zit. de Verneuil an Pichon, 10. 11. 1913, in: DDF 3, 8, 469. 
vor seiner Reise nach Rußland einen überaus günstigen Eindruck von der ökonomischen Entwicklung des Landes gehabt, so schrieb er nun in seinem Bericht an Außenminister Pichon vom 7. Juli 1913:

Les quelques jours que j'ai passés à Pétersbourg ont suffi pour me convaincre qu'elle était de beaucoup au-dessous de la réalité. Il y a là quelque chose de véritablement formidable qui se prépare et dont les symptômes doivent frapper même les esprits les plus prévenus. J'ai cette impression très nette que, dans les trente années qui vont suivre, nous allons assister en Russie à un prodigieux essor économique qui égalera s'il ne le surpasse, le mouvement colossal qui s'est produit aux États-Unis ${ }^{734}$.

Zu einem ähnlichen Urteil gelangte auch der Chefredakteur des angesehenen »Economiste Européen«, der im Jahr 1913 im Auftrag des Ministère des travaux publics das russische Eisenbahnwesen einer Analyse unterzogen hatte ${ }^{735}$. Im Rahmen einer Podiumsdiskussion, die sich im Februar 1914 mit der ökonomischen Lage Rußlands auseinandersetzte, und an der auch bedeutende französische Politiker teilnahmen, gelangte er zu der Schlußfolgerung, que la Russie, vers le milieu du présent siècle, dominera l'Europe tant au point de vue politique qu'au point de vue économique et financier ${ }^{736}$.

Insgesamt betrachtet ist aber nicht zu verkennen, daß unter den französischen Beobachtern die fiskalische und insbesondere die ökonomische Entwicklung weniger Beachtung fand als das rasche Anwachsen der russischen Militärmacht ${ }^{737}$. Damit lag aber dem Urteil, das sich die militärische und politische Führung Frankreichs von der Macht ihres Bündnispartners machte, ein Parameter zugrunde, der weit über die Grenzen ihres Landes hinaus für die in maßgeblicher Stellung außenpolitisch Handelnden allgemeine Verbindlichkeit besaß. So stand in den ersten Monaten des Jahres 1914 auch den britischen Beobachtern insbesondere die wachsende militärische Macht Rußlands vor Augen. In einem Bericht des Militärattachés, den dieser über die Botschaft und damit über das Außenministerium an das Kriegsministerium weiterleitete, gelangte Oberstleutnant Alfred Knox zu einem beinahe unheimlichen Urteil über die militärische Macht Rußlands. Es sei, so konstatierte er in einem Schreiben vom 19. März 1914, in dem er alle Facetten der

734 Zit. Ders. an Dens., 7. 7. 1913, in: DDF 3, 7, 309.

$735 \mathrm{Vgl}$. Rapport d'Edmond Théry sur la gestion des chemins de fer en Russie et le développement de leur trafic pendant les 10 derniéres années, 28. 9. 1913, in: CAEF, B 57026. Vgl. auch Théry an Dumont, 28. 9. 1913, in: ibid.

736 Zit. Evolution économique de la Russie, in: "La Vie financière" vom 4. 2. 1914. Unter den Gästen befand sich beispielsweise auch der ehemalige Kriegsminister Étienne. 737 So wurde weder im Außen- noch im Finanzministerium die fiskalische Lage des russischen Bündnispartners einer eingehenden Analyse unterzogen. Darüber hinaus stand das Finanzministerium den Attachés commerciaux grundsätzlich skeptisch gegenüber. Sprach doch Klotz in einem Schreiben an das Außenministerium davon: $A u x$ yeux du Ministre des Finances, se pose la question de savoir s'il convient d'imposer au budget l'entretien d'attachés commerciaux dont le rôle, resté jusqu'ici sans résultat utile, apparait aujourd'bui néfaste. Il y a là un point sur lequel je me permettrai d'attirer votre attention et celle de mes collègues au moment de la préparation du prochain budget. Zit. Klotz an Poincaré, 6. 11. 1912, in: CAEF B61035/2. 
russischen Aufrüstung gleichmäßig beleuchtete, only a matter of time till the army becomes a match for all western Europe ${ }^{738}$. An dieser Einschätzung des Militärattachés scheint sich auch der Direktor der militärischen Operationsabteilung des britischen Stabes orientiert zu haben ${ }^{739}$, und ähnlich gelagerte Urteile über die militärischen Möglichkeiten des Zarenreiches lassen sich in den Berichten des Botschafters und in den internen Vermerken des Außenministeriums finden. Buchanan berichtete im März und April 1914 jedenfalls gleich mehrfach über die russische Machtentfaltung, und auch er machte in diesem Zusammenhang auf die Auswirkungen aufmerksam, die diese Entwicklung für das Gleichgewicht der Kräfte haben mußte ${ }^{74}$.

Geteilt wurde Buchanans Beurteilung des russischen Wachstums von Nicolson, der schon zu einem vergleichsweise frühen Zeitpunkt, das heißt in den ersten Monaten des Jahres 1913, von der ever increasing military and financial strengt $b^{741}$ Rußlands gesprochen hatte und der Ansicht war: Russia is continually progressing in every possible way and is already, I think, one of the most formidable factors in Europe ${ }^{742}$. Diese Einschätzung des permanenten Unterstaatssekretärs sollte sich auch in den letzten Monaten vor Ausbruch des Großen Krieges nicht wandeln ${ }^{743}$, und mit ihr verbanden sich gravierende Konsequenzen. So sprach Buchanan davon: Unless Germany is prepared to make still further financial sacrifices for military purposes, the days of ber begemony in Europe will be numbered, as even without the co-operation of England, Russia and France combined will then be strong enough to confront the united forces of the Triple Alliance ${ }^{744}$. In naher Zukunft würde nach Einschätzung des Botschafters Rußland also so stark sein, daß es unabhängig von britischer Unterstützung handeln konnte, was natürlich auch die Beziehungen beider Staaten auf eine neue Grundlage stellen mußte: During the crucial years therefore, Russia will stand in need of our support and should we fail to give it when she appeals for it, England will no longer be numbered among ber friends ${ }^{75}$. Mag es prima facie unwahrscheinlich anmuten: In den

738 Zit. Army Programme and the Western Frontier, 19. 3. 1914, in: PRO/WO 105/ 1040.

$739 \mathrm{Vgl}$. Wilsons Randbemerkungen zu Army Programme and the Western Frontier, 19. 3. 1914, in: PRO/WO 105/1040: This is a most important Despatch. It is easy to understand now why Germany is anxious about the future + why she may think that it is a case of now or never. Henry Wilson 27. 3. 1914.

$740 \mathrm{Vgl}$. Buchanan an Grey, 18.31914, in: BD 10/2, 528. Vgl. ferner Ders. an Nicolson, 18. 3. 1914, in: BD 10/2, 529 und Ders. an Dens., 16. 4. 1914, in: BD 10/2, 538.

741 Zit. Nicolson an Buchanan, 25. 2. 1913, in: BD 9/2, 660.

742 Zit. Ders. an Dens., 22. 4. 1913, in: BD 9/2, 871. Vgl. ferner Ders. an Dens., 8. 4. 1913, in: NL Nicolson, PRO, FO 800/365, fol. 177. In diesem Brief sprach der permanente Unterstaatssekretär gar davon, daß Rußland the most powerful factor in Europe sei. Vgl. auch Ders. an Cartwright, 19. 2. 1913, in: BD 9/2, 632.

$743 \mathrm{Vgl}$. Nicolson an de Bunsen, 27. 4. 1914, in: BD 10/2, 540 und Nicolsons Vermerk zu: Granville an Grey, 18. 7. 1914, in: BD 11, 66.

744 Zit. Buchanan an Grey, 18. 3. 1914, in: BD 10/2, 528.

745 Zit. ibid. 
Quellen lassen sich auch auf seiten Frankreichs Befürchtungen nachweisen, die denen des britischen Botschafters ganz ähnlich gelagert waren.

Schon in seinem Bericht aus dem Dezember 1913 hatte der Militärattaché mit der Beschreibung der russischen Machtentfaltung eine Betrachtung ihrer außenpolitischen Konsequenzen verbunden und in diesem Zusammenhang der Sorge Ausdruck gegeben, daß sich der Bündnispartner aufgrund seiner kontinuierlich wachsenden Macht dem Einfluß Frankreichs entziehen werde ${ }^{746}$. Die Auswirkungen, die mit der russischen Entwicklung für den Zusammenhalt des Bündnisses verbunden waren, sollten den Militärattaché auch in den folgenden Monaten beschäftigen.

Il serait dangereux, so warnte er den Leiter der Abteilung II des Generalstabs erstmals in einem persönlichen Brief aus dem Frühjahr 1914, de considérer la Russie d'aujourd'bui comme semblable à ce qu'elle était il y a 15 ou 20 ans. Le développement du pays a été énorme et cela se traduit par une richesse croissant dans des proportions phénoménales ${ }^{74}$. Zwar verkannte de Laguiche nicht, daß die gänzliche Entfaltung der russischen Möglichkeiten nur mit fremder Unterstützung ins Werk gesetzt werden konnte; doch seinen Blick nachdenklich in die Zukunft richtend, erklärte er: Il faut se dire, que plus nous avancerons, moins la Russie aura besoin des autres nations, plus elle s'affranchira par suite de notre pression. Les gens qui disent qu'il faut lui parler dur et se faire payer très cher tout concours sont sur le point de se tromper. Evidemment il faut être: donnant, donnant; mais il faut aussi ne pas trop tendre la corde ${ }^{748}$. Hatte der Militärattaché mit diesem Brief erstmals eine deutliche Warnung nach Paris übermittelt und mit einem Hinweis auf die russische Machtentfaltung zu einem konzilianten Auftreten geraten, so sollte er unmittelbar vor Ausbruch des Großen Krieges in einen dramatischen Ton verfallen. Vor dem Hintergrund der innerfranzösischen Auseinandersetzungen um die loi des trois ans beschwor er den Messimy nahe stehenden General Brissaud $^{749}$ in einem Brief vom 13. Juli 1914 mit den Worten:

746 La Russie de nos jours, so gab er dem Kriegsminister unter dem Datum des 3. Dezember zu bedenken, n'est plus celle d'il y a 15 ans. Elle a une puissance, financière ou autre, bien plus considérable que jadis, même si elle a besoin, et pour longtemps encore, de l'assistance d'autres pays. Elle sent son développement s'affirmer immense, et ce voyage m'a convaincu de la réalité de ce développement, aussi accepte-t-elle moins facilement la pression ou même le contrôle de l'étranger, elle cherche même à déguiser à ses propres yeux l'aide qu'elle doit lui demander et cela nous force à savoir mesurer nos exigences. Zit. de Laguiche an Noulens, 3. 12. 1913, in: SHA 7 N 1478.

747 Zit. de Laguiche an Dupont, 14. 2. 1914, in: SHA 7N1478.

748 Zit. ibid. Vgl. auch Louis GARROS, En marge de l'alliance franco-russe. 1902-1914, in: Revue historique de l'armée, 6/2 (1950), S. 29-44, hier S. 32 f. Garros datiert diesen Brief irrtümlich in das Jahr 1912 und läßt darüber hinaus die politisch bedeutsame Schlußfolgerung des Militärattachés unerwähnt.

749 Georges-Henri Brissaud-Desmailet war zwischen 1912-1914 als Militärattaché in China tätig. De Laguiche wandte sich vermutlich deshalb an ihn, weil er im Jahr 1912 Mitglied des Generalstabs Messimys gewesen war. Vgl. Dictionnaire de biographie 
Vous verrez le Ministre, il faut que vous lui disiez la vérité sur la Russie et cela se résume pour moi en peu de mots: La Russie se développe d'une façon prodigieuse économiquement parlant. Nous nous approchons d'un moment où elle pourra se passer de tout le monde, de nous aussi parce qu'ou bien elle n'aura plus besoin de notre argent ou bien elle en trouvera ailleurs. [...] Elle a augmenté ses forces militaires d'une façon prodigieuse et, à elle seule, se sent assez forte pour n'avoir rien à redouter de personne. Le temps n'est plus où nous pouvions être un peu léger et traiter la Russie cavalièrement. [...] Si nous sommes mous, vagues, ne vous étonnez pas de voir l'alliance battre seulement d'une aile malade. On se trompe en France en croyant la Russie encore au temps d'il y a 4 ou 5 ans. Il pourrait nous en coûter cher de ne pas penser à cela et de simplement examiner ce que nous pensons en France ${ }^{750}$.

Berichte dieser Art und dieses Tonfalls erklären, warum der ehemalige Kriegsminister Messimy dem französischen Historiker Pierre Renouvin rückblickend sagen konnte: Le G[énér]al de Laguiche [...] était tout acquis à l'Empire Russe, il paraissait penser que la Russie nous faisait un grand honneur en nous accueillant comme Alliés ${ }^{751}$. Doch solch weitreichende Einschätzungen der russischen Möglichkeiten waren keinesfalls allein auf den militärischen Repräsentanten Frankreichs beschränkt, sondern wurden vielmehr auch vom Generalstab geteilt ${ }^{752}$.

Zwar hatte der russische Generalstabschef - wie schon an anderer Stelle bemerkt worden ist - noch im August 1911 bekennen müssen, daß man im Augenblick auf eine militärische Auseinandersetzung der europäischen Großmächte nicht genügend vorbereitet sei und die erforderliche Reorganisation des Militärs noch einen Zeitraum von zwei Jahren in Anspruch nehmen werde ${ }^{753}$. Doch war man im französischen Generalstab überzeugt, daß mit der militärischen Reorganisation Rußlands ein gewaltiges Potential zur Entfaltung gelangen würde. Passé ce délai, so bemerkte Dubail mit Blick auf die russischen Angaben zu Beginn des Jahres 1912 in den Beratungen des Conseil supérieur de la défense nationale, nos alliés disposeront d'une supério-

française, Bd. VII, Sp. 358 und Index biographique français, Mikrofiche 101, Eintrag $\mathrm{Nr}, 414$.

750 Zit. de Laguiche an Brissaud, 13. 7. 1914, in: MAE, Publications de la Commission des origines de la guerre de 1914-1918, 73/D.6.F.4. Notes divers. Pièces retrouvées dans les papiers du doyen Renouvin. Bei dem zitierten Dokument handelt es sich um eine maschinenschriftliche Kopie des Originals. Renouvin stieß vermutlich während seiner Arbeit an der Aktenedition auf dieses Schreiben, da der Militärattaché es in einem persönlichen Brief an den Leiter der Abteilung II des Generalstabs erwähnte. Vgl. de Laguiche an Dupont, 18. 7. 1914, in: SHA 7N1748.

751 Zit. Aufzeichnung Renouvins über ein Gespräch mit Messimy, 22. 2. 1923, in: NL Renouvin, IPR, Karton D - Juillet 1914, Dossier 5.

752 Auch darauf machte Messimy den Historiker aufmerksam. Vgl. ibid.: L'E.M. français s'était engoué [Lesart unsicher] de l'armée russe: il avait en elle la plus $\mathrm{g}$ [ran]de confiance. Dubail, qui doutait, a été en Russie en 1911 et en est revenu rretournés.

753 Vgl. Procès-verbal de l'entretien du 18/31 août 1911, entre les chefs d'état-major des armées française et russe, in: DDF 2, 14, 232 und insbesondere Annexe au procès-verbal de l'entretien du 18/31 août 1911 entre les chefs d'état-major des armées française et russe à Krasnoe Celo, in: SHA, 1K666. Vgl. ferner Procès-verbal. CSDN, 9. 1. 1912, in: SHA 2N1, VI/38. 
rité écrasante ${ }^{754}$. In den folgenden Monaten glaubten die Beobachter dann eine rasch fortschreitende Entwicklung feststellen zu können. Schon im Oktober 1912 konstatierte die Abteilung III des Generalstabs, daß die militärische Reorganisation des Bündnispartners in kurzer Zeit abgeschlossen sein werde ${ }^{755}$, und der Eindruck von einem raschen Erstarken der russischen Militärmacht setzte sich fort, als Joffre im Jahr 1913 nach Petersburg reiste ${ }^{756}$. Man hat bei uns keinen Begriff davon, so faßte er seine Eindrücke in einem Gespräch mit dem russischen Militärattaché zusammen, welch enorme Arbeit zur Zeit in Ihrer Armee geleistet wird [...]. Die russische Armee repräsentiert eine viel größere Macht, als man in Europa gemeinhin annimmt ${ }^{757}$.

Schon zu einem frühen Zeitpunkt läßt sich dann für den französischen Generalstab die Befürchtung nachweisen, daß Rußland aufgrund seines enormen Machtzuwachs der französischen Unterstützung gar nicht mehr bedürftig sei. So berichtete Nicolson in seinem, schon in anderem Zusammenhang behandelten Brief an Außenminister Grey, daß sich Joffre und auch Castelnau im Gespräch mit dem Leiter der militärischen Operationsabteilung des britischen Stabes tief beeindruckt von der russischen Machtentfaltung gezeigt hatten: They impressed upon Wilson that Russia was now exceedingly strong, both in her military organisation and also in ber financial condition, and was therefore far less dependent on French support, either in a military or a financial sense. In short, that Russia was now well able to look after herself, and might be inclined to take a line of ber own ${ }^{758}$.

Obgleich nun für die folgenden Monate - sieht man einmal von dem günstigen Eindruck $a b$, den Joffre während seiner Rußlandreise von der militärischen Macht des Bündnispartners gewonnen hatte - in dieser Deutlichkeit keine weiteren Einlassungen mehr überliefert sind, wird man mit Sicherheit annehmen können, daß die von Wilson übermittelte Wahrnehmung sich bis zum Ausbruch des Großen Krieges noch verstärkt haben muß. Gilt es doch in diesem Zusammenhang zu bedenken, daß die Unterredung mit dem Leiter der militärischen Operationsabteilung des britischen Stabes zu

754 Zit. Procès-verbal. CSDN, 9. 1. 1912, in: SHA 2N1, VI/38. Vgl. auch die übereinstimmende Auffassung Millerands, der er am 21. Februar 1912 im Rahmen der Zusammenkunft des kleinen Kreises der bedeutendsten militärischen und politischen Entscheidungsträger Ausdruck gab. Vgl. Conférence du 21 février 1912, in: NL Paléologue. Dokument im Besitz von Roger Lebon.

$755 \mathrm{Vgl}$. Note pour le ministre, 24. 10. 1912, in: SHA 7N1785. Bei dieser Aufzeichnung handelt es sich um ein Memorandum der Abteilung III des Generalstabs, in dem die Gründe dargelegt wurden, die für die Ausarbeitung des Plan XVII sprachen.

756 Vgl. Delcassé an Pichon, 12. 8. 1913, in: DDF 3, 8, 18 und Ders. an Dens., 21. 8. 1913, in: DDF 3, 8, 62. Vgl. ferner MATHIEU, Role of Russia, S. 137 f. Auch Paléologues Tagebuch bestätigt die günstige Auffassung, die Joffre im Sommer 1913 von der russischen Armee hatte. Vgl. PALÉlogue, Journal, S. 131 (Eintrag vom 14. Mai 1913).

757 Zit. Ignatjew an Danilow, 22. 1. 1914, in: IB I/1 77.

758 Zit. Nicolson an Grey, 24. 2. 1913, in: BD 9/2, 656. Vgl. NL WILSON, Diaries, IWM, DS/MISC/80, fol. 45 (Eintrag vom 14. 2. 1913). Aus dem Tagebuch Wilsons geht hervor, daß das Gespräch bereits am 14. Februar 1913 stattfand. 
einem Zeitpunkt stattfand, an dem die ersten Nachrichten über das russische Aufrüstungsprogramm noch nicht nach Paris gelangt waren ${ }^{759}$. Im Zuge seiner Umsetzung sollte aber nicht allein die Ausstattung der Streitkräfte erheblich verbessert, sondern darüber hinaus auch ihre Friedenspräsenzstärke von 1,3 Millionen Mann im Jahr 1913 auf 1,7 Millionen Mann im Jahr 1917 erhöht werden. Geradezu bescheiden nahmen sich im Gegensatz dazu das Heer des Deutschen Reiches und Frankreichs mit 780000 , respektive 700000 Soldaten aus $^{760}$.

Als gesichert kann ferner gelten, daß - und fast ist man geneigt zu sagen: natürlich - auch Paléologue weitreichende Schlußfolgerungen aus der russischen Machtentfaltung zog. Aus einer bislang von der historischen Forschung unbeachteten Aufzeichnung im Nachlaß des zeitweiligen Geschäftsträgers der französischen Botschaft in Sankt Petersburg geht in diesem Zusammenhang hervor, daß sich die Gedankenbildung Paléologues in denselben Bahnen bewegte, in denen auch sein britischer Kollege dachte. So notierte Doulcet unter dem Datum des 18. Juli 1914 über eine Unterredung mit seinem Botschafter: Il admire la rapidité avec laquelle la Russie développe ses forces, et prévoit qu'elle serait bientôt en mesure de se passer de nous si nous devenions par trop déraisonnables 761 .

Folglich war auch Paléologue zu der Einschätzung gelangt, daß Rußland seine Macht in einem Maße entfaltet hatte, daß schon in naher Zukunft die Unterstützung, die der Bündnispartner Frankreich in einer internationalen Krisensituation gewähren würde, diesem nicht mehr von der Notwendigkeit eines quid pro quo diktiert, sondern in entscheidendem Maße auf Wohlwollen und dies bedeutete letztlich auf den Vorleistungen beruhen würde, die Frankreich in einem Zeitraum erbrachte hatte, in dem Rußland noch des französischen Beistands bedurfte. Nach Einschätzung zahlreicher Repräsentanten der militärischen und politischen Führung sah Frankreich sich folglich im Juli 1914 mit einer Lage konfrontiert, in der die Entfaltung der russischen Macht den eigenen Handlungsspielraum beträchtlich eingeschränkt hatte.

759 Einen ersten, noch recht vagen Hinweis auf das Programm und dessen Umfang erhielt der Generalstab durch den russischen Militärattaché. Vgl. Renseignements communiqués verbalement par le colonel Comte Ignatieff au Général Joffre, 18. 3. 1913, in: SHA 7N1535. Erste detaillierte Informationen wurden dann durch ein Schreiben de Laguiches nach Paris übermittelt. Vgl. de Laguiche an Étienne, 1. 4. 1913, in: 7N1535. Vgl. auch Doulcet an Jonnart, 20. 3. 1913, in: DDF 3, 6, 29 und Delcassé an Dens., 21. 3. 1913, in: DDF 3, 6, 44. Eine umfassende Analyse lag dann mit der "Note sur les Projets d'augmentation de l'Armée Russe im Juli 1913 vor. Vgl. SHA 7N1535. Poincaré wurde über das russische Programm in allen Details noch einmal mit einer Note aus dem Sommer 1914 unterrichtet. Vgl. Note remise au colonel Aldebert à l'occasion du voyage du Président de la République en Russe, 6. 7. 1914, in: SHA 7N1535.

760 Zum sogenannten »Großen Programm» vgl. HerrmanN, Arming of Europe, S. 195-197, 205f.; STEVENSON, Armaments and the Coming of War, S. 315-326 sowie MENNING, Bayonets Before Bullets, S. 233-235.

761 Zit. 18 juillet 1914, in: NL Doulcet, MAE, PA-AP 240/22b, fol. 302. 
Vor dem Hintergrund dieses Zusammenhangs verliert aber insbesondere die These Krumeichs an Bedeutung, daß eine innenpolitische Entwicklung, nämlich die Auseinandersetzung um die loi des trois ans den außenpolitischen Handlungsspielraum maßgeblich beeinträchtigte ${ }^{762}$. Stellt die These, daß Poincaré nach den Parlamentswahlen im Mai/Juni 1914 der Ansicht gewesen sei, daß die loi des trois ans in naher Zukunft abgeschafft oder modifiziert werden würde, ohnehin eine Annahme dar, die aufgrund fehlender Belege nicht als gesicherte Erkenntnis gelten darf ${ }^{763}$, so gilt es insbesondere zu bedenken, daß eine Modifikation dieses Gesetzes den relativen Machtverlust Frankreichs nur hinauszögern, nicht aber hätte aufhalten können. Selbst ein unveränderter Fortbestand der dreijährigen Wehrpflicht hätte folglich den außenpolitischen Manövrierraum Frankreichs nicht erheblich erweitern können.

Wenn man aufgrund dieser Überlegungen den innenpolitischen Auseinandersetzungen um die loi des trois ans auch keine handlungsleitende Bedeutung für die Außenpolitik Frankreichs in der Julikrise zumessen darf, so machen die kontroversen Diskussionen über das Wehrgesetz doch darauf aufmerksam, daß für Frankreich den bündnispolitischen Manövrierraum erweiternde Alternativen zu einer weitgehenden Bindung an Rußland im Jahr 1914 nicht mehr oder doch nur noch in sehr eingeschränktem Maße zur Disposition standen und daß in dieser Hinsicht ein innenpolitischer Faktor eine aus anderen Gründen bestehende bündnispolitische Zwangslage zusätzlich verschärfte. Denn eine erneute Aufrüstung - und damit eine der klassischen Substitutionsmöglichkeiten einer Allianz - war Frankreich allein aus demographischen Gründen kaum noch möglich ${ }^{764}$. Erschwerend trat in diesem Zusammenhang noch hinzu, daß sich auch auf dem außenpolitischen Feld die

$762 \mathrm{Vgl}$. KRUMEICH, Aufrüstung und Innenpolitik, passim, hier insbesondere, S. 269. Ähnlich auch KRUMEICH, Å propos de la politique d'armement, S. $671 \mathrm{f}$.

763 Wenn der Verfasser die Quellenlage vollständig zu überblicken vermag, so ist kein einziger dokumentarischer Beleg für die These vorhanden, daß Poincaré im Sommer 1914 von einer Abschaffung oder Modifikation der loi des trois ans ausgegangen ist. Vgl. ferner Jean-Jacques BECKER, Les »trois ans et les débuts de la Première Guerre mondiale, in: Guerres mondiales et conflits contemporains 37 (1987), S. 7-26, hier S. 17-19. Der französische Historiker gelangt in seiner Untersuchung der Parlamentswahlen vom Mai/Juni 1914 zu dem Ergebnis, daß trotz des erheblichen Stimmenzuwachses der Sozialisten im Parlament keine Mehrheit für eine Abschaffung oder Modifikation der dreijährigen Dienstzeit vorhanden gewesen sei. Von einer unklaren Lage hinsichtlich dieser Frage spricht Krumeich in: Gerd KRUMEICH, Poincaré und der Poincarismus, in: Francia 8 (1980), S. 427-454, hier S. 447 f.

764 Vgl. Bertie an Grey, 28. 5. 1914, in: NL Bertie, PRO, FO 800/166, fol. 75: He [gemeint ist Doumergue, St. S.] is very much afraid that in a few months time Germany will use the excess above the anticipated amount resulting form the tax on capital for a further increase in the German Army which will necessitate some effort on the part of France to endeavour to keep pace with Germany. Owing to the lesser population of France it would be difficult to add the numbers of the active army. Probably the reserves might be improved as a fighting force and the numbers of guns be increased. 
Lage kaum günstiger ausnahm und bis 1914 Möglichkeiten, die den bündnispolitischen Handlungsspielsraum Frankreichs zu erweitern vermocht hätten, fortgefallen oder ungenutzt geblieben waren.

Denn daß es möglich sein würde, Großbritannien im Sinne einer Allianz mit genau definiertem casus foederis an Frankreich zu binden, um gegenüber dem östlichen Bündnispartner mit dem notwendigen Gewicht auftreten zu können, glaubte niemand in der außenpolitischen Führung ${ }^{765}$. Schon in anderem Zusammenhang ist deutlich geworden, daß die militärischen und die politischen Entscheidungsträger zwar einerseits die Frage des britischen Kriegseintritts mit verhaltenem Optimismus beurteilten, daß sie aber andererseits das britische Handeln nicht für alle denkbaren Konfliktfälle eindeutig vorhersagen konnten und ihnen dies angesichts der herausragenden $\mathrm{Be}-$ deutung, welche aus ihrer Sicht dem Faktor öffentliche Meinung für das Verhalten Großbritanniens im Kriegsfall zukam, auch grundsätzlich nicht möglich war.

Bedenkt man, daß die militärische Dependenz von einem Bündnispartner sich nicht allein aus dem relativen Machtgefälle zum Gegner, sondern auch aus dem Ausmaß des Konflikts und der Wahrscheinlichkeit resultiert, daß der Gegner diesen mit militärischen Mitteln lösen wird ${ }^{766}$, so wäre es für Frankreich nur dann möglich gewesen, der internationalen Konstellation neuen Manövrierraum abzuringen, wenn man sich im Stande gesehen hätte, den deutsch-französischen Antagonismus einzudämmen, der dem Bündnis mit Rußland, insbesondere seit der erfolgten Annäherung an Großbritannien, zugrunde lag.

Schon in Zusammenhang mit der Betrachtung des Bildes, das sich die militärische und die politische Führung Frankreichs vom Deutschen Reich gemacht hatte, ist deutlich geworden, daß es auch in den letzten Jahren vor Ausbruch des Großen Krieges nicht an Stimmen unterschiedlicher Provenienz fehlte, die sich für eine Politik der détente oder des Rapprochements gegenüber dem östlichen Nachbarn aussprachen. Doch Poincaré hatte schon in seiner Amtszeit als Ministerpräsident und Außenminister Bemühungen, die über den Abbau von Spannungsmomenten hinaus nach einer grundsätzlichen Annäherung an das Deutsche Reich strebten, ein rasches Ende bereitet.

Die Gründe, die für dieses Handeln maßgeblich wurden, waren unterschiedlicher Natur. So machte beispielsweise Paul Cambon seinen Bruder in

765 Vgl. Paléologue an Doumergue, 17. 2. 1914, in: DDF 3, 9, 322: J'ai répondu à l'Empereur que, pour l'Angleterre c'est un dogme de ne contracter aucune alliance, tant que le péril de guerre n'est pas immédiat. Vgl. ferner die entsprechende Aussage Paul Cambons gegenüber dem britischen Botschafter in Paris, in: Memorandum, 24. 4. 1914, in: NL Bertie, PRO 800/166, fol. 64. Vgl. auch das Memorandum, das in Vorbereitung auf den Besuch des britischen Königs in Paris entstand und in dem vermerkt wurde, daß es seit Canning nicht in der Tradition Großbritanniens liege, sich durch einen Allianzvertrag zu binden. Vgl. Note pour le Président du Conseil, 17. 4. 1914, in: DDF 3, 10, 111. 766 Vgl. SNYDER, Alliance Politics, S. 31. 
einem Brief vom 3. November 1912 darauf aufmerksam, daß es allein aufgrund eines innenpolitischen Faktors, das heißt aufgrund der Stimmungslage in der öffentlichen Meinung, unmöglich sei, eine entsprechende Politik zu verfolgen. Jules Cambon, der sich seit seiner Ernennung zum Botschafter in Berlin und auch in den letzten Jahren vor Ausbruch des Großen Krieges für einen entsprechenden Kurs eingesetzt hatte ${ }^{767}$, rief er noch rund ein Jahr nach der letzten großen Krise um das marokkanische Sultanat in Erinnerung:

Le coup d'Agadir est toujours présent à l'esprit de tous les Français et il ne faut pas t'obstiner à vouloir leur faire comprendre des nuances qui ne sont pas à leur portée [...] $\mathrm{Il}$ faut prendre les gens comme ils sont et les situations comme elles se présentent. [...] L'opinion en France à l'beure actuelle ne veut pas entendre parler d'entente avec l'Allemagne. [...] Tu es si loin de Paris et tu te rends si peu compte de la nervosité de tout ce monde qu'il faut te dire ce que je te dis. Tu es las, tu es agacé, tu vondrais voir faire une politique que personne en France n'est en état de conduire. Prends les choses comme elles sont et ne te mets pas martel en tête pour réaliser l'impossible ${ }^{768}$.

Doch es waren nicht allein innenpolitische Faktoren, die einer deutsch-französischen Annäherung nur eine sehr begrenzte Aussicht auf Erfolg gaben. Ein nahezu unüberwindliches Hindernis für eine solche Politik stellten darüber hinaus die im Frankfurter Frieden vom Deutschen Reich annektierten Provinzen dar. Wohlgemerkt: nicht etwa in der Hinsicht, daß Frankreich bis zum Ausbruch des Großen Krieges eine Außenpolitik geführt hätte, die auf eine militärische Auseinandersetzung zusteuerte, um sich des an das Deutsche Reich verlorenen Territoriums zu bemächtigen. Der Gedanke, daß der in Lothringen geborene Poincaré in der Julikrise 1914 eine als günstig eingeschätzte Gelegenheit ergriff, um den Friedensschluß von 1871 mit militärischen Mitteln zu revidieren, ist eine Legende, die erst im Rahmen einer politisierten Zeitgeschichtsschreibung und einer leidenschaftlich geführten Kriegsschulddebatte entstand ${ }^{769}$. Doch ebensowenig, wie Poincaré auf eine militärische Revision des Status quo ausging, war der Ministerpräsident und spätere Präsident bereit, durch eine grundsätzliche Annäherung an das Deutsche Reich diesem eine faktische Anerkennung auszusprechen. Denn gleich mehrfach und zu unterschiedlichen Gelegenheiten sprach Poincaré in den

$767 \mathrm{Vgl}$. insbesondere KeIGER, Jules Cambon.

768 Zit. Paul Cambon an Jules Cambon, 4. 11. 1912, in: NL Jules Cambon, MAE, PAAP 43/101, fol. 249.

769 Vgl. Notes journalières, in: NL Poincaré, BNF, Nafr. 16024, fol. 127 (Eintrag 11. 3. 1913). Zum Wandel des Bildes, das man sich im Deutschen Reich von der Person und dem Handeln Poincarés machte, vgl. Gerd Krumeich, Poincaré vu de l'Allemagne avant et après la guerre de 1914-1918, in: Jean LANHER, Noëlle CAZIN (Hg.), Raymond Poincaré, un homme d'État lorrain 1860-1934, Bar-le-Duc 1989, S. 127-137. Vgl. ferner Bertrand JOLY, La France et la revanche (1871-1914), in: Revue d'histoire moderne 46 (1999), S. 325-347. Der französische Historiker gelangt in seiner Untersuchung zu dem Resultat, daß es sich bei den Revanchisten um eine "winzige Minderheit « gehandelt habe. Vgl. ibid., S. 326, 340-347; das Zitat: S. 326. 
Jahren vor Ausbruch des Großen Krieges davon, daß es sich bei einer Annäherung an das Deutsche Reich um ein rapprochement handeln würde, dont nos souvenirs feraient tous les frais ${ }^{770}$.

Darüber hinaus schien Poincaré aber insbesondere auch deshalb eine deutsch-französische Annäherung unmöglich zu sein, weil er fürchtete, daß diese Frankreich in einen Antagonismus zu Großbritannien und Rußland führen würde und daß das Deutsche Reich dies letztlich ausnutzen könnte, um sich selbst auf Kosten Frankreichs mit den Flügelmächten des europäischen Staatensystems zu verständigen ${ }^{771}$. Deutlich wird diese Furcht im Zusammenhang mit einer Episode um den deutschen Hofrat Carl René, der als Mitglied eines Vereins für die deutsch-französische Annäherung in den ersten Monaten des Jahres 1912 in Gesprächen mit dem Herausgeber des "Matin", der französischen Botschaft in Berlin, dem Auswärtigen Amt und der Botschaft des Deutschen Reiches in Paris die Frage sondierte, ob nicht mit Verhandlungen über den Status des Reichslandes Elsaß-Lothringen die Grundlage für eine Entente zwischen beiden Staaten gelegt werden könnte ${ }^{772}$.

In einem Brief vom 23. März berichtete Jules Cambon, daß René in einer Unterredung mit einem namentlich nicht genannten Mitglied der Botschaft behauptet hatte, daß der Herausgeber des einflußreichen "Matin« ihn um ein Gespräch gebeten habe, um ihm seine Pläne einer évolution complète de la politique française darzulegen, que patronnerait Le Matin dans le sens d'un rapprochement ou plutôt d'une alliance formelle entre la France et l'Allema-

770 Zit. Notes journalières, in: NL Poincaré, Nafr. 16027, fol. 96 (Eintrag vom 13. 7. 1914). Vgl. ferner ibid. Nafr. 16026, fol. 39 (Eintrag vom 25.1. 1914) und Poincaré an Jules Cambon, 27. 3. 1912, in: NL Jules Cambon, MAE, PA-AP 43/58, fol. 27.

771 Nicht zuletzt scheinen auch sehr grundsätzliche Überlegungen Poincaré in seinem Handeln geleitet zu haben, wie aus den Annotationen eines Berichtes hervorgeht, den Jules Cambon im Januar 1914 an sein Außenministerium gesandt hatte. Dieses Mal war es der Staatssekretär im Reichsmarineamt, Alfred Graf von Tirpitz, der in einem Gespräch mit Madame de Faramond, der Frau des französischen Marineattachés, zu einer weitgehenden Annäherung zwischen beiden Staaten geraten hatte. Vgl. Jules Cambon an Doumergue, 19. 1. 1914, in: DDF 3, 9, 111 und Faramond an Jules Cambon, 17. 1. 1914, in: ibid. Vgl. ferner die Darstellung des Marineattachés in: FARAMOND, Souvenirs, S. $135 \mathrm{f}$. Doch Poincaré, der die Ausführungen des Staatssekretärs mit ersichtlich wachsender Verärgerung las, verband in seinen Aufzeichnungen den Satz: la paix du monde serait assurée et un magnifique avenir s'ouvrirait pour nos deux pays mit der Bemerkung: avenir d'bumiliation et de bonte pour la France, de triomphes économiques et de domination diplomatique par l'Allemagne. Zit. Notes journalières, in: NL Poincaré, BNF, Nafr. 1026, fol. 39 (Eintrag vom 25.1. 1914). In einem deutsch-französischen Bündnis, so wird man dieser Annotation entnehmen können, würde sich der Ansicht Poincarés zufolge Frankreich als Juniorpartner an der Seite des Deutschen Reiches und damit letztlich in einem für eine Großmacht unerträglichen Maße an Abhängigkeit wiederfinden.

772 Zur Person Carl Renés, der seit 1908 Mitglied des Zentralkomitees für deutschfranzösische Annäherung war, vgl. die Bemerkungen bei WILSBERG, Kooperative Momente und Konflikt, S. 294, 340, 346. 
$g n e^{773}$. In einer darauffolgenden Zusammenkunft hatte der Herausgeber des »Matin « dann René zugesichert, im Sinne einer deutsch-französischen Entente auf die öffentliche Meinung Frankreichs Einfluß nehmen zu wollen, sollte sich das Deutsche Reich zu Konzessionen in der Elsaß-LothringenFrage bereit finden. Im Auswärtigen Amt wollte Unterstaatssekretär Arthur Zimmermann dem Hofrat zudem umfangreiche Zugeständnisse, gar eine weitreichende Autonomie des Reichslandes in Aussicht gestellt haben, si la politique française évoluait $d u$ côté allemand 774 .

Was man im einzelnen von solchen, eher unrealistischen Plänen auch immer halten mag, entscheidend ist die Begründung, mit der Poincaré den Gesprächen umgehend ein Ende setzte. In einem Brief vom 27. März 1912 erklärte er dem Botschafter in Berlin:

$I l$ [gemeint ist die deutsche Reichsleitung, St. S.] semble poursuivre avec une obstination inlassable un rapprochement que seule une séparation complète du passé rendrait possible. Á écouter des propositions comme celles de $M$. Charles René nous nous brouillerions avec l'Angleterre et avec la Russie, nous perdrions tous les bénéfices de la politique que la France suit depuis de longues années, nous n'obtiendrions pour l'Alsace que des satisfactions illusoires,

und der Satz, den Poincaré dann seiner Mahnung folgen ließ, beleuchtet scharf die Problematik, die sich in den letzten Jahren vor Ausbruch des Großen Krieges mit einer Politik der partiellen Distanzierung von den eigenen Bündnispartnern verband. Fürchtete doch der Ministerpräsident bei einem Eingehen auf die Offerte letztlich isolés, diminués et disqualifiés, das heißt bündnislos, bündnisunfähig und mit beträchtlicher Einbuße an großmächtlicher Existenz dazustehen ${ }^{775}$.

Aufgrund der fehlenden Möglichkeit eines deutsch-französischen Rapprochements, aufgrund einer fast unheimlich anmutenden Machtentfaltung und eines überschätzten außenpolitischen Manövrierraums Rußlands sowie fehlender nationaler Machtmittel und internationaler Kompensationsmöglichkeiten konstituierte sich dann aber für Frankreich in der Julikrise eine bündnispolitische $Z$ wangslage, in der Poincaré und Paléologue eine uneingeschränkte Unterstützung des Zarenreiches selbst für den Fall erforderlich schien, in dem sich mit einem solchen Handeln das Risiko verband, den Großen Krieg in Europa führen zu müssen. Auf seiten Frankreichs glaubte allein Ministerpräsident und Außenminister Viviani sich dieser Logik entziehen zu

773 Zit. Jules Cambon an Poincaré, 23. 3. 1913, in: DDF 3, 10, 253. Vgl. auch KeIGER, Jules Cambon, S. 648; DerS., France and the Origins, S. 70 und WILSBERG, Kooperative Momente und Konflikt, S. $59 \mathrm{f}$.

774 Zit. Jules Cambon an Poincaré, 27. 3. 1912, in: NL Jules Cambon, MAE, PA-AP 43/ 58, fol. 24.

775 Zit. Poincaré an Jules Cambon, 27. 3. 1912, in: NL Jules Cambon, MAE, PA-AP 43/58, fol. 27. Der Botschafter brach daraufhin den Kontakt zu Carl René ab. Vgl. Jules Cambon an Poincaré, 29. 4. 1912, in: NL Jules Cambon, MAE, PA-AP 43/58, fol. $40 \mathrm{f}$. 
können, obgleich auch er ihr nicht vollkommen zu entfliehen vermochte, wie nun zu zeigen sein wird, wenn es festzustellen gilt, welche Konzessionsbereitschaft die Repräsentanten der Republik im weiteren Fortgang der Krise aufbrachten. 